\title{
WestVirginiaUniversity
}

THE RESEARCH REPOSITORY @ WVU

Graduate Theses, Dissertations, and Problem Reports

2003

\section{Dark Wilderness A Phenomenological Exploration Of The Idea Of Cave Wilderness}

\author{
Patricia E. Seiser
}

Follow this and additional works at: https://researchrepository.wvu.edu/etd

Part of the Forest Management Commons, and the Other Forestry and Forest Sciences Commons

\section{Recommended Citation}

Seiser, Patricia E., "Dark Wilderness A Phenomenological Exploration Of The Idea Of Cave Wilderness" (2003). Graduate Theses, Dissertations, and Problem Reports. 7991.

https://researchrepository.wvu.edu/etd/7991

This Dissertation is protected by copyright and/or related rights. It has been brought to you by the The Research Repository @ WVU with permission from the rights-holder(s). You are free to use this Dissertation in any way that is permitted by the copyright and related rights legislation that applies to your use. For other uses you must obtain permission from the rights-holder(s) directly, unless additional rights are indicated by a Creative Commons license in the record and/ or on the work itself. This Dissertation has been accepted for inclusion in WVU Graduate Theses, Dissertations, and Problem Reports collection by an authorized administrator of The Research Repository @ WVU.

For more information, please contact researchrepository@mail.wvu.edu. 


\title{
DARK WILDERNESS
}

\section{A PHENOMENOLOGICAL EXPLORATION OF THE IDEA OF CAVE WILDERNESS}

\author{
PATRICIA E. SEISER
}

Dissertation submitted to the

Davis College of Agriculture, Forestry and Consumer Sciences

at West Virginia University

in partial fulfillment of the requirements

for the degree of

\section{Doctor of Philosophy}

in

Forest Resources Science

Chad D. Pierskalla, Ph.D., Committee Chair

Michael A. Schuett, Ph. D., Research Advisor

Ronal Kerbo, National Cave Specialist, National Park Service

Steven B. McBride, M.S.

Henry W. Rauch, Ph.D.

Steven W. Selin, Ph. D.

Division of Forestry

Morgantown, West Virginia

2003

Keywords: Cave Wilderness, Cave Management, Caves, Karst, Wilderness, Stewardship Copyright 2003 Patricia E. Seiser 


\section{ABSTRACT \\ Dark Wilderness \\ by Patricia E. Seiser}

It has been almost forty years since the passage of the 1964 Wilderness Act and the establishment of the National Wilderness Preservation System. Forty years later, we still have not seen a wilderness that is not a surface environment. There exist neither subterranean nor marine wilderness areas. Efforts on behalf of cave wilderness have focused on the 1964 Wilderness Act legal definition of wilderness. Perhaps what is required is a different concept for the establishment of cave wilderness.

This study explored the idea of cave wilderness from a human dimension perspective, via focus groups, using stakeholders from two cave regions of the United States - Carlsbad Caverns and Mammoth Cave. Through this process a definition of cave wilderness, as well as, definitions of wild cave, developed cave, show cave, and commercial use cave were generated. The study reports on a proposed intent for a cave wilderness designation as well as legislation and management prescriptions.

Based on study findings the conceptual framework of wilderness was expanded from a two-dimensional model to a three-dimensional model, adding the human dimension to the wild and natural dimensions. A cave continuum model was developed which shows the interplay of these three dimensions of wilderness.

Findings of this study clearly indicate the need for an ecosystem management approach in the stewardship of cave and karst resources. 


\section{DEDICATION}

Some people can't stand it, but for some the dark feels like home.'

Dorothy Allison, Cavedweller

“There's no place like home."

Dorothy, The Wizard of $\mathrm{Oz}$

This is dedicated to all those for whom the Dark Wilderness feels like home.

And, to my Beloved Stephen. Home is wherever the heart is and my heart lies with you. 


\section{ACKNOWLEDGEMENTS}

I would like to thank all those who participated in the focus groups, without your participation, this study would never have happened. I truly appreciate your willingness to spend a few hours talking about caves and cave wilderness. I would also like to extend my thanks to the many people from the communities of Carlsbad, Cave City, Horse Cave, and Park City for their willingness to talk with me about my research.

Thanks go to my committee members for their support and guidance. Mike Schuett was a most excellent research mentor, whose patience and persistence is truly appreciated.

I would like to extend special thanks to: Stephen Mosberg, who served as my research assistant extraordinaire, chauffer, and faithful sidekick; the NSS Conservation Committee for the research grant; the ACCA \& NSS Bookstore for education material for the focus group participants, Ella Belling \& Kim Bjorgo, who showed true friendship by suffering through data coding and analysis for me; Roger Brucker, Paul Burger, Emily Davis, Tom Lera, \& Mike Werner for reviewing and critiquing my proposal; Kathryn Greever \& Virginia Seiser who reviewed, critiqued, and proofed both the proposal and dissertation; the caving community for their interest and support; Joe Abbott for his friendship and undying curiosity about my research; Christina Arevalo \& Emily Raker for being my friends despite my poor communication these last five years; Jim \& Val Werker, it is your fault; the Cave Gods, you know who you are; the Colorado Grotto, where "everything I learned about caving and cave protection" began; my family for supporting their crazy sister; and the kitties six - Tequila, Kahlua, Merry Mayhem, Patron, Mescal, \& Tesoro - who see in the dark (and helped keep things in perspective). 


\section{PROLOGUE}

What will cave wilderness ... mean to the caving public, the general populace, and to the park managers? Hopefully, it will mean the same thing to everyone that the caves so designated will be held in the public trust in such a manner and by such means that the wildness for which they are currently known will be sustained unimpaired by human alteration and impact into a far and timeless future; the caves will continue to hold mystery and adventure, and that the thrill of original exploration may always be just ahead, just around the corner or through a tight squeeze, out at the limits of time and endurance; that not everything has been inventoried and neatly disked onto a computer; and that the caves have been recognized for what they are - as important - as wild as any surface areas on earth (Ronal Kerbo, 1988, p. 433). 


\section{TABLE OF CONTENTS}

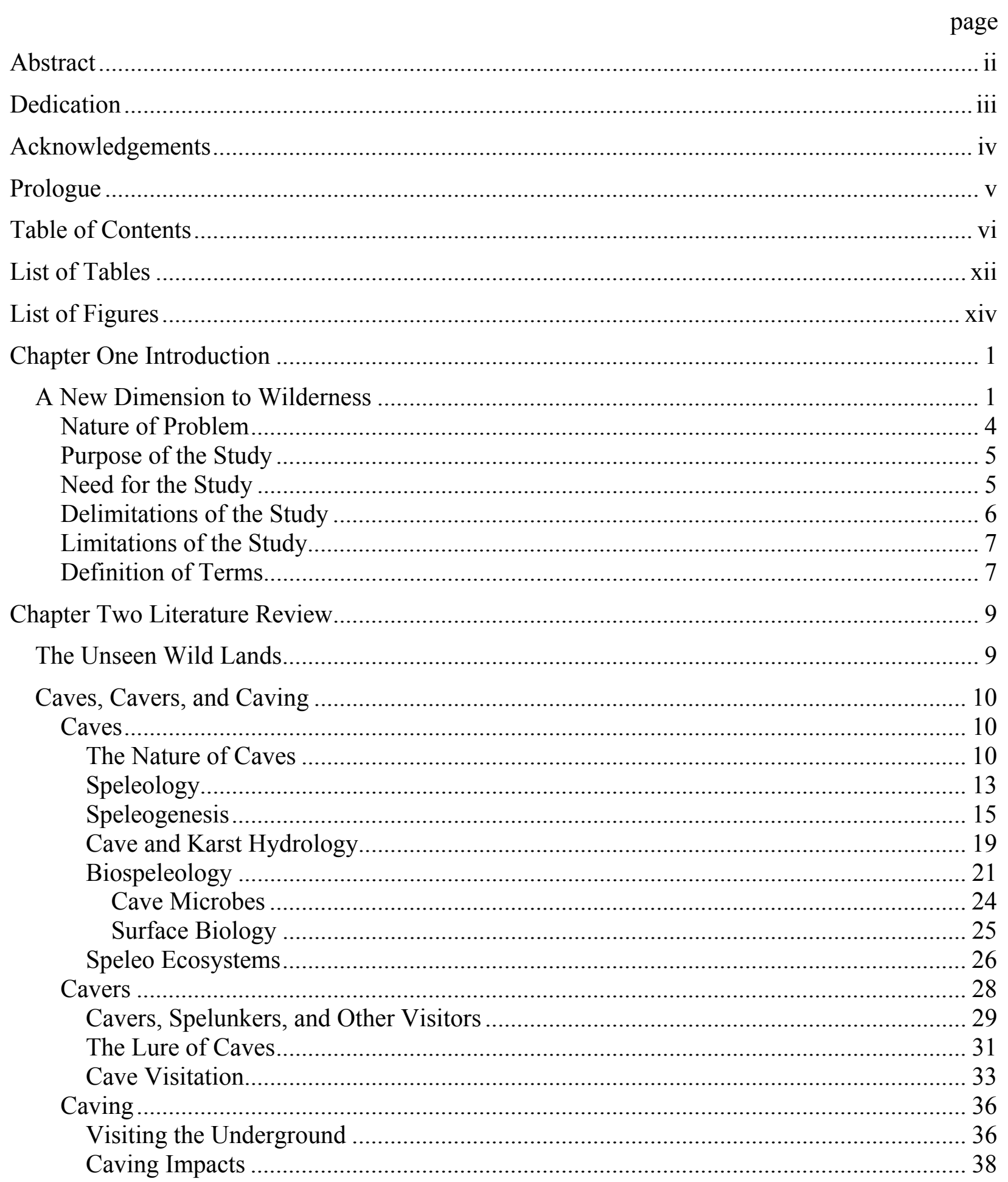




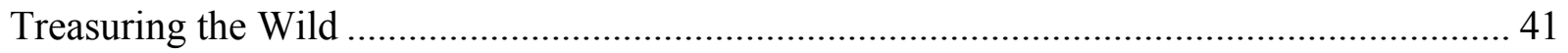

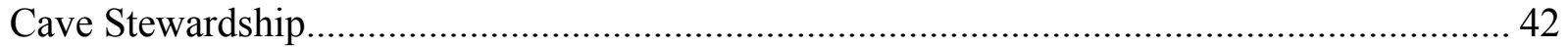

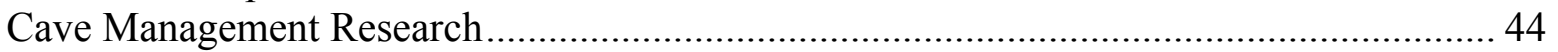

Shifting Management Perspectives .............................................................................. 45

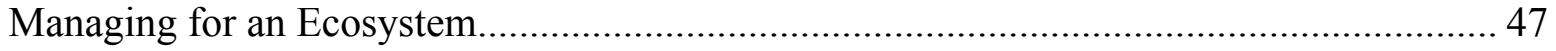

An Emerging Natural Resources Management Field ........................................................... 49

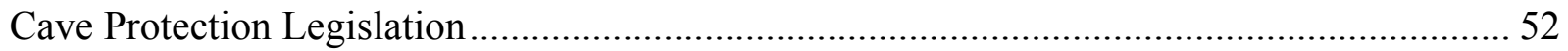

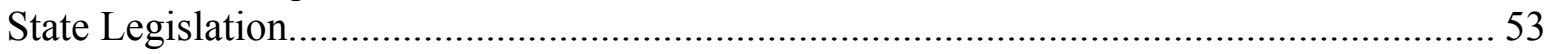

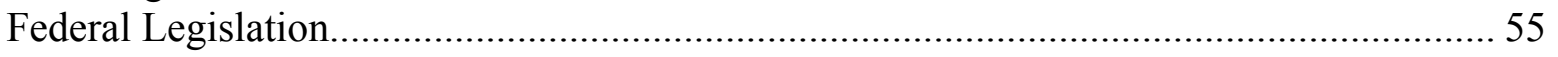

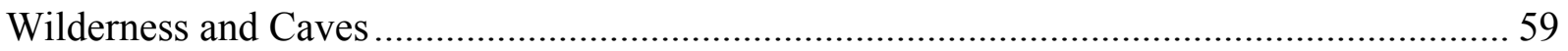

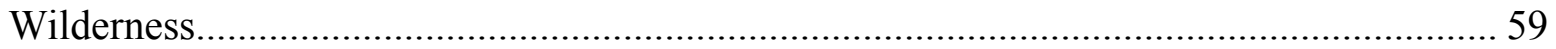

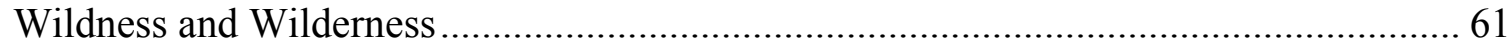

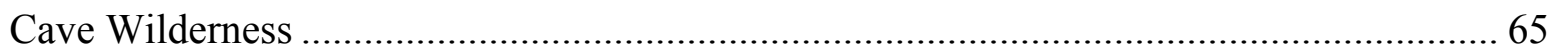

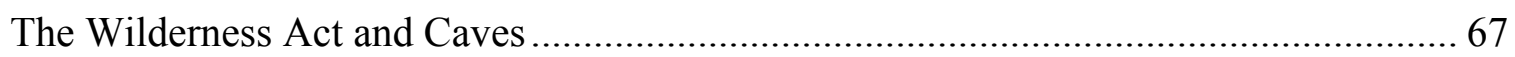

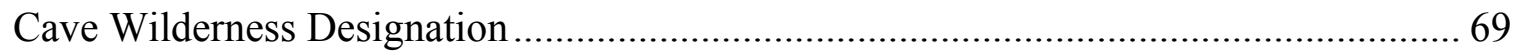

Caves and Wilderness Values and Meanings ……………………………………….... 71

Ecosystem Management and Meanings of Place........................................................ 75

Barriers to Wilderness Designation ............................................................................. 78

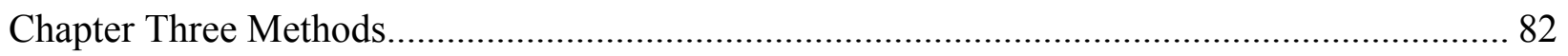

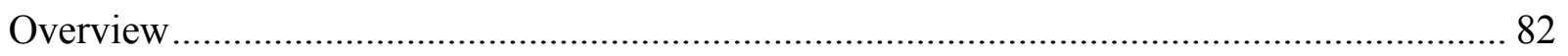

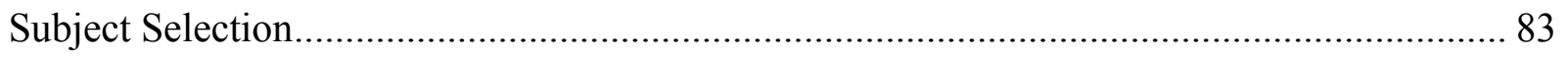

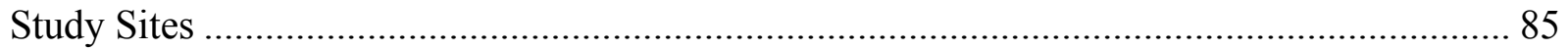

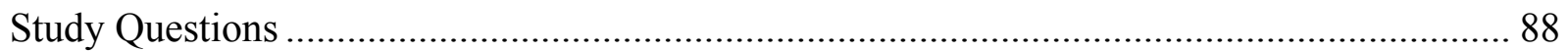

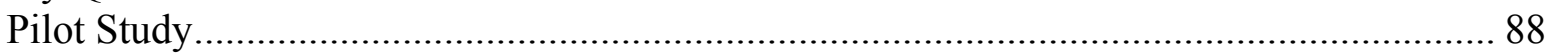

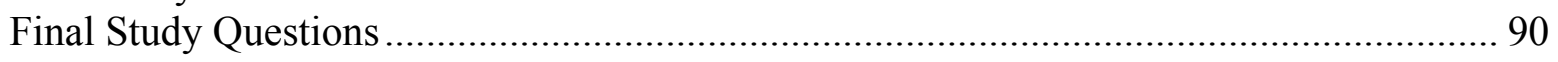

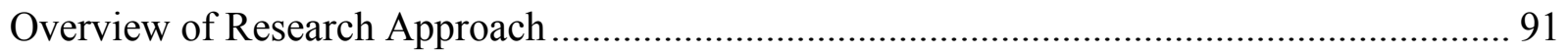

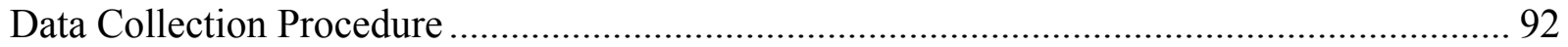

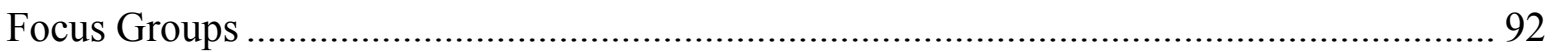

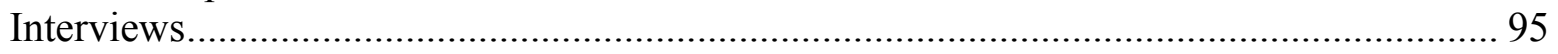

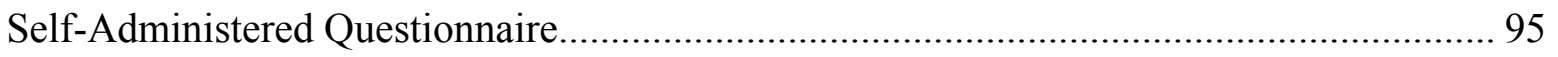

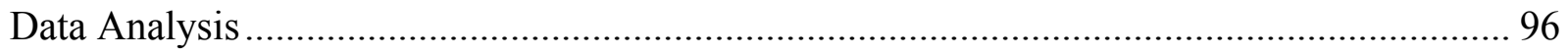

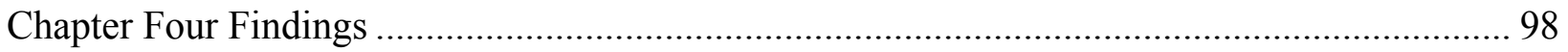

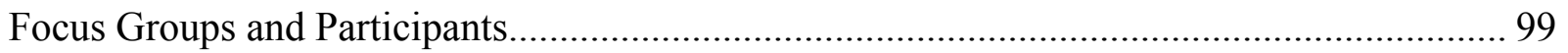

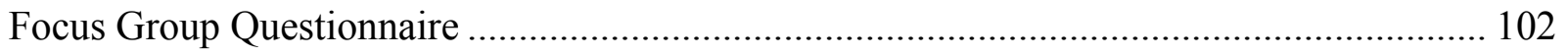

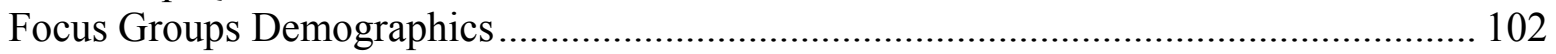

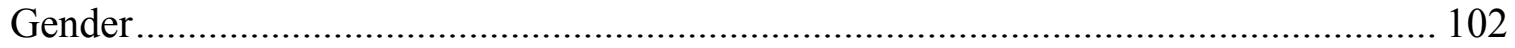

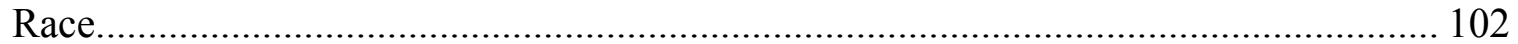

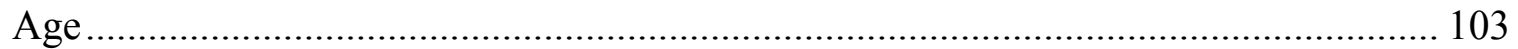

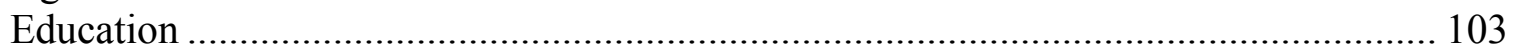


page

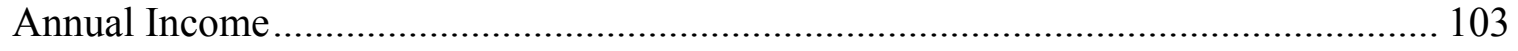

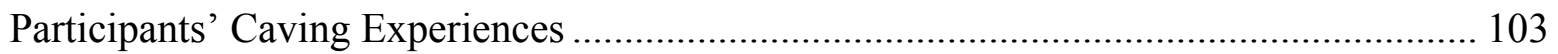

Caver versus Non-Caver Participants ..................................................................... 104

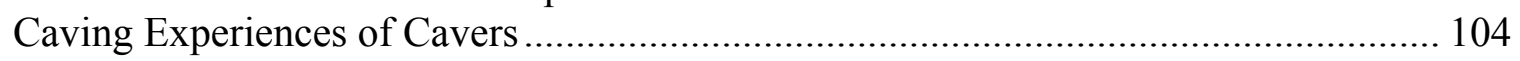

Caving Experiences of Non-Cavers....................................................................... 105

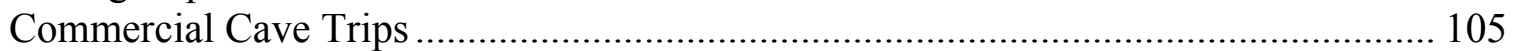

Kentucky and New Mexico Cave Visitation ........................................................... 106

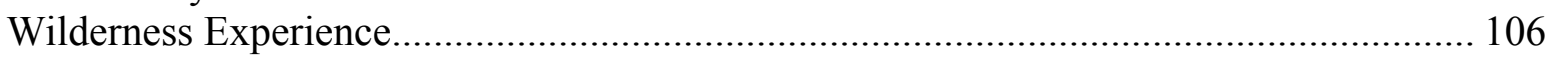

Focus Groups Sessions Results................................................................................... 107

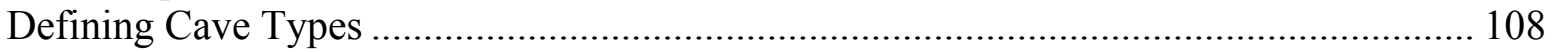

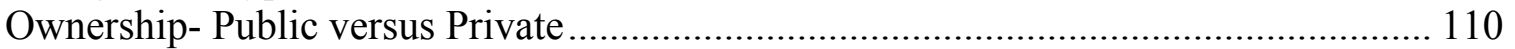

Commercial Cave versus Commercial Use ................................................................ 111

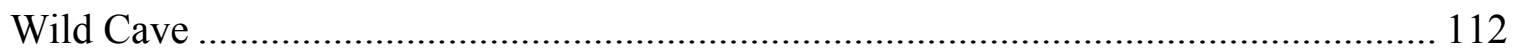

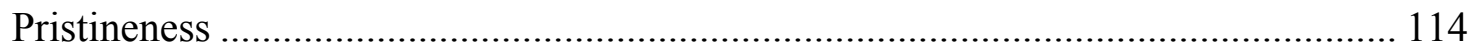

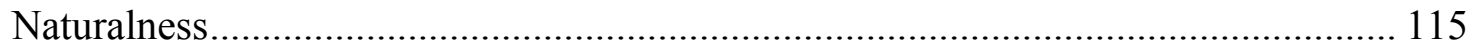

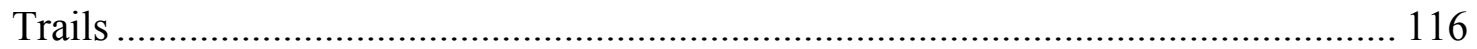

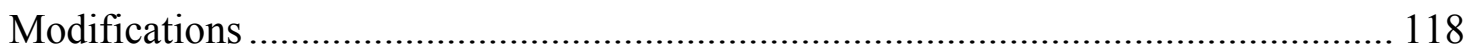

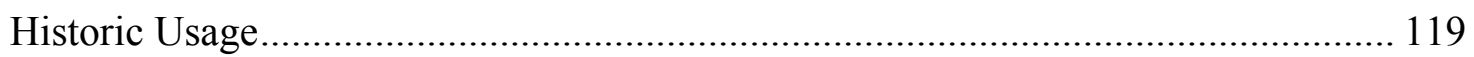

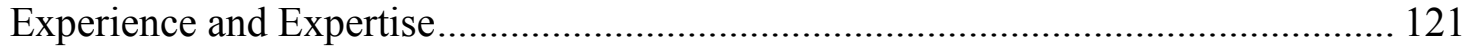

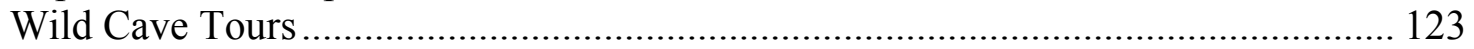

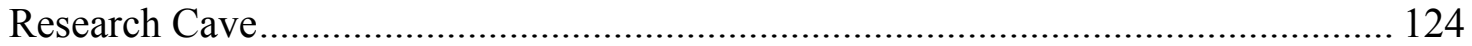

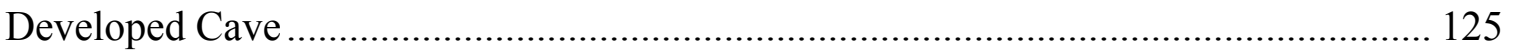

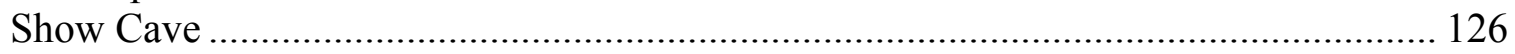

Wild, Developed, Commercial ............................................................................ 127

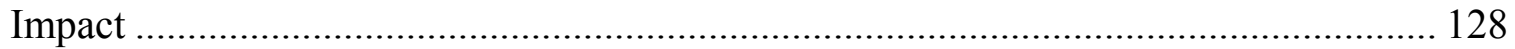

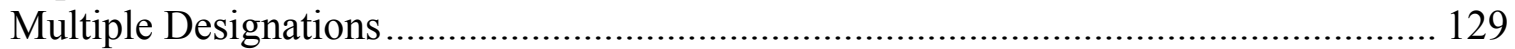

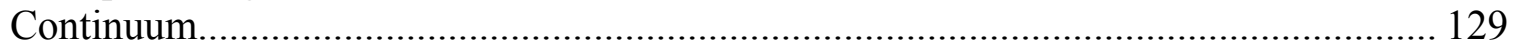

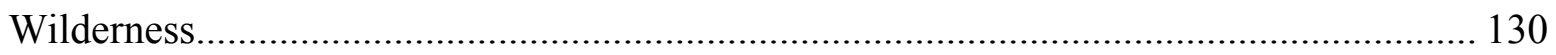

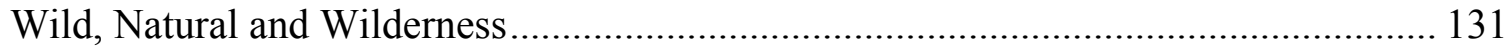

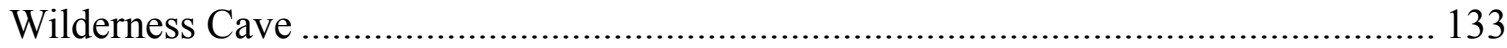

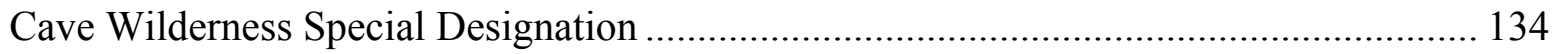

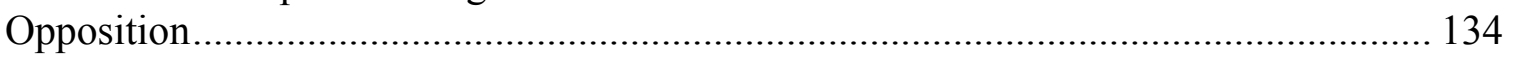

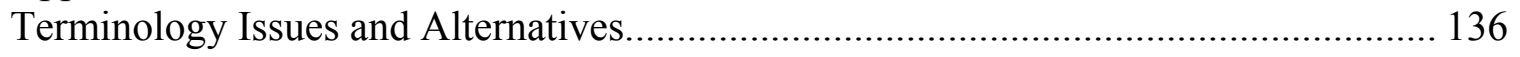

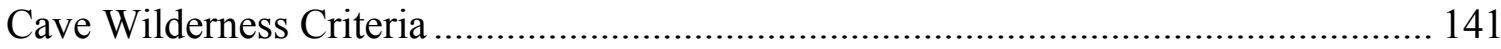

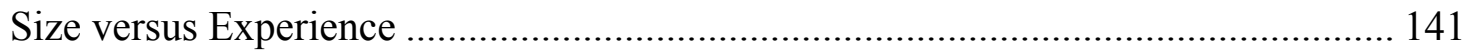

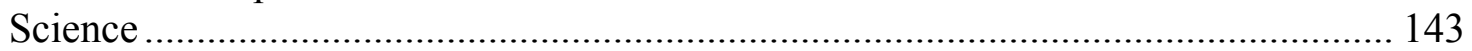

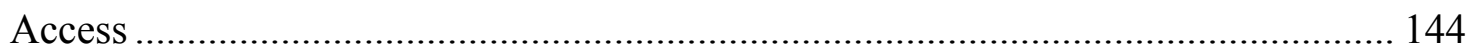

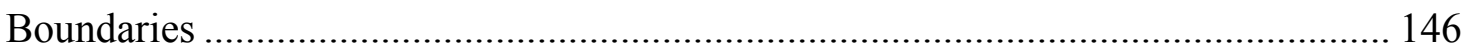

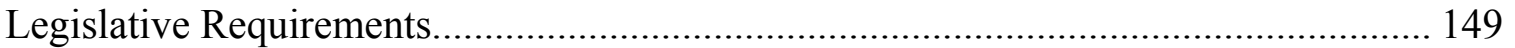

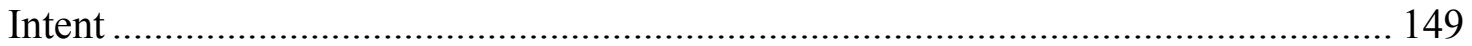

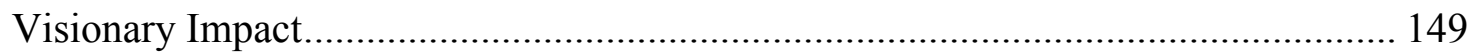

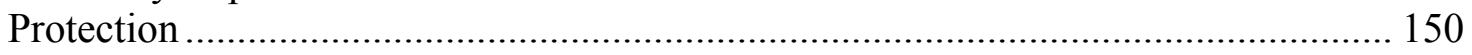

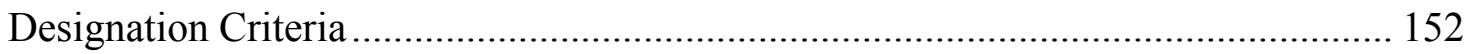

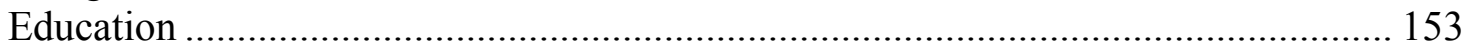

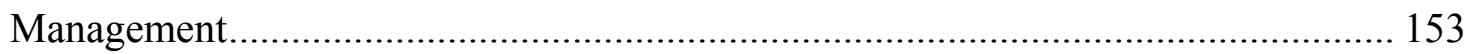


Designation Benefits \& Rewards........................................................................... 154

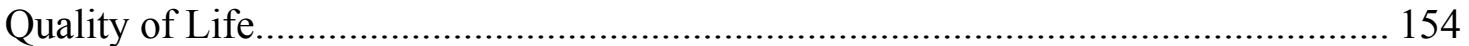

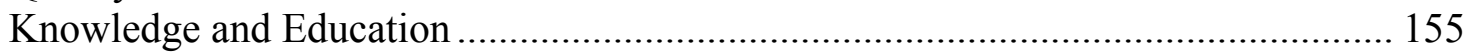

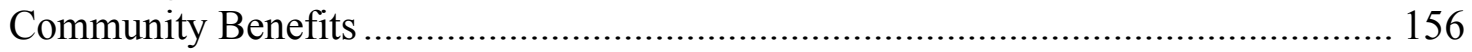

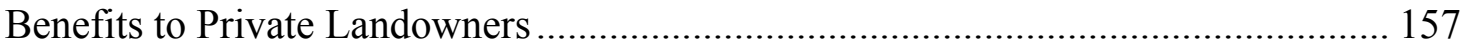

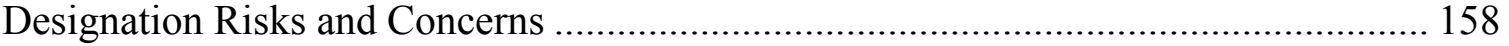

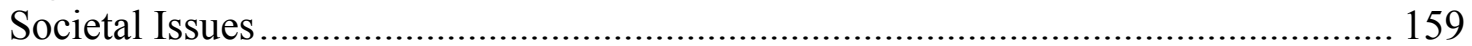

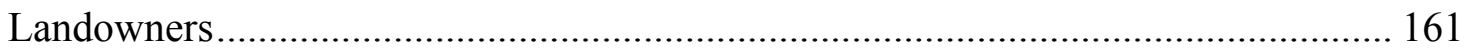

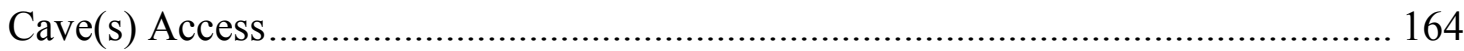

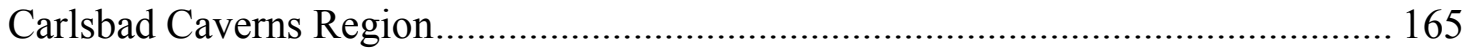

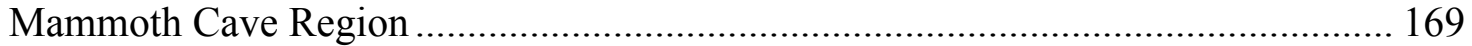

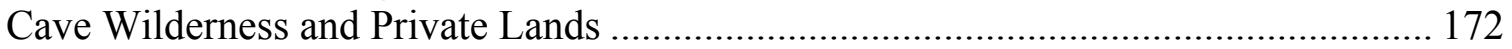

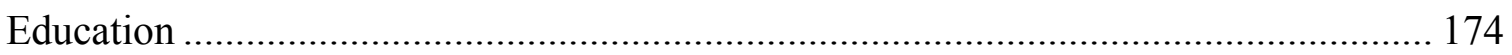

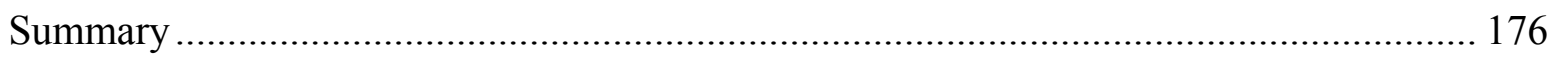

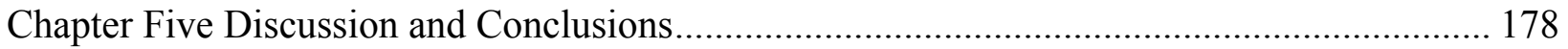

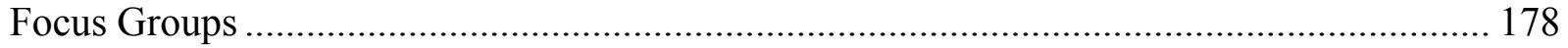

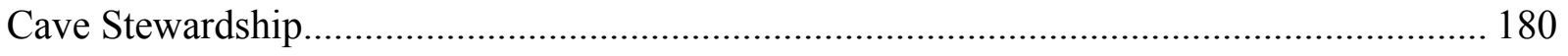

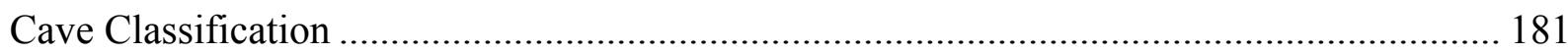

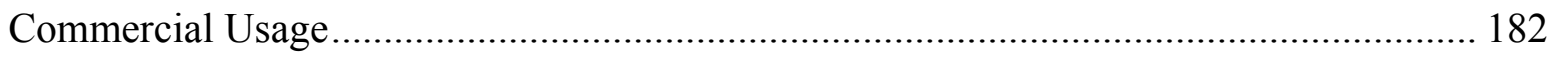

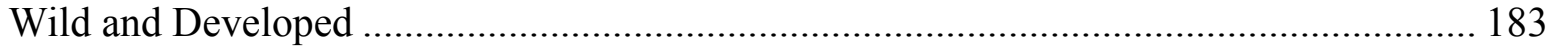

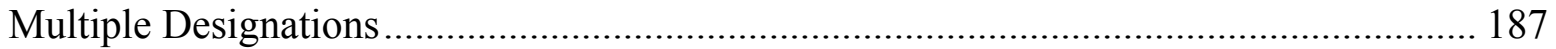

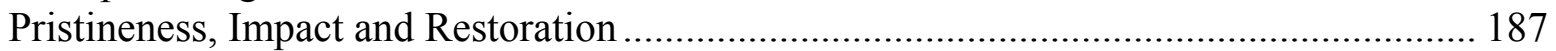

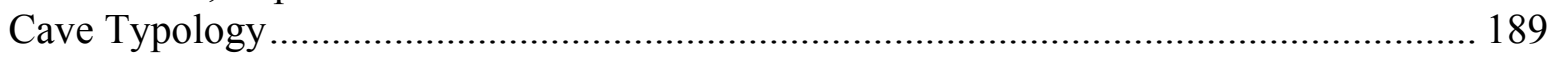

The Continuum of Cave Pristineness....................................................................... 193

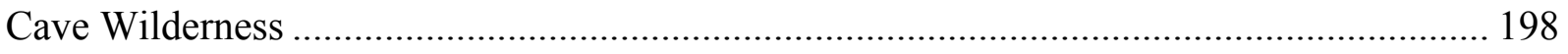

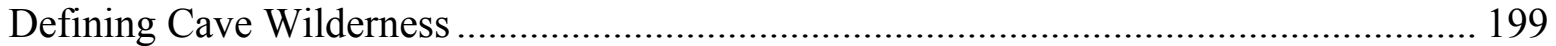

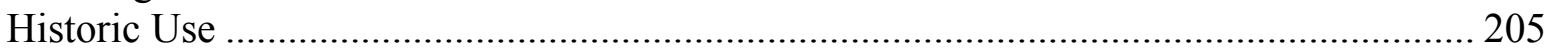

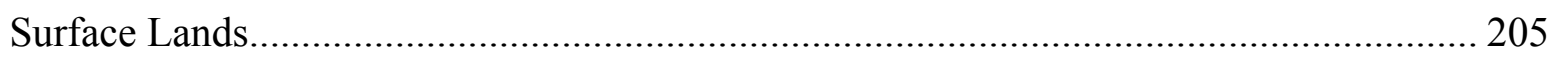

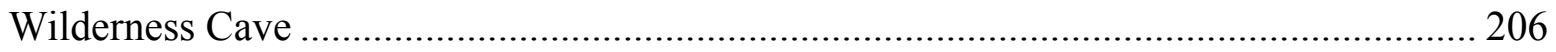

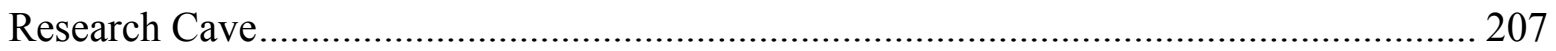

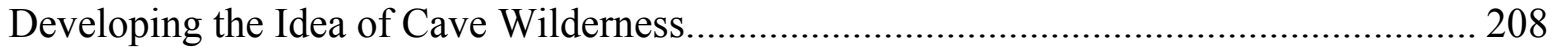

Criteria for Defining Cave Wilderness .................................................................. 210

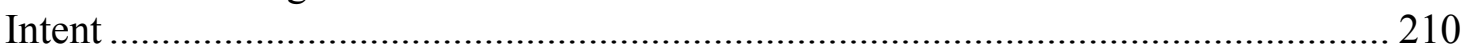

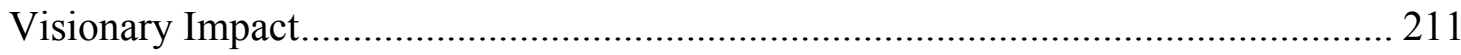

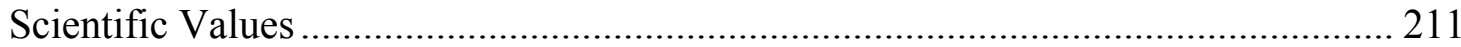

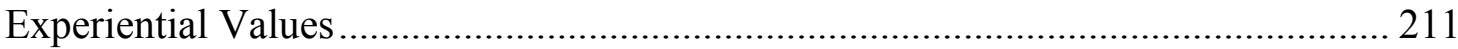

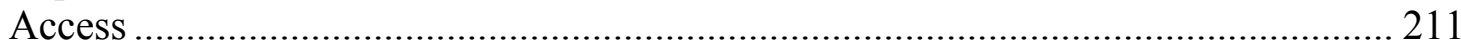

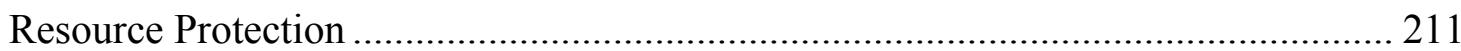

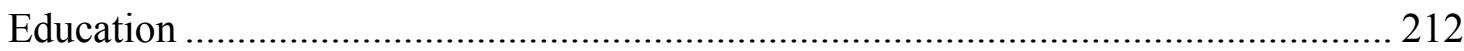

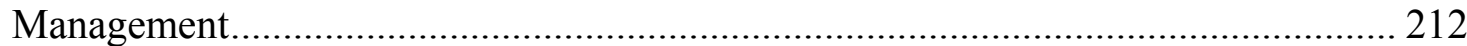

Proposed Definition of Cave Wilderness...................................................................... 213

Legislative and Stewardship Prescriptions ............................................................. 217

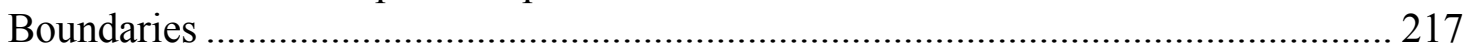




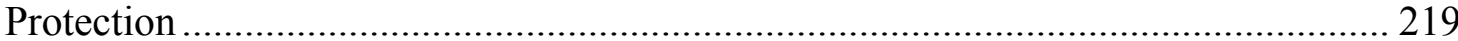

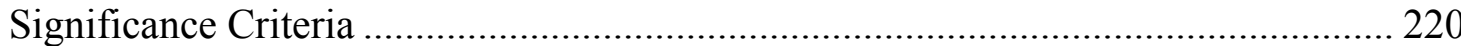

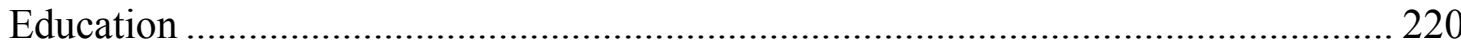

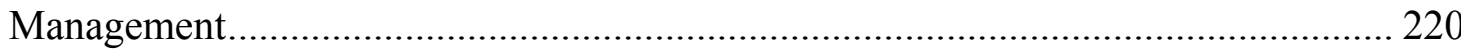

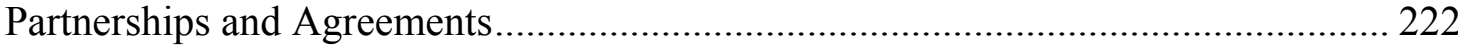

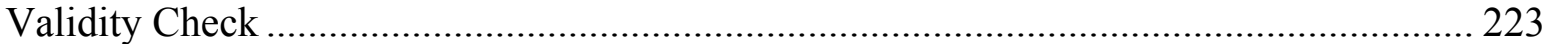

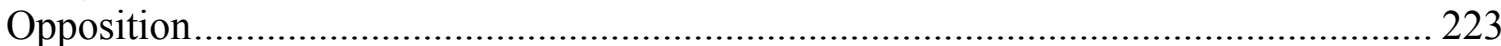

Wilderness Act Application Problems...................................................................... 223

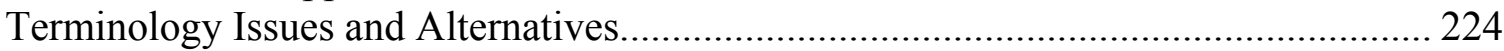

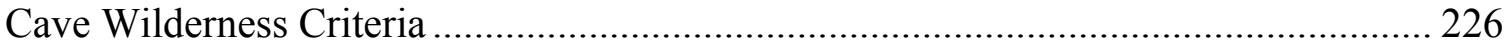

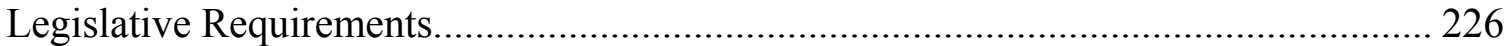

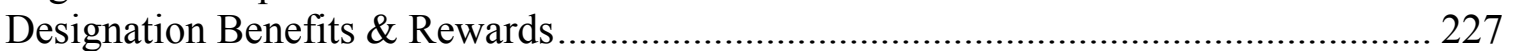

Designation Risks and Concerns ....................................................................... 228

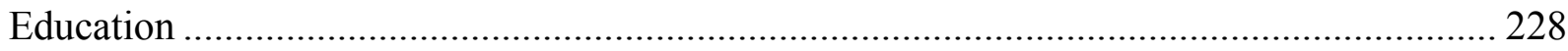

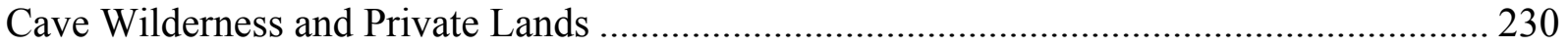

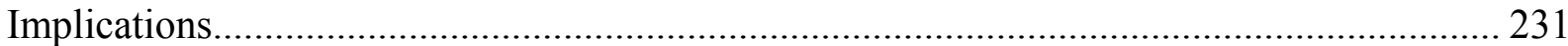

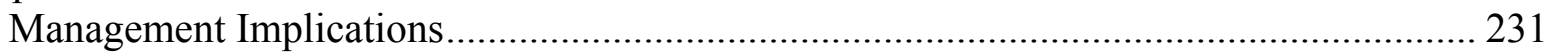

Theoretical Implications ................................................................................... 234

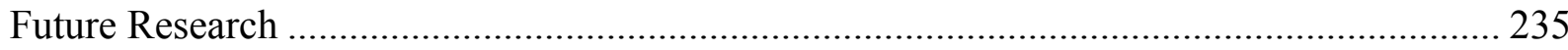

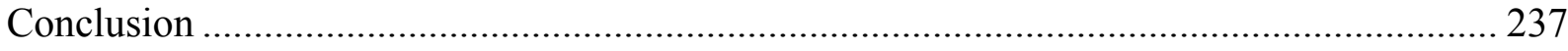

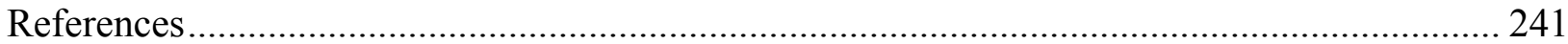

Appendix A State Cave Resources Protection Acts ........................................................... 254

Appendix B Federal Cave Resources Protection Act of 1988 ............................................ 259

Appendix C Lechuguilla Cave Protection Act of 1993 .......................................................... 265

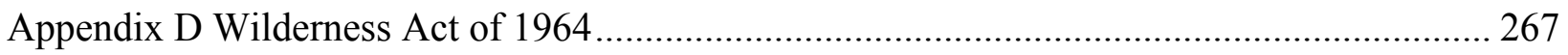

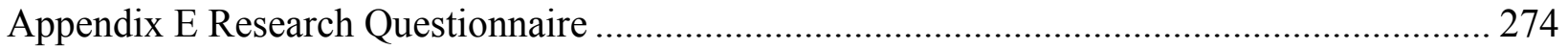

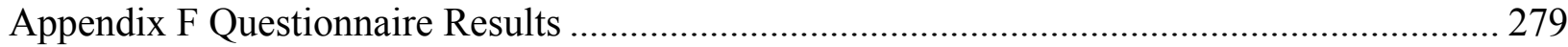

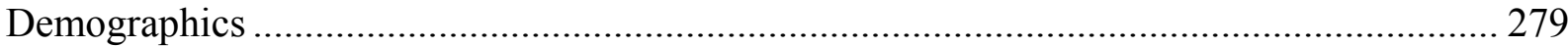

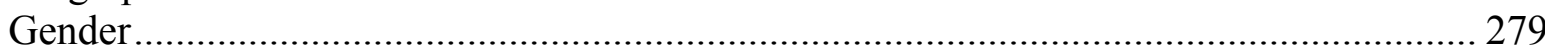

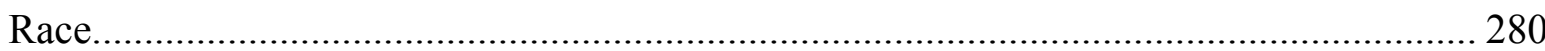

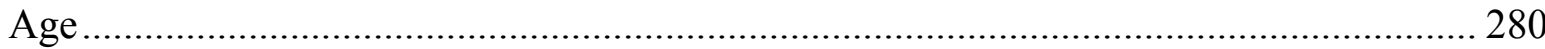

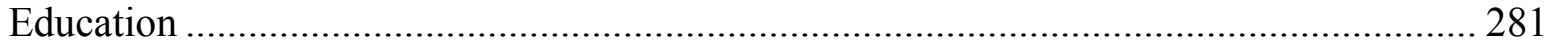

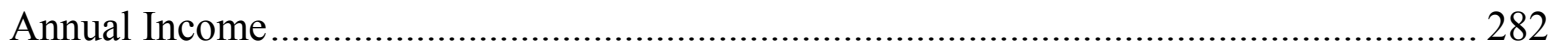

Caver versus Non-Caver Demographics.................................................................. 282

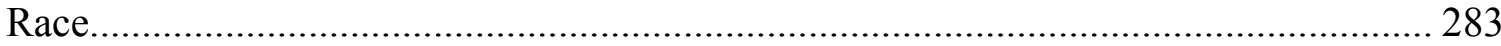

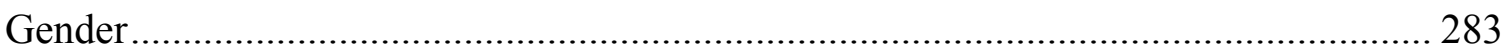

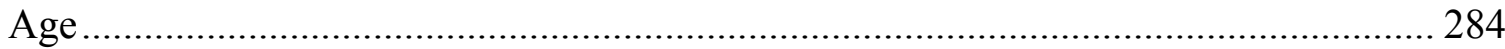

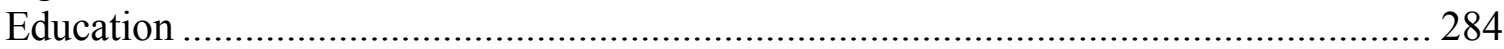

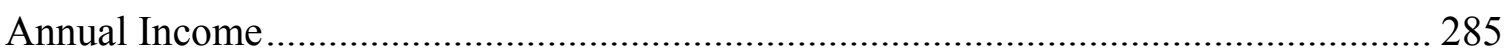

Comparisons of Caver, Non-Caver, and Focus Groups Venues.................................... 285 


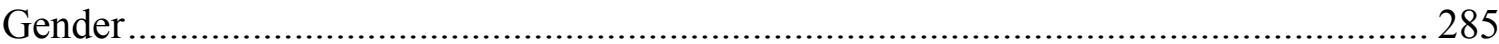

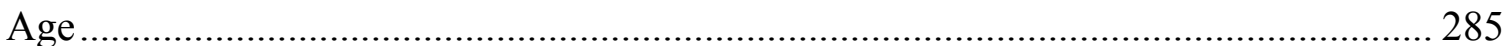

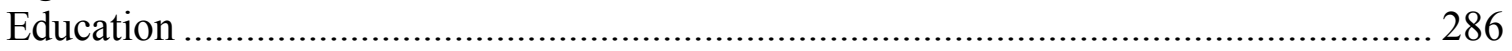

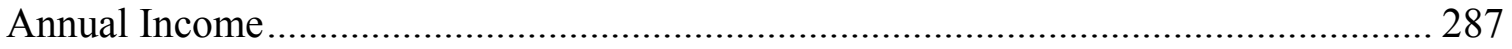

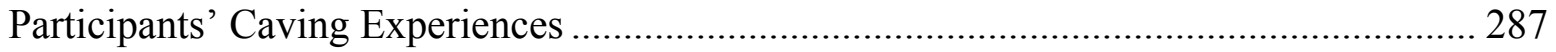

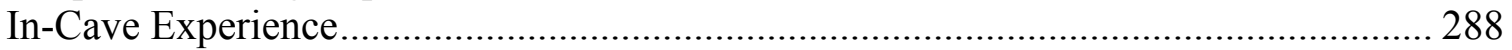

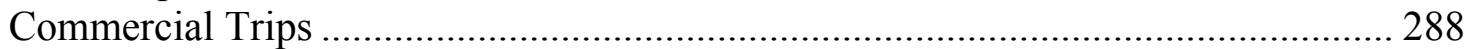

Commercial Spelunker/Wild Cave Tour ............................................................... 289

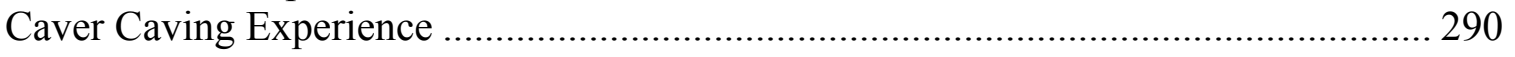

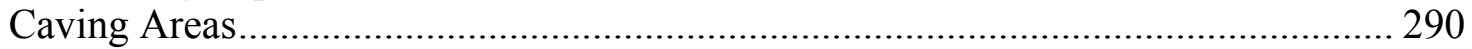

Caving Related Memberships .................................................................................. 291

Kentucky and New Mexico Cave Experiences................................................... 292

Non-Caver Caving Experience ............................................................................ 293

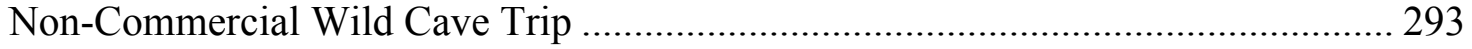

Kentucky and New Mexico Visited Caves and Cave Trips.................................... 294

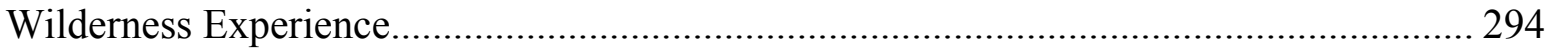




\section{LIST OF TABLES}

page

Table 1. Karst Speleogenesis Processes and Cave Examples................................................19

Table 2 Non-Karstic Speleogenesis Processes and Cave Examples.......................................20

Table 3. U. S. Participation in a Human Powered Outdoor Adventure Activity 1994-1995.........34

Table 4. Number of Days Participants Spent in One of the Four Newly Added Human Powered



Table 5. A Taxonomy of Wilderness Benefits................................................................ 74

Table 6. Cave Types Based on Cave Attributes and Human Impacts and Usage. .....................190

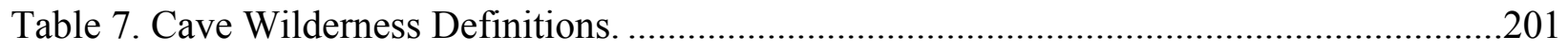

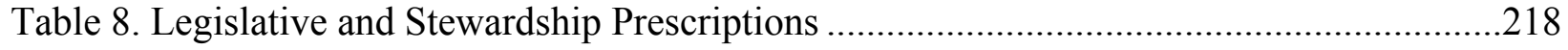

Table 9 Comparison of Opposition Themes, Cave Wilderness Definition and Prescriptions In Protection of Environmental and Wilderness Qualities of Caves..........................................224

Table 10. Problems Associated with Application of the Wilderness Act with Proposed Cave

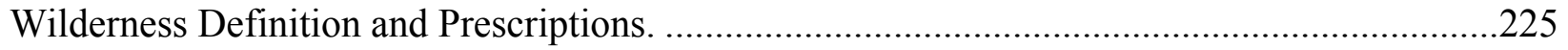

Table 11. Ability of Proposed Cave Wilderness Definition and Prescriptions to meet Designation

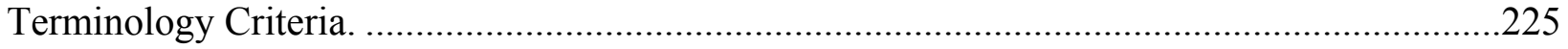

Table 12. Ability of Proposed Cave Wilderness Definition and Prescriptions to Meet Cave Wilderness Criteria.

Table 13. Legislative Requirements Addressed by Proposed Cave Wilderness Definition and Prescriptions.

Table 14 Ability of Proposed Cave Wilderness Definition and Prescriptions to Address Perceived Benefits and Rewards of Designation. .228

Table 15. Ability of Proposed Cave Wilderness Definition and Prescriptions to Address Perceived Designation Risks and Concerns Themes. 


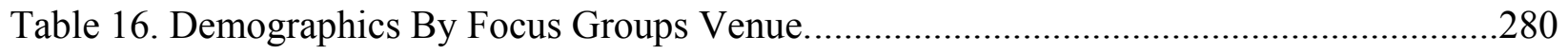

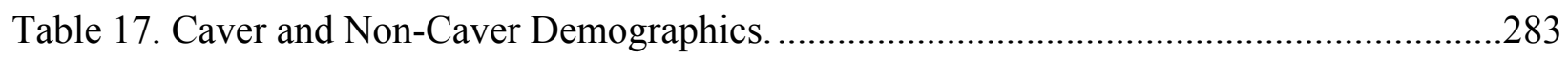

Table 18. Commercial and Guided Wild Cave Tours by Focus Group Venues...........................289

Table 19. Areas Cavers Caved by Focus Groups Venues. ........................................................2.

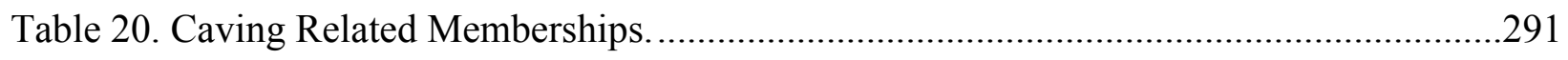

Table 21. Caver Kentucky and New Mexico Cave Experiences................................................293

Table 22. Non-Cavers' Non-Commercial Wild Caving Trips......................................................294

Table 23. Non-Caver Kentucky and New Mexico Caving Experience........................................295

Table 24. Wilderness Experience by Focus Group participants. ..................................................296 


\section{LIST OF FIGURES}

page

Figure 1. Interrelation of Cave Discovery, Cave Use, and Cave Management Around the Common Factual Base of Speleology. .14

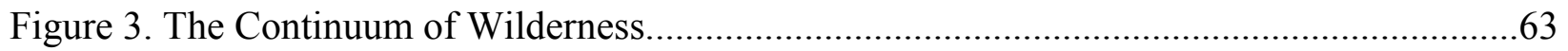

Figure 4. Focus Groups Participants Based on Venue......................................................100

Figure 5. Focus Group Participants Based on Community of Place.........................................100

Figure 6. Overlap of Community of Interest and Community of Place..................................101

Figure 7. Cave Continuum Based on Naturalness, Wildness, and Human Perspective. .............195

Figure 8. Comparison of Gender by Caver, Non-Caver, and Focus Groups Venues.................286

Figure 9. Comparison of Age Ranges by Caver, Non-Caver, and Focus Groups Venues. .........286

Figure 10. Comparison of Education by Caver, Non-Caver, and Focus Groups Venues...........287

Figure 11. Comparison of Annual Income by Caver, Non-Caver, and Focus Groups Venues...287 


\section{CHAPTER ONE}

\section{INTRODUCTION}

\section{A New Dimension to Wilderness}

From the time of the Europeans' first arrival in the New World, up to and including, their westward expansion across the North American continent, their perspective of wilderness was that of a place to be subdued and subjected to human's dominance. By the late 1800's, the EuroAmerican perspective of wilderness had begun to change. Gone was the wilderness frontier to be conquered and tamed by the pioneers. Wild lands were being replaced by a rapidly expanding industrial civilization, one in which mechanized transportation - trains and the automobile made it possible to access much of the American continent. It was becoming impossible to capture the wilderness experience of the pioneers; experiences that made America what it is today. The remaining wild regions began to be romanticized as symbolic of the hardship, solitude, and fortitude of the early pioneers. For some, wild lands represented "that which made our nation great." It represented the virtues felt to be important to the American character and ideal. Wild lands were an integral reminder of our nation's history; they were a visual, tangible connection with our past without which concepts such as frontier and pioneer become meaningless (Nash, 1982). The preservation of wild lands as wilderness would provide opportunities for visitors to seek out the solitude of the untamed lands, to meet the land on its own terms, and in a sense, to demonstrate the fortitude of the pioneers when faced with hardship, from which most Americans were insulated by the luxuries of modern living. Ultimately the concept of wilderness would be endowed with numerous meanings, representing many things to 
many people. Wilderness became not only a place, but also an experience (Bishop, 1983; Nash, 1982; Oelschlaeger, 1991).

The earliest descriptions of wilderness as "place" associated wilderness with forests and mountains, landscapes of sweeping vistas and a sense of space (Nash, 1982; Woods, 1997). Since then, wilderness has come to embody a wide variety of landscapes and ecosystems; some protected better than others, some not are protected at all - particularly those hidden from everyday view - either underground or underwater. Rivers were recognized as purveyors of wilderness with the passage of the Wild and Scenic River Act of 1968. As of yet, caves have not been recognized as purveyors of wilderness in their own right.

In a review of wilderness literature, it is interesting to note that when wilderness designation is discussed in association with caves it is referred to as "cave wilderness," phrasing not associated with other wilderness landforms. Neither forest wilderness nor desert wilderness is used when discussing the Otter Creek Wilderness of West Virginia or the Gila Wilderness of New Mexico. It is only in discussions regarding the potential of wilderness for areas within our oceans does one hear phrasing defining the wilderness - "ocean wilderness." What is it about caves and wilderness that necessitates the use of the phrase "cave wilderness"? Why is it that some feel caves are wilderness separate from surface designation? Is the use of "cave wilderness" recognition of some form of special management concerns not necessarily associated with other wilderness areas? Are there different or additional concerns regarding those who visit cave wilderness than there are for those who visit surface wilderness?

Increasing numbers of people seeking a wilderness experience visit designated and defacto wilderness. The expansion in outdoor recreation, both in terms of the numbers of people as well as the variety of activities, is associated with the wilderness movement. For many, the 
1964 Wilderness Act mandates for recreational use of wilderness. Increasing leisure time, as well as increasing discretionary income, is translating into increased visitation and recreation in the wild lands. Experiential recreational opportunities are increasing on a scale such that regions once rarely visited are now seeing large numbers of inexperienced visitors who often participate in guided recreational activities (Cordell, Teasley, Super, Bergstrom, \& McDonald, 1997). It appears that few landscapes and ecosystems are being spared this visitation, including caves. Unfortunately, heavy visitation is negatively affecting landscapes unable to maintain their integrity under such usage, threatening the very qualities that drew many visitors to the sites in the first place.

In some instances, recreational activities are occurring in non-traditional environments, including such activities as in-line skating in the deserts of the Southwest or rock climbing in the lava caves of the Pacific Northwest. Management considerations for the protection of wilderness sites and wild lands must include the recognition that it is not only the numbers of visitors that need to be regulated, but also the type of visitor activity. Bishop (1983) wrote that to maintain the quality of wilderness environments, it is critical that management "emphasize the preferences of users whose activities in the wilderness strongly depend on those qualities that are unique to wilderness settings rather than the opinions of users whose needs can be met in other than wilderness locations" (pp. 92-93). In order to preserve the qualities of pristine cave wilderness, many who support cave wilderness would concur with Bishop. Current methods of managing wilderness recreational use are not necessarily appropriate for caves. Many caves are unable to recover from impacts incurred during visitation including, but not limited to, muddied and broken formations and trampled surfaces. The ability to preserve the qualities of cave wilderness will necessitate understanding what uses will be appropriate in a cave wilderness and which 
users will be given access if such restrictions are needed. The intent or purposes of cave wilderness will need to be defined.

It has been almost forty years since the passage of the 1964 Wilderness Act and the establishment of the National Wilderness Preservation System. Since then, from at least a national legislative standpoint, our definition of wilderness has evolved to include the human dimension of wilderness, acknowledging humans as part of nature, not separate from it. The first attempts to include caves as designated wilderness occurred at the wilderness hearings. Forty years later, we still have not seen a wilderness that is not a surface environment. There exist neither subterranean nor marine wilderness areas. Efforts on behalf of cave wilderness have focused on the 1964 Wilderness Act legal definition of wilderness. Perhaps what is required is a different concept for the establishment of cave wilderness. Perhaps it is time to add the human dimension - stakeholders' values and perceptions of caves and cave wilderness.

\section{Nature of Problem}

Federal and state laws exist to protect caves and cave resources, and a federal law mandates federal agencies to protect significant caves (reference Chapter Two, Cave Protection Legislation and Appendixes A, B and C for discussion of specific laws). Despite attempts to establish cave wilderness in Kentucky and New Mexico, there exists no cave wilderness as defined by the Wilderness Act of 1964 and subsequent Wilderness Acts. Current interpretation of the 1964 Wilderness Act asserts that any surface deemed wilderness includes that which lies below (Stitt, 1991). However, the reverse is not equally true, as many caves that could be considered designated wilderness in their own right exist beneath lands that do not fit within current legal definitions of wilderness. 
The idea of cave wilderness raises numerous questions ranging from the obligate management questions regarding boundaries and access, to the more esoteric ones such as who wants cave wilderness and what purpose(s) could such a designation serve. An understanding of what cave wilderness could or should be remains unclear.

\section{Purpose of the Study}

The purpose of this study is to explore the idea of cave wilderness from a human dimension perspective. This study will attempt to: 1) determine if a separate wilderness designation is desired and the reasons for that goal, or lack thereof; 2) develop an understanding of the meanings and values attached to cave wilderness from the perspective of stakeholders cavers and non-cavers - who perceive their lives to be affected by caves and/or a cave wilderness designation; 3) identify perceived benefits and risks incurred with cave wilderness designation; and 4) explore potential stewardship policies and plans.

\section{Need for the Study}

Numerous articles have been written that call attention to the need for a cave wilderness designation; yet, existing research regarding cave wilderness has been limited primarily to investigations into the legislative possibilities for the establishment of cave wilderness (Bishop, 1988; Bishop \& Huppert, 1990; Gamble, 1981; Ganter, 1990; Goodbar, 1982; Halliday, 1993a, 1993b; Halliday \& Stitt, 1992; Hummel, J. B., 1982; Huppert, 1993, 1995; Huppert \& Wheeler, 1992; Kerbo, 1988; Kerbo \& Roth, 1989; McClurg, 1988; Miller, 1990; Smith, 1988; Stitt, 1976b, 1982b, 1991; Watson \& Smith, 1971; White, 1988). The authors discuss the potential use of existing legislation to establish cave wilderness, focusing primarily on the 1964 Wilderness 
Act. Research into wilderness benefits and values as they apply to caves is lacking. So, too, is research into the public's interest in establishing policies and procedures appropriate to the stewardship of caves and any potential special designation(s). The question here is not whether cave wilderness should or should not exist; rather, it is that of individuals' perceptions and values regarding the concept of wilderness as it may apply to caves.

It is hoped that the results of this study will begin to reveal the complex and intangible values stakeholders have regarding caves. It will attempt to provide information useful to natural resources managers, local and regional land planners, other government agencies, and special interest groups in the development of policies and practices associated with stewardship of cave resources. These findings may aid in the development of potential legislation for cave wilderness predicated on the 1964 Wilderness Act, or they may lead in other directions to paths unknown and new, to be considered in Congressional designation of cave wilderness.

\section{Delimitations of the Study}

1. Focus groups were used as the primary research tools.

2. Subjects were selected based on criteria established a priori and on their willingness to participate in this study.

3. The samples were drawn from two specific caving regions in two states selected by the researcher.

4. A self-administered questionnaire was used.

5. Cave experience and skill level were assessed by self-report.

6. Procedures protected subjects from intimidation by the presence of or responses made by other study participants. 


\section{Limitations of the Study}

1. A small demographic area focusing on two specific regions limited the ability of the researcher to generalize these results to larger populations.

2. The samples of residents from the two regions were limited to those individuals who were recommended by federal, state, and local government officials or by other contacted residents.

3. The samples of cavers was limited to those individuals who attended a caving event sponsored by the National Speleological Society (NSS), or an organization affiliated with the NSS, or who were included as a result of participating as a resident.

\section{Definition of Terms}

The following terms are used throughout this study:

Cave: Any naturally occurring void, cavity, recess, or system of interconnected passages which occurs beneath the surface of the earth or within a cliff or ledge and which is large enough to permit an individual to enter, whether or not the entrance is naturally formed or manmade, including any natural pit, sinkhole, or other feature which is an extension of the entrance (based on the Federal Cave Resources Protection Act of 1988, Section 3).

Caver: An individual who has the skills and tools to safely visit a wild cave with minimal impact and who professes a genuine interest in caves and in the activity of caving.

Community: "The psychological sense of community is an experience, generated with the interplay of individual and group, which engenders the perception of belonging, and ameliorates feelings of isolation...The sense of community may be associated with 
affiliations other than those within a geographically defined space” (Bishop, Chertok \& Jason, 1997, p. 195).

Human Dimensions: “A variety of people-oriented management considerations and a crossdisciplinary range of inquiry" (Jacobson \& Mallory, 1998, pg. 263).

NSS: National Speleological Society, the national caving organization in the United States. Local chapters are called grottos.

Speleo: Of or pertaining to caves.

Stakeholder: "Any group or individual who can affect or is affected by the achievement of the organization's objectives" (Freeman, 1984, pg. 46).

Wilderness: Land that is untrammeled, free of human control. See the Wilderness section of Chapter Two for further discussion of the definition. Use of capital ' $\mathrm{W}$ ' is used to indicate a legally designated wilderness. Use of lower case ' $w$ ' indicates defacto wilderness.

Wildland: Land that is in a natural condition. 


\section{CHAPTER TWO}

\section{LITERATURE REVIEW}

In more ways than one, the underground was the only true wilderness remaining. The lead where Frieda had been injured had been discovered Tuesday. Thursday of the same week Anna found herself sitting, staring at Holden's beloved cave pearls. She would be the twelfth or thirteenth person ever to walk where they were going, ever to see whatever it was they were going to see. No animal human or otherwise - had made its home here. No planes flew overhead in any real sense. Helicopters couldn't airlift the lost and injured to safety. The cave was within easy walking distance in miles to restaurants and VCRs, yet the far rooms of Lechuguilla were among the most remote places on the globe. Intellectually, Anna could see the attraction. Viscerally, she still wanted to go home (Nevada Barr, Blind Descent 1998, pp. 27-28).

\section{The Unseen Wild Lands}

The phenomenon of wilderness is, as traditionally perceived, a wilderness seen. As we progress in our understanding of our environment and the need to protect and conserve it, so too should we broaden our concept of wilderness to include wilderness unseen - whether it be underground, underwater, or even in the far reaches of outer space. However, attempts to apply the idea of wilderness and its legal definition to cave wilderness have met with difficulty.

Caves are often viewed as dark, mysterious, and unwelcoming holes in the ground, foreboding places of little to no value. Yet, for some, caves are one of the last remaining frontiers for adventure, wilderness, and exploration. In acknowledgment of these qualities, a few have sought national recognition for caves in the form of wilderness designation, the highest honor our nation can bestow upon a habitat. 
Responsible management of natural resources, such as wilderness habitats, needs to be guided by a philosophy that integrates the meanings and value of a landscape. Ecosystem management uses the concept of place to generate awareness of the processes by which resources and ecosystems are constructed politically and socially (Williams \& Patterson, 1999). What wilderness status means to those who seek the depths of the earth or to those who live on the surface lands above caves is unknown. It would be useful to understand the meanings of place associated with caves and cave lands in order to develop a concept of cave wilderness that incorporates cultural and symbolic meanings attached to caves, one that lends itself to ecosystem management.

To understand the desire to protect, preserve and celebrate caves, it is necessary first to understand the nature of caves and to understand the nature of those who seek to enter these wild frontiers of adventure, exploration, and scientific study.

\author{
Caves, Cavers, and Caving
}

\title{
Caves
}

\section{The Nature of Caves}

It is hard to imagine water flowing through solid rock. Yet, it does, first seeping through microscopic cracks, dissolving away soluble minerals found in the rock, eventually forming minute conduits on its way to the lowest point possible. In time, the chemical and mechanical action of water may form passages large enough to be traversed by humans. It is these that we call caves. In actuality, this is rather a simple explanation and one that addresses only one of 
several processes that result in the development of caves. What exactly is a cave and how does it relate to the landscape? Moreover, of what significance are caves to the surrounding surface environments?

The concept of caves is both geologic and anthropomorphic in origin (White, 1988). Geologically, caves have traditionally been defined in relation to subsurface spaces and moving water. White (1988) defines caves as “... voids that remain after portions of the carbonate rock have been removed by dissolution in circulating groundwater" (p. 264). Gillieson (1996) provides a similar scientific definition for caves: "a natural cavity in a rock which acts as a conduit for water flow between points" (p. 1). Both are excellent definitions from a karst hydrology and geomorphology perspective. Yet, these definitions are limiting. The first defines caves from a karst perspective, and both imply that meteoric water is the primary agent in cave formation.

An anthropomorphic or non-scientific definition of caves is that of natural spaces underground, through which a human can, in some fashion, move into total darkness. Although simplistic, this definition does not limit caves to a specific lithology nor speleogenesis (the process of cave development). It does, however, eliminate rock shelters that do not extend into darkness, even though some well known rock shelters bear cave names such as Old Man's Cave in Ohio and Cave-In-Rock in Illinois (Brucker, 2001b).

Curl (1964) describes a cave as a natural cavity beneath the earth's surface, defining a cave not as an object but as space. Accordingly, the description of a cave entails the specification of the boundaries, setting a minimum dimension to eliminate inclusion of smaller cavities as caves. In this case, the minimum dimension is that of a human explorer. Curl (1964) defines other features fundamental to the concept of cave: cave connection, surface connection, and cave 
entrance; noting that not all caves have surface connections or entrances. Each of these features has importance in the establishment of stewardship policies and management plans.

The Federal Cave Resources Protection Act of 1988 provides a legal definition of a cave:

The term "cave" means any naturally occurring void, cavity, recess, or system of interconnected passages which occurs beneath the surface of the earth or within a cliff or ledge (including any cave resource therein, but not including any vug, mine, tunnel, aqueduct, or other manmade excavation) and which is large enough to permit an individual to enter, whether or not the entrance is naturally formed or manmade. Such term shall include any natural pit, sinkhole, or other feature which is an extension of the entrance (The Federal Cave Resources Protection Act of 1988, Section Three).

For the full text of the Act, see Appendix B of this study.

Three environmental zones are recognized relative to change in environmental light conditions from entrances to the deepest part of caves. The entrance zone is that region of the cave that receives sunlight at some point throughout the year. The twilight zone is a transition zone, that region of the cave that is indirectly lit during some hours. The dark zone is the portion of the cave that is in total darkness at all times throughout the year (Camacho, 1992; Juberthie, 2000). The presence or absence of these environmental zones may be used to delineate between caves and rock shelters, which typically lack dark zones. Rock shelters are often designated as caves by historians, archeologists, and mapmakers (White, 1988). While rock shelters have significance of their own, they may need to be addressed separately in management plans regarding caves and karst. It should be noted that caves lacking surface entrances and connections also lack entrance and twilight zones.

Curl (1964) asks, "Why be concerned about the definition of a cave" (p. 1). Citing a variety of cave definitions, Curl concludes, “... there are in principle as many definitions as there are uses for these definitions" (p. 2). A definition of "cave' is necessary in order to clarify which type of natural subterranean cavity is being addressed (Curl, 1964; Sweeting, 1973). A 
descriptive definition of cave, which is inclusive of fundamental features, yet not restrictive to specific lithologies or speleogenesis, will be important in the establishment of stewardship policies and management plans. In defining the concept of cave, we begin to qualify management and policy-making goals and needs.

Most caves are found in karst terrains. Karst represents an important element of geodiversity, and one of management significance. The term karst denotes a distinctive type of terrain characterized by landform types and landscapes that are the product of interior drainage and removal of rock to form sinkholes, uvala, sinking creeks, caves, and remnant rock pinnacles resembling haystacks or towers. The term "karst" derives from the Kras district of Northern Yugoslavia, which is the type site for karst. The characteristics of this region received extensive study and are defining features for a classical karst landscape (Ford \& Williams, 1989). From a narrow perspective, karst refers to any area that has been shaped by solution processes. In a broader sense, karst is a dynamic, interwoven system of landforms, life, energy, water, gases, soils, and bedrock. Disturbance of any one of these characteristics will have some impact upon the rest of the system (Watson, Hamilton-Smith, Gillieson \& Kiernan, 1997).

\section{Speleology}

The study of caves, speleology, is closely linked to the study of karst, its geology, geomorphology, and hydrology. For Cvijic, a nineteenth century German geologist, the study of caves was in many ways a separate discipline from the study of karst: it is speleology, a discipline as distinct in itself as geography or geology (Sweeting, 1973). Speleology encompasses all aspects of cave science, many of which are interconnected. Some deal with the cave itself as a phenomenon; others are concerned with what lives and occurs within the cave 
environment (Shaw, 1992). Scientific work in caves is of two types: 1) research in scientific fields focusing on specific questions (e.g., the genesis of caves, adaptation of cave fauna); and 2) the process of exploring, surveying, and recording the caves themselves and their contents (Shaw, 1992). "Scientific truths" are accurate descriptions of the origin, sequential growth, passage patterns, and subsequent natural destruction of caves. Objects of scientific investigation include the caves themselves, their environment, the biota, and past and present human use of caves. Speleology includes exploration, surveying, cartography, inventorying cave geology, hydrology, archaeology, geomorphology, and related activities such as history and folklore recording (Brucker, 2001b). Figure 1 depicts the interrelationship of cave discovery, cave use, and cave management, overlapping around the common factual base of speleology (Brucker, 2001b)

Speleology, particularly inquiries of an archeological and paleontological nature, began

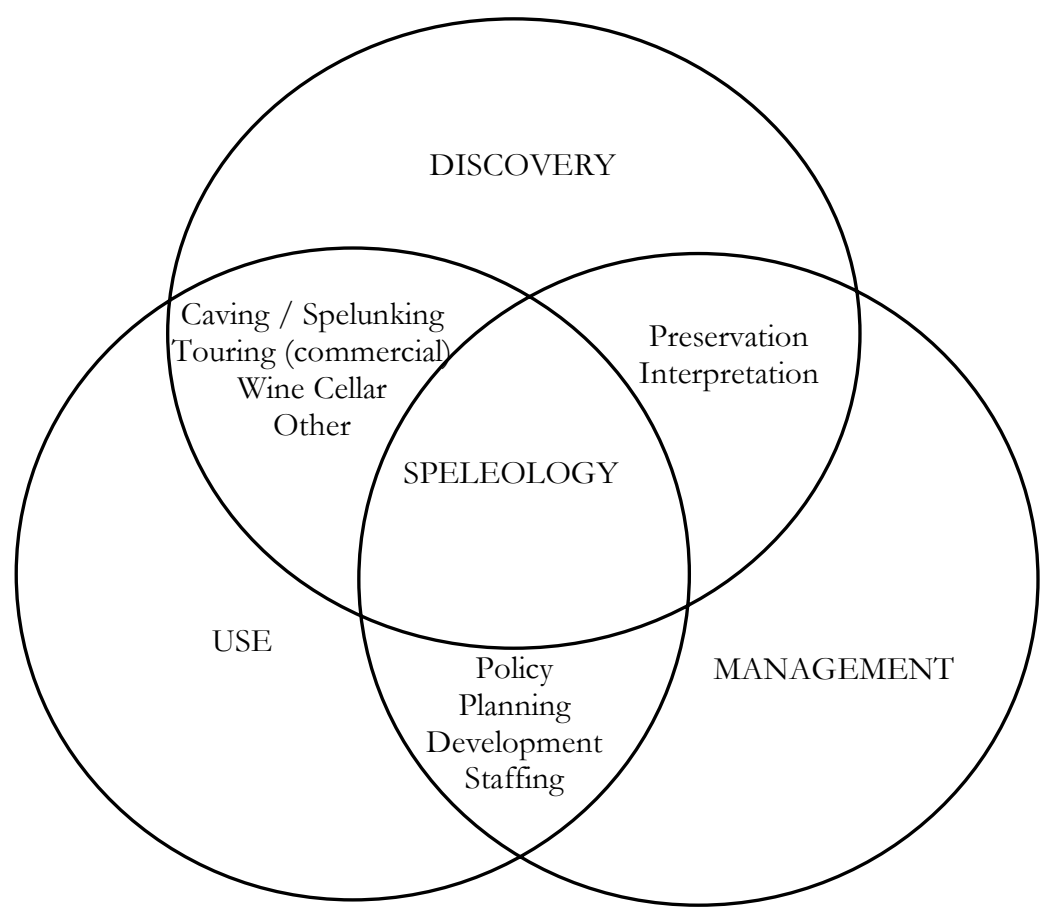

Figure 1. Interrelation of Cave Discovery, Cave Use, and Cave Management Around the Common Factual Base of Speleology (Brucker, 2001b). 
long before the development of caving as a recreational activity. The acquisition of scientific knowledge runs parallel to the history of cave explorations (Camacho, 1992). The Chinese began to explore, document and commercially exploit caves centuries before European scientific studies of caves. The study of extant fauna of European and American caves was occurring by the mid-nineteenth century. The physical aspects of speleology - geology, hydrology, and geomorphology - were well established by the beginning of the twentieth century (Chapman, 1993).

The study of speleology is not a 'gentleman's' activity: it requires a willingness to spend extended periods of time in potentially uncomfortable and dangerous environs, undergoing hours of strenuous activity just to reach a study site, activity which may involve traversing water-filled passages or employing technical rope work, including rappelling and climbing. The men and women who choose to pursue speleology find themselves engaged in a sporting science.

\section{Speleogenesis}

The mysteries and scenery of the cave had the same dignity that belongs to all natural objects, and which shames the fine things to which we foppishly compare them (Ralph Waldo Emerson, Illusions, 1876).

Caves occur in a diversity of environments and rock types, and form in various ways. Caves form by acidic water seeping down through the earth, flowing through the bedrock, and/or rising upward from deep underground. Caves also form by the uneven cooling of lava and by the movement of wind and water. They are found in limestone, marble, gypsum, salts, sandstone, basalt, talus, and glaciers. Caves are found in alpine, tropical, subtropical, temperate, arid, and ocean environments. They may be dry or water filled. They may contain speleothems or be of undecorated bedrock. Speleothem is an all-inclusive term covering a variety of depositional cave 
formations; ranging from the familiar stalactites, stalagmites, columns, and flowstone, to the not so familiar helictites, moonmilk, and hydromagnasite balloons. Caves may be small or large, have few or many rooms and passages, and have vertical or horizontal passages and entrances.

To understand the variety of caves it is necessary to have an elementary understanding of speleogenesis. This will aid in understanding why caves occur where they do and why they are significant.

Caves are characteristically associated with karst. In general, karst identifies terrain having distinctive characteristics of relief and interior drainage caused by a higher degree of rock solubility than is typical in non-karst terrains. The term is also used descriptively to refer to rock, water, streams, caves, and other features making up such landscape (Jennings, 1971). Karst terrains display three essential characteristics: 1) soluble rocks, primarily carbonate rocks such as limestone and dolostone, or evaporite rocks, such as gypsum, anhydrite and halite; 2) soluble features, with dissolution occurring along the bedrock surface, fractures, and bedding partings planes; and 3) pirating or diversion of surface water, via openings such as fractures, cavities, and pore spaces (Rauch, 1999).

The development of the subterranean hydrology is the basis of karst. The dissolution that occurs along these hydrological pathways result in distinctive surface and subsurface landforms (Ford \& Williams, 1989; Sweeting, 1973). Caves are an example of subsurface landforms The four essentials necessary for cave development are: 1) a source of water; 2) rocks with cracks; 3) removable rocks; and 4) a drain (Brucker, 2001a).

Some characteristics of karst can manifest without other characteristics being present, as when dissolution features can originate underground without apparent relationship to the land surface. Karst drainage systems can operate underground without obvious relation to the surface, 
being represented solely by underground forms (voids, including caves), drawing their input water and discharging their output water from other nonkarstic rocks (Klimchouk \& Ford, 2000).

Caves formed by the dissolution of bedrock by flowing water are called solution caves (White, 1988). This form of speleogenesis occurs in rocks of varied lithology and can involve a variety of dissolution mechanisms operating under different physical constraints (Klimchouk, Ford, Palmer \& Dreybrodt, 2000). Complete dissolution of limestone or other rock is unnecessary for removal by solution and transport. In some limestones, the matrix containing grains of less soluble materials may be dissolved, freeing the grains of lower solubility for transport by moving water and possible later dissolution (Brucker, 2001a). Four dissolution mechanisms have been identified as being responsible for the development of solution caves.

The traditional explanation, or mechanism, is cave formation by the dissolution by shallow circulating groundwater carrying dissolved carbon dioxide, resulting in a weak solution of carbonic acid. Carbonate water caves occur where meteoric water sinks underground through the sinkholes, sinking streams, or epikarst, and moves in the rocks without any major artesian confinement. These types of caves account for over $90 \%$ of the explored and mapped solution caves that are longer than a few hundred meters. Caves related to surface recharge tend to be the most easily accessible and thus form the majority of the documented caves (Klimchouk et al. 2000). Three additional hypogean speleogenesis mechanisms were recognized during the last thirty years. Caves formed by these processes are common (White, 2000).

Mixing-zone or halocline caves are the result of additional dissolution created by mixing waters saturated at different carbon dioxide partial pressures producing an undersaturated solution capable of further dissolution. This can account for bedrock dissolution deep within a limestone mass. Cave development also occurs when mixing of carbonate saturated fresh water 
with carbonate saturated salt water. Cave development also takes place in the active mixing zone along the halocline in coastal karst. Mixing zone (halocline) caves were recognized as a distinct new speleogenetic type with a characteristic morphology (White, 2000).

The upwelling of deep-source thermal water may form hydrothermal caves. These types of caves are often associated with ore deposits (White, 2000).

Sulfuric acid caves are formed by limestone dissolution by sulfuric acid. A source of sulfuric acid is the oxidation of sulfide minerals, primarily pyrite, that occurs dispersed in many carbonate rocks. The oxidation of $\mathrm{H}_{2} \mathrm{~S}$ in deep waters seeping upward into carbonate rock masses from nearby petroleum deposits is a more important sulfuric acid source (White, 2000).

All rock materials are soluble to some degree, but the most fully developed karst is found in rocks that are of high solubility, most commonly limestone. Solution also occurs in other carbonate rocks, such as dolostone, and in evaporite rocks, such as gypsum and halite. These are all considered true karst. Such rocks represent approximately 30\% of the earth's surface though they vary in their ease of karstification (Gillieson, 1996; Watson et al. 1997).

Under favorable conditions (sufficient time and environmental stability), true karst terrains may develop in lithologies considered relatively insoluble, such as sandstone, quartzites, basalts, and granites (Gillieson, 1996; Watson et al. 1997; White, 1988). Table 1 lists karstic speleogenesis examples. The most numerous, the largest and the most complex caves are formed by karst actions in soluble bedrock (Jennings, 1971).

Solutional processes result in karst caves as described above. Other processes result in lava tubes and ice caves, including glacial caves and geothermal ice caves (White, 1988). The formation of caves as a result of mechanical processes is relatively independent of the rock composition. Results are aeolian caves, sea caves, tectonic caves, suffosion caves, erosion caves, 
and talus caves (White, 1988). Landforms resembling karst, but created by non-karstic processes are often referred to as pseudokarst. Table 2 lists examples of nonkarstic speleogenesis.

During its lifespan, a cave may undergo an assortment of speleogenesis processes, including karstic and nonkarstic speleogenesis. The speleogenesis of caves is varied and can result in some truly magnificent caves, spectacular not only from a human perspective (visual, historical, economic and anthropological), but also, of importance from an environmental perspective (geological, hydrological and biological) (Jennings, 1971).

Table 1. Karst Speleogenesis Processes and Cave Examples (Gillieson, 1996; White, 1988).

\begin{tabular}{|l|l|l|l|}
\hline \multicolumn{4}{|c|}{ KARSTIC SPELEOGENESIS } \\
\hline \multicolumn{1}{|c|}{ Caves formed primarily by chemical processes (strongly dependent on host rock composition) } \\
\hline $\begin{array}{l}\text { ROCK TYPE } \\
\text { limestone, dolomite }\end{array}$ & \multicolumn{1}{|c|}{ CAVE TYPE } & \multicolumn{1}{c|}{ PROCESSES } & EXAMPLE \\
\hline $\begin{array}{l}\text { Carbonates, e.g., } \\
\text { limestone, dolomite }\end{array}$ & Solution Cave & Carbonic Acid & Mammoth Cave, KY \\
\hline $\begin{array}{l}\text { Carbonates, e.g., } \\
\text { limestone, dolomite }\end{array}$ & Solution Cave & Hydrothermal & Carlsbad Cavern, NM \\
\hline $\begin{array}{l}\text { Carbonates, e.g., } \\
\text { limestone, dolomite }\end{array}$ & $\begin{array}{l}\text { Mixing-Zone or } \\
\text { Halocline Cave }\end{array}$ & $\begin{array}{l}\text { Mixing or Saturation Difference } \\
\text { Freshwater/Saltwater Interface }\end{array}$ & Walkuala Springs, FL \\
\hline $\begin{array}{l}\text { Evaporites, e.g., gypsum, } \\
\text { halite, anhydrite }\end{array}$ & $\begin{array}{l}\text { [Type of Evaporite] } \\
\text { Cave }\end{array}$ & Dissolution & Alabaster Caves, OK \\
\hline $\begin{array}{l}\text { Silicates, e.g., sandstone, } \\
\text { basalt, granite, laterites }\end{array}$ & [Type of Silicate] Cave & Silicate solution & Bat Cave, NJ \\
\hline
\end{tabular}

\section{Cave and Karst Hydrology}

The hydrology of regions with caves has important bearing on the availability of water. In some areas underground drainage patterns are different from surface drainage. Caves can pirate water from one region to another. Alpine caves usually have rapid changes in elevation over short distances and can drain water quickly, leaving surface environs in arid or near arid 
conditions. Lava tubes may also provide rapid transport of water away from the region of rainfall. This is significant as it prevents water from entering the deep groundwater system.

The subsurface karst system typically functions independently of, and with more complexity than, the surface drainage systems above them. The size and shape of the karst groundwater systems often have little or no relationship to the overlying surface drainage systems. The direction of flow frequently cannot be predicted based on surface topography or geologic mapping and the discharge is not always localized at one spot as occurs in a surface drainage basin (Baichtal, 1995).

Table 2 Non-Karstic Speleogenesis Processes and Cave Examples (Gillieson, 1996; Rauch, 2003; White, 1988).

\begin{tabular}{|c|c|c|c|}
\hline \multicolumn{4}{|c|}{ NONKARSTIC SPELEOGENESIS } \\
\hline \multicolumn{4}{|c|}{ Caves formed primarily by chemical processes (strongly dependent on rock composition) } \\
\hline ROCK TYPE & CAVE TYPE & PROCESSES & EXAMPLES \\
\hline $\begin{array}{l}\text { Basalts, typically } \\
\text { Pahoehoe }\end{array}$ & Lava Tubes & $\begin{array}{l}\text { Solidification of rock around } \\
\text { active flow }\end{array}$ & Craters of the Moon, ID \\
\hline Glacial Ice & Ice Caves & Melting of ice along channel & Cosemos Cave, AK \\
\hline \multicolumn{4}{|c|}{ Caves formed primarily by mechanical processes (essentially independent of rock composition) } \\
\hline $\begin{array}{l}\text { Soil: fine-grained, poorly } \\
\text { consolidated sediments }\end{array}$ & Suffosion Caves & $\begin{array}{l}\text { Dissolution and granular } \\
\text { disintegration (soil piping) }\end{array}$ & Officer's Cave Ridge, OR \\
\hline $\begin{array}{l}\text { Most rocks, especially } \\
\text { bedded and foliated rocks, } \\
\text { with well-developed } \\
\text { jointing }\end{array}$ & Littoral or Sea Caves & $\begin{array}{l}\text { Scour by wave action on sea } \\
\text { cliffs, some exudation }\end{array}$ & $\begin{array}{l}\text { Apostle Islands National } \\
\text { Lakeshore, Wisconsin }\end{array}$ \\
\hline $\begin{array}{l}\text { Any rock; good jointing } \\
\text { and lubricating beds }\end{array}$ & Tectonic Caves & $\begin{array}{l}\text { Large scale movement of rock } \\
\text { mass }\end{array}$ & Lamar Cave, PA \\
\hline Massive rocks & $\begin{array}{l}\text { Talus Caves } \\
\text { Rock Shelters } \\
\text { Boulder Caves }\end{array}$ & Pileup of boulders & $\begin{array}{l}\text { TSOD Anorthosite Talus } \\
\text { Caves, NY }\end{array}$ \\
\hline $\begin{array}{l}\text { Massive sandstones, } \\
\text { Loosely cemented }\end{array}$ & Aeolian Caves & $\begin{array}{l}\text { Granular disintegration and } \\
\text { wind transport; scouring by } \\
\text { wind-driven sand }\end{array}$ & Old Man's Cave, $\mathrm{OH}$ \\
\hline $\begin{array}{l}\text { Many rocks, especially } \\
\text { granular lithologies, with } \\
\text { alternating resistant and } \\
\text { nonresistant beds }\end{array}$ & Erosion Caves & $\begin{array}{l}\text { Erosion and slumping - granular } \\
\text { disintegration aided by seepage } \\
\text { moisture }\end{array}$ & $\begin{array}{l}\text { Not typically considered } \\
\text { caves }\end{array}$ \\
\hline
\end{tabular}


A cave is sensitive to water and nutrients entering the cave system. Water and nutrients enter a cave from its recharge area, which includes some land surface and some underground area, including microscopic passageways. The boundaries of the recharge area can be determined by hydrogeological investigation. It is essential to protect the water quality and nutrient loading in the cave's recharge area in order to protect the cave (Bishop \& Huppert, 1990).

Karst conduits can easily transport pollutants away from the source of contamination. In karst regions, water is the primary instrument for surface events to cause subsurface environmental impacts (Gillieson, 1996). Subsurface drainage systems may also serve as hidden reservoirs for pollutants, defying detection until a major storm event or a series of events flush the pollutants through the system to points of detection on or near the surface. This can seriously affect private and public water supplies.

Pollutants - human sewage, industrial and agricultural pollutants, toxic chemical dumps, and animal wastes, especially poultry and cattle - affect not only those living downstream (of surface and subsurface drainages) but also have serious consequences for the biota of the cave systems. Sewage causes significant increases in the population of sewage-loving organisms and a loss of species diversity (Brucker, 2001b). As the health of a cave system goes, so goes the quality of our water.

\section{Biospeleology}

Caves are not isolated environments and studies MUST be conducted in the context of the surrounding surface environments. Surface environments, directly overhead and from surrounding regions, affect the physical habitat of the cave (e.g., water and air chemistry) as well as providing additional nutrient sources for cave biota (Camacho, 1992). The transition zone 
between the surface and underground ecosystems is an important ecotone. The varying surface/subsurface interfaces (caves, pits, sinks, and springs) comprise boundaries that are spatially fixed, separating diurnal changes in light from the permanent darkness. The resulting environmental zones serve as filters for biotic and abiotic fluxes (Gibert, 1997). Unique habitats, such as caves and their entrance zones, occupy a small percentage of the total land base, yet they are disproportionately important as wildlife habitats (Maser, Rodiek \& Thomas, 1979).

Caves serve as permanent or temporary habitats for many species. Thus, caves play an important role in the ecology of these species (Saugey, Heidt \& Heath, 1988). The variety of species that depend on caves during a critical period in their life cycle is remarkable and underestimated (Culver, 1986).

Biospeleology is the study of subterranean habitats and biota (cavernuncoles). Chapman (1993) describes the cave environment as voids bounded by walls of rock; however, unlike previous definitions, there are no limits placed upon a cave's dimensions. Cavernuncoles may be found in spaces accessible by humans or located in impenetrable cavities, the interstitial spaces. Distinctions can be made between interstitial and 'cave' habitats based on distinct biotas. The distinction between terrestrial cave habitats and freshwater aquatic cave habitats is not as clearcut, though there is a clear distinction between communities present in either region and those found in marine cave habitats (Chapman, 1993).

From a human perspective, caves are extreme environments, inhospitable for unaided human occupation. However, for a small group of biota this is not the case. The physical criteria that make them habitable to cavernuncoles include: absence or presence of light; air and/or water filled space; high relative humidity (typically greater than 95\%); relatively low and constant temperatures (near mean annual surface temperature above cave, dependent on altitude and 
latitude, and on morphology of the caves with little daily or yearly fluctuation); generally low levels of food for predators or scavengers; microclimate of specific locations within the cave (especially near walls and in cracks - characterized by thermic and hydric exchanges between the air and wet walls); energy sources; and trophic dynamics (Juberthie, 2000; Peck, 1997).

Cave biota fall into one of five ecological-evolutionary categories: accidentals, trogloxenes, troglophiles, troglobites, and stygobionts. Accidentals do not have a regular association with caves, often having fallen or washed in. Trogloxenes, the cave visitors, do not complete their entire life cycle within caves. An example of trogloxenes is cave-inhabiting bats, who must exit caves to feed. Troglophiles, the cave lovers, complete their entire life cycle in caves, but can live in non-cave environments and include crawdads and cave crickets. Troglobites (terrestrial habitats) and stygobionts (aquatic habitats), the cave dwellers, have evolved adaptations to suit the cave and groundwater environment and are unable to survive outside these environments. These animals typically have visibly distinctive cave-related body features and less evident physiological or behavioral specializations that restrict them to living in subterranean habitats. Troglobites include the blind cavefish (Camacho, 1992; Peck, 1997).

Environmental zones play a part in location of biota within a cave. Zonation of plants, associated with the decrease of light, has been described from the entrance to the dark zone; leafy plants and ferns of the entrance are replaced by hepatics and mosses, and then by algae on the rocks (Juberthie, 2000).

Beyond entrance regions, few terrestrial vertebrates inhabit caves, those that do include bats, small rodents, and the guacharo (oilbird). The majority of cave-dwelling biota includes aquatic vertebrates, invertebrates, bacteria, and fungi. The list of species is ever-increasing as exploration of caves continues. 
A wide variety of fauna has adapted to terrestrial and aquatic niches in subterranean habitats. Within the United States, a large diversity of cave-evolved and cave-limited species is known (Peck, 1997). Cave species of many invertebrate groups, such as spiders and millipedes, are better known than the surface species. Many cave-limited species have yet to be described (Culver, 1989). For example: the study of mites found underground is just beginning (Brucker, 2001b). As much or more data is available on detailed species distribution in caves than for almost any other habitat (Culver, 1989). Over 1300 species (401 stygobiontic species and 906 troglobitic species) restricted to cave and groundwater habitats have been identified in the contiguous United States, especially in the Southeast, Texas, and California (Peck, 1997).

A large diversity of cave fauna occurs in six karst regions in the United States: Florida limestone areas, Appalachians, Cumberland Plateau, Interior Low Plateaus, Ozark Plateau, and Edwards Aquifer. Highly diverse fauna occurs in the lava tubes of Hawaii. Other regions with at least some cave invertebrates include: Guadalupe Mountains, Sierra Mountains, Columbia Plateaus, etc. (Culver \& Holsinger, 1992). No cave region exists in which all the caves have been biologically explored (Culver, 1989). Advances in scientific understanding and technology make it possible to ask new questions regarding what might exist in different cave environments, thus continuing the search for life.

\section{Cave Microbes}

Cave microbial communities represent ecosystems deep within the dark zone of a cave, which support eucaryotic communities of protozoa and invertebrates (Northup, Angert, Reysenbach, Peck \& Pace, 1997). Sulfur, iron, and manganese deposits are good habitats for chemolithoautotrophic bacteria. Chemolithotrophic biotas obtain nourishment through the oxidation of inorganic and organic compounds; as opposed to heterotrophic biotas, which obtain 
nourishment through the utilization of organic material to synthesize living matter. Heterotrophic and chemolithoautotrophic forms may be found in terrestrial or aquatic environments in caves (Northup, Carr, Crocker, Hawkins, Leonard \& Calvin, 1992).

Cave geomicrobiology is a relatively new field. Some heterotrophic and chemolithoautotrophic microbes may be actively involved in the erosional precipitational phases of speleothem development (Northup et al. 1992). Cunningham (1991) was the first to suggest deposition of some forms of speleothems due to biological activities. Chemolithotrophic bacteria provide organic nutrients for heterotrophic bacteria and fungi upon which to feed. Their byproducts result in a variety of depositional features. This process is similar to the process described for deep-sea hydrothermal vent systems. Biokarst is the study of agents (bacteria, algae, fungi, and lichen [surface only]), which are important in deposition, and erosion of calcium carbonate (Viles, 1984). Geomicrobial exploration is increasing the number of known, but little understood bacteria, fungi, and other organisms.

\section{Surface Biology}

Only limited information is available on the importance of the karst landscape to a region's plant and animal life. Caves have been used as resting and denning sites for deer, bear, wolves, and small furbearers. They have also been used as natal den sites for otters. Some bird species including dippers, thrushes, and swallows use cave entrances for nesting and feeding. Seabird rookeries, including cormorants and pigeon guillemots, have been found in littoral caves (Baichtal, 1995).

The karst landscape influences productivity of associated aquatic habitats via geochemistry mechanisms, contributing to productivity in aquatic environments through carbonate buffering capacity and carbon input dissolved from the limestone bedrock. This 
geochemical influence has significant downstream effects on the aquatic food chain and biotic community. It appears that these karst aquatic habitats may be eight to ten times more productive than adjacent non-karst dominated aquatic habitats. The karst aquatic habitats support a higher biodiversity, have higher growth rates for smolts and resident fish, exhibit less variable water temperatures and flow regimes, and contain unique habitat affecting species distribution, abundance, and adaptations (Baichtal, 1995). Changes in nutrient and sediment loads in cave waters can have significant impact on fisheries in karst dominated aquatic habitats.

\section{Speleo Ecosystems}

Scientific descriptions of components and functions of cave and karst ecosystems are still evolving. In a sense, speleology is still in its infancy (Lewis \& Baichtal, 1997). Few studies exist documenting the importance of the cave and karst environment to surface and subsurface biota. In Alaska, the U.S. Forest Service has begun to investigate the role of these areas to plant life, fisheries, and wildlife (Blackwell \& Associates, 1995).

Research is needed in the geochemical and hydrological components of the karst ecosystem. Biological studies need to focus on characterizing the contribution of karst/cave waters to the productivity of aquatic systems, and describe the past and present biospeleology of karst systems. Studies are needed to aid in understanding the relationships of cave microhabitats and morphology in relation to faunal usage (such as bats). A thorough understanding of the systems involved will be crucial in avoiding damage to cave and karst systems through uninformed management (Lewis \& Baichtal, 1997).

Knowledge and understanding of the cave environment is slowly expanding; however, it is evident that much more is yet to be learned. The study of cave ecosystems may provide 
knowledge useful in preventing further environmental degradation and for future human endeavors, such as environmental decontamination and medical treatments of deadly diseases. It has the potential to expand our perspectives on what life is.

Caves and karst are unique, nonrenewable resources, many with features of potential national and international significance. Blackwell and Associates (1995) list attributes associated with karst resources identified in the literature, including: contribution of runoff water to significant fisheries streams; rare troglobitic invertebrates; cave use by large mammals, birds and bats; opportunities to study evolution and adaptation of cave dwelling invertebrates; the relationship between karst formations and forest productivity; recreational potential of unexplored cave resources; and the aboriginal, cultural and paleontological significance of caves and karst landscape.

The potential of human impact on subsurface environments, including caves, is immense. Changes may occur to cave biota, cave hydrology, cave atmosphere, and speleothems (Gillieson, 1996). Numerous activities can potentially have negative impacts upon karst and adjacent nonkarst terrains. The effects of these activities and resulting impacts to the karst can lead to degradation of the cave ecosystem (see Figure 2). While degradation to the cave environment may arise from outside events, human visitation to caves can have significant impact in and of itself. What is needed is an understanding of who is visiting caves, why they are visiting, and how frequently they visit. 


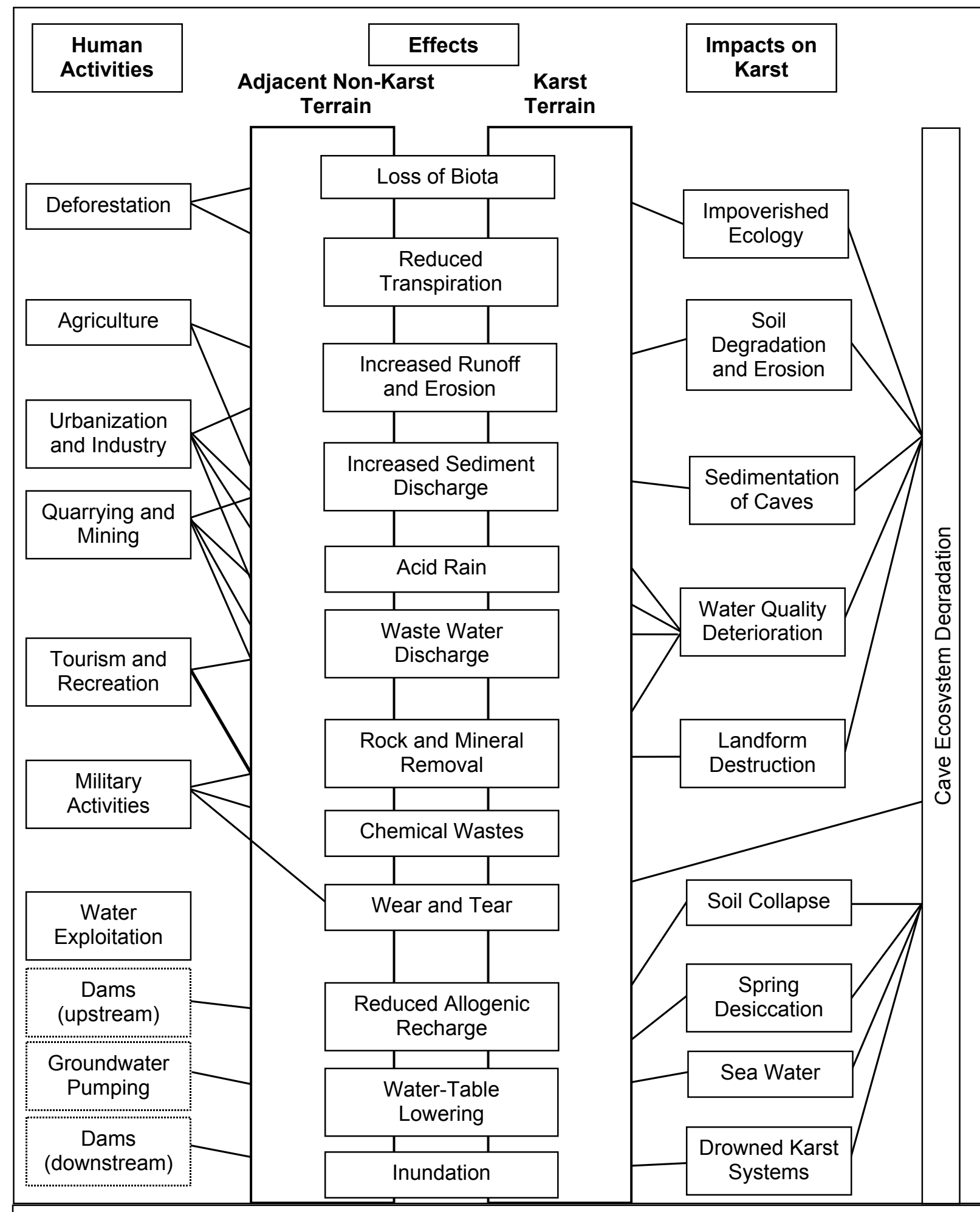

Figure 2. Effects and Impacts of Human Activities on Cave and Karst (Williams, 1993). 


\section{Cavers, Spelunkers, and Other Visitors}

Those who are passionate about caves and caving refer to themselves as cavers; this prevailing over any other title they may have (e.g. occupational, educational, military). Why they go into caves is complex, but at least two motives stand out: the desire to explore the unknown (curiosity) and the physical challenge (Watson, 1966). Many people may attach special importance to outdoor activities in which they participate; the physical challenge provides a sense of vitality not available indoors (Cordell, McDonald et al. 1997). Wilde (1981) elaborates upon motivations:

Primarily it is the element of mystery that surrounds the unknown; and adventure, challenge, danger and uncertainty that attracts cavers to caves. The physical challenges are also closely related to the intellectual challenges and aesthetic rewards. Spiritual, intellectual and physical satisfaction are high on the motivational scale; as are the social and interpersonal relationships formed by the team work required to achieve a successful assault upon a cave. The selfactualizing effects of achievement and companionship are two of the paramount rewards of caving. Also high on the motivational scale is the power, dynamism and harmony of nature and the natural environment (p. 7).

Cavers place great emphasis on the exploration and mapping of caves, as well as the discovery of new caves. In the underground it is still possible, as it is nowhere else on earth, to enter regions never before seen by humans, to place the first careful footsteps, to engage with the spirit of exploration. Although only a few have traveled to the moon, there are places underground that have experienced fewer visitors than have set foot upon the moon. The basic objective of caving is to enter the cave, traverse it to some destination, and return to the surface. A simple goal, yet the accomplishment of this goal is a challenge occasionally requiring technical rope work, rock climbing, and the manipulation of one's body through small crawlways, up and down crevices, and through streams and water-filled passages. It is strenuous activity and requires physical skill and, at times, courage (White, 1988). 
Spelunking is a term with which many people are familiar. From the early 1940's through the early 1970's, cave explorers referred to themselves as spelunkers (Davis \& Werner, 2002). However, this is no longer the case and is politically and technically incorrect (Brucker, 2001b). Among the caving community, spelunkers are an anathema to caves and caving. Knutson (1994) delineates between cavers and spelunkers, defining cavers as those individuals who are trained in current exploration techniques and are knowledgeable about safe and responsible caving. Simply put, spelunkers are not. Spelunkers are typically seen using handheld flashlights, lanterns, or candles, and a baseball cap may be the extent of head protection. These are the people who often have the greatest impact on undeveloped caves as they lack understanding of the need to pass carefully during their adventure underground. They may leave behind garbage as well as their names on cave walls, they may harass the wildlife, and they may break and collect cave formations as souvenirs of their experience. Although spelunkers, individually, are considered occasional visitors to caves relative to the number of visits by individual cavers, it takes only a few careless visitors to forever change the face of a cave.

Scientists who enter the field of speleology may do so because they first were cavers. They may become cavers because of their passion for their field of interest takes them into the realm of speleology. That is not to say that all scientists who enter caves are or become cavers, nor are they specifically interested in speleology. (Outer) Space exploration has generated interest in (inner) space research and experimentation. The search for extraterrestrial life, astrobiology, and, more specifically, the search for life underground on sulfur-rich Mars, lead to research on Earth's underground lifeforms in caves of sulfuric-acid origin. These projects brought speleologists (caver scientists) and non-caver scientists together in the study of cave 
geomicrobiology (Boston, 2001). Driving curiosity and a sense of wonder are perhaps the two characteristics, which above all, unite the caver and the scientist (Chapman, 1993).

Recently, another group of visitors to undeveloped caves has appeared - that of commercially guided tours (often referred to, within the caving community, as pay-for-cave trips). While a few commercial guided trips may fall in the category of spelunkers, many are led by trained guides and provide participants with proper equipment and some training. These groups can be considered on par with novice caver trips. However, the conservation and education component may not be as strong on commercial trips as it is on caver led trips. A majority of the organizations offering commercial trips may best be described as adventure recreation operations, and typically offer other outdoor pursuits such as rock climbing, mountaineering, biking, and hiking.

Not all uses of caves are considered appropriate, particularly when the use displays a lack of understanding of the fragility of the cave environment and has the potential to attract additional use that is potentially destructive, especially when engaged in by the uncaring thrill seeker. Cavers frown upon the dissemination of cave location information to the general public. Most locations are not made public, to protect the cave and its resources. This is often the case with caves found on federal lands, which fall under the regulations of the Federal Cave Resources Protection Act of 1988 (see Appendix B).

\section{The Lure of Caves}

People visit caves for various reasons. They visit in such guises as tourists, scientists, spelunkers, cavers, climbers, and even as eco-challenge participants. The one common factor may be curiosity, though the direction this curiosity may take can vary. Chapman (1993) 
describes the lure of caves as "... a curious fascination about caves that seems to affect people of all ages and all cultures. Even as children, we have a kind of longing for caves, seeing them ... as a source of adventure and excitement - a gateway to the unknown" (p. 9).

Our popular literature is pitted with tales of caves. Perhaps the most widely known is Mark Twain's The Adventures of Tom Sawyer, in which Tom and Becky become lost in a cave. Caves have become a central focus of numerous writings, in a variety of genres, including Robert Warren's novel The Cave, Nevada Barr's mystery Blind Descent, and Michael Ray Taylor's philosophical adventure travel book Dark Passages. Cavers have written books about the exploration of specific caves. Many individuals have been lured into the field of caving by books such as those written about the exploration of caves within the National Park system. Examples include the Mammoth Cave trilogy: The Caves Beyond, by Joe Lawrence, Jr. and Roger W. Brucker, The Longest Cave, by Roger W. Brucker and Richard A. Watson, and Beyond Mammoth Cave, by James D. Borden and Roger W. Brucker; The Jewel Cave Adventure, by Herb and Jan Conn; and Deep Secrets (Lechuguilla Cave) by Stephen Reams, Lawrence Fish, Paul Burger and Patricia Kambesis. Magazines (from scientifically orientated journals to news formats) as well as numerous newspaper articles are released each year featuring caves, caving, and/or cavers. National Geographic has brought caves into our homes, via their television documentary Mysteries Underground. So too have various nature and adventure programs. Caving has even made it onto the giant screen with the MacGillivray-Freeman Films IMAX production Journey into Amazing Caves. Perhaps, then, it is not unusual to see an increasing number of people venturing into the darkness of caves. 


\section{Cave Visitation}

The number of cave visitors is on the increase. The 1994-95 National Survey on Recreation and the Environment (NSRE), coordinated by the U. S. Forest Service, showed that 94.5 percent of Americans sixteen years of age or older participated in at least one of the eightyone specific recreation activities, one of which was caving. Twelve years earlier, in 1982-83, the National Park Service coordinated a similar survey, the National Survey on Recreation (NSR). During this period, the population of the United States had increased $13.4 \%$. There was also an increase in the percentage of people participating in at least one activity, from $89 \%$ to $94.5 \%$. Comparisons of these two surveys indicated millions of new participants in traditional outdoor recreational activities, as well as a sizeable increase in participant numbers in four newly added outdoor adventure activities: rock climbing, mountain climbing, orienteering and caving; activities included because of their growing popularity (Cordell, Teasley, et al. 1997).

Human powered outdoor adventure activities included hiking, hiking to a summit, orienteering, backpacking, backpacking to a summit, mountain climbing, rock climbing, and caving. The four hiking and backpacking activities were considered as traditional recreational activities.

According to the NSRE study, an estimated 9.5 million people, 4.7 percent of the population, went on some form of caving trip at least once during the study year, a number equivalent to the reported participation in soccer. Of the other activities in the human powered outdoor adventure category, only hiking and backpacking related activities exceeded caving in the number of participants (see Table 3) (Cordell, Teasley, et al. 1997).

For the four newly listed outdoor adventure activities, participation rates were infrequent. Participation levels for at least half the participants, in any of the activities, were limited to once 
or twice a year (see Table 4) (Cordell, McDonald, et al. 1997). Of the four, caving was the one activity in which participation of one or two days accounted for a significant number of the participants, $79 \%$ (7.51 million). Whether or not participation in any of the activities would continue or even increase was unclear (Cordell, McDonald, et al. 1997). Although only 2\% of the participants participated one to two days a month (11-25 days per year), this represented 190,000 participants.

Table 3. U. S. Participation in a Human Powered Outdoor Adventure Activity 1994-1995 (Cordell, Tealsey, Super, Bergstrom, \& McDonald 1997).

\begin{tabular}{|c|c|c|}
\hline \multicolumn{2}{|c|}{$\begin{array}{c}\text { U. S. population over 15 years of age, participating in a human powered outdoor adventure activity 1994-1995 } \\
\text { (number in millions and percentage of population) }\end{array}$} \\
\hline Activity & Number (in millions) & Percent of Population \\
\hline Backpacking & 15.2 & 7.6 \\
\hline Backpacking to a Summit & 6.6 & 3.3 \\
\hline Caving & 9.5 & 4.7 \\
\hline Hiking & 47.8 & 23.9 \\
\hline Hiking to a Summit & 16.6 & 8.3 \\
\hline Mountain Climbing & 9.0 & 4.5 \\
\hline Orienteering & 4.8 & 2.4 \\
\hline Rock Climbing & 7.5 & 3.7 \\
\hline
\end{tabular}

Table 4. Number of Days Participants Spent in One of the Four Newly Added Human Powered Outdoor adventure activities (Cordell, McDonald, Briggs, Teasley, Biesterfeldt, Bergstrom, Mou, 1997).

\begin{tabular}{|c|c|c|c|c|c|c|c|c|}
\hline \multirow{2}{*}{ Activity } & \multicolumn{2}{|c|}{$1-2$ days } & \multicolumn{2}{|c|}{ 3-10 days } & \multicolumn{2}{|c|}{$11-25$ days } & \multicolumn{2}{|c|}{$>25$ days } \\
\hline & $(\%)$ & (M) & $(\%)$ & (M) & $(\%)$ & (M) & $(\%)$ & $(\mathrm{M})$ \\
\hline Caving & 79 & 7.51 & 18 & 1.71 & 2 & .19 & .01 & .001 \\
\hline Mountain Climbing & 56 & 5.04 & 36 & 3.24 & 6 & .54 & 2 & .18 \\
\hline Orienteering & 51 & 2.45 & 37 & 1.78 & 7 & .34 & 5 & .24 \\
\hline Rock Climbing & 60 & 4.5 & 30 & 2.25 & 8 & .60 & 2 & .15 \\
\hline
\end{tabular}


An additional thousand individuals claimed more than twenty-five days caving a year. These numbers are staggering, when taking into consideration that the national caving organization, the National Speleological Society (NSS), has an estimated membership of 12,000.

Cordell, McDonald, et al. (1997) arbitrarily defines an 'enthusiast' as the most active one-third of participants in an recreational activity, noting that the most enthusiastic one-third account for much higher proportions of the total participation in an activity. Specialized activities, such as caving, have fewer enthusiasts, than less specialized activities like hiking. However, these enthusiasts account for the majority of participation within each activity. Caving enthusiasts represented approximately 3.16 million people equaling $1.6 \%$ of the United States population (Cordell, McDonald, et al. 1997).

Human powered outdoor adventure activities are growing in popularity. The NSRE study showed that $37 \%$ of the population took part in some form of outdoor adventure recreation. The majority of the people did not often participate, many doing so only once or twice. This was especially true of caving. These numbers indicate that there is enough interest in these activities to represent potential markets for the outdoor recreation industry, not only in terms of equipment manufacture and retail, but also in terms of guide services and commercial outfitters.

Responsible caving requires a certain amount of specialized equipment as well as skill and knowledge. Opportunities exist for commercial outfitters to provide equipment, basic instructions, and guide services to those who have at least a passing interest in caves and caving. They can provide neophytes with a relatively inexpensive and safe introduction to the art of caving. However, just as commercial outfitters changed the image of whitewater rafting from a hard-core pursuit to a fun-in-the-sun activity for the family, so too could outfitters change the image of caving. 
A change in the image of caving, while perhaps improving the perception of cavers, will attract even more people to enter these fragile environments. Increasing numbers of people visiting caves, whether as a once-in-a-lifetime experience or a life-long passion, has far reaching consequences. One positive consequence would be a better understanding of what caves are and thus, hopefully, a greater appreciation for caves and an understanding of how they are integral parts of the world around us. Nevertheless, the negative implications far outnumber the positive possibilities. The increasing number of visitors, ranging from those with only a passing curiosity to those for whom caving becomes a passion, is placing greater pressures on caves and cave resources, many of which are extremely fragile or sensitive to intense visitation. To appreciate the potential extent of negative impacts to the cave environment one needs to understand the art of caving.

\section{Caving}

A lot of people who don't go into caves have theories about why other people do. There's talk that gets all fuzzy and Freudian around the edges, a lot of thumbsucking nonsense about figurative returns to the womb that makes cavers seem just a tad, oh, psychotic. The truth is simple enough: certain people go into caves because most folks don't. The urge is called exploration and everyone understands it to one degree or another. We were, all of us, explorers from our first breath, in a time our world expanded in wonder (Tim Cahill, A Wolverine Is Eating My Leg, 1989, p. 242).

\section{Visiting the Underground}

For the casual cave visitor, the traditional (and simplest) method for experiencing the underground landscape is the commercial cave. Commercial caves have been modified with trails, lights, stairs, and elevators, to provide easy access for visitors without special training or 
equipment (White, 1988). In the United States, over 200 commercial caves, privately and publicly owned, are open to the public (Gurnee \& Gurnee, 1990).

In addition to the standard tour routes, commercial caves often offer off-trail (a.k.a. spelunking or wild) cave tours in the same cave or in another cave on the property. The purveyor of these trips typically provides helmets, electric lights, and a guide. The participants are asked to wear old clothing as they will get dirty, an idea that can be a deterrent to some. The tour routes may or may not have been physically modified; ladders and handlines may be provided to facilitate ease of travel. A few offer trips of a more strenuous nature.

Trips into undeveloped caves, whether of commercial or private nature, require a certain amount of equipment, and dependent on the cave or area visited within a cave, a certain level of physical conditioning. A well-equipped cave visitor will have head protection in the form of a helmet or secured hardhat; a helmet-mounted light, as well as spare batteries and bulbs; extra lights; sturdy clothing, gloves and footgear appropriate for the nature of the cave; kneepads; and a small pack for food, water, extra warm clothing, and extra gear. Those ill prepared (physically, emotionally, mentally, or equipment-wise) for the cave environment may become a danger to not only to themselves but also to the cave.

Information regarding cave locations, access, and maps is generally not in the mainstream of public knowledge. The Internet has made it possible to find information on some caves; typically, these are caves known to local communities and have received heavy visitation, as well as damage over the years. The dearth of publicly available information is primarily due to cavers' desire to protect caves from the acts of the unknowing and uncaring. When cavers express concern regarding cave conservation issues, it is derived from direct observations of noncaver behaviors and from learning about the impacts of their own actions. Actions cavers 
deemed acceptable even as little as ten years ago are no longer considered appropriate based on today's understanding of the cave environment. The standard of behavior prescribed by the conservation ethic continues to rise as the caving community gains a greater understanding of the intricacies of the cave environment.

The nature of caving requires an understanding of one's physical, as well as psychological limitations. Often the way in is the only way out. Cell phones and the majority of radios do not work in cave environments. There are no helicopter rescues. Help for lost, tired or injured cave visitors may be hours away, if not longer, and is dependent on how soon notification for assistance is received. When entering a cave, people need to be aware of the consequences of their actions and to be willing to accept responsibility for their own behavior as well as for others in their group. In spite of these dire warnings, caving can be a very rewarding experience as well as a great deal of fun. Caving is not for everyone, particularly not for those who suffer from claustrophobia, fear darkness and/or fear equipment failure. It is hoped that those who enter a cave, even if they may never return to visit again, leave with an appreciation for why others find caves fascinating environments to explore and study.

\section{Caving Impacts}

All visitors to caves have an impact on the cave itself, its environment, and its contained biology. Anyone entering a cave is guilty of causing some degradation to the cave, knowingly or unknowingly (Gillieson, 1996). Upon entering a cave, it may take a few minutes to adjust to the darkness and gain one's 'cave legs'. It is surprisingly difficult to move on uneven surfaces under limited lighting conditions. Add to that narrow passages, climbing, crawling, mud, and water, and it becomes easy to understand how people new to caves can have an impact on a cave as 
they move through it. A misplaced hand or foot can leave marks that may last years if not forever. Footprints and handprints also become targets for more impact as the next visitors interpret these as additional hand or foot holds to utilize. Formations accidentally broken or intentionally collected (an illegal act in a majority of States and on all Federal lands, if obtained without a collection permit) will not grow back in anyone's lifetime. Low light conditions and small passageways contribute to an increased potential to inadvertently destroy cave creatures.

Gillieson (1996) lists some specific effects of recreational visitors to caves (these are especially true in caves that are heavily visited and do not have some form of access control):

- Enlargement of entrance and passages by traffic or digging.

- Erosion of rock surfaces due to grooving by ladder and rope or direct lowering by foot traffic.

- Compaction of sediments with its effects on hydrology and fauna.

- Cave vandalism and graffiti.

- Carbide dumping and littering.

- Introduction of energy sources from mud on clothes and food residue.

- Introduction of human feces and urine to cave leading to water pollution.

It should also be noted that in the past, cave scientists have caused significant impacts to the cave environment in the course of their research. This damage includes excessive and often unnecessary breakage and collection of formations and biota, unfilled excavation pits, marking of study sites and survey stations with inappropriate materials and methods, and the abandonment of monitoring equipment in the cave. These practices are no longer considered acceptable and in some cases are considered highly unethical (Gillieson, 1996). This can be an important issue when contrasting the potential loss of scientific knowledge with the loss of cave 
resources particularly when in a wilderness setting (Berger, Overbaugh \& Stankey, 1990; Kiernan, 1997).

The entry of a single cave visitor may have little noticeable impact upon a cave; however, they do introduce changes in heat, light, and nutrients (tracked in, shed from clothing and body, or dropped while eating). Increase visitor numbers and impacts become apparent (Stitt, 1977). Physical effects include sediment compaction, erosion, and muddy hand and boot prints (Gillieson, 1996). Even the rock surfaces can become impacted (Stitt, 1977).

In a study of the effects of social, biophysical, and managerial conditions on tourism experiences within the Great Barrier Reef World Heritage Area, Shafer and Inglis (2000) noted that there was little information on how much detail (in terms of damage to the coral) visitors perceived in underwater environments, nor if they could judge the cause of the damage. In a discussion on the objective quality of wilderness (determined mainly by physical and biological conditions), Shin and Jaakson (1997) noted that in some instances, wilderness campers failed to notice weak, unhealthy, or damaged conditions as damage. It is probable that this would hold true for cave visitors.

On a human timescale, caves are essentially non-renewable and impacts are cumulative and possibly synergistic (Stitt, 1977). Speleothem damage and soil compaction are examples of impacts that are irreversible. Flooding of lower levels obliterates footprints in some caves. Physical changes can have severe repercussions on a biological level. Compaction of sediments may have a domino effect, resulting in increased water flow through the cave; associated erosional events may result in the infilling of cave pools and reduced aeration, causing a die-off of biota due to suffocation. Foot traffic around entrances can result in changes within the cave 
due to increased inward movement of fine sediments. It may also reduce the availability of energy-rich food sources for various cave biota.

In general, there are two forms of threat to caves and the cave environment: those that are the result of surface activities, and those that are the result of cave usage and visitation. There exists a close relation between the level of usage of a cave and the level of impact. Cavers have come to recognize that they too are often the primary cause of the damage (Chapman, 1993).

\section{Treasuring the Wild}

There is little question that caves, in their natural state, have scientific value, and they often contain spectacular scenery. Nor is it doubted how easily their unique environments, biologically and physically, can be damaged. It is even understood how relatively rare they are and, when judged by the standards of surface habitats, caves are indeed rare features (Chapman, 1993). Reasons for protecting caves range from habitat protection and preservation of scientific study sites to recognition of cultural importance and the economic benefits of tourism (Watson et al. 1997). Caves have been recognized as national treasures, some receiving congressional protection even before the official establishment of the National Park Service in $1916^{1}$. Caves have even been recognized legislatively, on both federal and individual state levels, as places to be protected. What is missing is the recognition of the value of the untamed wildness that can be

1 There are eight National Parks and Monuments established specifically to protect a cave: Wind Cave NP (1903), Oregon Caves NM (1906), Jewel Cave NM (1908), Lehman Caves NM (now part of Great Basin NP) (1922), Timpanogos NM (1922), Carlsbad Caverns NP (1923 - NM, 1930 - NP), Mammoth Cave NP (1926) and Russell Cave NM (1961). Other National Parks and Monuments contain caves, especially lava tubes; however, caves were not the primarily reason for the establishment of the park or monument. 
found within caves, the recognition that is given to surface environments, that which is called Wilderness.

Worboys, Davey and Stitt's (1982) geographical consideration includes the concepts of remoteness and of wilderness value, yet the establishment of specific wilderness designation for caves or components of cave systems does not exist in their classification system. This failure to recognize the wilderness of caves and its value to those who explore the wildness is a failure to recognize the existence of wilderness in extreme environments which cannot sustain human life unaided by advanced technologies manufacturing light and/or air (e.g. some wilderness areas are water filled, such as submerged caves).

Caves, like rivers and streams, flow through (or rather beneath) landscapes of varied usage, naturalness, and ownership; and, just as rivers and streams have or have not been modified by human actions, so too caves. Unlike rivers and streams, cave boundaries are not always clearly defined; many caves are even now being explored or have yet to be discovered. Not knowing where the cave goes or does not go, knowing only that it continues somewhere, cave cartographers must be tempted to place on maps lacking definitive boundaries the notation from the map makers of old, "Beyond here be dragons." Defining "cave wilderness" may be as elusive as defining cave boundaries and as haunting as the dragons of yore.

\section{Cave Stewardship}

In the United States, the early nineteenth century saw the tentative beginnings of cave management as caves began to be commercialized by private citizens and corporations. By the start of the twentieth century, the federal government had become involved in cave management, with the establishment of national parks and monuments dedicated to the interpretation and 
preservation of caves. A few state and local governments were also involved in cave management. By the 1950's, cavers (represented by the National Speleological Society) had entered the field of cave management. Despite cave management's 150-year history, there existed little in the literature regarding cave management. Each group existed in its own void, managing caves for their own goals and purposes. Little communication or interaction occurred between the groups, regarding the subject of cave management (Stitt, 1982a).

By the late 1960s, a working relationship between cavers and federal agencies had begun to be established. Stitt (1982a) noted “...cavers had discovered that if they did the work, and actively involved themselves in cave management, that they could have a significant influence on the cave management policies of various federal agencies, especially on the local level" (p. 53). It was being recognized that without cavers, managers would know little about the resource they were trying to manage. Cavers knew what was in the caves and where the caves went. This would prove to be an important first link between a user group and the managing agencies.

The first National Cave Management Symposium occurred in 1975. It marked a major milestone in the development of cave management. It brought together those responsible for the management of caves from the private and public sectors, as well as the cavers who not only used the caves, but also were essentially the only ones who had primary knowledge of the caves. Since then, symposia have occurred on national, regional, and international levels. Stitt (1982a) stated:

Cave management symposia have proved their value in several ways. They have provided a forum for cave managers to meet and discuss their mutual problems. They have enabled the publication, in concise form, of a large body of works on cave management. They have encouraged an on-going interest in cave management on the part of a large number of land managers, cavers, and cave owners... (p. 54).

What was true then, is still true today. 
Proceedings of the National Cave and Karst Management Symposia have been one of the primary resources for cave management. Much of the information has been research focused on the biology, geology, hydrology, or archeology of caves. Surprising little of the information is on research regarding the human dimension of cave management.

\section{Cave Management Research}

Although numerous studies have been published on speleological sciences, research regarding cave management is lacking. Zuber (1977) wrote the first academic work on cave management, entitled "A Compendium of Components Relevant to Cave Resource Management." His thesis focused on the components relevant to cave resources management (the physical cave resource, the users of that resource and the resource users' experience) and suggested options available in cave management. Much of his information came from the first National Cave Management Symposium and 'caver publications' (publications of the National Speleological Society and the Cave Research Foundation), as well as cave-related books published for the general public. While his work focused on the recreational use of caves (a factor of the times), it provided the first synthesis of cave management. Two years later, 1979, Huppert wrote a doctoral dissertation entitled "Cave Conservation in the United States: A Historical Perspective and Analysis." The work provided insights into where cave conservation (including management) had come from, who were the primary actors, and where cave conservation and management was heading. Both works are still relevant, providing an essential background for cave management of today. Theirs would be the only academic work in the area of cave stewardship to be conducted in the United States during the 20th century. Numerous 
speleo-scientific works have and continue to be conducted in other fields, contributing to the development of management policies and guidelines.

Academic work outside of the United States included a Jensen's project "A Cave Management Strategy for Alberta," completed in 1991; it drew heavily upon U.S. cave management practices and policies. New Zealand has accounted for at least four works. Wilde's 1981 Bachelor's thesis “Caves. The Cave and Karst Resources of New Zealand” discussed an ecological approach to cave management. Wood (1981) discussed management of caves for wilderness values in his 1981 thesis "Cave Wilderness. The Reconciliation of Conservation and Use." Lewis's 1995 thesis, entitled "Sustainable Tourism. A Case Study of Waitomo Caves," focused on impacts of tourism and the protection of natural resources as pertains to developed and wild caves. A study on recreational impact assessment, mitigation, or monitoring in caves was conducted by Bunting (1999) in his Master's thesis entitled "The Impacts of Recreational Caving on the Physical Environment of Wild Caves."

\section{Shifting Management Perspectives}

At the 1981 symposium, Stitt (1983) noted an enlightened approach to the management of government-owned caves, due in part to an increased awareness of and involvement in cave conservation. Since that time, one of the most significant changes for cave management has been the recognition of the importance of cave resources stewardship aside from the management of those who visit these caves.

The shift in perspective is reflected by the change in cave-related experience and job titles for federal cave managers, a significant difference from those who attended the first symposia. At the 1975 symposium, of the speakers from three federal agencies managing caves, 
none bore the term 'cave' in their job title. Today, the U.S. Forest Service, National Park Service, and Bureau of Land Management all have "National Cave Specialists" and local or regional level cave specialist/resources positions have begun to appear, although specific titles and responsibilities vary among and within each agency. A significant change from the first symposium is the increase in cave management positions, filled by those who explore and understand the resource - cavers. The majority of current cave specialists have developed an interest in caving outside of their work. They specialized in a scientific field (geology, biology, hydrology, etc.) because of their interest in caves and caving, or their area of specialization led them into caving. The demand for qualified individuals to work in cave management is expected to increase steadily (Nieland, 1992).

One of the greatest difficulties in the stewardship of caves is the lack of qualified cave specialists to fill current (and potential) management positions. These positions require individuals with an understanding of surface management and knowledge of cave resources. The employment of competent cave specialists has the potential to do much more toward the protection of cave and karst resources than any other action. Some of the tasks a cave specialist would be expected to perform include: developing management plans; conducting inventories; defining classifications; issuing permits; and serving as liaison and public relations contact for local caving organizations (Goodbar, 1982).

By the late 1980's, a major shift in focus occurred in cave management responsibilities and priorities, from caves as recreational curiosities, with its concurrent focus on protecting cave resources from recreationists, to caves as special entities to be conserved. This shift necessitated an expanded perspective on protection of caves from the potential impacts of various cave resource activities, including surface activities. 


\section{Managing for an Ecosystem}

At many cave sites where previous management practices had focused on caves and individual karst features, management has expanded to include addressing potential impacts from activities outside the cave, recognizing the need for assessing cave and karst as functional ecosystems, considering physical and chemical attributes and associated living flora and fauna. This perspective integrates cave resource management into land management planning on par with other natural resources (Mullins, 1993; Stokes \& Griffiths, 2000). Despite this shift in management focus, caves are still threatened. Carpenter and Busch (1993) observed, "at a time when caves are finally being recognized as something more than commercial tourist attractions" (p. 57), they are under continual environmental assault; subjected to damage and destruction from mining, logging, grazing, agriculture, and dumping activities, as well as urban sprawl. In some cases, preexisting laws give priority to non-cave related resource extraction activities. As a result, it is difficult if not impossible to protect some cave resources (Chase, 1995).

An assortment of cave management approaches have been tried, many based on surface management concepts for related renewable resources such as carrying capacity and limits of acceptable change. These have proved to be unacceptable when applied to an essentially nonrenewable resource. Current approaches include systems of cave classification and visitor impact management (Gillieson, 1996).

The traditional management approach has moved from the simplistic approach of regulating visitor numbers in a cave (easy to implement), to a more complex approach which takes into consideration both human dimensions and environmental factors. The issue is now seen as one of balancing conservation and preservation needs with recreational experiences and scientific research. Two goals are to identify the quality of recreational experience appropriate to 
a specific cave environment and to determine the environmental conditions consistent with that use (Gillieson, 1996). This does not necessarily mean that all caves need to be open to recreational use or even scientific exploration. The possibility always exists for leaving caves "undiscovered," to be explored by future generations of scientists, explorers, and recreational cavers. Focusing protection only on caves and access to caves should be considered an inadequate approach as it may greatly underestimate the biological, cultural, and geohydrological significance of the resource area (Blackwell \& Associates, 1995).

Although the management approach takes into consideration human dimensions and environmental factors, it is still focused on the cave itself. It often ignores the surface ecosystem (karst or otherwise) of which caves are part. Management practices need to be developed that include surface areas (karst and nonkarst) as well as the associated cave characteristics, providing protection for both these environments (Blackwell \& Associates, 1995). As management practices continue to improve, it is hoped that they will eventually expand to include the surface ecosystem, instead of focusing on one component of the total system - the cave.

Various management tools have evolved that establish the value and fragileness of a cave, and consequentially the degree of access. Establishing the import of a cave or cave passage is a first step in the development of a cave management plan. Criteria used in evaluations include geological, geomorphological, hydrological, biological, archeological, cultural, and geographical considerations (Worboys, Davey \& Stitt, 1982). The extent of cave access is dependent on a variety of criteria: safety, fragility, scientific value, exploration, and skills required to negotiate the cave without damaging (or further impacting) the resource. In large, complex caves, a similar system of zoning may be utilized (Gillieson, 1996). 
Managing for caves and karst, and management of those who visit them, covers a variety of cultural and biophysical resources, as well as numerous aspects of human dimensions. Management of such areas involves balancing the enjoyment of visitors with the protection of a broad spectrum of biophysical and cultural resources (Shafer \& Inglis, 2000). Given the many ways in which caves are formed and the environments in which they can be found, management cannot be unilateral. This does not preclude the establishment of universal management goals, such as survey, inventory, and environmental protection. Just as management of the Brazilian rainforest is different from the rainforest of the Puget Sound and Puget Sound is different from the Alaskan rainforest, so too does the management of caves and karst environment differ across regions.

An increasing recognition regarding the significance of cave, karst, and pseudokarst resources comes with an increasing awareness of their vulnerability. Caves, associated features, and resources are an integral part of the karst landscape. Caves and their surface landscapes must be managed as an ecological unit to ensure protection of the cave resources (Baichtal, 1995). The goal of the cave and karst management is to maintain and protect the natural karst processes and the productivity of the karst landscape while providing for other land uses where appropriate. Management includes assessing a karst resource's vulnerability or sensitivity to a proposed land use, and recognizing the differences in intensity of karst development across the karst landscape (Baichtal, Swanston, \& Archie, 1996).

\section{An Emerging Natural Resources Management Field}

Today cave management (and its complementary field of karst management) is an emerging field within natural resource management, taking its place beside traditional fields such 
as forestry, range, wildlife, and recreation management (Nieland, 1992). As with any new field, limited educational and research opportunities exist at some of the nation's colleges and universities. Western Kentucky University's Center for Cave and Karst Studies (established in 1978) offers course work on geology and hydrology of caves as well as an introduction to caving and a history of exploration of Mammoth Cave. The center's primary focus is on karst groundwater. In the spring of 2001, the Bureau of Land Management offered its first agency course on caves and karst management; it had been over ten years since the National Park Service had offered a similar course. As of yet, no formal university program exists for teaching the art and science of cave and karst management in the United States. A need exists for formalized cave stewardship and management educational programs, including the development of appropriate textbooks on the subject.

One problem with successful [recreation-based] cave management is that it is inherently self-defeating, the better the educational programs, the more visitors (Sullivan, 1985). Cave visitation has been steadily increasing, not only in developed caves, but also in wild caves (Cordell, MacDonald et al. 1997, Wilson, 2002). This increased visitation is coming into conflict with resource protection concerns. An emphasis on the recreational use of a cave may cause the resource base to suffer, and other equally important attributes of the cave may become of secondary concern. These resources need to be given equal consideration with recreational use when determining how and for what use a cave is to be managed. In many cases, it may be possible to accommodate recreation while still protecting other cave resources. However, in some instances, other resources will be of greater priority than recreational use. While archeological, paleontological, and Native American resources are protected under law, no such mandate exists to guarantee recreational use of all caves (Chase, 1995). 
In order to protect caves from the general public's use and impact, the caving community had maintained a low profile. The result was a lack of public awareness regarding caves, cave conservation, and cave management. This translated into a lack of support for funding and thus a lack of resources for government-related cave management programs (Stitt, 1985). Stitt (1985) recommended a higher public profile, educating the public regarding the value of caves, while at the same time not encouraging them to visit wild caves. It was felt that an increased awareness and understanding of caves might result in greater support for cave management. Greater support could mean greater protection for caves. This call for public education would come at an important time in caving history. Education is a powerful tool for promoting cave conservation; opportunities to utilize this strategy are often missed (Jensen, 1991).

Although significant cave discoveries were being made across the country prior to this, 1987 would mark the beginning of the end for caving as a relative obscure activity. While the National Speleological Society was ramping up its public education programs on cave protection, events were transpiring to bring caving to the public's attention as never before. 1987 was the year that three weeklong caving expeditions (involving cavers from all over the country) each doubled the known extent of Lechuguilla Cave, in Carlsbad Caverns National Park, New Mexico. It is difficult to conceal the excitement generated as the known extent of a cave goes from a little over a mile long to three miles in one expedition, then doubles to six by the end of the second expedition, and finally doubles again to twelve miles by the end of the third expedition. The explorers wrote stories for local, regional and national caver publications Writers and photographers published stories in numerous popular and scientific magazines. Articles appeared in newspapers around the country. The Denver Natural History Museum produced a 
video, shown nationally on PBS stations. The exploration captured the heart and imagination of the general public as well as the caving community.

Caves continued to remain in the public eye. In 1991 the exploration and discoveries in Lechuguilla Cave appeared as a feature article in National Geographic (Cahill, 1991) a significant fact as the only other times such articles appeared was in 1924 and 1925, on Lechuguilla's sister cave, Carlsbad Cavern (Lee, 1924; Lee 1925). Since that time, cave exploration has bee the subject of several feature articles. A nationally publicized multi-day rescue in Lechuguilla cave, just one month after the National Geographic article, highlighted the risks explorers face. In addition to the media coverage of caves, the public began experiencing caves outside the traditional experiences provide by show caves. The rise in popularity of adventure recreation attracted increasing numbers of individuals participating in cave-related adventure recreation. This also resulted in the increase in the publishing of high adventure formatted cave stories. During the past fifteen years, or so, caves have been brought to the general public's attention on more levels and in more ways (including recreational) than ever before.

\section{Cave Protection Legislation}

The beginning of the twentieth century marked America's recognition that caves were part of the nation's natural treasures by the inclusion of "cave parks" in the National Park System. However, recognition that these natural treasures were more than mere sideshow attractions, that caves are significant and valuable components of the ecosystems in which they are found, that they require active stewardship and protection, would not occur until the end of the twentieth century. 
By the 1970's, the National Speleological Society (NSS) had initiated a public education program focused on developing public awareness and understanding regarding the significance and vulnerability of caves. At the same time, a few cavers would have an effect on a more personal level; they had become federal employees, whose jobs dealt with the management of caves, thereby placing themselves in the forefront of developing public cave policy. The results were an increase in protective legislation, specifically for caves, on state and federal levels, possibly attributable to the development of public awareness and understanding of values associated with caves.

\section{State Legislation}

Initial cave protection legislation was not focused specifically on protecting caves. Its origin lay in the concept of private property and its protection. The first cave laws were probably established for the benefit of commercial cave owners, as the laws were drafted to protect commercial caves from vandalism while still allowing the right to remove formations from other caves to sell to tourists. They did not directly protect the cave and its environs; they primarily protected the landowner from loss (Stitt, 1976a).

The passage of cave protection laws acknowledges, publicly and legislatively, that caves and their biophysical features are of value. All current cave protection acts have been enacted or revised since 1976, with the exception of Oklahoma's 1967 law. The same period saw the revocation of three states' cave-related laws during sessions aimed at removing 'unnecessary' laws from state records. The mid 1970's through early 1990's may be considered the 'glory years' of state cave protection legislation (Huppert, 1999). Currently only 25 states and protectorates have cave protection laws. Appendix A includes a listing of states, federal 
protectorates and other U. S. legal entities cave protection laws. It describes specific actions and associated penalties covered under the law.

Several states have been identified where the enactment of cave protection legislation needs to be a priority. Alaska's southeastern caves are under threat from timbering; the ecological significance of these caves to the region's other natural resources (e.g., fishing industry) is only now being understood. Many of the western states such as Colorado, Wyoming, and Utah lack cave laws. Large portions of these states are federally owned, thereby providing caves located on these lands protection under various federal statutes. Other states requiring legislative attention include Minnesota, Iowa, and New York, as well as the U.S. protectorate of Guam (Huppert, 1999).

The effectiveness of state cave laws is unclear as it requires 1) identification of intruders/vandals; 2) request of cave owner for prosecution; and 3) recognition on the part of law enforcement of the seriousness of cave vandalism, trespassing and theft (Huppert \& Wheeler, 1982). Enforcement can result only with the understanding by law enforcement officials and the public regarding the key roles caves have in the ecosystem. Positive environmental ethics cannot be legislated; it comes via education of land managers and landowners, as well as the public at large (Kerbo, 2000).

An example of a successful criminal prosecution under State cave protection legislation occurred in Kentucky in 1997. A break-in, vandalism, and theft occurred in a cave that is part of the Mammoth Cave System. Just after the discovery of the break-in and destruction, cave formations where discovered for sale in a local rock and mineral shop, an activity illegal in the State of Kentucky, under the State's cave protection law. The shop owner identified the individuals from whom he obtained the formations (coincidently, the same individuals signed the 
cave register on the day the break-in occurred). Expert testimony, through scientific investigation, identified the formations as those stolen from the specific site within the Mammoth Cave system. The individuals were convicted under the cave protection law. Although the formations have been returned to the cave, only a few have been pieced back together. The damage is evident and will be everlasting (Brucker 2001a; Palmer, 1999).

State laws vary in the extent of coverage; many protect all cave features (formations, biota, water, archeological remains, etc.), while some apply only to formations. Some laws protect only state-owned caves; others protect caves on private lands (Huppert, 1995). The more recently enacted legislation tends to be the most encompassing and is more inclusive of the various elements comprising cave ecosystems, and with greater penalties (Huppert, 1999).

A few states included landowner liability protection within the cave protection legislation, including Ohio, Maryland, Virginia, and West Virginia. A number of state laws provide landowners liability protection for non-fee access of caves on their lands. In some states this protection is extended via recreation related laws (e.g., Kentucky and Alaska).

While people traditionally consider cave habitats as 'dry-land' environments, these cave protection laws, as well as liability protection laws, are applicable to submerged caves. This is an important consideration in states such as Florida and California.

\section{Federal Legislation}

Prior to 1988 , no federal cave protection legislation existed. This did not preclude the protection of some cave resources under statutes aimed at other concerns. These statutes include: the Antiquities Act of 1906, the National Parks Act of 1916, the Historic Sites Act of 1935, the Historic Preservation Act of 1966, the Wild and Scenic Rivers Act of 1968, the National 
Environmental Policy Act of 1969, the Endangered Species Act of 1973, the Archeological and Historic Conservation Act of 1974, and the Archaeological Resources Protection Act of 1979. In addition, protection of cave resources can occur under numerous environmental statutes concerned with groundwater protection (Huppert, 1979; LaMoreaux, Powell, \& LeGrand, 1997; Halliday \& Stitt, 1996) ${ }^{2}$.

With the passage of the Federal Cave Resources Protection Act of 1988 (FCRPA, see Appendix B), Congress added cave stewardship to the national agenda. A landmark act, FCRPA directed the Secretaries of the Interior and Agriculture to inventory and list significant caves on Federal lands, as well as provide for the management and dissemination of information regarding caves and cave locations (Kerbo, 1997). The passage of the Act acknowledged the need to protect "an invaluable and irreplaceable part of the Nation's natural heritage" and stated, "in some instances, these significant caves are threatened due to improper use, increased recreational demand, urban spread, and a lack of specific statutory protection" (Federal Cave Resources Act of 1988, Section 2).

Confidentiality of cave locations was a critical component of FCRPA, exempting the cave location information under the Freedom of Information Act. However, this did not preclude the release of cave locations for visitation if such visitation would not put the cave at risk of damage and would further the intent of the Federal Cave Resources Protection Act.

The intent of the Federal Cave Resources Protection Act is to protect cave resources, not karst resources. However, it is important to recognize that the majority of caves and associated features and resources are an integral part of the karst landscape (Baichtal, 1995). FCRPA does

\footnotetext{
${ }^{2}$ See LaMoreaux, Powell, \& LeGrand's 1997 article for an extensive listing of Federal and International laws that can be applied to protecting groundwater in karst areas.
} 
not mention the term karst despite the fact that the majority of caves are found in karst environment. The Act failed to address surface issues as applied to karst and cave protection.

The protection of cave and karst areas gives rise to various special issues. The boundaries of any of these systems may be difficult to determine. Cave and karst groundwater systems cannot be delineated by the surface watershed area, of which the karst may be only a part. The subterranean divide that bounds the groundwater watershed often is different from the surface divide. Effective cave and karst management of many protected areas involves non-government lands and the need for negotiation of conservation agreements or easements with private landowners and managers (Watson et al. 1997).

It is fundamentally important to recognize that the proper protection of caves and karst is not just a matter of preserving rare, beautiful or scientifically interesting natural features. In most cases, protection has far-reaching environmental implications, which in turn generate significant economic impacts. In particular, proper management of karst is an essential element of water resources management; water critical to the well being of regional flora and fauna, as well as to humans (Watson et al. 1997).

A major concern regarding FCRPA is that it states that cave conservation should not interfere with the development of oil and gas and mineral resources. Balancing interests in developing oil and gas resources with the protection of cave and karst lands and the water resources associated with them is a challenge (Goodbar, 1999). Directional drilling provides a method to avoid drilling impacts to cave and karst resources while allowing for access to oil and gas resources. Such technology would allow for the continuation of mineral exploration and extraction, without placing cave resources at risk. This method laterally moves the drilling platform off the area of concern to a location requiring a directional well to hit the downhole 
target. The directional portion of the well is typically below any cave or karst resource (Goodbar, 1999). Changing technological considerations will be important in the on going efforts to protect cave and karst resources.

While there are concerns regarding the Federal Cave Resources Protection Act, it helped establish the values of caves beyond that of recreational usage and it acknowledged the importance of cave management on a national level. Five years following the passage of the Federal Cave Resources Protection Act, Congress recognized the importance of protecting not only a cave, but also the need to protect its surrounding lands, another step forward in Congressional recognition of cave and karst stewardship. The Lechuguilla Cave Protection Act of 1993 was enacted "to protect Lechuguilla Cave and other resources and values in and adjacent to Carlsbad Caverns National Park," New Mexico (reference Appendix C for the complete act). The Lechuguilla Cave Protection Act withdrew all Federal lands within the boundaries of a cave protection area from all forms of mineral and geothermal leasing (Kerbo, 1997). Not only did this Act suspend new oil and gas, mineral or geothermal leasing within the cave protection area, it authorized the Secretary to cancel any existing leases (with appropriate compensation). This was an important step in congressional recognition that caves and their resources are on par with other natural resources in terms of value and importance.

The Lechuguilla Cave Protection Act addressed two additional features of note: 1) the issue of multiple surface ownerships (National Park Service and Bureau of Land Management); and 2) it designated a surface protection area based on cave potential rather than currently explored passage. It should be noted that the surface of the National Park Service portion of the cave protection area was designated as wilderness prior to the exploration of Lechuguilla. The same is not true of the Bureau of Land Management portion. In addition, the only known 
entrance to Lechuguilla Cave is located on the National Park Service portion. As groundbreaking as the Lechuguilla Cave Protection Act was, it failed to provide wilderness designation.

The majority of the State cave resources protection laws have been passed since 1976 . The two Federal protection laws were passed in 1988 and 1993. The passage of these laws indicates an increased understanding of and appreciation for cave resources. This can be attributed to increased speleo-related scientific research and dissemination of knowledge through public (and legislative) educational programs. However, despite increasing recognition for the need to protect cave resources, there exists no legislation to celebrate cave resources - no cave wilderness designations have occurred. It takes more than environmental awareness to obtain legislative action. It takes continual public support, support that may be gained through an understanding of the public's values and concerns regarding wilderness, caves, and a potential cave wilderness designation.

\section{Wilderness and Caves}

\section{Wilderness}

The movement to preserve and protect the American wilderness has a long history. The first major piece of wilderness specific legislation was introduced in 1958. Six years and numerous revisions later, it was passed by Congress. We know it today as the Wilderness Act of 1964 (see Appendix D). Since then, additional acts have created additional wilderness areas as well as expanded upon the idea of wilderness. The Wilderness Act of 1964 created a legal definition of wilderness, upon which all existing wilderness designations were based:

A wilderness, in contrast with those areas where man and his works dominate the landscape, is hereby recognized as an area were the earth and its community of 
life are untrammeled by man, where man himself is a visitor who does not remain. An area of wilderness is further defined to mean in this Act an area of undeveloped Federal land retaining its primeval character and influence, without permanent improvements or human habitation, which is protected and managed so as to preserve its natural condition in which (1) generally appears to have been affected primarily by the forces of nature, with the imprint of man's work substantially unnoticeable; (2) has outstanding opportunities its for solitude of a primitive and unconfined type of recreation; (3) has at least 5000 acres of land or is of sufficient size as to make practicable its preservation and use in an unimpaired condition; and (4) may also contain ecological, geological, or other features of scientific, educational, scenic, or historical value (Section Two c).

The definition of wilderness has transformed over time as the values attributed to wilderness have expanded and the philosophical justifications for preservation have evolved. An excellent perspective on the concept of wilderness, its evolution in the American psyche, and the future of wilderness may be gained from a review of the works of four writers: Max Oelschlaeger The Idea of Wilderness, Roderick Nash Wilderness and the American Mind, Michael Frome Battle for the Wilderness and Paul Sutter Driven Wild. The meanings of wilderness shift and change along with the shift and change in the values and attitudes of those offering the definitions. The evolving definitions of wilderness are tightly linked to the values wilderness contains for people. Future definitions and meanings will probably relate to yet unknown wilderness values (Hill, 1994).

Many who write about wilderness refer to the Wilderness Act of 1964 for a definition of wilderness. Numerous writers focus on the first sentence of this legal definition as the core meaning of the term wilderness. Shea (1999) describes the definition as fitting, even eloquent, yet the images and emotions evoked by the word "wilderness" go beyond the language of the Wilderness Act. In this all-important sentence, wilderness is defined as a natural area that is unfettered, free, and not permanently occupied by humans. This then became a criterion for wilderness. When wilderness preservation is discussed, it typically refers to allowing an area that 
exists apart from humans to continue to exist without human controls. This definition of wilderness expresses an ideal concept of wilderness. Wilderness is an undeveloped, untrammeled area that exists apart from us and is valued in a positive manner. In other words, wilderness refers to non-human forces, processes, relationships, and entities (both living and dead) that have a non-cultural, natural history and embody a form of more-than-human autonomy (Woods, 1997).

According to Woods (1997), a wilderness preservation ideal is comprised of three components: metaphysical, normative, and political-legal. The metaphysical component consists of ontological and scientific claims about what wilderness is and what we can say exists in wilderness. The normative component captures the values found in, or ascribed to wilderness. The political-legal component is a protecting umbrella under which wilderness and its values are preserved. From this model is generated policy claims regarding the best way to achieve the preservation of wilderness by providing legal protection brought about by political means (Woods, 1997).

\section{Wildness and Wilderness}

Wildness is an essential quality of wilderness. Thus, wilderness is land that is considered wild. Wildness can be defined as a function of two independent qualities: naturalness and freedom from cultural control (untrammeled). Wildness increases in two directions along gradients of freedom and naturalness. Freedom progresses from tight cultural (human) control to no-control or "self-willed" (Aplet, Thomson \& Wilbert, 1999). The lack of controlling cultural forces is critical for establishing the presence of wildness. Woods (1997) uses the term "wildness" to express the same idea. Five identifying features of wildness are: 1) the 
spontaneous agency of non-cultural nature (autonomy); 2) non-cultural genesis due largely to non-cultural presence and control for a length of time that need not extend continuously to the first appearance of freedom; 3) it can re-emerge over time in the absence of cultural forces; 4) it exists on a continuum defined by degrees of human impacts; and 5) it can be predicated of humans and human activities to the degree to which humans and their activities are shaped by non-cultural as well as non-rationally bound forces (Woods, 1997).Like freedom, naturalness exhibits similar degrees of progression. Naturalness progresses from artificial to pristine (Aplet et al. 1999). Naturalness has five defining features: 1) it has a non-cultural genesis; 2) it has a non-cultural history; 3) it denotes a distinctive causal continuity with the past; 4) it exists on a continuum that is defined by degrees of human cultural impacts; and 5) it can be predicated of humans and their activities to the degree to which humans and human activities are shaped by non-cultural forces (Woods, 1997).

Perceptions of wildness vary among people. However, it appears that there is a narrow range of characteristics contributing to the freedom and naturalness of a place. The literature suggests that the attributes of wild land contributing to its freedom are 1) the degree of opportunities for solitude; 2) remoteness from mechanical devices; and 3) the extent to which ecological processes remain uncontrolled by human intercession. Attributes contributing to its naturalness are 1) the degree it maintains natural structure; 2) the extent it remains unaltered by human construction; and 3) the level it is unpolluted. Individually these attributes need not be at the highest level in wilderness; however, jointly, they define the qualities of freedom and naturalness, thus aiding in the measurement of wildness (Aplet et al. 1999).

These same attributes of freedom and naturalness have significance in defining the continuum of cave wilderness, from commercialized, developed, undeveloped and heavily 
visited, to wild and wilderness caves, receiving limited visitation. This may have relevance in determining whether wild cave and wilderness may be contained within the same cave or cave system that has had portions commercialized or developed.

Three common defining features are evident in examining the properties of naturalness and freedom in wildness. First, these properties are for the most part defined as being noncultural (non-anthropocentric). Second, naturalness and freedom are common to all wilderness areas, but other properties/values may be found in any given wilderness. Third, naturalness and freedom are embodied in different physical, biological, and ecological levels (Woods, 1997). Wilderness is where freedom and naturalness are highest (see Figure 3). These characteristics can be attributed to any parcel of land, regardless of size or ownership. Thus, wilderness is not limited by size or ownership (Aplet et. al. 1999). Wilderness is also not limited to the surface of the earth, it may be found in subterranean or marine environments.

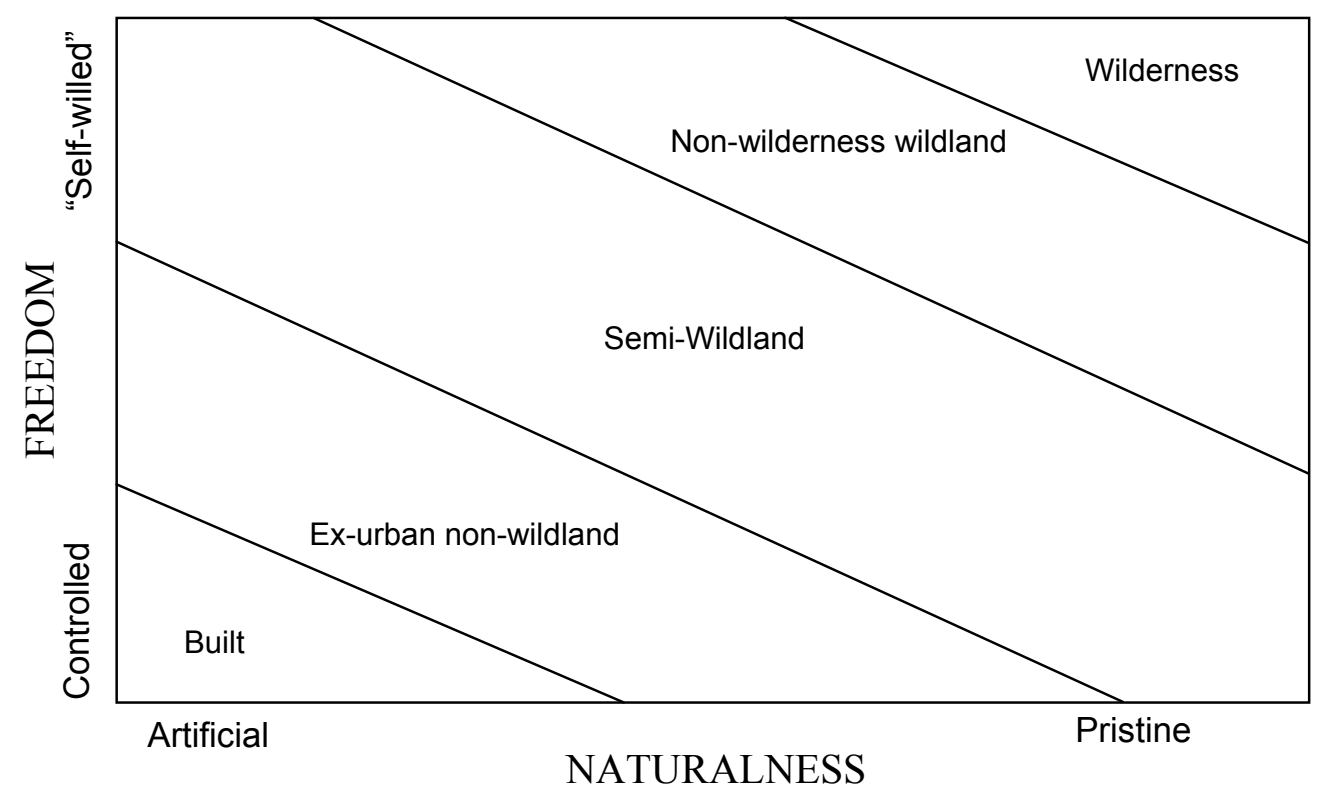

Figure 3. The Continuum of Wilderness (Aplet, Thomson \& Wilbert, 1999). 
As mentioned previously, wilderness may be defined as lands where freedom and naturalness are the highest, and may be embodied in different physical, biological, and ecological levels (Woods, 1997). However, not all ecosystems and natural landforms are represented in the wilderness system, though many currently exist in defacto wilderness (Glicksman \& Coggins, 1999). Measuring an ecosystem and/or landform by its degree of wildness can aid in the identification of wilderness sites - de facto or legal. Glicksman and Coggins (1999) assert that official wilderness should be expanded to include ecosystems and landforms not currently represented in the wilderness system. This would include karst lands and, more specifically, caves.

Wilderness is more than a legally defined land category; it is also a geophysical reality. Geographically, wilderness is any place that is relatively untouched by humans and remains undeveloped. Legally, wilderness consists of those places that have received Congressional designation and are thereby protected from future development. These places are known as official wilderness. A wider range of geographic wilderness is compatible with official wilderness. It may be possible, through implementation of other or new federal land management statutes, to address problems in the establishment and management of uncommon wilderness (Glicksman \& Coggins, 1999). Thus far, all official wilderness areas have been created from lands already owned by the federal government. Many national recreational areas, including river and trail systems, have been created from a combination of public and private lands, utilizing purchase, condemnation, exchange, zoning, and cooperative agreements as the means of acquisition and enforcement. Neither geography nor laws are barriers to doing the same for wilderness (Glicksman \& Coggins, 1999). 


\section{Cave Wilderness}

We speak of its being our cave, and we certainly think of it as our creation. It was not there before. Until cavers went through it.... Like the notion and existence of wilderness, it depends on human recognition and appreciation for its being (Watson, 1976, p. 11).

During the same period as the evolution of cave management policies and practices, members of the caving community were campaigning for the establishment of cave wilderness. The start of the twenty-first century marked America's recognition that caves needed protection from environmental degradation and abuse; cave stewardship had come into its own. Caves had acquired an unusual state of valuation, recognized as an ecosystem deserving of active management and protective legislation, and yet denied the highest recognition of value accorded to a habitat, that of wilderness status.

Caves are natural systems, similar in most ways to other natural systems. The one exception is that caves are not renewable on a time scale that is appreciable. Once existing cave formations are damaged or destroyed, they are essentially gone forever. There is little room for error related to management decisions; what is changed, is changed forever. There is only one chance to keep a cave wild and natural, to keep as wilderness. Once that is gone, there is no going back (Smith, 1988).

Smith (1988) made a superb analogy, comparing caves to books in a university library. The books available for general circulation might be likened to those caves developed for tourism. As restrictions are placed on the circulation of and access to various books, so to can be said of caves. The more restricted the access, the less impact on the caves. The library's greatest treasures are to be found in the rare book room, a once in a lifetime opportunity for the researcher and explorer of knowledge. The materials contained within are far too delicate and valuable for even random contact. Access is closely guarded. Those permitted to view the 
materials are scholars and scientists who are pushing back the frontiers of knowledge. There are caves that are just as delicate and valuable; they are part of the Nation's treasures and need to be closely protected. Access may need to be limited to scientists and explorers, those pushing the frontiers of knowledge and of the unknown.

Caves represent one of the greatest, and perhaps least understood, environments that we have left in the world today. They are one of the last frontiers on Earth. Caves are one of the last unmapped areas of the continental United States. The same can be said for many other nations. Below the surface are vast areas untouched and unseen by humans. Few wilderness areas are as pristine as that which lies below the surface (Stitt, 1976b).

At one time wilderness began at the edge of the unknown. The wilderness of today is significantly different from the wilderness of the past. It has been surveyed, mapped, and assessed. It has become bounded and protected. Wilderness is still a landscape that awes and inspires, but it has also come to mean a landscape defined by the lack of visible human modification. There are no longer places left on the map of the nation that are denoted with "Beyond here be dragons." Unknown wilderness is extremely rare. Caves, many small compared to other land formations, are unknown wilderness (Ganter, 1990).

Caves as potential wilderness are the embodiment of the legal definition of wilderness. They are areas where the earth and its community of life are uncontrolled by the activities of humans. They are places where humans are only visitors, lacking the ability to traverse the total darkness without the aid of light, something that cannot be obtained by using cave resources. However, there is more to wilderness than just physical requirements. There is an inference that it must affect people in a particular way. It is necessary to differentiate between the physical aspects of wilderness and the experience of wilderness (Watson \& Smith, 1971). The idea of 
wilderness has been thought of both as a place that is free and a place in which to be free, a place and an experience (Aplet et al. 1999). A wilderness experience may be composed of aesthetic appreciation, feelings of self-reliance, and a perspective of remoteness from day-to-day activities and instruments of humans. Thus, another definition of wilderness is that which provides the experience of wilderness (Watson \& Smith, 1971).

Kerbo (1988) asked why should cave wilderness be such a critical concern in protecting cave resources, particularly when caves in wilderness areas appear to be protected and federal agencies have various management options available for protecting other caves. However, management policies and plans can be relatively easy to be changed. Caves may have passages extending beyond surface wilderness. In both cases, caves could be exposed to extensive damage from development activities. Trails, lights, parking, and other assorted visitor facilities can affect caves on an ongoing basis. Such changes can occur in spite of current protected status and without extensive public hearings. Wilderness designation would require an act of Congress, as would removal of such designation. Cave wilderness designation would protect designated caves from further exploitation. A wilderness designation for caves would show land management agencies and the public that the commitment to cave management is as serious as any other resource protection. Wilderness is not limited to surface lands; it is not one-dimensional (Kerbo, 1988).

The Wilderness Act and Caves

During the years that the Wilderness Act was under Congressional consideration, numerous studies and hearings were conducted. The Outdoor Recreation Resources Review 
Commission (ORRRC), in its 1962 Study Report No. 3 under the section: Summary of Major Findings and Recommendations, noted the potential wilderness value of caves:

Rivers and caves are considered in the report as important potential wilderness resources, and we have attempted a limited inventory of wilderness rivers and discussion of cave preservation in appendixes to the full report. It is apparent that special study is needed to develop suitable definitions for these recreation resources, which can be applied in survey and management efforts (ORRRC p.4).

The study report also included a report submitted by de Saussure in Appendix B entitled Cave Resources This report, as well as testimony by representatives of the National Speleological Society, was taken under review during preparation of the final draft of the Wilderness Act (Stitt, 1982b; Stitt, 1993).

Although the Wilderness Act of 1964 made no specific mention of caves, cave conservationists felt that Congress was aware of their potential as wilderness and had intended to include them, just as other natural features were included without specifically being named (Stitt, 1982b). Despite caves not being specifically mentioned, conservationists concluded that caves were not excluded from wilderness designation. A new term was coined - "underground wilderness" (Stitt, 1983).

The terms cave wilderness, subterranean wilderness and underground wilderness are synonymous. Much of the literature regarding cave wilderness has used the term underground wilderness. The term cave wilderness will be used here, to clearly delineate natural underground voids, caves, from manmade structures, such as mines and tunnels.

Unlike the conservationists' interpretation of the Wilderness Act, the National Park Service took the stance that caves were not eligible for inclusion in the National Wilderness Preservation System precisely because the Wilderness Act did not specifically mention them (Stitt, 1993). A statement to this regard was included in the National Park Service's "Draft 
Environmental Statement for the Master Plan and Wilderness Study for Mammoth Cave National

Park," released on 24 April 1974:

Much of the discussion about "underground wilderness" has focused on the Flint Ridge Cave System, which has been studied and mapped by scientists since 1947. The proponents of underground wilderness feel that the language of the Wilderness Act is broad enough to cover this concept except for the "semantic problems of subsurface acreage." Surely, caves are places where "man himself is a visitor who does not remain," and they provide truly "outstanding opportunities for solitude." On the other hand, the words "landscape," "area," and "land" all appear in the definition of wilderness in the Act and each refers specifically to the surface of the earth, according to the dictionary. Clearly, when considering passage of the Wilderness Act, Congress did not extend the concept of wilderness to caves or cave systems. In view of the fact that underground wilderness was not identified in the Wilderness Act, nor have underground wildernesses been established subsequently, the National Park Service neither endorses nor proposes underground wilderness for Mammoth Cave National Park (p. 48).

In June of 1974, Robert Stitt (acting as conservation chairman for the NSS) wrote a legal brief contesting the National Park Service's assertion that there existed no legal justification for cave wilderness given that caves were not part of the land. He demonstrated that, from a legal perspective, land encompassed both the surface and the subsurface. He also demonstrated that land could be divided by horizontal boundaries as well as vertical ones (Stitt, 1993). In a 1975 letter from the Department of Interior to the President it was noted: "there is no legal barrier to the designation of subterranean lands as wilderness" (Stitt, 1993). The legal brief helped obtain the recognition and acceptance of the legality of the concept of cave wilderness.

\section{Cave Wilderness Designation}

Attempts to obtain underground (cave) wilderness designation occurred several times, first at Mammoth Cave National Park and later at Carlsbad Caverns National Park. Both areas contained caves of significant value, underground lands of substantial acreage in their own right, 
and although linked geologically and biologically to the surface, the caves' wilderness characteristics are independent of surface conditions (Stitt, 1983).

Two cave wilderness proposals for Mammoth Cave National Park have been submitted to the National Park Service. In 1967, the National Speleological Society submitted a proposal entitled "A Wilderness Proposal for Mammoth Cave National Park." It was unsuccessful. The Cave Research Foundation submitted a second proposal, by Davidson and Bishop, in 1971, entitled: "Wilderness Resources in Mammoth Cave National Park: A Regional Approach." It, too, was unsuccessful. In 1972, Stitt and Bishop proposed underground wilderness in New Mexico, in a report entitled: "Underground Wilderness in the Guadalupe Escarpment: A Concept Applied." It, too, was unsuccessful in achieving cave wilderness designation. Such designation would have established an administrative priority for managing caves and their resources, providing additional protection, raising the standards of care, assuring that the cave would be adequately protected and managed (Stitt, 1983).

The above proposals dealt with caves that do not underlie surface wilderness. Interpretation of the Wilderness Act of 1964 is that wilderness designation extended from the surface of the land downward. If the surface was wilderness, than it protected features underground. However, if the surface was not wilderness than there could be no underground wilderness.

Despite the National Park Service's and the Department of the Interior's acceptance that no legal barriers existed for designation of cave wilderness, the U. S. Forest Service in 1984 disallowed caves as qualifying for wilderness status under the Wilderness Act (Bishop \& Huppert, 1990). Official recognition that caves have wilderness qualities came in 1988 when the 
National Park Service made it official policy that caves having all entrances within a wilderness area will be managed as wilderness (Bishop \& Huppert, 1990).

In 1988, Lechuguilla Cave, located beneath wilderness lands in Carlsbad Caverns National Park, New Mexico, was proposed for cave wilderness designation. The proposal had been developed with approval from the Park Unit; however, it did not obtain support from the

National Park Service. While cave wilderness designation was not obtained, the proposal eventually resulted in the Lechuguilla Cave Protection Act of 1993. A separate surface and subsurface wilderness designation was filled with implications that the National Park Service and Congress were not prepared to address.

\section{Caves and Wilderness Values and Meanings}

Murphy (1996) noted that research conducted on the meaning of wilderness has been limited. Further research is needed regarding the meanings associated with definitions of wilderness, the values of wilderness, the experience and perceptions of wilderness.

Murphy (1996) states that there exists a global image of wilderness. In a wilderness meaning study, Heberlein (1982) reported that within three diverse study groups, the terms forest, wildlife, quiet, and solitude were used to define wilderness. Hallikainen (1995) reported similar findings in a study of Finnish people. Wilderness was defined by both tangible and intangible qualities. While wilderness may initially invoke images of forests and mountains, it need not be scenic as long as it is natural and offers solitude (Graber, 1976). Wilderness is more than a physical entity; it is an experiential collection of impressions (Bishop, 1983).

Murphy (1996) noted that wilderness could be represented by different environments and may have variations in descriptions, yet meanings associated with wilderness were similar 
between visitors and non-visitors. Regardless of visitation, emotional and spiritual aspects of a real or hypothesized wilderness experience were similar. The similarity in these personal definitions, as well as legal definitions and past writings, will have implications for the meaning of wilderness and its management as a legal entity (Murphy, 1996).

The meanings and definitions of wilderness will continue to shift and change as the values and attitudes of those who define wilderness shift and change. These evolving definitions of wilderness are linked to the values wilderness holds for humankind; as such, future wilderness definitions and meanings may be affected by values yet unknown (Hill, 1994).

In discussions of wilderness designation seldom, if ever, has the specific environment (landscape) been used in describing the proposed wilderness site. Yet, in discussions of wilderness designation for caves the term used is 'cave wilderness'. Why, is this an example of another evolution in the definition of wilderness? Is there a difference in the meanings and values associated with surface and subsurface environments?

Justifications for wilderness preservation arise from values ascribed to wilderness. These values are attributed to the benefits experienced by individuals, society, or nature. Wilderness values range from utilitarian to non-utilitarian and include experiential, scientific, heritage, aesthetic, spiritual, and symbolic (Nash, 1982; Frome, 1997; Hendee \& Dawson, 2002). Rolston (1989) listed twelve wilderness values: market value, life support value, recreational, scientific, genetic diversity, aesthetic, cultural symbolization, historical, character-building, therapeutic, religious and intrinsic natural value. Haas, Herman, and Walsh (1986) identified three types of values associated with individuals who experience wilderness vicariously: option for visitation, existence of wilderness (irregardless of visitation) and bequest value (to future generations). Bishop (1983) listed seven values associated with the wilderness experience: solitude, the 
absence of man-made features, opportunity for a spiritually uplifting experience, learning about nature, tranquility, personal reflection, and communion with nature. In his work on concepts of wilderness valuation, Hill (1994) proposed a taxonomy of wilderness benefits comprising three primary categories: personal, social, and intrinsic values, as noted in Table 5. This list is based on previous work of others as well adjustments made by Hill. While comprehensive, Hill's taxonomy of wilderness benefits should not be considered as the last word, as new values and benefits (or variations of them) are identified.

It should be noted that not all of these values are complimentary, thus leading to potential conflicts in the management of a legally protected area (Murphy, 1996). Bishop (1983) noted that some recreational values might be reasons for visiting wilderness, but can be experienced in non-wilderness settings. These "should not take precedence over those over those subjective elements that are generally believed to be available only within wilderness boundaries" (Bishop, 1983, p. 84). Management should give preference to wilderness visitors whose activities strongly depend on those qualities that are unique to the wilderness setting, rather than to visitors whose needs can be met in non-wilderness settings (Bishop, 1983).

Caves hold personal and societal benefits and values found in wilderness (Gamble, 1981; Huppert 1993; Watson \& Smith, 1971; Zuber, 1977). The intrinsic values of caves make it evident that caves can fulfill the criteria necessary in a wilderness site (Huppert \& Wheeler, 1996). Kerbo and Roth (1989) note that caves not only emphasize wilderness qualities and benefits; they also allow individuals to experience the spirit of exploration and adventure.

Wilderness designation is a concept created to accommodate our greatest feelings, maintained to guarantee the opportunity of attaining inner strength, and protected to remain isolated from the day-to-day activities and works of man. Based on these considerations, the 
wilderness of caves is an example of what is meant in discussions of wilderness and of places where wilderness experience may be had (Watson \& Smith, 1971).

Table 5. A Taxonomy of Wilderness Benefits (Hill, 1994).

Personal Benefits

I. Personal Recreational Benefits (accruing primarily to individuals and might or might not benefit society at large)

A. Developmental (desired changes in self concepts and skills)

1. Self-Concept

2. Self-Actualization

3. Skill Development

4. Self-Definition

B. Therapeutic/Healing

1. Clinical

2. Non-clinical (stress mediation/coping

C. Physical Health

D. Self-Sufficiency

E. Other Personal Wilderness Recreation-Related Benefits

II. Other Personal Benefits (non-recreational benefits that accrue to individual on-site and off-site wilderness users)

A. Social Identity (development/maintenance of desired social relations with family and others)

B. Educational

C. Spiritual

D. Esthetic/Creative

E. Subsistence

III. Personal Off-Site Benefits (benefits that accrue primarily to off-site users of wilderness)

A. Symbolic (benefits from options to realize that actions are being taken in support of preservation related beliefs)

1. Resource Stewardship

2. Anti-anthropocentricism/Moralistic

3. Option Demands

4. Other

B. Commodity-Related (benefits to individuals form goods produced from wilderness such as those related to water and to grazing by domestic animals)

C. Nurturance

IV. Transformative Benefits (possibly accruing to individuals without their direct preference in such a way as to alter current value structures)

Social Benefits

V. Social Benefits (accruing across individuals to society collectively or to large segments of society)

A. Aggregate Personal Benefits

B. Spin-off Benefits

C. Historical Cultural Benefits

D. Preservation-Related Benefits

1. Representative Ecosystems

2. Species and Genetic Diversity

3. Air Visibility

4. Unique Landforms

5. Historic Sites

6. Educational Values

7. Scientific Laboratory

8. Moral and Ethical Stewardship (options for future generations)

E. Quality of Life

F. Economic Benefits

1. National Economic Development

2. Local/Regional Economic Development

G. Subsistence

$\mathrm{H}$. Religious

VI. Normative Benefits (possibly accruing to society's well-being without its direct preference)

Intrinsic Benefits

VII. Inherent/Intrinsic Benefits (accruing to the survival of nonhuman organisms)

A. Organismic Benefits

B. Species Benefits

C. Ecosystemic Benefits

IIII. Ontological Benefits (possibly accruing to individuals, society, and the Creator as understanding of reality increases)

IX. Divine Benefits (possibly accruing to some God or Creator) 


\section{Ecosystem Management and Meanings of Place}

Protected areas are established to protect and conserve an assortment of aesthetic, cultural, and natural values, as well as to protect the features that attract people to them for purposes of recreation and tourism. The push for cave wilderness designation and the growing number of visitors to wild caves has brought attention to the need for information on how people value caves, cave resources and ecosystem, as well as how they value the cave visit experience.

To better plan for use and allocation of natural resources, land managers must consider social variables along with biophysical factors. In moving toward a holistic understanding and management of an area and its resources, managers are looking for ways to merge sociological and ecological information (Selin, Schuett \& Carr, 1997; Stein, Anderson \& Kelly, 1999).

This management framework is called ecosystem management. The philosophy behind this approach places humans within the ecosystem and requires an understanding of the local community and stakeholders if it is to be implemented. The human dimensions of ecosystem management have not been well researched (Stein, Anderson \& Kelly, 1999).

Understandings of nature and of human relationships with the environment are cultural expressions used in defining people and their histories. When attempting to identify and understand the potential human consequences of changes in the natural environment, it is important that these consequences are understood from the many cultural and social definitions of places and landscapes (Greider \& Garkovich, 1994). When considering wilderness, the change would be in land use designation, which may restrict or modify how the land is used, but would not necessarily result in actual change to the physical landscape environment

In human geography, defining the concept of place requires an understanding of how the landscape is related to local human culture and history (Sagoff, 1992; Williams \& Patterson, 
1999). Understanding the meanings and values associated to place on both a spatial and temporal scale is important in ecosystem management. In ecosystem management, the concept of place focuses on the process by which resources and ecosystems are politically and socially constructed. Intangible meanings, such as cultural, social, and expressive meanings, have become part of the emerging ecosystem management paradigm. Meaning in this context includes socially or symbolically constructed interpretations of places and landscapes (Williams \& Patterson, 1999).

An analysis of place attachment and association with the natural resources allows for understanding how the natural resource is defined and valued by those who live and recreate in association with the resource. Understanding place attachment can be important in understanding how people view management plans, and can be used to identify stakeholders who should be incorporated or accounted for in the planning process (Bricker \& Kerstetter, 2000).

Place attachment can be utilized to aid in understanding how people view natural resource management plans and alternatives. It has been shown that recreationists who demonstrated a higher level of specialization also indicated stronger feelings toward place identity (Bricker \& Kerstetter, 2000). Place identity may be associated with a specific site or associated with a setting. In the case of cavers involved in scientific activities such as exploration and mapping, place in terms of caves can be both site specific (particularly if they are involved in project caving) and associated with a setting, that is caves that typically do not received visitation from individuals not associated with scientific endeavors. Understanding sentiments and emotional bonds between people and the environments in which they live or visit is critical in ecosystem management processes (Bricker \& Kerstetter, 2000). 
Recreation is one of the major uses of wilderness. Wilderness managers and the public alike are beginning to focus more on values beyond the purely recreational use of wilderness. Much of that recreational use is an expression of the greater value of wilderness. Its meaning extends beyond merely seeking a wilderness experience but is a statement of the human value of that type of place. A "sense of place," depends on not only how we value or use wilderness when we are there, but also how we value it when we are not there. Wilderness has cultural meaning to us; individuals bring their own cultural meanings and expectations with them to create their wilderness experience (Cook \& Borrie, 1995).

An important principle in ecosystem management is that we must consider and function within both ecological and human defined boundaries. The sense of place represents a continuum between environmental versus social features important to an individual. Lived experiences, which shape an individual's sense of place, play a role in perception of and importance of environmental and/or social boundaries (Cantrill, 1998). Recognition of these broader boundaries is necessary for framing the specific problems and characteristics that make this a place-based approach. It also has implications for decision-making. It requires identifying stakeholders with varying interests in the ecosystem. It also facilitates their participation in the design and implementation of appropriate natural resources management goals and plans (Griffis \& Kimball, 1996).

The increasing number of visitors, with a wide range of interest levels ranging from those with only a passing curiosity to those for whom caving becomes a passion, is placing greater pressures on caves and cave resources, many of which are extremely fragile or sensitive to intense visitation. Wilderness designation creates one form of protection. With this mode of 
protection, some caves and their resources can be protected in perpetuity, not only from encroaching surface development, but also from the impact of over-visitation.

Before wilderness resource management policies and plans can be developed, consensus must first be reached on which landscapes, environments, or ecosystems constitute wilderness and on what activities are deemed acceptable in these environments. Wilderness is valued for a variety of reasons. The ability to manage natural resources will be improved if the perceptions and preferences of those who will be affected by the policies and plans are known and taken into consideration (Lutz, Simpson-Housley, \& DeMan, 1999).

\section{Barriers to Wilderness Designation}

Several articles have been written discussing barriers to cave wilderness designation. Such barriers include: opposition by private commercial interests; lack of support from federal land management agencies; lack of known boundaries; the view that it is unnecessary as other special management options already exist; restricted access to cavers and scientists; exclusion of physically handicapped; exclusion of untrained individuals; and public apathy (Bishop \& Huppert, 1990; Hummel, J. B., 1982; Huppert, 1993, 1995; Miller, 1990). Some of the concerns noted in these articles will be addressed here.

The wilderness designation proposal for Lechuguilla Cave included restrictions on access in order to protect the fragile cave environment. Opponents argued that such a wilderness designation would be elitist, it would reserve caves such as Lechuguilla only for cavers. However, there are times when caving for its own sake must be secondary to more important purposes. In those cases, each person entering the cave must be willing to contribute something to the general understanding of caves (Smith, 1988). Because not all caves are the same, access 
restrictions for specific purposes and reasons may not be necessary for all caves. Access to a wilderness cave should not come from legislation designed to protect cave resources, but from one's own knowledge, skills, and abilities (Kerbo \& Roth, 1989).

The reality is that most wilderness areas are restricted, simply by the nature of the skills required to access and experience the area, skills such as hiking, backpacking, climbing, mountaineering, rafting, etc. Access restrictions may change on a seasonal base. Most wilderness visits require that individuals must face the wilderness on its on terms. What is unusual about cave wilderness is that it cannot be viewed from afar. It does not offer the traditional scenic landscape vistas that can be seen from a roadside turnout, along a trail or a scenic fly over. In not being a visible wilderness, cave wilderness restricts access in a way never before experienced. It is not a viewable landscape as traditionally experienced.

Surface wilderness boundaries are delineated by legally defined boundaries established via the use of aerial photographs or landsat imagery. It is not as easy to do the same for caves, especially those that are still being explored and mapped. The fact that a cave is still being explored seems to be a significant problem for some natural resource managers and legislators when considering wilderness designation. The lack of complete knowledge regarding cave resources has served as a reason for not designating wilderness. Tousley (1976) argues that lack of knowledge of either the scope or the significance of cave resources makes it premature to decide which portions of the caves should be reserved in wilderness status. This seems to be a self-defeating attitude. Caves by their very nature, may never be completely known. While it is possible, and necessary, to conduct a preliminary survey of cave resources to determine the significance of the cave, not knowing cave resources completely would seem to add a higher 
quality to the caves as a wilderness, making them an intriguing wilderness resource and contributing to the wilderness experience (Stitt, 1976b).

One of the greatest barriers to cave wilderness designation is the lack of understanding of cave resources and cave ecosystems. This lack of understanding can account for lack of support for cave wilderness among federal agencies, conservation groups, and the public. Much of the lack of understanding and interest may be attributed to the fact that caves are not typically part of the landscape view as are forests, mountains, and rivers. In addition, it has only been in the last fifteen to twenty years that caves and caving have gained such extensive media attention. Public education programs in various venues (schools, fairs, television programming, etc.) may be the best way to further people's understanding and appreciation for caves. Without public interest and support for cave wilderness designation, it is unlikely that land management agencies will push for such designation.

Since the passage of The Wilderness Act of 1964, several attempts have been made to have caves or portions of caves declared wilderness (Stitt, 1991). All have failed. The passage of two acts, The Federal Cave Resources Protection Act of 1988 and The Lechuguilla Cave Protection Act of 1993, has renewed interest in the establishment of cave wilderness. Although the idea of cave wilderness is not new among some organized cavers (in particular those belonging to the Cave Conservation and Management Section of the National Speleological Society), it is still an evolving concept and is not well understood, nor frequently thought about, by the majority of cavers. If the concept of cave wilderness is not well defined among organized cavers (those belonging to a local, regional or national cave organization), it can be assumed that the concept is also unfamiliar to the general public, even to those whose lives or livelihood are affected by karst. 
This study is an investigation into the human dimension of the phenomenon of cave wilderness, to develop an understanding of the meanings and values attached to the concept from the perspective of stakeholders - cavers and non-cavers who perceive their lives to be affected by caves and/or a cave wilderness designation. It will attempt to provide natural resource managers with information vital to an ecosystem management approach. In addition, these findings may lead in directions different from the Wilderness Act of 1964, to paths unknown and new, in consideration of Congressional designation of cave wilderness. 


\section{CHAPTER THREE}

\section{METHODS}

\section{Overview}

The intent of this research was to explore the meaning of cave wilderness from the perspective of stakeholders (cavers and community members) in two caving regions in the United States - Kentucky's Mammoth Cave region and New Mexico's Carlsbad Caverns region. These sites differ culturally and geographically. This study was designed to identify how stakeholders in the two different regions value and perceive caves, cave ecosystem management, and cave wilderness.

This study is a phenomenological inquiry. The aim of phenomenological research is the clarification of meaning(s) associated with a phenomenon (Pickles, 1983). This insight aids in the understanding of everyday experience and knowledge, laying the foundation for future efforts (McDonald, 1993). In establishing the framework or foundation of meaning for a phenomenon, such as cave wilderness, it becomes possible to construct sound empirical scientific and/or political theories, management practices, and policies (Pickles, 1983).

A descriptive approach was used to examine values and perceptions of caves and cave wilderness. This approach allows researchers to describe rather than predict phenomena (Henderson, 1991). In research addressing emerging issues, especially those not previously studied, it is not possible to address all variables fundamental to social and cultural values and land management. Although research has been conducted regarding values and wilderness, 
research regarding similar values in a management environment is relatively new (Stein, Anderson \& Kelly, 1999). In addition, little research has been published regarding social and cultural values associated with caves, cave management, and cave wilderness.

This chapter will discuss the specific research design method including: subject and site selection, sampling design, study questions, pilot study, and data collection and analysis procedures. A combination of focus groups and self-administered questionnaires were used to obtain an understanding of the range and depth of selected stakeholders' perceptions of caves and cave wilderness (Winter, Palucki \& Burkhardt, 1999). This study had originally intended to include interviews as an additional data collection tool. However, difficulties in scheduling interviews in a timely manner necessitated dropping that portion of the study.

\section{Subject Selection}

A purposive sampling approach was used to gather data from specific groups of people, known as stakeholders. This approach was used to obtain the most comprehensive understanding of a phenomenon such as cave wilderness (Henderson, 1991). This technique allows researchers to obtain a description of what particular groups of people living in a region believe (Miles \& Huberman, 1994). It must be noted that this approach does not allow the extension of findings to other regions or even other groups in the same region.

The research project investigated stakeholders in two cave regions that may have an affect on or be affected and/or impacted by cave and cave wilderness management policies and potential legislation. Participants were recruited based on membership in selected target populations, stakeholders who have a vested interest in the cave and karst environment. For the 
purpose of this investigation, cave-related stakeholders fall into one of two, potentially overlapping, communities and are defined as:

1. Community of Interest (those who use and/or participate in the stewardship of caves and karst)

(a) individuals who utilize the caves in these regions for recreation, exploration and/or research in the selected study sites;

(b) individuals who own or manage wild or developed caves (irregardless of ownership or commercial use);

(c) government officials (elected and administrative officials) responsible for decisions impacting caves or cave management (on a state, or federal level);

(d) special interest organizations that have an interest in cave and karst environments.

2. Community of Place (those who work, reside on, or own land in cave and karst regions)

(a) local business owners or employees involved in a non-resource extraction business (e.g. restaurant, grocery, hotel);

(b) individuals who earn a living via a natural resource extraction industry (e.g. oil, gas, coal, potash, forestry);

(c) local government officials (elected and administrative officials) representing community interests that may impact cave stewardship;

(d) residents.

Each of these communities/stakeholder groups may have different perceptions of caves, cavers and caving, as well as different reactions to the idea of cave wilderness. This dual 
community approach is a useful organizing structure when examining diverse public interests (Winter, Palucki \& Burkhardt, 1999). Utilizing stakeholders from communities of interest and communities of place establishes the research focus and the depth of information from deliberately selected groups of individuals as opposed to a statistically representative sample of the population (Morgan, 1988).

Participants were not meant to be representative of the larger population potentially affected by the cave ecosystem management and cave wilderness status. Stakeholders are more likely than other community members to understand the issues, beneficial impacts, and negative impacts involved in cave ecosystem management and cave wilderness.

Research participants were selected based on recommendations from government officials (based on interactions with individuals who have expressed an interest in or concern about cave management or wilderness issues); recommendations by organizations whose primary focus is in cave stewardship issues, as well as on the researcher's familiarity with individuals' backgrounds. Recommendations from other individuals or organizations, and a snowball technique were also used to discover individuals who may be able to contribute valuable perspectives that may not otherwise come to the researcher's attention.

\section{Study Sites}

Two caving regions in the United States were selected as focus sites for this research project - Kentucky's Mammoth Cave region and New Mexico's Carlsbad Caverns region. These sites vary geographically, culturally, historically, and economically. Kentucky and New Mexico vary greatly in size, population, and land ownership. Kentucky is the 36th largest state in the United States in area, with $4.2 \%$ of the land in federal ownership, 26th in the nation (U. S. 
Census Bureau, 1999). Kentucky has over 4 million residents (U. S. Census Bureau, 2003a). New Mexico is the fifth largest state in the United States in area, with approximately $32.4 \%$ of the land in federal ownership, 10th in the nation (U. S. Census Bureau, 1999). New Mexico has approximately 1.8 million residents (U. S. Census Bureau, 2003b). Both states depend economically on agricultural and natural resources extraction industries.

Kentucky and New Mexico differ in land ownership and usage, designated wilderness areas, and in cave ownership (wild and developed) and cave management. Karst regions of Kentucky and New Mexico differ in speleogenesis resulting in distinct differences in the nature of the caves and their relation to the surface landscape. Even the history of cave visitation, usage, and exploration vary dramatically between the sites. Both Kentucky and New Mexico contain a National Park that was established based on the presence of one specific cave, though numerous additional caves are found in both park properties.

Caves in the Mammoth Cave region of Kentucky are formed primarily by the carbonic acid solution process. Surface features such as sinkholes and disappearing streams provide strong indications for the presence of subsurface drainage features such as caves. The Mammoth Cave region is heavily populated with caves. It also has a long history (over 150 years) of private commercial cave ventures. It is highly unlikely for an individual to live or work in the region without knowing of the existence of one or more caves.

Caves in the Carlsbad Caverns region of New Mexico were formed primarily by the sulfuric acid solution process. Apart from the actual cave entrances or paleoentrances, there are few features on the surface lands to indicate the subsurface potential for cave development. Other than Carlsbad Caverns National Park, there is little history of commercialization of caves 
found in the region. The potential exists for individuals to live or work near caves and never suspect the existence of subterranean karst features such as caves.

Within the boundaries of Kentucky's Mammoth Cave National Park lies a significant portion of the Mammoth Cave System, currently the longest known cave in the world with approximately 346 mapped miles of passages (Gulden, 2003a; Gulden 2003b). Mammoth Cave National Park was designated a World Heritage Site in 1981 and made part of an International Biosphere Reserve in 1990 by the United Nations Educational, Scientific and Cultural Organization (UNESCO). It is important to note that portions of Mammoth Cave lie beneath lands of private ownership.

New Mexico's Carlsbad Caverns National Park contains Carlsbad Cavern, which is currently the 11th longest cave in the country, $44^{\text {th }}$ in the world, at over 30 mapped miles (Gulden, 2003a; Gulden 2003b). Carlsbad contains one of the largest known rooms in the world, the Big Room, 17th largest by surface area (though not ranked in terms of volume); it is the largest known room in the US (Gulden, 2003c). Carlsbad Caverns National Park was designated as a World Heritage Site in 1995 by UNESCO. The Park is the site of another large, undeveloped cave, Lechuguilla Cave, the 3rd longest cave in the United States and 5th longest in the world, with 109 mapped miles. Lechuguilla is also the fourth deepest in the United States at 1594 feet in depth (Gulden, 2003a; Gulden 2003b). Lechuguilla Cave is the first cave to receive Congressional protection (the Lechuguilla Cave Protection Act of 1993) other than a National Park Service designation.

In both Kentucky and New Mexico, the National Park Service works closely with volunteers to explore, map, and conduct other scientific activities to learn about and document 
caves located within each of the parks. Volunteers work independently or under the auspices of an organization dedicated to the exploration of one or more caves in each of the regions.

It was felt that these distinctly different regions would provide a wide range of experiences and values from which stakeholders could draw in discussing their perspectives regarding caves, cave ecosystem management and cave wilderness.

\section{Study Questions}

The research questions were compiled after reviewing published papers regarding cave wilderness, and were based on the researcher's expertise, and personal interviews with cavers, cave owners/managers, and federal employees responsible for the management of caves. These questions covered three topics: 1) nomenclature - creating working definitions of terms; 2) cave ecosystem management; and 3) cave wilderness. The questions were tested during a pilot study conducted in the summer of 2000 .

\section{Pilot Study}

The pilot study was conducted at the National Speleological Society's convention held in Elkins, West Virginia, June 2000. Study participants involved cavers with varying interests and experience levels, as well as non-cavers. In addition, a much smaller study was conducted using employees (teachers and staff) at a private school located in Baltimore, Maryland. Study participants included 94 individuals who identified themselves as a caver (experience levels varied) and 19 individuals who identified themselves as a non-caver, for a total of 113 participants. The pilot questions were presented in a questionnaire format. Following completion 
of the questionnaire, study participants were encouraged to discuss the study's format. In some cases, comments were noted on the actual questionnaire.

Responses reflected the different experiences and interests in outdoor recreational activities, as well as potential knowledge regarding caves and caving; despite these differences, all responses were consistent with the intent of the questions being tested. As a result, some questions were modified to elicit responses that were more detailed or to gain specific information relevant to the study.

The question asking for names of caves visited was modified for the actual study. The question was changed to ask the approximate number of caves visited, instead of the names of caves visited. In addition, a question was added asking number of cave trips taken. The changes were made to accommodate the extensive experiences of some of the cavers who participated in the study. The purpose of the original question was to aid in determining caving experience of the study participants. Knowing specific caves visited in a region was irrelevant to the purpose of this study.

The questions: "What does developed cave mean?" and "What does wild cave mean?" were modified and expanded to the following question: "How are the following terms defined: wild cave, developed cave, and commercial cave?" This was done to clarify and define terminology used.

The question "What does wilderness mean?" was modified to: "Do the terms wild and wilderness have the same meaning (e.g. wild area vs. wilderness area; wild cave vs. cave wilderness?" This was done to clarify responses in the actual study.

Review of written responses, discussions with study participants and input from questionnaire reviewers resulted in the addition and or restating of several questions. Based on 
comments of pilot study participants, as well as input from questionnaire reviewers, it was determined that focus groups would be a better tool in eliciting in-depth responses.

\section{Final Study Questions}

The following questions were asked during the focus group sessions. Responses elicited further questions for clarification or exploratory purposes.

- How are the following terms defined: wild cave, developed cave, and commercial cave.

- Do the terms wild and wilderness have the same meaning (e.g. wild area versus wilderness area; wild cave versus wilderness cave)?

- What purpose(s) and goals could a cave wilderness designation serve?

- Is there a term other than "cave wilderness" that could be more appropriate in describing these purposes/goals? If so, what could it be?

- Can an entire cave be considered wilderness? Can portions of caves be considered wilderness? At what point does cave wilderness begin? Is it separate from surface wilderness?

- Is there a need for a wilderness designation by legislation, for caves? Why or why not?

- What concerns (risks) are there in regard to a wilderness designation?

- What benefits (rewards) are there in regard to a wilderness designation?

- Could there be a difference in the management of cave wilderness than traditional wilderness practices? Why or why not? If so, what forms of management practices would be expected that differentiate from traditional wilderness management? 
- Can this concept be applied to caves extending to lands under private ownership? Could a different designation be used for private lands? If so, what could it be called?

\section{Overview of Research Approach}

Focus groups are often used as a tool for knowledge gathering in a phenomenological inquiry (McDonald, 1993). Focus groups are a unique data collection technique that benefits from group interaction to elicit rich experiential data (Krueger, 1994). The value of focus groups is principally in assessing the meaning attached to nomenclature. In order to reduce ambiguity (fear and confusion) the use of widely understood nomenclature is essential. The opinions of a focus group are used to discover "loaded" words (Brucker, 2001b). The focus group format, via group dynamics, may stimulate discussions, encouraging articulation of concerns, attitudes, and perceptions in depth. Such discussion can provide insights, literal and hidden, into the research topic (Fleitas, 1998; McDonald, 1993). The researcher is provided with detailed viewpoints, capturing the complexity of the human experience in a way that cannot be achieved through other methodological approaches (Krueger, 1994; Krueger, 1995; Morgan, 1993). Focus groups can be used to discover how to bring clarity to a research problem. Thus, they can be used to explore topics and generate hypotheses. This is particularly valuable when working in a new research area (Carey \& Smith, 1994; Morgan, 1988).

Focus groups can be used as the sole research strategy on a project exploring a new research area; they may also be used in conjunction with other data sources such as interviews and questionnaires (Morgan, 1988; Carey \& Smith, 1994). As with focus groups, interviews may be used as a tool for knowledge gathering in a phenomenological inquiry. Interviewing allows for in-depth examination of a topic, operating in a discovery mode (Henderson, 1991). 
Purposive sampling is part of a strategy that is concerned with theoretical sampling of constructs, rather than random sampling. In a qualitative research approach, the number of participants is determined based on saturation. Saturation is reached with simultaneous data gathering and analysis. It occurs when the researcher realizes that the data collected are repetitive and no additional new information is being found (Henderson, 1991).

\section{Data Collection Procedure}

\section{Focus Groups}

This research approach normally requires the use of three or four focus groups, though more may be necessary if the topic is complex. Four focus groups were conducted with members from the community of interest (relative to Kentucky and New Mexico caves). Five focus groups were conducted with community of place members: three focus groups in Kentucky and two in New Mexico. In total nine focus groups were conducted, involving 65 participants.

A concern was the number of individuals within each of the focus groups. Krueger (1995) noted that the most effective focus groups were composed of six to eight participants, a change from former recommendations of eight to ten. For complex topics, or when participants have expertise on the topic, consideration should be given to using smaller groups. Focus group sizes ranged from two to twelve (Caving Event Focus Groups: 8, 9, 10, 12; Kentucky Focus Groups: 2, 3, 4; New Mexico Focus Groups: 3, 9). Variations in group sizes were a result of participations failing to attend or, in some cases, the inclusion of individuals invited by the participants themselves. Reasons for failures to attend included: scheduling conflicts, forgetfulness, storm events, and unknown. The large number of participants in the Caving Event 
focus groups can be directly attributed to focus group sessions having being held on site of the event. Participants were easy to locate prior to the scheduled focus group session.

Although some of the focus groups were small in number it was felt that, based on the overall data collected per focus group venue, the small numbers were not a detraction to the study. It was felt that the breadth of discussions was similar within venues. What may have been lacking was the depth of information that might have been gathered with greater attendance.

Focus groups were led by the researcher. An assistant was present to manage notes and recording media. Field notes were maintained during and following focus group and sessions.

Focus groups utilized the interview guide approach which identifies topics and issues to be covered but does not identify a specific protocol for asking questions so that questions may be asked as appropriate to the progression of the interviews (Henderson, 1991). The appropriate use of the guide allowed the researcher the liberty to delve deeper when necessary, skip areas previously covered, and follow new topics that may arise (Morgan, 1988). The same approach was to have been used during interviews.

The discussion topics, with associated questions, were organized into a guide that was followed roughly in the same order from group to group. The guide was used to provide a loosely structured discussion format. The researcher functioned as a discussion facilitator. The facilitator had limited interaction during group discussions, provided direction when it was deemed necessary to aid group interaction, provided opportunities for further in-depth discussion before moving on to a new topic, and when necessary, introduced a new question or topic.

Attempts were made to recruit ten participants for each stakeholder focus group. Six to eight actual participants were the target number. However, two additional participants were invited, in the event that not all participants are able to attend. Participants were selected based 
on community of interest and community of place. Specific individuals were selected based on the researcher's knowledge of an individual, public records and recommendations of others.

Focus group sessions were scheduled to run for a maximum two hours, providing a halfhour cushion to minimize disruptions of group dynamics by early leavers (Morgan, 1988). The sessions were held in an environment such as a classroom or meeting room. One focus group was held in a local cave. Participants were seated at tables or at student desks (chairs only in the case of the in-cave group) and arranged in a U-shape configuration with the facilitator at the head.

Each session began with the reading of a standardized opening statement providing information on the general purpose of the study and introducing the researcher. Rules of participation, including the use of courtesy, the importance of an open discussion, and confidentiality were covered at this time. Participants were informed that the sessions were being video and audio taped for the purpose of data collection; that the tapes would remain the property of the researcher and would not be available for review for any purpose other than data collection. Participants were given the opportunity to request that the session not be taped. In the event of public presentations, segments of audio or videotapes in which a participant may be identified would not be used without permission from the participant.

During each focus group session, the moderator noted discussion highlights, including working definitions, on large format paper. Completed pages were placed in locations easily visible to all participants. The purpose of this technique was three fold. First, it provided a visual reminder of defined nomenclature; second, it was used to clarify and reduce lengthy commentary to short succinct statements; and, third, it served as an aid for participants to determine if further discussion is necessary or if it was time to move on to new topics. 
At the conclusion of the focus group session, participants were asked to complete the self-administered questionnaire, which had been distributed to the participants at the start of the session. An "additional comments" portion of the questionnaire was provided to allow individuals the opportunity to note thoughts regarding discussion topics that may not have been expressed or may have been withheld during the focus group session. Comments reflected ideas expressed during the sessions or were of a different nature.

\section{Interviews}

Interviews were to have been conducted with select focus group participants and would have targeted participants who were unable or unwilling to participate in a focus group, when it was felt that their contributions would have been important to developing a comprehensive understanding of the phenomena of cave wilderness. Interviews would have used the same topics and questions used in the focus groups, as well as questions that might have developed as a result of the focus group sessions. Selection would have been based on: 1) the need to follow-up on remarks made during the session deemed significant to the research goals; or, 2) an individual's area of expertise or experiences that might lead to developing a clearer picture regarding the phenomena of cave wilderness. Interviews might also have been conducted when targeted participants were unable or unwilling to participate in a focus group, when it was felt that their insights would have been valuable in illustrating the phenomena of cave wilderness.

\section{Self-Administered Questionnaire}

Individuals selected for focus group participation were asked to complete a questionnaire at the end of their session (reference Appendix E). The questionnaire was made available at the 
start of each session. All responses were strictly voluntary. Clarification of questions was done at the beginning and end of each session. The questionnaire gathered information on participant's cave and wilderness related experiences, and socioeconomic and demographic data. The purpose of collecting such information was to help provide an accurate sense of who was participating, particularly useful due to the small size and nonrepresentativeness of the participants (Morgan, 1988).

\section{Data Analysis}

The phenomenological analysis of data focuses on uncovering the meanings of beliefs and attitudes through in-depth study of descriptions and narratives (Fleitas, 1998). Plans for analysis should begin by returning to the goal of the study, which will guide the researcher in selecting the appropriate method of analysis - content analysis, ethnographic approach or a combination of the two (Carey \& Smith, 1994; Krueger, 1994; Morgan, 1988). These methods range from a general approach with the purpose of identification of broad concepts, to very detailed analyses of transcripts (Carey \& Smith, 1994). Due to the extensive quantity and depth of data collected an ethnographic approach for analysis was used.

NVivo ${ }^{\circledR}$, a qualitative data analysis computer program, was utilized in the analysis of taped transcripts and completed questionnaires. This program allows text to be coded and viewed in multiple ways, including original context to prevent loss of data during the coding process.

Transcripts were constructed from the tapes, with two transcribers (the researcher served as one transcriber) listening independently to ensure accuracy of the transcripts. A master transcript for each session was produced from the two independent transcripts. 
The master transcripts were coded for major themes. Data for specific topic areas were analyzed for similarities and differences. Identified themes and concepts that appear to link substantial portions of the data together served as a basis for a developing narrative (Winter, Palucki \& Burkhardt, 1999; Fleitas, 1998). Saulnier (2000) suggested that conceptualization of the data coding, data aggregation, groupings, and sub-groupings; be reviewed by two additional analysts to determine validity and clarity of data organization. Once any necessary adjustments are made, the resulting data should undergo final analyses. The results should then be reviewed by analysts to ensure that they reflect the entire data set and accurately interpret the data (Saulnier, 2000).

This study utilized three additional analysts. The first was the research assistant. Because the assistant had attended all focus group sessions, it was felt that his first hand knowledge and impressions would serve as an excellent coding validity check. However, because he is a caver and has close ties to the researcher, two additional independent analysts were used. One is employed in the field of recreation and the other is a doctoral candidate in the field of fisheries management. Neither one are cavers, nor had been on a caving trip with the researcher at the time of the analysis.

Caving experience, wilderness experience, socioeconomic, and demographic information gathered from the questionnaires were used to describe the study participants. In-depth quantitative analysis of the data was not appropriate due to the small sample size and nonrandomness of participant selection (Morgan, 1988). 


\section{CHAPTER FOUR}

\section{FINDINGS}

This study was an investigation into the human dimensions of the phenomena of cave wilderness. The intent of this research was to develop an understanding of the meanings and values attached to the concept from the perspective of stakeholders - cavers and non-cavers, who perceive their lives to be affected by caves and/or a cave wilderness designation. This study attempts to provide natural resource managers with information vital to an ecosystem management approach to cave stewardship.

Research results are reported first from data gathered via the questionnaire, and second, from responses elicited during focus groups' discussions. Demographic data collected via the questionnaire are described by focus groups' venues: Caving Event, Kentucky and New Mexico. Caving experiences and wilderness visitation as reported by participants are also described.

Discussion of results from focus groups' discussions begins by defining nomenclature critical to overall discussion topics. This includes the establishment of working definitions for terms introduced by the researcher as well as terms and concepts introduced by the focus groups' participants. Next, discussions regarding wild and wilderness themes are described. Finally, the idea of cave wilderness and issues relevant to cave ecosystem management themes are portrayed. 


\section{Focus Groups and Participants}

The research project investigated stakeholders in two cave regions that may be affected and/or impacted by cave and cave wilderness management policies and potential legislation. As discussed in chapter three, cave-related stakeholders fell into one of two overlapping communities. These communities are defined as:

- Community of Interest: those who use and/or participate in management of caves.

- Community of Place: those who work, reside, or own land in cave and karst regions.

The primary research format was the use of stakeholder based focus groups conducted in one of three venues: Caving Event, Kentucky and New Mexico. The Caving Event venue was an annual multi-day event attracting cavers from across the nation. The Kentucky venue was comprised of stakeholders from three communities who closely associate themselves with Mammoth Cave National Park. The New Mexico venue was comprised of stakeholders from the Carlsbad area who associate themselves with Carlsbad Caverns National Park.

Nine focus groups were conducted during the course of this study. For the purpose of these discussions, focus groups will be identified in groupings based on venue - Caving Event, Kentucky and New Mexico. The overall focus group participation was sixty (see Figure 4). Four focus groups were held during a caving event in 2001. There were thirty-nine Caving Event participants, accounting for $65 \%$ of overall participants. Caving Event focus group sizes ranged from eight to twelve participants in attendance. Three focus groups were conducted in the Mammoth Cave Region, Kentucky during 2002. Nine individuals participated in the Kentucky focus groups, accounting for fifteen percent of overall participation. Kentucky focus groups had two, three, and four participants. Two focus groups were held in the Carlsbad Caverns Region, New Mexico during 2002. The New Mexico focus groups totaled twelve participants involving 
twenty percent of overall participation. New Mexico focus groups had three and nine participants.

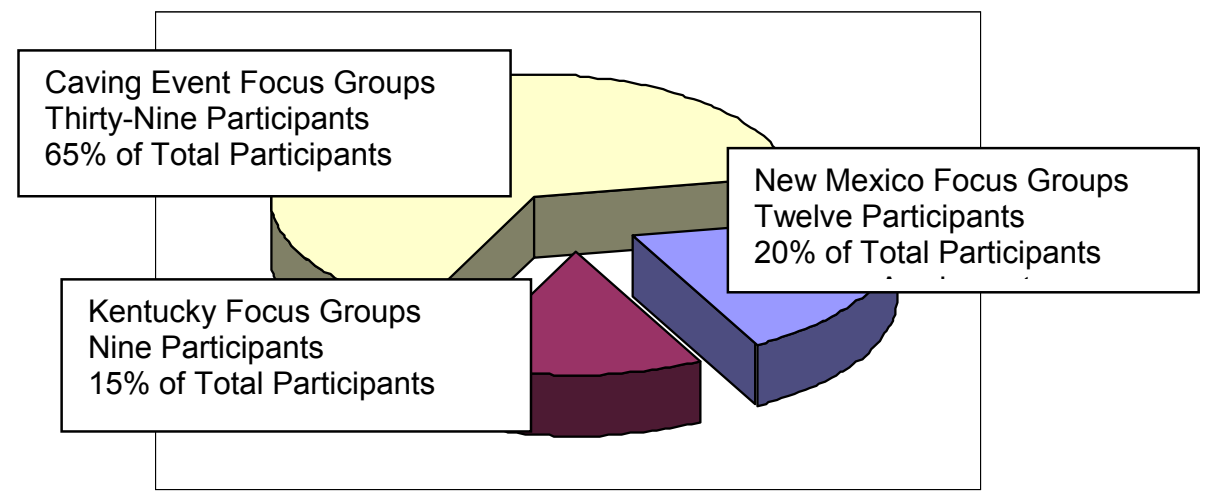

Figure 4. Focus Groups Participants Based on Venue.

Figure 5 depicts focus group participants based on Community of Place (Kentucky, New Mexico or other). The Caving Event focus groups' participants contained seven individuals from the State of New Mexico, three specifically from the Carlsbad Caverns area. These focus groups also included three participants from the State of Kentucky, two of which were from the Mammoth Cave region.

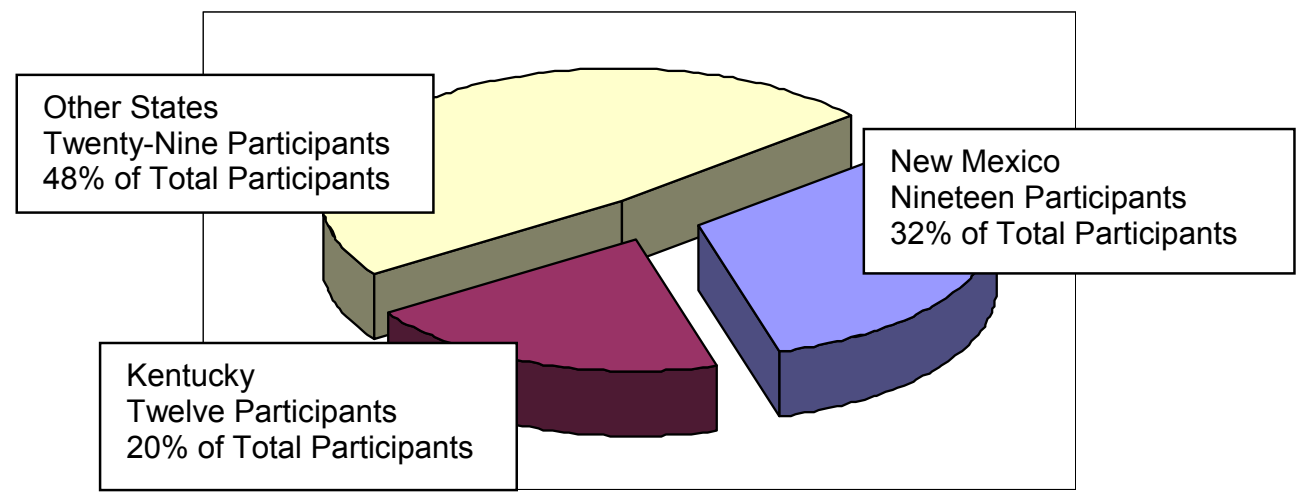

Figure 5. Focus Group Participants Based on Community of Place.

The Community of Interest, as described earlier, includes those who use and/or participate in the management of caves. Cavers are a crucial component of this Community of Interest. The focus of this research, caves and cave wilderness, strongly suggests that cavers will 
have a strong interest in the outcome of this research. As such, participant identification as a caver or non-caver may have a bearing on the nature of this discussion. For the purpose of this study, identification as a caver is considered a defining criteria for inclusion in Community of Interest. Of the fifty-four questionnaire respondents, forty-one $(76 \%)$ identified themselves as cavers. This included six of the nineteen (32\%) Kentucky and New Mexico focus groups respondents. All responding Caving Event participants identified themselves as cavers.

Examination of those respondents identified as a caver (Community of Interest) by Community of Place (Kentucky, New Mexico, other) shows an overlap in the two communities as displayed in Figure 6. The Caving Event focus groups (primarily Community of Interest) had ten $(29 \%)$ respondents from the States of Kentucky and New Mexico, with five (14\%) specifically from the Mammoth Cave and Carlsbad Caverns regions. The Community of Place focus groups (Kentucky and New Mexico) showed overlap with Community of Interest, with four $(44 \%)$ of the Kentucky participants and two (20\%) of the New Mexico respondents identifying themselves as cavers.

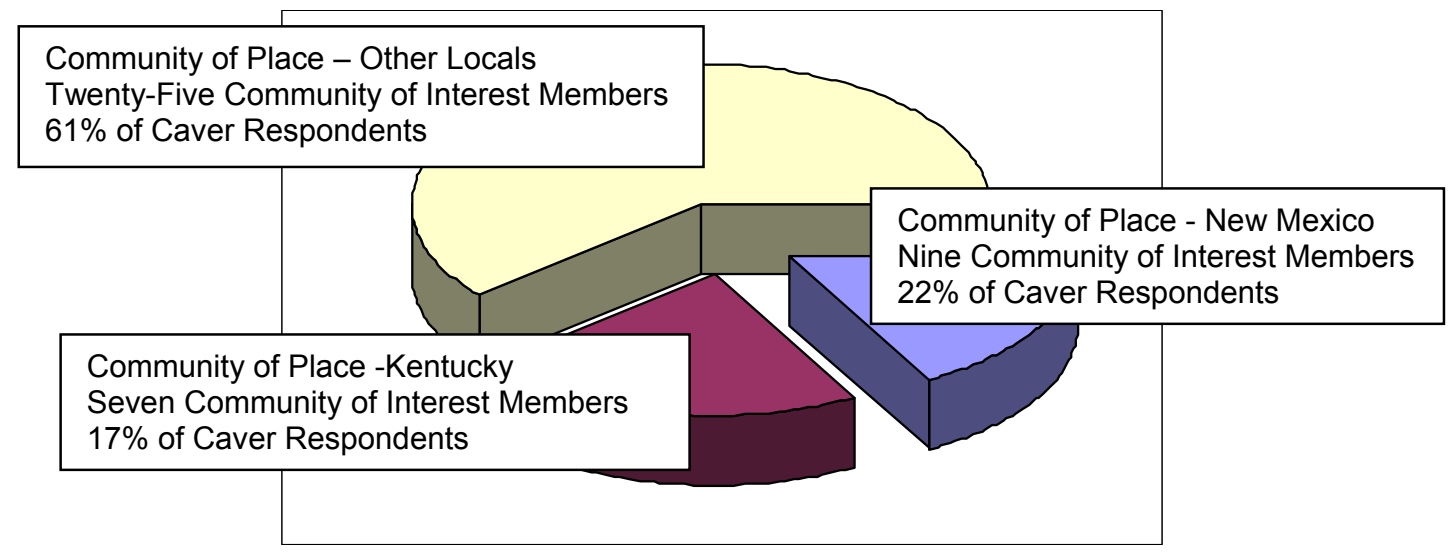

Figure 6. Overlap of Community of Interest and Community of Place. 


\section{Focus Group Questionnaire}

Questionnaires were completed during focus group sessions. Fifty-four participants (90\%) submitted a questionnaire, though not all responded to all questions. Thirty-five of the thirty-nine participants $(90 \%)$ in the Caving Event focus groups submitted questionnaires. All nine $(100 \%)$ of the Kentucky focus groups' participants submitted questionnaires. Ten of the twelve $(83 \%)$ participants in the New Mexico focus groups submitted questionnaires. The following sections are an overview of questionnaire findings. A more complete review can be found in Appendix F.

\section{Focus Groups Demographics}

\section{Gender}

Thirteen of the sixty focus group members were female, accounting for $22 \%$ of the total participants. Forty-seven males represented $78 \%$ of the focus group participants. Ten females attended the Caving Event focus groups, comprising $26 \%$ of these focus groups' participants. Three females attended the Kentucky focus groups, making up 33\% of these focus groups' members. There were no female New Mexico focus groups' participants.

Race

There was virtually no racial diversity within the focus groups. Fifty-three of the respondents identified themselves as Caucasian. One respondent identified himself/herself as Asian. 
Age

Questionnaire respondents ranged in ages from twenty-nine to eighty-one. The Caving Event focus groups respondents' median age was 47.5, with a standard deviation of 8.97 . Both Kentucky and New Mexico focus groups respondents' median age was 62. Standard deviation for Kentucky was 11.3 and New Mexico was 12.59 .

\section{Education}

All questionnaire respondents reported a minimum education level of high school or equivalent diploma. Twenty (37\%) of the respondents have Bachelor degrees (fifteen Caving Event, one Kentucky, and four New Mexico). Fifteen (28\%) have Masters (nine Caving Event, four Kentucky, and two New Mexico). Five (9\%) have Doctorates (five Caving Event).

\section{Annual Income}

Forty-six of the focus groups' participants responded to the annual income range question. Annual income varied among the three focus group venues. Thirty percent of respondents (fourteen) earned $\$ 50,000$ - 74,999 annually. Twenty percent (nine) had annual earnings of $\$ 35,000-49,999$.

\section{Participants' Caving Experiences}

Sections of the questionnaire covered caving experiences. Caving experience questions covered commercial cave tours and wild cave trips. In addition, cave-related experiences specific to Kentucky and New Mexico caves were covered. Responses reflected participants' experiences with caves throughout their lifetimes. 


\section{Caver versus Non-Caver Participants}

Focus group participants were asked to identify themselves as caver or non-caver. No definition was provided for these terms, allowing participants to identify themselves based on personal criteria. As noted earlier, forty-one (76\%) focus groups' respondents identified themselves as cavers. All thirty-five Caving Event focus groups' respondents identified themselves as cavers, accounting for $65 \%$ of all respondents. Four (44\%) Kentucky focus groups' respondents and two (20\%) New Mexico focus groups' respondents identified themselves as cavers (seven and four percent of all respondents respectively).

The high percentage of cavers within the focus groups is possibly attributable to the lower number of participants within the Kentucky and New Mexico focus groups, relative to the number of Caving Event participants. However, there is nothing to suggest that the caver/noncaver ratio for either Kentucky or New Mexico would decrease or increase with increasing numbers of participants. It should be noted that the number of participants is too low to suggest that they represent the overall populations for their respective regions. Demographic comparisons of caver and non-caver participants may be found in Appendix F.

\section{Caving Experiences of Cavers}

Cavers varied in areas that they frequently caved in. Eight (20\%) described their primary caving area as regional. Another fifteen (37\%) described their caving as on a national and international level. These numbers indicate exposure to different cave types as well as different caving attitudes - regionally and/or culturally based. 
Memberships in speleo-related organizations may be indicative of level of interest in caving. Thirty-seven $(90 \%)$ of the cavers held a membership in at least one cave-related organization.

\section{Caving Experiences of Non-Cavers}

Degree of familiarity non-cavers have with caves may have some bearing on how they perceive the need for cave protection. Non-cavers were found only in the Kentucky and New Mexico focus groups. Six (46\%) of the non-cavers indicated having participated in noncommercial wild cave trips, indicating some degree of non-commercial wild cave experience among these participants.

\section{Commercial Cave Trips}

What constituted a commercial cave trip or commercial spelunker/wild cave trip was left to the respondents' interpretation. In addition, there were participants, within all three focus group venues, who had served as cave guides at one time or another; some were still active. It was left up to the discretion of those individuals who had led commercial trips to include or not include these trips in their personal counts.

Forty-three (72\%) participants responded to the question regarding having taken a commercial cave trip. All had indicated having taken one or more commercial cave trips. Seventy percent of the respondents had been on more than ten commercial cave trips. These numbers indicate a familiarity with commercial cave trips for all participants. This was true of all focus groups. 
Forty-five (75\%) of all participants responded to the question on commercial wild cave tour participation. Twenty-one (39\%) participants had not participated on a commercial wild cave trip. Twenty participants (37\%) had participated on one to five commercially guided wild cave tours. Responses indicate limited experience with commercial wild cave trips.

\section{Kentucky and New Mexico Cave Visitation}

Because two focus groups' localities were based specifically in cave regions (Mammoth Cave region, Kentucky and Carlsbad Caverns region, New Mexico), it was important to identify the level of familiarity participants from the three focus group venues had with caves in those two states.

The majority of cavers had visited caves in both regions. Only one (2\%) caver had not visited a Kentucky cave versus eight (20\%) who had not visited a New Mexico cave. This indicates that caver participants are fairly familiar with caves found in both states.

All responding non-cavers had visited at least one cave with one or more trips, in their respective state. Only one non-caver from each state had visited a cave in the other state. These responses indicate non-caver participants have some degree of familiarity with caves within their corresponding state and little to no familiarity with caves from the other locality.

\section{Wilderness Experience}

Familiarity with Wilderness may or may not have bearing on wilderness discussions. Focus group participants were asked if they had ever visited a Wilderness area and if they would visit again. The majority of respondents from the New Mexico and Caving Event focus groups had previously visited a Wilderness area, 89\% (eight) and 97\% (thirty-three) respectively. Four 
(57\%) of the seven Kentucky respondents had visited wilderness. These numbers indicated varying degrees of experience with Wilderness areas among the focus group participants.

\section{Focus Groups Sessions Results}

Focus group questions covered three main themes: nomenclature; wild and wilderness concepts; and the idea of cave wilderness. Refinement of topics occurred as discussions evolved. The original research questions used in all focus group discussions were as follows:

1. How are the following terms defined: wild cave, developed cave, and commercial cave?

2. Do the terms wild and wilderness have the same meaning (e.g. wild area vs. wilderness area; wild cave vs. cave wilderness)?

3. What purpose(s) and goals could a cave wilderness designation serve?

4. Is there a term other than "cave wilderness" that could be more appropriate in describing these purposes/goals? If so, what could it be?

5. Can an entire cave be considered wilderness? Can portions of caves be considered wilderness? At what point does cave wilderness begin? Is it separate from surface wilderness?

6. Is there a need for a wilderness designation by legislation, for caves? Why or why not?

7. What concerns (risks) are there in regard to a wilderness designation?

8. What benefits (rewards) are there in regard to a wilderness designation? 
9. Could there be a difference in management of cave wilderness than traditional wilderness practices? Why or why not? If so, what forms of management practices would be expected that differentiate from traditional wilderness management.

10. Can this concept be applied to caves extending to lands under private ownership? Could a different designation be used for private lands? If so, what could it be called?

The Caving Event focus groups were conducted first. Following these sessions, two new questions were generated and used in the subsequent Kentucky and New Mexico focus groups:

1. Is wilderness defined by an individual's experience in a specific landscape (environment)?

2. What defines a wilderness experience? Can a wilderness experience occur in a nonwilderness area? Why or why not?

Unless otherwise noted, findings are based on responses from any and all focus groups and focus group venues. Due to the exploratory nature of this research, determination of significance of comment or discussion was not limited to the number of times similar comments/discussions occurred in other focus groups or focus group venues. Significance was also based on ability of comment to generate further discussion, summary nature of comment, and/or nature of question eliciting response (i.e. question asking for list).

\section{Defining Cave Types}

Defining terms wild cave, developed cave and commercial cave did not prove as simple as it first appeared. During the course of the focus groups' discussions, concepts evolved, definitions changed and, as was true for all focus groups, a new term, show cave, was introduced. One focus group introduced the concept 'research cave'. This will be elaborated 
upon later in this section and reintroduced in discussions regarding special designations. In all cases, discussions defining one term often made use of other terms. Defining terms within terms would lead to refinement and/or clarification of term definitions.

Focus group participants raised three points in regard to establishing nomenclature. First, non-cavers would have very specific definitions. While this research involved non-cavers, these individuals did reside in a cave region and possibly had a greater understanding of caves and cave usage than the average public in non-cave regions. However, one non-caver's comment did lend support to this idea of specificity:

Participant: Actually, you're probably asking the wrong people this question, because if you asked non-cavers I think you'd get some real specific answers. A commercial cave is a cave that I pay my money, I go in and I see, that's right, it's a tour cave. A wild cave would be a cave that has no developments. I can go in but I need my own lights and all that. And I think that if you ask them again, the non-cavers, a developed cave has something in it, maybe some trails, maybe some lights. I think we're so involved in caves we start doing this. So I really think that you can define those, and yes, I agree, one cave can be another. Just like for years we talked about classifying caves and trying to put a cave into a box. Well, you don't put a cave into a box, but you still can get some good information there. And, it might be that this part of the cave is this and this part of the cave is this. So, you're not even talking about the whole cave (FG2).

Participant: Well, I'll throw out a layman's view. I'm not a caver. The only time I've been in a cave is on a commercial tour here at Carlsbad Caverns. What it would mean to me is, without having any experience; I would say a wild cave would be one that is untouched by a man in terms of having trails or lights. And, I would consider a developed cave one that would have trails and lights and maps made of it. And then, a commercial cave I would consider one that's advertised, has concessions, charges fees, and has roadways leading to it, and organized tours (FG9).

A potential corollary would be that cavers would not have such clear-cut definitions. This will be seen to be true, not only of cavers, but, of non-cavers who are familiar with caves. 
Second, the establishment of terms' definitions would be important to government agencies for integration with policy-related concepts such as wilderness. This is illustrated by the following quote:

Participant: I think it's going to be really important to discuss these terms with governmental agencies and use them in concepts that they already have in place for surface wilderness, would probably be the best key because that is a concept that they already understand. I really think you're on the right track here with, in terms of degree - commercial caves, developed cave, wild cave and then the wilderness cave. That seems to be the range of degrees. I believe they'll understand them, the clearest and the most easiest, and hopefully the best path (FG2).

The third point pertains to the perspective taken in defining these terms - the cave or the cave user, as illustrated in the following discussion:

Participant: But are we making the definition from the point of view of the cave or from the point of view of the user of the cave.

Researcher: I think you can go both ways, which complicates things. Participant: Of course, it does and of course, you can. And what, there are several approaches you can take. One is, it seems to be that we're talking about a cave wilderness; we're talking about getting back to, getting caves in their wild stage. And then, our definitions need to relate to what's been done to that cave to change that wild state. And can you or can you not go back (FG7).

In establishing nomenclature, it should be noted that definitions might vary based on an individual's knowledge and/or experience. Establishment of definitions may be important for integration with policy related concepts such as wilderness. It is important to understanding the perspective taken in defining these terms - the cave or the cave user.

\section{Ownership- Public versus Private}

The topic of ownership evolved during some focus groups' discussions attempting to define cave types. The topic of whether public versus private ownership might be a distinction within a cave designation was discussed; however, it was not a primary determining factor for 
assigning a designation. All four Caving Event focus groups as well as one of the New Mexico focus groups discussed the potential of differentiating between publicly owned (State or Federal ownership) and privately owned caves. The distinction was made primarily to delineate between developed caves that are operated "for profit" (typically, privately owned caves) versus those caves that generate income (via fee collections), but are "not for profit" ventures (typically, government owned caves). No consensus was reached as to whether it was necessary to have terms that delineated profit-making versus income-generating businesses. Perhaps additional terms are unnecessary when terms such as government (or public) and private are descriptive of ownership rather than descriptive of the cave. In addition, "for profit" and "not for profit" are management goals, which can exist regardless of the degree of development of the cave:

Participant One: Where do you throw government owned caves in there, both federal and state governments?

Participant Two: Well, they're commercial and...

Participant Three: They're definitely developed.

Participant Four: Ownership doesn't come into this type of breakdown (FG1).

\section{Commercial Cave versus Commercial Use}

For all focus groups, discussions regarding "commercial cave" began by identifying a commercial cave as one in which people pay to "go and see." Further discussion introduced the terms "developed cave," "show cave" and "wild cave." In addition, discussion turned to nontourism commercial uses of caves. Although, there was some suggestion that ownership might determine whether a cave could be considered a commercial cave, overall tendency was to not include ownership as criteria for defining commercial cave. Consideration was given to avoiding the use of the term commercial cave. As usage was a defining criteria; a more appropriate term would be "commercial use:" 
Participant One: A saltpeter cave, even before they showed tourists through the cave it was still a commercial operation correct? Because they were making money from the cave.

Participant Two: Wild mined caves are developed caves (FG 1).

Participant One: Those are commercial purposes, uses.

Participant Three: So, a commercial cave doesn't necessarily mean that people are paying you to see it, just hauling guano out of it, it is still a commercial cave.

Participant Four: I think show cave would be a better term.

Participant One: Commercial just means they are profiting from it (FG1).

Based on focus groups' discussions five elements were identified that define commercial usage of a cave. First, commercial usage generates income, income that may accrue to the user or the owner of the cave. Second, usage is not limited to tourism; usage may range from agriculture to resource extraction. Third, commercial usage may vary in degree of impact, from low to highly destructive of the cave environment. Fourth, degree of wildness or development of a cave is not a factor in determining commercial usage. Fifth, the charging of administrative fees does not necessarily constitute commercial usage.

\section{Wild Cave}

Participant One: What does it need to be or not to be a wild cave?

Participant Two: Probably it would be easier to not to be (FG1).

Discussions regarding defining 'wild cave' were far ranging, covering modifications to the cave environs and the establishment of trails, cave usage, and individuals' perceptions of what is wild. The following quotes are examples of these discussions:

Participant One: To me those two words there, wild cave is just an undeveloped cave. I term it no facilities, no walkways, no electricity. It could be open to the public, could it not? A wild cave? But, generally I think about it as undeveloped. No lights, no trails, no handrails.

Participant Two: No steps or anything. I agree with that (FG5).

Participant Three: I would take a little bit of exception with the most natural state because we put gates on caves that we consider wild. We leave bolts inside caves 
and hangers inside caves for rigging that we consider wild. So, I understand the intent of what you're getting at. But...

Participant Four: And that just makes it even more not clear. It's very gray what's wild, what's developed. If you put a few bolts in now is it developed?

Participant Three: There are your virgin wilderness, like Lechuguilla cave, is wilderness legally it has a gate; it has rigging points and things like that. And, if I recall from the Wilderness Act, where the developments of people will be minimum. But, still there are trails and so forth. Just minimizes, it doesn't mean zero (FG3).

Participant Five: I'd like to add another word to possibly, to the wild cave, and that's the term hazardous un-mapped, unexplored. I assume if people haven't been there they are unmapped.

Participant Six: But a lot of the caves that are wild are explored are mapped.

Participant Seven: Lechuguilla is certainly one of them.

Participant Eight: I would think a lot depends on the expertise of the people using it. The general public, a lot of caves would be wild to the general public, to a spelunker...

Participant Seven: A good many or most of the wild caves, at least, well most of the wild caves have been mapped and so, from that standpoint ...

Participant Five: If you found a new one though, and it was not mapped, I don't know if a new cave is a wild cave.

Participant Six: It is.

Participant Seven: Definitely.

Participant Eight: Just because the others are mapped doesn't make them any less hazardous and challenging, you're just not as apt to get lost (FG8).

Based on focus groups' discussions, five primary elements of a wild cave were identified.

First, a wild cave is in its most (or close to) natural state. It is undeveloped and substantially unimpacted. Second, visitors are required to take a wild cave on its own terms. The cave is undeveloped; there are no lights, steps, or ladders. There are no improvements to facilitate travel by or to insure the safety of the public. The cave may be hazardous; there are no safe guards, such as handrails or fences, to ensure visitor safety. Hazards may also include unstable rocks and flooding as well as other dangers. Visitation typically requires special gear, such as lights, helmet, and clothing. Third, modifications to the cave are intended to allow access, to make travel possible, for safety of explorers, and may require some expertise to use. Modifications are typically done by cavers for use by cavers. Fourth, a wild cave may or may not be mapped; 
exploration may or may not be an on going process. Last, it is possible to have commercial usage of a wild cave, such as guided wild cave trips. Such usage does not detract from its wildness.

Six major themes were derived from discussions: 1) pristineness, 2) naturalness, 3) trails, 4) modifications, 5) historic usage, and 6) visitor's experience \& expertise.

\section{Pristineness}

Discussions regarding the pristine quality of a cave typically arose during discussions of changes to a wild cave. Caving Event focus groups were most likely to address the idea of pristine (or pristineness) directly, explicitly using the term pristine, whereas the Kentucky and New Mexico focus groups often approached the concept indirectly. These two focus group venues usually did not use the term pristine, but, instead referred to the idea of pristine as "a truly wild cave", one in which man has not entered. This was one of the few times that focus groups approached the same concept utilizing different terminology.

Four elements of pristineness were identified from focus group discussions. First, a pristine cave is one in which there have been no impacts from human activity. Man's presence is absent. Impact was viewed not only from human entry standpoint (subsurface activities), but also from surface activities that contaminate ground water (i.e. a cave without a surface entrance may not be considered pristine if impacted by surface contaminants). Surface activities may also affect the pristineness of a cave, without introducing contaminants (such as exclusion of water or nutrients, or mining activities). Second, there is gradation in the pristine condition of a wild cave, dependent on how much of it has been impacted by human activities. Third, a wild cave is no longer pristine once development has begun. Fourth, a restored cave, which may appear wild and natural, is not a pristine cave. 
Discussions regarding the need to protect the pristineness of a cave or area within a cave also mentioned those from whom these areas need to be protected. One Caving Event focus group discussed the potential need to protect pristine areas not only from non-cavers put also from cavers who may not appreciate the pristine nature of the site:

Participant: I think, something I have a problem with, about the management, like [Name's] post. You can take it a good way or a bad way. Don't take new cavers there because they won't appreciate the pristine nature of it. Therefore, they'll just bring their friends back and trash it. I've seen some really experienced cavers walk right across a bed of gypsum flowers. If you take his post at face value and say don't take new people there because they won't appreciate it. Well, you know the old adage is the only way to protect the cave is to blow the damn thing shut so we don't go in there (FG1).

This line of discussion will be of importance later in discussions regarding the establishment of a special designation for caves.

\section{Naturalness}

The idea of appearance, as in "it appears natural," was raised during one focus group.

How deep does one need to look in order to define "pristineness?" This will be important in later discussions of wilderness. The following illustrates this concept:

Participant: This brings up an interesting question as far as there's no answer to it. We're splitting hairs when talking about terminology and definitions. We're getting the same, well, it looks natural, does that make it natural? And is it just appearance? And something I was talking with [Name] about just beforehand, depending on what your goal is or what your use is, it could be visually natural. It could be, I'm a geochemist, so you could talk about it being chemically natural, and I'm particularly concerned with isotopes and water. There is a situation in Carlsbad where pools have had water added to them from outside. And if someone just carried water into a wild cave and dumped it into a pool, I think most people would say it's still a wild cave, but from my perspective that cave is permanently modified and useless for my research. So, it could get isotopically modified versus isotopically wild. I mean there's all sorts of gradations here (FG2). 


\section{Trails}

Trails play a critical role in delineating between wild and developed caves. Initial attempts at defining wild and developed caves touched upon the presence or absence of trails. As discussions progressed, trail elements were qualified to include type and intent of trail creation. It should be noted that any trail was considered as impact, or modification to the cave. The following discussion segments illustrate the difficulties with trails as a defining element of a wild or developed cave:

Researcher: You drew a distinction there between trails and improved trails.

Participant One: Yes, sir.

Researcher: What if you have to put steps in? Do you put that down as improvements?

Participant One: When we lead a scout troop into a wild cave, they are very careful to tell the boys to stay to the trail, in other words, the path that is already established. Don't let them go off and disturb the natural soil. That's not a developed trail, but it is a trail.

Participant Two: But I think there's a difference between impact and development. It's that you've got groups of people going through leaving their footprints in a little trail and because we've been there that has impacted the cave but nobody has purposely developed it to make it a trail.

Participant One: Correct (FG3).

Participant One: The thing is about trails, you have that are developed to make it easy for people to walk down the trail, such as Carlsbad. And then you have flagged trails, like in Lechuguilla, that have never been purposely altered to make them easier to walk down but are instead are flagged to keep the traffic in one place so as not to spoil the rest of it, nor to guide you for that matter. The trails in Lechuguilla don't really have road signs to guide you, the point is just to keep you off the rest of the floor so it doesn't get trampled, so its kind of a different purpose to a trail.

Participant Two: Kind of routes instead of trails.

Researcher: So you think there is a difference in a route versus a trail?

Participant Two: I do.

Researcher: So the route is the one that is the flagged trail.

Participant Two: Well, that's one kind of route, yeah, that's a developed route, I guess you would call it.

Participant Three: Or maybe just established...

Participant Two: Established would be best.

Participant Three:...through traffic, it has been established here, but hasn't really been developed or altered, just putting flags on it to identify it. 


\section{Participant Four: And to direct you (FG8).}

It is the essence of trails that they make it possible for individuals to access the interior of a cave. Criteria for trails acceptable in wild caves were identified from focus groups' discussions. First, trails in wild caves typically develop naturally, through visitation. Second, the potential exists for planning trail placement. Trails created purposely are laid out with the intent of resource protection: to contain impact, to guide around delicate areas. Third, trails are unimproved, but may be delineated by flagging or by rock cairns. Fourth, wild cave trails are not created for ease of traveling, i.e. they are not designed to facilitate visitation by the general public.

Some discussion occurred in which it was debated whether trails were a form of development. The use of this terminology has important implications in defining acceptable modifications within a wild cave as well as in specially designated caves and wilderness uses of caves:

Participant One: Flagging modifies it.

Participant Two: I would call that development, yes I do.

Participant Three: I would hold that development guided, that's guided. Because you're not building a trail through the cave, you're guiding the people, to stay on the trail so you're not developing a trail.

Participant Four: You're not developing it in the sense that you are building it, but you are developing it in the sense that you're delineating where people should go to protect the rest of it. There is some development there, even though it is minor, it's not the same as building something.

Participant Five: You're making development decisions that are, you are determining methods to, you are implementing methods to confine impact.

Participant Three: But I would say that would come under, to me, limited impact. I would still consider that wild, because it is still limited impact. You're just concentrating the impact in just one area so you get a walk down trail, but if you average out in a normal cave that walk down trail you wouldn't see it because there would be footprints all over the place.

Participant Five: I would call that wild also, because you're preserving the wildness of the rest of the, through this fairly development technique, if you want to call it development, but there is certainly a decision process (FG4). 
As noted earlier, one criterion for a wild cave is that the cave is in its most natural state, it is undeveloped or substantially undeveloped. The intentional establishment of trails with the goal of confining impact is an example of "substantially undeveloped." It will be important in future discussions, policies, or legislation that development be clearly defined to avoid potential misunderstandings or conflict with management goals and objectives.

\section{Modifications}

In addition to establishing trails, discussions occurred regarding acceptable modifications or impacts, which may occur within a wild cave such that it retains its wild aspect. Acceptable modifications is discussed in the following quote:

Participant One: It depends what the passage modification is and the development. At Breezeway, it's because some of the cavers are lazy and I think don't necessarily want a sense of wilderness when they're in there. They just want it to be easy, which means it's developed; it's not wild anymore as far as I'm concerned. So, it wasn't developed for income it was it just developed for ease of traveling.

Researcher: Does any modifications make it developed? How about setting bolts? Participant One: No, because you've not developing, not modifying the passages. You're making it easier, possible to travel, easier to travel.

Researcher: So, you delineate the difference between developed and what you said?

Participant Two: No, I would have to disagree.

Participant Three: I have to disagree with that too. Because, if you don't, in a developed cave you're not taking the cave on it's own terms. In a wild cave, I would say a wild cave is one that you're truly taking the cave or exploring the cave on its own terms while moving through it.

Participant Two: But even in a wild cave, you do put bolts down. Sometimes not to, sometimes that's the only way to do it, but sometimes it's to make it slightly easier and it's safer.

Participant One: No, I say there's a difference between safety and making it easier. A bunch of the ropes in Lech are not because you can't do it with them, it's just because you don't want to risk someone falling.

Participant Two: Safer.

Participant One: So, I'd argue that bolts are not passage modification they're safety or making passage possible (FG4). 
Discussions defining acceptable modifications occurred in all focus groups. However, Caving Event focus groups went into more detail regarding modifications acceptable in a wild cave. This may be a difference between cavers and non-cavers. As discussed earlier, non-cavers may have more specific definitions than do non-cavers. In all focus groups, discussions reiterated the point that defining acceptable modifications was fraught with gray areas.

Five primary elements of cave modifications that affect the integrity of wild cave were identified based on focus group discussions. First, gates are not considered deterrents to a cave's wildness. Second, artificial entrances or entrance enhancements are not necessarily deterrents to a cave's wildness. Third, modifications that are designed to increase accessibility for non-cavers reduces the cave's wildness and have potential to remove the cave from wild status. Fourth, modifications designed to facilitate ease of travel detract from the wildness of a cave; such modifications are considered forms of development. Fifth, allowable modifications are those that make it possible for a trained individual to traverse a portion of a cave or are designed to enhance safety. Modifications include the placement of ropes, bolts, and hangers.

\section{Historic Usage}

The historic use of specific caves can be established through written and oral histories, as well as via the physical evidence left behind in the caves. Discussions concerning the historic use of caves were introduced by three focus groups, one from each of the venues. Discussions touched upon the following two questions: 1) how does historic use of a cave change the wildness of a cave, and 2) does it matter if it is recent or ancient history? The following best illustrates the concerns regarding historic usage of a cave and if/how such usage changes the wildness of a cave or sense of wild experience within the cave:

Participant One: Certainly large saltpeter operations and large-scale guano mining operations have a permanent effect on the cave. 
Researcher: How about restoration then, if they had gone in and lets say restored saltpeter and other things, took out trails...?

Participant One: I think there would be tremendous resistance to doing that because of the historic...

Participant Two: Yeah, these are archeological sites.

Participant One: Maybe that means a whole new category.

Participant Three: Well I guess that brings up an issue if you had, let's say, some use of that cave eons ago, certainly hundreds of centuries ago, in the Indian sense or something like that. Was that cave development and is that cave no longer eligible to be considered a wild cave? Because the native indigenous populations are no longer using it, there hasn't been any traffic in that cave for extended periods of time and now someone goes back into it. Are they entering a developed cave? Burial sites and things like that. Is that cave development?

Participant One: We surveyed a cave over in Lane County we encountered manmade rock wall deep inside the cave and found numerous, numerous artifacts throughout the cave.

Participant Three: Did you feel like when you entered the cave you were going into a wild cave?

Participant One: It felt wild at first.

Participant Three: Did you consider it developed or commercial after you found those things?

Participant One: It certainly wasn't commercial. I have no idea why the indigenous people were in there or why they built the wall at all.

Participant Three: It seems like we have sort of a gray area here. Does man's influence change it from a wild cave to a developed cave in any sense? If someone's buried in there, in a ceremonial sense, thousands of years ago, does it now become a developed cave or is it in a wild state when you reenter it? Those are pretty gray areas.

Participant Four: I think part of the problem is the way you're describing developed.

Participant Five: And I think we're getting...

Participant Four: Because impact is the reality.

Participant Three: I think that's what comes to mind (FG3).

Participant: When you say human impact then I think of Bill Austin's discovery of footprints, this is probably fifty years ago, discovery of footprints twelve hours deep in the cave, that were made 3600 years ago, and there was those human fecal remains, and junk that those woodland people left in the cave...It was commercial purposes for instance that led those kids to go in the Crystal cave six or seven years ago and chip away onyx formations and stupidly to write their names on the wall of the cave, when they did. That's a commercial, a low-grade commercial use of the cave and very destructive. So, you got a whole continuum from prehistory to the present from wild to developed (FG 7). 
Participant One: Well, maybe an the addendum to what [Participant Two] said, to currently used, because you have to consider Deep Cave a wild cave, wouldn't you? But there's a Jim White ladder hanging in there.

Participant Two: Yeah you're right.

Participant One: Ladders and trails that aren't used for touring or visiting the cave, maybe not historical, because actually if you think about Big Bone cave in Tennessee, it's got that whole underground railway from the saltpeter mining days, made out of wood.

Researcher: So, excluding historical?

Participant One: Yeah, excluding historical, maybe that's what I'm trying to say (FG9).

In the case of these three focus groups, there was concern was regarding the physical evidence of historic usage of a cave, and if and how such usage changes the wildness of a cave or the sense of wild experience during a visit to the cave. No discussions occurred regarding whether the existence of written or oral documentation of cave usage affected a cave's wildness. It would appear, in the examples presented, that historic use of the cave did not necessarily detract from a sense of wildness of the cave. This topic should be further pursued, as it has possible implications in any potential special designation for wild caves.

\section{Experience and Expertise}

Discussions occurred in all focus groups on how individuals' perceptions of the wildness of a cave differs based on experiences and cave/caving expertise (knowledge and skills). These perceptions may influence how they define a cave's degree of wildness or degree of developedness, as discussed here:

Participant One: I want to add something to all of that, I think that part of that, is going to depend on where you grew up, like people who grew up in the city versus growing up on a farm like I did. Because for me like going to Mammoth Cave on like the quote tourist tours was a completely different experience than doing the wild cave tour, because that's more like, I think for a lot of people, the tours that they do in a commercial cave might be considered to be wild to them, because they're in an urban environment all the time they're going on vacation to see something. Where the people that are, like the cavers, are more into like exploring and things and the early pioneers and stuff like that so it's a completely 
different type of experience that people coming from different backgrounds are looking for (FG4).

Participant Two: It's not just where you grew up, it's certainly your whole back log of experience, but your experiences changes as you move through life. For example when someone becomes injured, or has a physically, a long term physically impairing injury it can, wilderness or wild condition can suddenly become very different, because they feel diminished and they can feel that they can no longer operate in the same environments as before.

Researcher: So, not only their life experiences but also any physical changes they experience?

Participant Two: Yes (FG4).

Participant Three: Well you have a wild cave like Goat Cave which is almost nothing and then you go to, you just go along the way to longer caves, more difficult caves each one of these steps winnows out who's gonna go in there because of skills and abilities.

Researcher: Does that change then, somebody's skill level, changes whether it's developed or wild?

Participant Three: It doesn't change whether it's developed or wild, but it changes perhaps where on that line, that spectrum you have there ...

Participant Four: So wild is hard and developed is easy, huh?

Participant Five: Well, I think that has to be a, not only a continuum of what it is that's in the cave that facilitates one to go through it, but also the perception of the individual that's visiting the cave. To someone that's an experienced caver, might find it fairly easy and straightforward, but somebody was only been caving a few times, would see the same cave and say whoa, this is really wild. This is something I am not used to. But a very experienced person may say this is not too bad. I can see evidence that there's a major elephant trail rolling through here, but somebody who is not used to looking at that might not recognize that so it's a perception, an individual perception (FG8).

Based on focus groups' discussions, nine factors were identified that may heighten an individual's perception of a cave's degree of wildness. First, lack of knowledge about the cave environment (i.e. not being able to identify impacted areas). Second, use of special clothing (typically non-street attire) and special gear such as a helmet and light. Third, experience offtrail, away from developed tourist routes, and access to restricted areas. Fourth, the need for special skills (caving abilities), even though it is not necessary to have additional skills or caving abilities, nor does it need to be physically challenging, to have the sense of a wild cave experience. Fifth, the presence or absence of a guide. Sixth, the degree of perceived risk. 
Seventh, knowledge (or lack thereof) regarding history of the cave's usage. Eighth, cave locale relative to populated areas. In general, in the United States, eastern caves are more likely to be found near populated areas than are western caves. Finally, individual origins; individuals from urban environments may have lower standards for perceiving wildness. Individuals from more rural environments may have higher wildness standards. In general, the perception of wildness and degree of wildness was subjective, one based on one's personal experiences and physical capabilities.

\section{Wild Cave Tours}

Within all focus groups, discussions addressed the use of caves for wild cave tours.

Discussions about wild cave tours occurred during attempts to clarify definitions of cave types.

Participant: And a lot of operations now are offering wild cave tours, in which you still need a little of expertise in attire and so on, even though it's a commercial outfit (FG1).

Participant: An interesting question, that's bothering me or that is interesting...And we [karst preserve] would lead trips into the cave, didn't charge for it. Nobody went, unless they were NSS, by themselves, or at least one qualified caver. However, we'd take Boy Scout troops, whatever, church groups this sort of thing, in, and they didn't go in without a guide. There was no charge and no improvement to the cave, but there was a lot of improvements to the cave preserve. Does that make that a developed cave? It's a led tour but no money, no development other than on the surface (FG3).

From focus groups' discussions, four elements of wild cave tours were identified: primary function of guide, requirements of participants, participants' perceptions, and tour localities. First, a wild cave tour may or may not be guided for commercial purposes. For example, guides may serve primarily as monitors for resource protection purposes. Second, tour participants require at least a minimum in special gear and expertise. Third, tours may occur in heavily traveled portions of cave, in which participants may still have the perception of being in 
a wild cave. Fourth, tours are not limited to a wild, undeveloped cave. Tours may occur in wild portions of a developed cave.

\section{Research Cave}

The idea of a "research cave" was introduced by one of the New Mexico focus groups.

While all groups discussed the importance of scientific values associated with caves, only one

focus group suggested a specific, special designation in recognition of those values:

Participant One: I'd consider Lechuguilla Cave to be a wild cave myself, basically because it's not really open to the public. Its basically a gigantic research laboratory, and I know that everybody with any kind of entrenched interest in Lechuguilla wants to keep it that way because it is such a delicate environment, and also, because it is unexplored in a lot of its passageways. They haven't found the end of it. In that sense, a cave which is under exploration, even like Carlsbad, well, I would consider Carlsbad to be a commercial cave in this thing, but basically it is also as you put it, a wild cave, has many undiscovered passages.

Researcher: So a cave can be partially commercial and partially wild?

Participant One: I would say so or a hybrid and that's good, there's nothing wrong with calling something a hybrid, I suppose. But I, myself, hope Lechuguilla is never opened to the public. I cannot imagine shooting elevators and such down into Lechuguilla, although I've never been myself. I know the beauty of it. So, I'm hoping forever that Lechuguilla remains a cave of great beauty and a research laboratory; otherwise, it will really get messed up. We are lucky to have a gigantic commercial cave here, one of the biggest in the world, and it is, for the main part, I think it will satisfy the needs and tastes of 95 percent of the people who are interested in at least taking a look at caves, the caving community not being that huge...

Researcher: [Name] how about you?

Participant Two: From where we sit now I would not consider Lechuguilla as a wild cave. Too many people have been there and have had access to it and gone through it. The trails have already been set and established in there. It's a research cave to me and I would hope it can remain that way...

Researcher: Would you say then that, you were saying that you do not consider Lechuguilla Cave a wild cave do you consider it developed them?

Participant Two: No is not developed.

Researcher: So, there is some sort of continuum?

Participant Two: There is an interplay of different designations but I don't know how it would describe Lechuguilla. That thing's had thousands of people going through it and a wild thing is something that means you pretty much have to stay out of the way. But you can't do that in research. You have to take research in, to have a research cave. Therefore, I would put that as a research cave rather than a wild cave. 
Researcher: Is that something different than a developed cave?

Participant Two: Oh yes.

Participant One: What is a research cave?

Participant Two: A research cave would be open to people who have qualifications to make decisions on the cave and what it means. If you are going to have to walk two miles to get to see something pretty, the public is not going to like that. That is what Lechuguilla amounts to. Too many places, I have not been in the cave, but I have talked to, and I've watched a number of slide shows on it, and it is too far between the beautiful spots. To the caver, it is fantastic; to the public, it is (unintelligible). That's not a commercial cave, that is not a cave that, where, you want to (unintelligible) but it has tremendous potential for research (FG9).

Although this concept of a research cave was introduced during discussions of wild cave the possibility exists, as noted above, for research to be conducted in both wild and developed caves. This concept may have significance in conjunction with special designation discussions.

\section{Developed Cave}

Participant: There was a lady that asked me last week, now if I take this trip Joe is it the civilized trip? I said yes ma'am that's the civilized trip. We've got lights and we've got handrails (FG5).

Discussions regarding developed cave encompassed a broad range of topics, from what constitutes development and reasons for development, to discussions regarding impact versus development. Similarities in responses existed among all focus groups. An example of defining developed cave is as follows:

Participant: I would think of a developed cave as a cave that has been made accessible to non-cavers. Because all of the things you were just talking about with bolts and ropes left in caves those are not for non-cavers. Those are for cavers to use and it still could be a wild cave. But to just take anybody off the street to go walk through a developed cave is a whole different experience and yet it is one that they would enjoy but they would not want to be in a wild cave (FG3).

Based on focus groups' discussions the following four elements where identified regarding developed cave. First, and foremost, development is equated to "not taking the cave on 
its own terms." Development involves modifying the cave for convenience and/or monetary gain. Second, development events can vary in type, from resource extraction to tourism. There are different degrees of development, and possibly a combination of events, occurring during separate periods or concurrently. Third, development often occurs for commercial usage, particularly tourism. Fourth, a developed cave may not always be commercially active. Development may have occurred for some purpose, but the cave currently is no longer shown to the public or mined.

Development is often viewed as an improvement for visitation. By facilitating access by the public, development eliminates the need for special gear, clothing, and lights. Modifications include lights, developed trails, stairs, and handrails. Improved trails (purposely designed, intentionally laid out and constructed) are a critical element of these types of developed caves. Development such as trail placement can be used to contain or prevent additional impact. Modifications may also include infrastructure - parking lots, rest rooms, and gift shops, for example. Such development eliminates the need for special clothing, gear, or skills required for visiting the cave. Caves developed in this manner are typically referred to as show caves.

\section{Show Cave}

Focus groups introduced a subcategory of developed cave called "show cave:"

Participant One: There are probably two types of commercial caves, you got your show cave, and you've got...

Participant Two: Everything else.

Participant One: ...everything else. It evens out in a way.

Participant Two: Exactly.

Participant Three: Yeah, I mean granted, over 90 to $95 \%$ probably when we think of commercial cave we think of a show cave...

Participant One: Exactly. 
Participant Four: If you would exclude cavers, you'd probably be more like $99 \%$ are going to think a developed or a commercial cave that's a show cave, that's the only reason you'd go there because you want to see it (FG1).

During these discussions, five elements of a show cave where identified. First, a show cave is a cave developed for tourism purposes. It was noted that development may be limited and the cave used primarily for wild cave tours. Second, purposefully developed trails are designed to enhance the visual experience of the show cave visitor; they are designed for scenic purposes. Third, show caves typically required no expertise on part of the visitor. Fourth, a show cave provides a different type of experience than a wild cave trip. Finally, a show cave is created with a commercial intent.

The commercial aspect of a show cave implies operation for profit. However, it was noted that not all show caves are operated with the primary goal of generating profit. Such caves, typically those operated by federal or state governments, are operated with a primary goal other than profit generation, though these operations may be income generating. The question was raised as to whether these caves should be called something different to note differences in operation goals, based on ownership. Little consideration was given to this question, implying that ownership had no bearing on cave type.

\section{Wild, Developed, Commercial}

The following statement was exemplary in differentiating wild cave and developed cave from commercial usage:

Participant One: Can we say that wild versus developed is a description of physical modification rather, as opposed to, the use of the cave?

Participant Two: That's what I would call it rather than its use (FG2). 
Impact

Focus groups' discussions defining cave types generated discussions on impacts to the cave environment from human activities. During these discussions, focus groups addressed the idea that while all development is impact, not all impact may be considered development (example: graffiti or formation removal). Impacts may be the result of intentional actions or incidental to other activities. Impact may also be modern or historic in origin. A cave can be so heavily impacted that it is no longer considered wild. The question was raised whether an impacted cave can return to a wilder state:

Participant One: Something like Tamers has saltpeter vats or did. I would consider it a wild cave at this stage in its life.

Researcher: So it can revert back to wild?

Participant One: Yeah, I think so.

Participant Two: Well gee, do you mean wild or do you mean just no longer commercial, because unless you restored it back to predevelopment conditions then is it really wild?

Participant Three: We're saying though that you can have commercial uses in caves that have no development. So, if you cease those commercial uses, doesn't it revert to a wild cave at that point?

Participant Four: I think it depends on how much you've developed it. Like, if you say all that was in there was little tiny vats and no one went in for a hundred years, it would be pretty much back to wild. But, like, say you pour concrete and you put up a bunch of rails and you totally altered it, I think that development would continue to have impact on the cave even if somebody wasn't in there for a hundred years.

Participant One: Certainly large saltpeter operations and large scale guano mining operations have a permanent effect on the cave (FG3).

Participant One: One of the caves that was at the Idaho convention, I can't remember the name of it, it was a commercial cave.

Participant Two: The Ice King.

Participant One: Yeah, and, it's like, yeah, it was developed at one time. And as you walk in right now it certainly is a wild cave because as they point out through the clear ice there are the old paths four feet under ice now. It's as undeveloped... It was developed at one time, but its wild now (FG1).

The potential exists for impacted caves to return to a wild(er) condition. Agents of return may be human based (restoration activities) or nature based (e.g. flooding). The return of a cave 
to a wild(er) state may not mean that it has returned to a natural condition. The perception of the quality of the reversion may vary, dependent on an individual's experience (caver/non-caver, familiarity with cave environment). The perception of wildness and type of impact will have important considerations in management and special designation plans.

\section{Multiple Designations}

Discussions occurred among all focus groups regarding the possibility of multiple designations existing within one cave or cave system. The consensus was that the possibility existed for a cave to have different designations for different areas of the cave, regardless of whether the cave had been developed and/or commercialized. It was noted that while "the essence of the cave" may determine its primarily designation, this does not preclude the possibility of assigning other designations to specific areas within the cave. In addition, in a cave, which is partially developed, "paths less traveled" may occur beyond the developed portions of the cave, and those may be wild and unexplored areas.

\section{Continuum}

Focus groups described cave designations as existing on a continuum. This continuum included aspects of development and impact. The continuum begins at pristine/wild and natural and ends at heavily impacted/destroyed. This continuum is multi-directional, going from wild to developed or impacted to wild again. There is an interplay of different designations, an interlacing of degrees of impact and degrees of development with the wildness component. It was noted that a cave's placement on the continuum is also based on the type of experience(s) the cave or area of the cave has to offer. Finally, it was noted that placement is non-exclusive - a 
cave may have multiple site designations and therefore have regions that fall on different areas of the continuum.

\section{Wilderness}

Focus group discussions on wilderness and cave wilderness were often entwined. This section will address those components of the discussions that specifically concerned the idea of wilderness.

Discussions regarding wilderness focused on the 1964 Wilderness Act. While most participants displayed a basic understanding of the Wilderness Act, the degree of familiarity varied. Not surprisingly, those most familiar with all aspects of the Act worked for federal agencies responsible for wilderness stewardship. Misunderstandings ranged from the inability to identify which federal agencies were responsible for wilderness areas to lack of knowledge about what activities were permitted within a wilderness area. A few participants thought wilderness areas were closed to visitation or had restricted access. The idea that wilderness represented restrictions on access and permitted activities had bearing on discussions regarding the idea of cave wilderness.

All focus groups established the idea that there are two sides to wilderness. There is wilderness as defined by legislation and wilderness as defined by an individual's personal experiences and background:

Participant: Would you say that the boundary of the people who are coming out on vacation their boundary where they now feel like they're in a wilderness is much lower than any of us as experienced cavers? But, we all aren't we pushing that boundary? Certainly, where I felt I was in wilderness as a kid was half an hour from the entrance in Swivels Cave climbing up and down ladders, but now it's like I can do most of the cave and never really feel like I've gotten away from the entrance (FG 4). 
Participant One: To me it would vary. If you brought a person here from Brooklyn, New York and put them in Mammoth Cave National Park to me that's real wilderness to them. I think the opinions vary, in my opinion. But you know the people, Mammoth Cave is unique because actually it was taken from the people that lived there, eminent domain, condemnation. To them that was their home. But in a few years, if this person came from Brooklyn, Patricia, that's a wilderness, but if my grandmother lived there to me that's home. I'll go over there and I used to go out and play in the back and I was told that it was on the hill and I went there and the cows grazed over here. And you see, it's depending on what your environment was don't you think?

Participant Two: Yeah at one time it was farmland.

Participant One: That's right. And I doubt if you would find a descendant that lives in the park that would call Mammoth Cave a wilderness in any circumstance. Because that's home to those people. That's our home. It's not a wilderness. We've lives there for five or six generations. So, see, that park is unique. It's not like no one ever lived there. It's a rural community that's been transferred to a national park by demolishing the buildings and letting the vegetation grow. So, it's a little bit different than a wilderness out in Alaska. Do you see my point (FG 5)?

While wilderness, as defined by legislation, has fairly rigid constraints, it was suggested that the wilderness as defined by individuals' experiences is far more variable. The idea of wilderness defined by experience led to brief discussions regarding wilderness experience. This idea will be further explored in the section on cave wilderness.

\section{Wild, Natural and Wilderness}

All focus groups discussed elements of wild and wilderness:

Participant: My own definition, and you can add to this, wild would be, in my comprehension, no one has been there and knows about it. Wilderness would be some use by professionals. Wild, there's just nobody uses it. It's really out there (FG5).

Participant: Yes, I would say wild has not been changed at all, and wilderness it would be the same thing but a couple of concessions made to make it more comfortable (FG9).

For all but one participant, wilderness and wild where different parts of a continuum of wild to non-wild lands, with wilderness somewhere closer to wild, than to the center of the 
continuum. One individual felt that there was no difference between the two. Elements of wild, as discussed by the focus groups, included the idea that wild lands are regions less traveled by people and where the potential exists that no one had to have visited the site. Wild lands were defined as lands relatively untouched by man, not necessarily unexplored, but unchanged by human activities. Wilderness was defined similarly. However, wilderness included modifications such as trails and signs to facilitate use of the area.

Focus group's participants recognized two types of wilderness. First, there exists legislated Wilderness, found on Federal and State lands. Legislated wilderness is designated with a capital W. Second, there exists de facto wilderness, lands not legislated for protection, but having wilderness characteristics. These lands can be private or federal in ownership. Defacto wilderness is designated with a lower case w.

Focus groups discussed the management of legislated wilderness. Wilderness is managed for specific qualities, but, not so with wild lands. Wilderness is protected, unlike wild lands that can be developed in some manner. Wilderness is land set aside for protective purposes, not only for the wildlife in it, but for the ecosystem. Wilderness designation determines future usage of land; it places restrictions on management and usage of land to maintain wild state. Wilderness has organized special uses. Wild lands are representative of non-use. Wilderness is also an area of limited access, especially in the sense of mechanical access.

Focus groups discussed various elements of wilderness (legislated or de facto). In wilderness, the presence of man (including impact) is minimal. Wilderness is a matter of scale, such that it provides a sense of isolation and remoteness. Wilderness has a lack of infrastructure and provides a sense of self-reliance. Wilderness provides individuals with the sense of achievement on her/his own terms and a sense of discovery - the feeling of being the first ones 
there. It was noted that the definition of wilderness, degree of wildness and of naturalness, is dependent on the type of wilderness one is looking for (for example: visible or chemical).

The concepts of natural and wild were specifically addressed in four focus groups. Discussion topics included wild versus natural, restoration activities, and perceptions of natural.

If it is natural then it is wild. However, the reverse is not necessarily true. Appearing wild is not always equated to being natural. In addition, looking natural does not mean it is natural. The difference exists between impacted and modified. A pristine cave is both wild and natural.

It may be possible to restore a cave to a wild state, but it may not be returned to a natural state. Restored formations are not natural, though they may look better than damaged formations. The question was raised: does the lack of naturalness change the wildness of a cave? Natural to what degree (visually, chemically)? Just as gradations existed in the wildness of a cave, so do gradations exist in the naturalness of a cave.

One focus group participant defined natural as nature allowed to continue at will. Nature is part of wilderness. The perception of a restored cave's wildness and naturalness may vary between caver and non-caver. Individual differences in adventure/wilderness experience may make it possible for caves that are wild and not natural or that have been restored/reclaimed to be considered wilderness.

\section{Wilderness Cave}

Five focus groups discussed the concept of wilderness caves. Wilderness caves were defined as caves found within a designated Wilderness area (versus caves potentially designated as wilderness areas in and of themselves). 
Most discussions centered on questions regarding protection of these caves: 1) Are they protected in the same way as surface wilderness? 2) Does a cave under surface wilderness need special protection? 3) In order to protect these caves, how can access be controlled? and 4) Can caves in wilderness areas be gated?

Discussions turned towards federal agency management of the caves. It was noted that the National Park Service had established policies for caves, such that they would be managed as wilderness unless the cave failed to meet specific requirements. It was noted in several focus group discussions that the Forest Service, as well as the Bureau of Land Management, were establishing similar policies.

Differentiating between a wilderness cave and a cave wilderness has important philosophical and management implications.

\section{Cave Wilderness Special Designation}

Focus groups' discussions regarding cave wilderness designation were wide ranging. It is important to note that focus groups' discussions pertaining to special designation for caves (cave wilderness or otherwise) and associated topics do not necessarily denote support for or opposition to special designation. For the purpose of these discussions, the term cave wilderness will be synonymous with special designation.

\section{Opposition}

Opposition to the need for a cave wilderness designation addressed four broad themes: 1) natural obstructions to visitation; 2) current management practices; 3) existing laws; and 4) the need for protective action on the part of private landowners. 
The first theme, natural obstructions, recognized that the difficulties associated with access and/or traverse of the cave would protect the wilderness dimension of the cave.

Participant: You know, if some place is truly a wilderness, it doesn't really need any help from the government, at least in terms of underground, to stay that way, it's just too damn hard to get to, nobody can get there, physically get there, you know. I mean, for instance, in the back of Dry Cave, you know, you were in there is a kid exploring, right? There's places in the back of Dry Cave, we know there are leads, there ain't no human being been to them and I don't know any climber that would go there right now...It's just too god damned hard to get to (FG8).

This was the only theme that addressed protection of wilderness values through non-human intervention.

The second theme addressed current management practices of caves on federal lands:

Participant: I don't know how much we would gain but I think we do have some caves in this area that need to be protected and kept from being abused and I think they should have control of them and do have (FG8).

Under this theme, it was noted that on federal lands, access to many caves is currently managed to protect and preserve the caves. It was noted that the National Park Service currently has a policy in which any cave that does not have a management plan will be managed as a wilderness cave. Other federal agencies are in the process of developing a similar policy. It was also noted that restricted access did not necessary equate to protection of wilderness. Restricted access to caves for scientific study purposes has nothing to do with wilderness values or protection of such values.

The third theme in challenges to a cave wilderness designation was the presence of existing laws. It was suggested that it would be easier to protect the wilderness values of caves by using already exiting legal mechanisms:

Participant: I don't think you need a label. I like what [Name] said, if you need to protect the cave because it's a water source then you use the clean land, air, water act or whatever that thing is. If you need to protect the cave because of potential of polluting things by virtue of drilling through it then you have to have to have a 
law that controls how drilling operations are handled and do everything you can to prevent the damage from the drilling activity (FG8).

Participant: I think we need to somehow extend all the laws. It would be better if it were better understood. But we need to make clear that those ought to extend to caves. It's not necessarily clarifying the law, but clarifying knowledge of the law (FG7).

Some participants felt that the application of current laws and regulations to cave resources protection as well as efforts to expand the public's knowledge of and understanding of existing protective laws will provide adequate protection for caves, making the establishment of a special designation such as cave wilderness unnecessary.

The final theme in objections to cave wilderness designation is the need for protective action on the part of private landowners. There is the sense is that the issue of cave preservation is more of a problem in the private sector rather than in the public sector, especially on lands where people are not aware of the presence of caves:

Participant: We've seen the devastation that can happen when uneducated choices are made, or maybe choices where made when some of those new names of what could happen, but non-the-less for whatever reasons, the wrong decisions were made (FG7).

It was suggested that what needs to be looked at: 1) what is to be accomplished, 2) what is to be protected, and 3) how it can be done. The next step would be to see if it can be accomplished by working with people directly instead of creating more bureaucracy through new legislation. The educational aspect of these discussions is further explored in the section on legislative criteria and at the end of this chapter.

\section{Terminology Issues and Alternatives}

All focus groups expressed trepidation about using the term wilderness to describe a special designation for caves. In some cases, misgivings had a regional component; however, the 
fundamental nature of the concern was applicable to either study site (Kentucky and New Mexico).

The problem lies in the difficulty of defining wilderness. Focus groups' participants described wilderness as not being as 'warm and fuzzy' as perceived by others. There are many misconceptions associated with the term. Wilderness was described as a political term, fraught with political implications and politically charged. In the eyes of many participants, wilderness had developed a bad name:

Participant: We had this wilderness hearing over there. And the venom that spewed would kill a million snakes, and the ill will that was in that hearing room at Mammoth Cave could have scalded a thousand dogs. And we never heard more about wilderness. But we've heard a great deal about improving the ecological conditions above and below ground (FG7).

Participant: The real problem is that, that the word "wilderness" has gotten so politically charged that it is impossible to talk about it (FG8).

Participant: And, my contention is the term wilderness provides so much static between point $\mathrm{A}$ and point $\mathrm{B}$ that the message that $\mathrm{A}$ wishes to communicate to $\mathrm{B}$ doesn't get through.

Researcher: Does using the term cave wilderness, does that help modify it in any way or just the word wilderness, even within that term, is too much?

Participant: The presence of the idea of wilderness (FG7).

Based on focus groups' discussions, it would appear that past history regarding Wilderness hearings and the actual implementation of a Wilderness designation has left many people with negative images of legislated wilderness. It is not the idea of wilderness that they opposed, rather it is the legal ramifications (real or imagined) that they disliked.

Focus groups discussed the suitability of applying the Wilderness Act to caves. Eight arguments for not applying the Wilderness Act to caves were identified: 1) designed for surface environments, 2) may be limiting, 3) strings attached, 4) visitation problems, 5) not for private 
lands, 6) wilderness is 'out west', 7) not traditional perception of wilderness, and 8) not in my backyard.

Wilderness designation has a lot of precedent on the surface that may not be directly applicable to the subsurface. It was not designed to serve the needs of cave protection. Wilderness legislation was designed to protect surface environments; the same is true of wild and scenic designations.

If the Wilderness act is used to designate a cave wilderness, then it would include the surface as wilderness. This type of designation would limit what could be done in terms of designating caves under non-wilderness lands.

There is the perception that there are too many strings attached to the designation, generating a lack of trust in the real intentions behind the designation. Participant: "And there was just this mystery about it, what's going to be going on in there too. What is the real deal about this? There was a suspicion about it" (FG7). It was felt that a wilderness designation is designed to keep people out and restrict activities, even though it may be in the name of protection; the focus was on restriction, not protect. From this point of view, it does not really protect, because the protection is always centered around keeping things out.

It was felt that when something is designated as Wilderness, it loses its wilderness characteristics because of extensive visitation and associated management practices. Giving a place a special designation attracted people to visit the site and increased likelihood of impact. The use of any terminology that people are already familiar with, that already draws attention, draws visitation, is not in the best interest of the caves. 
Wilderness designation is associated with state and federal governments and private organizations such as conservancies. Wilderness is not associated with private landowners. Using a wilderness designation on private lands may be problematic.

Participant: I guess what I would have to say is that I go back to the term wilderness being a legal and political designation, in that wilderness, people in the west, deed-holders like myself, public land ranchers, we have a feeling that wilderness is perpetrated on us by the eastern establishment, if you want to call it that (FG8).

Several participants expressed the feeling that "wilderness is out West." Such a perception would make it difficult to consider caves in the East as wilderness sites.

Some participants felt that it is difficult to think of caves as wilderness. Americans have grown up with the perception that wilderness is the great outdoors and caves do not seem to be part of the great outdoors. Being in a cave is not the same as being outside, out-of-doors. Caves do not typically have the same dimensions, the same vistas as other environments.

Participant: After talking about this wilderness area for a while, now I'm kind of split. If you take something like Lechuguilla or something else that's away from here, classifying that as a wilderness area doesn't bother me. When you start talking about something like Mammoth Cave, then I don't like it. You know what I'm saying. It's almost like, yeah it's good out there, but not good here.

Researcher: Not in my backyard?

Participant: Not in my backyard, only because of what Mammoth Cave means to this area and to the people who work and live here (FG6).

Some participants felt that a cave wilderness designation might be acceptable, but not locally.

The "not in my back yard" perception was based on concern for how such a designation would impact the local people economically and personally.

Limited discussions occurred regarding alternatives to using the term cave wilderness:

Participant: So, as far as the name itself it doesn't really bother me. That's just something for me I would have to get used to it being called that. As long as I understood the connotation, what the meaning behind that, for that certain place or particular area (FG6). 
Participant: We're talking, it seems to me it's more important to talk about how we're going to treat our caves, rather than how we're going to designate them. But in that, [Name], it's important, you're going to have to call it something. You're going to have to talk about what's happening in some way or another (FG7).

Focus groups suggested that an alternative term is needed to address several important aspects.

Wilderness is terminology that people are already familiar with, that already draws attention, draws visitation, and is not the way to go for caves. There is a need to create a new term specifically for caves and cave environments, and to use terminology that distinguishes between subsurface or surface.

The alternative name must have clear definition. The term needs to have connotations of pristine quality. Use a term that describes the situation of isolation that is not the same thing as saying designated wilderness. It needs to be a completely non-sexy designation, so that it does not draw attention or attract additional visitation.

Various alternative terms were suggested. No one suggestion stood out as being acceptable to all within a focus group. Discussions covered criteria for a new term, as well as suggested terms.

Participant: Using terminology like cave wilderness, the friends, and folk I know around won't buy into using that type of term. It will turn the folks off I know immediately, and any other similar type adjectives, you could change the word or term, ...I just don't believe that term will fly here now. Fifty years from now maybe, I don't know, ten years from now, I don't know. That term is not sellable term here today (FG7).

Cave Preserve and cave refuge where suggested:

Participant: Overall I think the name cave wilderness, to me a lot of what's been said actually means cave preserve. I think cave preserve is a term that probably has a lot more applicability to the things that we've been talking about, both in terms of private lands or caves like Lechuguilla. I would call that more a preserve. So, as a semantics concept I would argue that it's a good term to push on legislators in laws. We want to preserve caves because we want people to experience them in a way that preserves them (FG2). 


\section{Cave Wilderness Criteria}

During discussions on the idea of cave wilderness, one or more focus groups identified factors important in developing cave wilderness special designation. From these discussions, four themes were identified: 1) size versus experience, 2) science, 3) access, and 4) boundaries. These themes were often overlapping (complementary) and occasionally potentially conflicting.

\section{Size versus Experience}

The physical dimension of wilderness as defined by the 1964 Wilderness Act generated discussion regarding its applicability to caves. Discussions focused on the difficulty of applying the 5,000 acre minimum to a cave:

Participant One: Okay, how does the Wilderness Act then translate to and impact the cave systems?

Researcher: That's what I'm asking you.

Participant One: That's what I thought. That's the reason why I asked that question. Because I think that is a hard, hard thing to define whenever you got these caves. When you're looking at the wilderness act and it says 5,000 acres, then you've got something, I say 5,000 acres of wilderness area, then you've got some strict guidelines there as to what you have to use...Now, if there's not anything in the wilderness act that has the specifics with the caves...(FG8).

It was suggested that instead of, or in addition, to using a physical dimension to help define the size of a cave wilderness, it should be measured by intangible dimensions experienced during a wilderness experience.

Participant One: What you're saying, and what most of us are saying, it's not the structure of the cave, it's the situation that makes it a wilderness. It's like you just said. You go in at 12:00 to that cave with 3,000 other people that's not a wilderness cave. But you go back to that same spot at 1:00 in the morning with you and two or three friends and that could be a wilderness.

Researcher: So, it's our experience that makes it a wilderness?

Participant Two: That's right (FG2). 
If it is not the structure of the cave, but the experience that makes it a cave wilderness, the question was raised: in trying to establish cave wilderness, is the discussion really about wilderness experience?

Participant: The part of wilderness that really fascinates me here is the thought of designating certain caves for wilderness experience and how that interacts with preservation. And can that be done? If that could be done, I think it would be a very interesting experiment. I wouldn't want to try that on a big scale either (FG2).

Participant: We want to preserve caves because we want people to experience them in a way that preserves them (FG2).

A goal of cave wilderness is to protect and guarantee a wilderness experience.

Discussions of wilderness experiences in caves included illustrations of the concepts of solitude, remoteness, and self-sufficiency:

Participant: ...to go caving in a wilderness experience, to me, would be I've got this cave for the day, I opened it and locked it back behind me and it's mine and my group's for the day and so no outside impact (FG2).

Participant: But, on the other hand, I certainly would think I would recognize that there are places I have been physically that in the English language sense of "wilderness", they've got to be a wilderness, yet, if I could've gone straight through solid rock, I was no more than a few thousand feet from civilization. And an example I would give of that would be, during the rescue of [Name] from Lechuguilla, I had two teams working in the far eastern end of the cave and for me to have gotten in contact with those people I would've had to send another team for a day and a half into the cave to find them, and they would have had to gather them up and all spend a day and a half getting back out of the cave. And so, effectively, those people were out of reach to me to use them to help in the rescue. Even though, literally, if I could have had a laser beam or something I could have gone straight through the rock 6,000 foot and I would have been in to those people. People in Japan were watching the rescue on CNN news and these guys that were less then a few thousand feet from the actual rescue physically had no idea in the whole world that anything like that ever happened. Well, there has got to be some term to describe that situation of isolation, you know. Does that make sense? It's not the same thing as saying designated wilderness (FG8).

Participant: Can I add this, this is an antidote form England, we have a big cave ... which is 60 kilometers long now and it had one entrance and you go through the cave and its like several hours to the back of the cave. But, somebody 
discovered a dome which, that looked like it, connected to the surface and started digging on it, and opened up the second entrance. And, everyone got upset because they felt that they lost the sense of the wilderness. When they were back there three hours from the entrance they felt that they were in the wilderness. And, I think for them, and to a lot of people, you're responsible for yourself, there's no one who is coming to get you, come rescue or whatever. But now, because that other entrance is there and only five minutes away, they lost that sense of wilderness because they lost the sense of touch with the infrastructure to protect them. I can understand that, especially for me, my experience with wilderness. If I'm in Fairy Cave and I'm way back in the most miserable part of Fairy Cave which is still like an hour from the entrance I don't feel like I am in the wilderness I am in a wild cave there, but I'm not in wilderness. When I'm in Lech and I'm like four or five hours from the entrance, and we're camping down there, I absolutely do feel like we're in the wilderness. I think, for me, its how far am I from the infrastructure of 'somebody else can take care of me', when I feel like I'm getting away from that is when I feel like I'm in the wilderness. Maybe it's the same for Joe Blow public, at what point does he cross the boundary where it's like oh my goodness I'm taking care of myself now. This is wilderness (FG4).

Unlike surface wilderness, it is difficult to 'see' the area that is receiving the designation, the subsurface lands. Defining the scale of a cave wilderness may best be determined by the ability to provide for a wilderness experience; an experience that offers the perceptions of solitude, remoteness, and self-sufficiency.

\section{Science}

All focus groups discussions on what purposes and goals a special designation such as cave wilderness would serve centered on protecting scientific resources:

Participant: I don't know a use yet for the eyeless fish, I don't know a use yet, but they may discover that eyeless fish are really useful in the treatment of AIDS. Let's get these eyeless fish, they got something in there, and we could use those, but we're going to destroys those if we keep all these caves open all the time (FG5).

Participant: Who cares that they're the last unexplored frontier, because of that we don't know enough about them, this is an opportunity to go into an environment that we have not impacted on our planet and study ecosystems that are undamaged. We've never really had an opportunity to do that before and now we have the tools to do it, and we are getting so much information from those environments, beyond how life developed on the planet, how it could develop on other planets. So, the scientific potential is vast for these areas, what we can learn. 
For most people, if you say the cave needs to be protected, it's very delicate, we have these formations, we have these complex ecosystems, they're not going to get that, but when you say it's this incredible scientific resource, which it really is, then they're like oh science well that's important please do that (FG4).

Participant: ... research to understand our resources and how they interact with other resources, from taking that information and data and using that to educate not just the public, but to educate our land managers.... I think research is an important part of the whole protection, because if you don't truly understand how something works then how are you going to come up with the most effective ways to help protect, and preserve, and manage those resources (FG3).

The knowledge gained from the scientific research would be utilized for educational purposes - education of the public as well as the land managers. The protection of scientific resources went beyond protection for current exploration and other research purposes:

Participant: Why do you want to preserve this, is it for current scientific study, is it for future scientific study. Let's don't exhaust all of resources, with science, we may discover in a hundred years we may find that science in 2002 was just in its infancy. Let's do what we need to do to learn to as much as we can about what's beneath us and leave it in such a way so that two generations hence they won't say oh you've wiped out the footprints (FG7).

Participant: I like having the idea that there are some caves, while we know about entrance no one ever goes into, at least not until we can hover thru and not have impact on the cave, in some future Star Trek sort of place. Because I think we need to, we're continually learning, and the processes change and the techniques change and we need to go into certain caves, but we need to keep some cave alone (FG4).

One goal or purpose, of a special designation would be to protect the caves' scientific values and resources, for study now and in the future, to preserve future discovery opportunities.

Access

One of the concerns in establishing a special designation such as cave wilderness was access:

Researcher: So anybody should be given access to the surface. And, why is that different than a cave?

Participant One: Because the cave is absolutely non-renewable. Somebody, you know if you get a pass to go into what I would deem as a cave wilderness area, it 
just takes one person to go in there and take what he wants and that piece is nonrenewable. As far as the surface goes, those flowers will grow back. That little seedling they pulled up there will be more of those to come along, unless they take something that is absolutely rare. But, there is more chance of renewability on the surface than there is, because in caves there's virtually no chance.

Participant Two: Or not in our lifetime.

Participant One: Not in several lifetimes (FG 6).

Participant One: You know trees grow back faster than stalactites. And there's not gonna be much recovery underground in our lifetime.

Participant Two: It may never recover.

Participant One: That's what I was saying. The surface can recover don't you think?

Participant Two: It changes. Whether or not it recovers back to the original, but it will change.

Participant One: But underground the change is so slow. Some of that might not ever recover until the end of the world. Because it's so slow creating (FG5).

Participant: What is the point of a special designation if no one goes there? Why establish a cave wilderness if no one is ever going to use it (FG6)?

Researcher: Would you be comfortable with people having limited access to parts of caves?

Participant Three: Yeah, limited, but just to close it off totally, no, that's what he's saying.

Researcher: I don't think you guys would be either, to close it off totally?

Participant Two: No.

Researcher: Just restricting access?

Participant One: Totally, no. I would never want to see any part of the world closed off totally, just the door slammed shut and say nobody else in here. Because I think there has to be exploration. By the proper way, not by guys going in there and, you know, having their way of kicking whatever they want to out of the way. Somebody who knows what they're doing, whether they're schooled, or they're trained all their life or something like that, because it does have to be kept in its, like Lechuguilla, like its pristine condition. But, I would never want to see the door shut on anything permanently. I think you can protect something and still visit it (FG6).

It was noted that restricted access was viewed as potentially necessary to protect the cave and its resources, but that it should not include closing the cave permanently. The potential exists to be able to protect a cave and still visit it. 
New Mexico and Kentucky focus groups noted that cave wilderness should not be established just for recreational purposes. Particularly, it should not be established to provide a playground for cavers. "It's not for recreational use, it's for exploratory and documenting (FG6)." "How can you maintain an area as a wilderness if you let people recreate out there (FG7)?"

While resource protection was a primary reason for limiting access to special designation caves, other justifications for limiting access included the existence of other caves open to the public. As an alternative to developing the caves for visitation by the public, the use of photographic and videographic materials can provide visual access to a restricted cave. These images would be collected as part of the documentation process during research activities.

The provision of a wilderness experience and restricted access are potentially conflicting management goals. This will be further explored in chapter five.

\section{Boundaries}

Discussions arose regarding surface and subsurface boundaries for cave wilderness. For some participants, the idea of cave wilderness had to include the surface:

Participant: Well one thing too, and the Park Service came up against this, when Lechuguilla was going pretty strong, the Park Service was trying to get congress to designate Lechuguilla as the first true, federally designated big $\mathrm{W}$ wilderness, that was fine until the ranchers started hearing about it, and so does that mean that since we don't know the true extent of the cave, if it goes out, if the cave runs out from underneath the known boundary of the Park which is wilderness, under the BLM land for example or under private land, you've just extended wilderness, it's an ever expanding wilderness and to me there is no use having a cave designated as wilderness without designating the lands above it as wilderness (FG4).

Participant: And we know enough about caves now to know that what's done above them impacts below them. And whether it is designated at the onset or not, that the above area will be wilderness if they want to keep below level wilderness they will eventually have to keep above level wilderness. They'll have to (FG7). 
Including the surface as part of a cave wilderness recognizes the difficulty in separating/isolating the subsurface from surface lands. There are important intrinsic environmental connections between the two areas. A holistic approach in wilderness management includes both elements. Some discussion occurred concerning the inclusion of the entire drainage of a region. While it would be ideal to protect the entire drainage, it would not be practical. A last justification for including the surface in a cave wilderness designation was that it would allow for the inclusion of karst surface features.

For other participants, the potential existed for subsurface wilderness to occur without the surface being wilderness:

Participant: Because that's, we're talking a lot about with caves, is that we think a cave wilderness with a non-wilderness above it might put some development restrictions on the kinds of development that occur above to protect the wilderness of the cave. But if the development doesn't affect the wilderness of the cave, then it's perfectly alright in this example (FG 2).

Participant: ...to achieve some level of compatibility between economy and ecosystems. So that, we're not talking about not using the land, not conducting business, but just doing it in a way that we don't undercut ourselves and kill off the ecosystems that ultimately the economy depends on (FG3).

Some participants felt that while protecting the surface with the subsurface was ideal, it was not necessary. It was felt that it would be possible to define wilderness underground different from wilderness on the surface. Surface activities should not necessarily preclude underground wilderness designation - although current usage may have to be modified or restricted with such a designation:

Participant: ... that cave wilderness has to include surface wilderness. I feel that that limits the definition of cave wilderness too much, because I think that there are plenty of caves back East that by [Name's] definition, in fact almost everything from the Mississippi east could never be a cave wilderness. I think there's got to be a way to designate certain caves as wilderness area, essentially regardless of what has gone on, what's going on, on the surface. Otherwise, 
you're eliminating the whole East coast, the Eastern half of the country from it (FG1).

Defining cave wilderness in a manner which allows for surface areas to not be wilderness, provides the opportunity to designate caves that would otherwise not receive special designation. This would particularly be beneficial for caves found in the eastern United States.

Focus groups discussed another aspect of a cave wilderness zone or an inter cave boundary:

Participant: But now if there was a, for example, Mammoth Cave, discovered other passages and there was certain life forms or certain rarity in them, then I could understand why they would call that part a wilderness area (FG6).

In focus groups' discussions, it was thought that it would be possible for a show cave to have a commercial component and still have a wilderness component. The qualification determining a wilderness component was that it must be 'unaffected' by the rest of cave. 'Unaffected' must be determined from the human perspective - using unaided senses (visual, aural, olfactory) and instrumentation (chemically). In addition, the site must have a healthy ecosystem.

The possibility of a wilderness component for a show cave may be in conflict with the idea that the surface must be wilderness for a cave wilderness.

In discussing boundaries, one focus group discussed the concept of a buffer zone. A buffer zone would protect the cave. It would be necessary that the buffer zone include surface regions that are utilized by cave animals (such as bats and crickets) as well as the drainage basin for the cave. Although this concept received relatively little attention, it can have significant ramifications on the establishment of a cave wilderness site. 


\section{Legislative Requirements}

Focus groups discussed the intent of special designation legislation such as cave wilderness. During the course of these discussions, one or more focus groups identified factors crucial in developing legislation for cave resources special designation. Based on these discussions, six themes were identified: 1) intent, 2) visionary impact, 3) protection, 4) designation criteria, 5) education, and 6) management concerns.

Intent

An important consideration in developing special designation legislation was in determining the intent of the designation. The question was raised: Is the designation for caves (resource protection) or for people (recreation, knowledge)? It is necessary to define what is being protected or from who/what:

Participant: Are we talking about people? Are we talking about places? And if we're talking about preserving caves, are we talking about preserving them for their own sakes or preserving them because they are of value to humanity? If so, then we've got to define that value (FG7).

Participant One: I don't know if scientists need it or researchers need it. Cavers may need it.

Participant Two: Lawyers need it in terms of cave law. We need a way to punish, and we have a way in Kentucky, to punish people who come into the cave and destroy it. That one happened to be on federal property (FG7).

Identification of who may be served by this form of legislation may be useful in helping to identify the purpose of the legislation.

\section{Visionary Impact}

Developing legislation that looks to the future was a reoccurring theme in all three focus group venues. The following two comments best illustrate this point:

Participant: But, it is important to preserve caves and not just simply for the beauty, not for the wild, wilderness of it, but for the future of everybody and the world (FG7). 
Participant: The pretty words are worth something, the philosophy, the statement of value to future generations. It doesn't have a direct management impact, but I think it has a visionary impact (FG2).

Participants expressed the idea that legislation should go beyond today's knowledge and values to protect caves. Legislation needs to address the future, by preserving cave resources for future generations' needs and values. By preserving caves for the future, it is possible to protect the possibilities of future discoveries.

\section{Protection}

Special designation legislation needs to be more than "feel good legislation," it needs to actually provide protection for cave resources:

Participant One: I see it like that because generally the surface will recover much, much quicker generally than underground [Name]. Don't you think?

Participant Two: Yeah, recover from...

Participant One: From abuse.

Participant Two: Or change, human change.

Participant One: You know trees grow back faster than stalactites. And, there's not going to be much recovery underground in our lifetime.

Participant Two: It may never recover.

Participant One: That's what I was saying. The surface can recover don't you think?

Participant Two: It changes. Whether or not it recovers back to the original, but it will change.

Participant One: But underground the change is so slow. Some of that might not ever recover until the end of the world. Because it's so slow creating (FG5).

Participant: I think there is a need [for a special designation] because of the small numbers and easily destroyed by irresponsible people And, I know there seems to be a lot of caves, but still there is a limit to the underground environment. We know they are easily destroyed. Well, they're easily damaged they're easily abused, fragile (FG5).

Focus groups elaborated on what protection of cave resources meant. Discussions addressed the cave resources to be protected and the threats from which they needed protection. 
Special legislation needs to provide for physical aspects of a cave - preservation of the cave's natural state and its original resources, and recognition of resource fragility. Legislation also needs to provide protection for the human dimension aspect of a cave - protection of physical and social sciences values, aesthetic values, and wilderness values. Legislation should also include the protection of future discoveries, including survey and mapping activities as well as other scientific research.

Focus groups noted that legislation needs to be a tool for protection from human activities that would degrade the resource. This would include addressing surface as well as subsurface activities that may have adverse impact upon the cave resources. In addition, legislation needs to protect the cave from management and policy changes (i.e. set aside permanently so it cannot be developed in the future). Management can change, but special designation would provide permanent protection that cannot be obtained simply through management plans and policies.

It was noted that the potential exists to develop a system in which caves that need more protection receive it, with wilderness at the extreme end of the spectrum. Special designation legislation could be used to determine the degree of protection a cave would receive. Legislation could provide for a range of special protection categories with associated differences in management practices. Multiple categories could address variations in allowable forms of land use.

Caves such as Carlsbad Cavern or Mammoth Cave are worthy of preservation and worthy of protection. There is a need to find some designation for such a cave despite development and the existence of non-pristineness of areas within the cave. Although it would be difficult to call such caves wilderness caves, they are still worthy of preservation. 
Legislation providing for variations in special designation could be used to address situations in which caves have been developed, particularly show caves, and yet have areas within them that are worthy of special designation. The goal is not to stop showing these caves to the public, but rather that of protection and provision of management tools to ensure protection of specific non-developed portions of the cave.

While recognizing the potential need for special designation, it was noted that the use of such a designation should be discriminating in application. It should not be applied "just because it is there and should be protected." Special designation for a cave should be used when it is recognized that the cave and its resources require special protection for preserving the resources.

\section{Designation Criteria}

Focus groups touched on the need for legislation to establish criteria defining what would make a cave worthy of cave wilderness designation:

Participant One: There has to be some value criteria in there too. It's got to be an outstanding example of something. Outstanding resources, outstanding geological speleothems, hydrology for the local area, whatever it is, you can't just take any little feature.

Participant Two: It's got to be all those criteria, it's got to be everything.

Participant One: Yeah, it's got be of great value, significance.

Participant Three: I think educational too.

Participant Two: Yes, significance (FG1).

Legislative criteria, establishing the "worth/significance" of a cave, need to be similar to those values that are to be protected by the legislation. It was noted that it was important that the significance be based on all criteria as opposed to meeting one or more of the criteria. It was also noted that establishment of criteria must address the idea that the perception of significance varies among people with different interests. 


\section{Education}

Generating public awareness of the significance of caves was identified as another feature important to developing special designation for caves. Specially designated caves can serve as educational resources (with or without visitation):

Participant: If we go through the process of trying to pursue some kind of designation, it should be for the purpose of creating broader community outreach and a broader forum for education about caves and karst obviously for the protection of cave and karst. But in order to protect you've got to educate. So, the education aspect of any kind of designation would just be paramount (FG4).

\section{Management}

Focus group discussion of legislation criteria noted that legislation defines what is going to be regulated. Legislation needs to provide functionality in terms of a management structure.

Focus groups noted that the special designation needed to recognize that cave wilderness would have to be managed differently than surface wilderness because it is a very different environment. In addition, the legislation must recognize that each cave is different. It would be necessary to tailor management practices to meet specific cave needs. Specific management should evolve from cave resources - physical and social sciences resources and access/skills requirements. Focus groups noted the importance of including local participants in the development of wilderness policies and management plans:

Participant: I think that the biggest thing is that we have to get people to the table, in our wilderness plan that are also landowners. That are also cave owners, maybe that are not cavers, but understanding what we think, and respecting their rights to private ownership, as well as trying to promote conservation, protection of the caves, and trying to balance that and also trying to create something that is fair and equitable (FG1).

The importance of input from local citizens' is underscored by examples of sacrifices of those who lost their lands, via eminent domain, in the creation of Mammoth Cave National Park. 
It was noted by the Kentucky and New Mexico focus groups that cavers should be included in the development of special designation and management practices, for the purposes of developing conservation plans and preservation philosophy, but not if their intent was to gain recreational access to the exclusion of all others. The Caving Event focus groups recognized the concerns noted by these focus groups. One Caving Event focus group discussed the need for cavers to recognize that they too can have significant impact on caves and will not be exempted from the legislation.

Cave wilderness legislation would need to address technology issues such as what is allowable and what restrictions will exist. Examples given of issues that would have to be addressed included providing for construction of cave gates, use of diving gear, or the ever popular issue of bolting.

\section{Designation Benefits \& Rewards}

Focus groups discussed potential benefits and rewards that may be derived from some form of special designation (cave wilderness or other). Based on these discussions, four themes were identified: 1) quality of life, 2) knowledge and education, 3) community benefits, and 4) benefits to private landowners.

\section{Quality of Life}

The quality of life theme included discussions covering three broad topics - environment, preservation of wildlands, and concern for future generations.

Discussion regarding the environment ranged from broad statements such as "good for the health of the planet" to benefits that are more specific. Benefits included protection of water 
quality and protection of animal species. Protected animals would include endangered species as well as protection of species that are beneficial to humans (example: bats and insect control).

Special designations that provide for protecting aboveground as well as belowground environments makes conservation planning possible. Such planning allows sites to serve as a benchmark for surrounding areas and similar environments. Because the lands will remain unchanged (other than natural processes), they will serve as a constant for comparison when looking at other ecosystems.

Discussions regarding the benefits of protection of wildlands ranged from broad statements to specific ideas. The feeling expressed was that whatever can be done to preserve wilderness is for the best. With increasing population pressures, there is a need to protect caves, specific caves or specific cave systems, from development and resource extraction activities (e.g. strip mining or oil and gas drilling). Special designation can be used to discourage use of motorized vehicles by visitors who wish to have a different type of wilderness experience than that intended by the Wilderness Act. The knowledge that there are places "out there" that are not being impacted by people is good.

Special designation can serve as an alternative way of preserving an area for future generations, as opposed to other types of usage, which include trail building and serving as a tourist attraction. It can protect current recreational opportunities for future generations, providing opportunities to enjoy current activities with children and grandchildren.

\section{Knowledge and Education}

The knowledge and education theme included discussions regarding new discoveries as well as assorted learning opportunities that might be available. Special designation could provide 
for protection of future discoveries. The protection of cave resources may preserve the possibility of future discoveries; the use of such knowledge may prove to be beneficial.

The specially protected caves can serve as an education resource in two ways. First, the caves can be studied to better understand the ecological processes of the region. Second, what is learned about the cave and cave resources can be used to provide the public with education regarding management practices (what, why, consequences...). With this knowledge, the public can have informed input regarding management decisions for the resource area.

\section{Community Benefits}

Community benefits included two broad categories: open spaces and tourism. Discussions on benefits of open spaces were limited and occurred only in Caving Event focus groups. Special designations that allowed for local or private "wilderness" designation could provide open spaces in communities. Discussions focused primarily on the use of special management open spaces in new developments for the benefit of the local residents, but also provide for protection of cave resources. It was noted that these open spaces did not necessarily allow open access to the caves that were being protected. Discussions addressed how special designations may serve as an attractant, thus being of value to the local tourist industry:

Participant: ...if you keep things as a wilderness area where the public is not allowed access to it but you publish photographs and books and stuff on it, to me that sparks an interest of the people who want to seek out beautiful things and they realize we'll never get into that one, but there's other caves in the area we can. I think by having wilderness areas that you can't go into, it will divert people to other places that are open to the public (FG6).

The promotion of cave wilderness sites may create enough curiosity that people will visit the area and tour the caves that are open to the public. However, the idea that cave wilderness would not be open to visitation by the general public may have the effect of scaring people off as will be discussed in the Designation Risks and Concerns section. 


\section{Benefits to Private Landowners}

Discussions of potential benefits to private landowners ranged from access, to services and incentives, to economic benefits of owning land adjoining wilderness lands.

Caving Event focus groups emphasized the importance of allowing landowners to continue to earn a living from their lands. The provision and support of infrastructure, and access to specialists, to enable individuals to continue current income-generating land uses in an environmentally friendly manner, would be extremely beneficial.

If changes in land use practices are necessary to stop or prevent additional environmental damage, it might be desirable for the government to provide financial aid for implementation of expensive procedures/processes. Although it was felt that not everyone would expect special compensation, it would be desirable. It was thought that some may not want anything from the government, yet, that they would want to protect the cave too. Remuneration may not be required to instill desire to protect the cave.

There is precedence for compensation for cessation of current activities (such as agricultural practices) to protect the cave(s). Similar plans already exist to allow croplands to lie fallow. However, participation must be an option. It was felt that landowners should not be forced to stop activities. Participation must be voluntary. It was thought that some landowners would participate and some would not.

Adjacent landowners could benefit from living next to a wilderness:

Participant: But that just shows the inherent value in wilderness. That people, people want to have their house right there on the edge of the wilderness and be able to look out over the wilderness and know that it's not going to be developed, so that they aren't going to be looking into somebody else's window when they look out into their backyard (FG1). 
Land located next to wilderness has intrinsic value, such as science, privacy, and knowledge of a peaceful environment (there would never be manufacturing or other related industry next door). In addition, having wilderness as a neighbor increases the economic value to properties that are adjacent to a wilderness area.

Having a cave wilderness as a neighbor may serve as impetus for people to designate privately owned caves as a resource for protection in perpetuity. This would require some form of incentive. The other side of the economic argument is the belief that designation of private property as a nature preserve or wildness area, through conservation easement, devalues property. The land no longer has commercial use value, which enables the owner to take a deduction for the reduced value of that property.

Caving Event focus groups noted that a benefit to landowners that may be derived from a special designation would be the enactment of legislation that would provide for liability abatement. Limitation of liability might be a benefit to property owners and land managers.

\section{Designation Risks and Concerns}

Focus groups discussed risks and concerns associated with a special designation. The group venues expressed many of the same concerns. However, each group placed more emphasis on certain items than did the other focus group venues. Caving Event focus groups' primary concerns were: 1) a special designation would attract visitation; 2) a special designation would be of little value if adjoining landowners were hurt economically; and 3) a special designation would be ineffective in preserving the resource if adjacent landowners did not understand the need to protect the resource through their land management practices. Kentucky focus groups' primary concerns were: 1) a special designation dissuading visitation to region and associated 
economic impacts; and 2) a general distrust of any federal actions due to past experiences associated with establishment of Mammoth Cave National Park and previous attempts at establishing wilderness designations within the park boundaries. New Mexico focus groups' primary concerns were: 1) loss of leaseholders' ability to ranch in an economical manner; and 2) local governments' loss of oil and gas revenues due to mineral withdrawals associated with wilderness designation.

Five themes were identified from the focus groups' discussions, three of which are: 1) societal issues, 2) landowners, and 3) access. Two additional themes dealt with specific regional issues (Carlsbad Caverns and Mammoth Cave).

\section{Societal Issues}

Societal issues addressed by focus groups fell into three broad subjects: financial costs and responsibilities, government distrust, and future limitations.

Concerns about financial costs fell into three topics: 1) administrative costs, 2) costs to local communities, and 3) costs to private citizens:

Participant: How is going to administer all this and how much is it going to cost? And you know, are they going to go into every cave in the world? Can you image how long it would take to designate every cave in this area. I can just see people saying oh my Lord what a waste of time and money and nobody's got any money for it (FG7).

Although the subject of administrative costs was raised in only one focus group, it is an important concern in the implementation and management of any special designation site, whether park or wilderness area. Of greater import (in terms of focus groups' discussions), was whether the public was willing to accept financial responsibilities for financial loses to local communities and to private individuals:

Participant: That's one of the problems that a lot of resource protection measures is they tend to focus on the immediate area or the immediate people when often 
times you're dealing with a common resource. And many people are benefiting and many people are using that so the pain should be equally spread out so it makes it more acceptable both financially and politically too (FG3).

Participant: Right, even though something may be done on BLM or forest service land; it is the local governmental entities that suffer the economic hardship. And people in New York say, "Well, I am a citizen and a taxpayer of the United States of America, I own part of that." I am going well yeah maybe you'd better start paying your share of the bill (FG8).

Financial ramifications of special designations that can accrue to private citizens and to the local community, do not affect the people who live elsewhere who like to know that cave wilderness exists. Financial costs vary based on community location, land ownership, and land uses. Sections on Carlsbad Caverns and Mammoth Cave regions elaborate further on financial costs concerns.

Distrust of the government was the second subject under societal issues:

Participant One: It's the misunderstanding and the, fear sounds like such a heavy word, fear with being designated a world heritage site. People just go oh that means that the UN now controls it. No that's not what it means. It's that sense of who's in charge, who says what, people like to feel that if they own that land and they can say what happens to it. Participant Two: Or even if they don't own the land.

Participant One: Or even if they just use the land. Sometimes it's just a matter of people using the land, and not having any say in it (FG4).

Participant: I just have a problem with calling a cave a wilderness. Like I said, I have a problem. The main problem is that legislation will probably come down and making Mammoth Cave for instance or other caves a wilderness and then eventually close them down. That's my problem. That's about all, that's mostly my concern (FG6).

Focus groups' participants addressed mistrust of any federal designation of land, discussing personal and observed concerns. Distrust of the government, and its use of special designations of lands, centered on questioning the real intent of these designations. One participant acknowledged the use of scientists to support these special designations, and questioned whether the government's interest was contrary to the interest of scientists and others. 
The third discussion subject under societal issues dealt with the inability of wilderness designation to adapt to future needs:

Participant: I can see the need to preserve the cave. But, do we need to stack another area of restrictions on it that are irrefutable and unchangeable? That's the big thing with me with wilderness. It says you may not ever, forever, from now to eternity, touch this land for this purpose. And I don't like that. I don't know what the future holds or where we're going or what we're going to do (FG9).

Participant: But I think there is ways to protect them and still develop around them...And that's what worries me about the wilderness designations, if you just come in and say this is the way it's going to be, then you eliminate any potential for some of this new technology and development that could come along we might want to do in and that's what worries me about the wilderness designation (FG8).

Participant: And, wilderness, I don't know, just the term wilderness seems so untouched, but oppressive, like not progressive, I think (FG7).

Focus groups discussed the permanence of special designations relative to future needs. One participant expressed the concern that already there existed too many wilderness areas and too much land locked up from future use. The concern was that wilderness designations prevent potential for future development. Greater flexibility is needed. What looks good today may be unreasonable in the future. It was felt that Wilderness designation eliminates any potential for use of new technology for resource extraction.

\section{Landowners}

Focus groups' discussions of risks and concerns associated with landowners covered four areas: 1) restrictions, 2) fear, 3) economic loses, and 4) landowner relationships.

Focus groups discussed how the establishment of a wilderness might result in intrusions on property rights:

Participant: There's a cost to private landowners, there's a cost that needs to be in balance in some how. Okay, 'cause it's one thing, we've all heard the stories about the federal government coming in and saying you can't do this to your land, 
you can't do that to your lands, and oh, by the way you can't sell it. So...it's a taking (FG1).

Participant: As long as there's the perception by the private landowner or whatever that this something that you're going to do is going to affect their control over their land then that makes it more difficult. It may not be the case, but that's the perception (FG3).

Participant: I'm just, I hate for, we're getting too much, too many restrictions, and we can't do anything. I have a problem with that. It's your property; you can do with your property whatever you want to. Well maybe if you're going to endanger something that would be different. But I have a problem with the government or state government or federal government or anybody else telling you can't do this or that (FG6).

Participants identified the following potential concerns: intrusion into property owners' rights due to restrictions of land uses, fear of eminent domain, limitation of freedom, lack of control and lack of say in the decision process.

Discussions regarding landowner risks and concerns touched briefly upon the idea of landowners' fears:

Participant One: Their concern about, a lot of times is, is my land, which is right next to the federal, is that what they're going to take next.

Participant Two: And they are basing that on previous history.

Participant Three: A lot of times previous history, a lot of times it's just rumor people just stirring everybody up but still it's all those perceptions (FG4).

Participants identified two sources of fear: fear of "what's next?" based on previous experiences and/or mistrust of the government and fear of change.

Focus groups' discussions addressed two forms of economic concerns that landowners may face: devaluation of land and loss of livelihood. Participants noted land associated with special designations such as wilderness might lose value due to restrictions placed on the type of activities that may occur on the land. Land that may otherwise have been developed for resource extraction purposes or other land uses would lose that economic value. It was noted that the 
addition of regulations associated with wilderness under private land might also result in lose of property value.

Environmental regulations, associated with cave wilderness adjacent to or beneath private

lands, may threaten the landowner's/user's livelihood:

Participant One: They understand it [scientific value], but I guess what I'm saying is that when it comes down to the bottom line if it's between putting food on the table and going for science, they're going to put food on the table.

Participant Two: But that's not wrong, because you can't save every cave...but you should never, I don't think there is anything you should ever do to put anybody in that position. Majority of people who own large areas of land with caves on, I don't think are going to be in a position "well this is going to cost me my livelihood." I don't think the changes that we're going to be suggesting to these people are livelihood changes. It might just be don't throw your refrigerator in the sink hole, throw it over there if you've got to throw it somewhere, things like that, which I don't necessarily think are going to damage people livelihood, but if it is, if it is something major, then that's where infra-structure can step in and help these people (FG4).

Types of economic impacts to a landowners' and/or business persons' ability to earn a living can

be region specific. Addition discussions on this topic are addressed in the sections on Carlsbad

Caverns Region and Mammoth Cave Region.

Caving Event focus groups expressed concern over losing positive working relations with

landowners because of special designation policies:

Participant: I think that will be important to point to landowners is you're not dictating their choice, everything they want to do can be done, it's just that there is always a different approach to the same problem which gives them the solution they want and protects the cave environment (FG4).

Participant: And it's really touchy when you come into a place and you try to tell people who have lived there all their lives, that they don't know what they're doing, they didn't know what they're doing, and you want to help them. The government has come to help you (FG7).

These focus groups' participants felt it was important that, in protecting caves, the message to landowners was not “it's wilderness, you can't do this, and you can't do that." It was important 
that the emphasis be placed on finding ways to mitigate negative impacts to the cave environment, to find solutions, not build barriers.

\section{Cave(s) Access}

Focus groups' discussions regarding access to caves covered visitation issues associated with caves on public lands. Discussions regarding access to caves on public land covered three important subjects: 1) the public's right to view, 2) discrimination and, 3) over visitation.

Participant: ...it's hard for me to sit here and say that Lechuguilla Cave or any other cave shouldn't be developed, because after all it does belongs to the people. But, by the same token, Carlsbad Caverns is not nearly as pretty a cave now as it was 30 years ago, 40 years ago... But there has to be, any time you open up to the public, you're going to have some deterioration of the resource. But, by the same token, there's certain method that has to be opened up to the public because of, it belongs to the people and they need to see it (FG8).

Discussions regarding the publics' right to view caves on public lands occurred primarily

in the Kentucky and New Mexico focus groups. The public's right to view is linked to concerns that special designations would limit/restrict who would be allowed to visit the sites:

Participant: I think that when you designate and put restrictions on things, [Name] hit the nail on the head, it's always to keep people out and restrict activities, even though some of that might be in the name of protection, it doesn't really, the protection is always centered around of keeping things out (FG8).

Participant: But to go and say we are just not going to let anybody in here except certain people which is always the desire of certain people, I think those kinds of designations just are fraught with discrimination that probably shouldn't happen (FG8).

Concerns regarding restricted access occurred primarily in the Kentucky and New Mexico focus groups. Discussions included the idea that public lands should be available to all people, regardless of physical or experience/skill limitations. There was a perception that a wilderness designation was a form of elitism, providing access for only a few select individuals, at the exclusion of all others. 
Discussions occurred regarding the attraction of wilderness and associated overuse.

Concerns regarding the overuse of wilderness areas occurred primarily among Caving Event focus groups:

Participant One: It would have management impact though if that cave was declared as a wilderness everyone would want to go see the wilderness. Every time a president declares a monument, every one rushes out to see the monument, to see what the big deal is. It's the same with wildernesses.

Participant Two: You can think of this as a alternative way of preserving it for future generations as to the, well lets build trails and attract tourists.

Participant Three: I'll give you a good example of that is Guadalupes, back in the early 80's. There was a single group that was cavers for wilderness at Guadalupes. And when that was designated as a de facto wilderness, the visitation increased well over a thousand percent within that next year...I'm not sure when that designation was actually done. But that was the only major increase to the area and to caving that's ever been logged. Boom, I mean, the graph just shot up when the de facto wilderness was declared.

Participant Two: I think a lot of that might be because it took a lot of publicity to get that declaration and the publicity told people what was there and they said hey I want to go see it.

Participant Three: And the basic situation was we want this because of all the caves, all the pristine caves (FG2).

Participant: When it becomes a bureaucratic nightmare, or when it just exceeds the bounds of, getting in the way of, having a wilderness experience it becomes a, it becomes part of the problem instead of part of the solution. Yeah, I think wilderness areas need to be, have people who are, received permits to be there number one, someone knows they're there; they're responsible for their actions in that area. And I think that serves as a certain deterrent for a lot of people...(FG9).

Wilderness attracts visitation simply by its existence. The number of people that visit wilderness can be overwhelming, negating the wilderness experience, as well as having the potential to significantly impact the site. Trying to protect the pristine aspects of caves via a wilderness designation may be the end of their pristine qualities.

\section{Carlsbad Caverns Region}

Focus groups raised issues specifically associated with the Carlsbad Caverns region. Discussions occurred primarily among New Mexico focus groups' participants. Limited 
discussions also occurred in Caving Event focus groups. These discussions cover four subject areas: 1) local communities, 2) private business owners, 3) government intrusions, and 4) East versus West.

New Mexico focus groups discussed how wilderness designations affect local economies:

Participant: It's something that is probably somewhat unique to this part of the country, not entirely, but more so here than a lot of places. Oil and gas revenues are very important to Eddy County, and this part of the country. The county budget just for the general part of the county budgets we have been getting somewhere between 6 and $7 \frac{1}{2}$ million dollars a year off the taxes, just oil and gas, and that does not include the gross receipts expended on drilling these wells and what not. And when they were looking at withdrawing the minerals up there for protecting Lechuguilla Cave, I took the stand that, look if you going to withdraw, I don't disagree that Lechuguilla Cave needs protected, that's not even issue here. But, if you start doing that, the local governments need compensation for their potential loss of revenue. ...But, those things have to be taken into consideration, if you're going to go in and protect a resource, which, like I said, I don't disagree, the Caverns and Lechuguilla need protected, I won't argue that with anybody but, I will argue the part that the local people should not have to suffer the impact of those lost revenues. Of course, I had one of the park service people, what was his name, the one that was acting superintendent there for a while, [Name], I cannot remember his name. But anyway he told me: you know, my mother lives in Michigan, and she will tell you that she owns as much of that as you do and I said: well, tell her to send a check us down here for taking care of her land. So those things have to be part of the equation when you look any kind of wilderness designation (FG8).

Participant: Another thing too, any way you look at it, that is, part of the tax base of the county, of the local governments. And the city probably gets less, other than that, other than the gross receipts that are from the people or the money that is spent within the city limits. The schools, just about half of the money collected from the oil and gas taxes goes to the local school system. And when you go to taking that much of that money out of the school system, it's got to be made up somewhere else. Everybody argues education, education, which is, we've got to have it, but you're really playing a major impact on the school system and local governments when you do that. And, I can think of ways it could be done and of course what we always get thrown back to us is the county collects PILT taxes. We do, but that is strictly to compensate for the loss of the tax base on the land itself. It has nothing to do with the oil and gas revenues that we collect from this and that. So, that's not a legitimate argument either (FG8). 
Wilderness designation changes land usage, such as reduction in public ranch lands and cessation of resource extraction activities. Lose of revenues associated with those activities impacts local governments and communities' economies.

Participant: I do think, that if they are going to pursue that kind of thing, that the local government's tax base has to be taken into consideration and the impact that it has on the local taxpayers and everything because they're the ones that's going to bear the brunt of the expense. I don't see a whole lot of benefit to it as it's structured (FG8).

Tax revenues from ranching and oil and gas activities are considered community assets. Loss of these assets places the onus on local taxpayers - increased taxes and less to show for it. Remunerations to local governments for lost tax revenues are expected if wilderness designations occur.

New Mexico focus group participants discussed how wilderness designation could potentially affect local private business owners. Resource extraction activities and public land ranching were two primary areas of concern. A special designation that would affect, for example, timber and mining contracts, was viewed as an encroachment on private enterprise. Limitations affecting public land ranchers were viewed as affecting private property interests.

Participant: And another thing, besides oil and gas, as a public lands rancher, and a lot of federal people will argue this point with me, but I have a leasehold interest in that ranch, there's a value attached to that lease. ... The wilderness designation is going to basically take away from me my private property interest. ...And, you know, a wilderness designation that includes the surface limits what I can do. The potential exists where it could financially ruin some of these public land ranchers (FG8).

A cave wilderness designation that would include the surface and includes limitations associated with wilderness designations has the potential to financially harm public land ranchers. These ranchers have leasehold interests, with economic value. A special designation will potentially 
devalue this private property interest. Lose of private property value is addressed further in the Landowners section of Designation Risks and Concerns.

New Mexico focus groups' participants noted the potential for indirect impacts to other local businesses if major industries leave the region.

A third area of concern was the intrusion of government controls over private lands:

Participant One: The cave is not something necessarily something they think about, it's already under their land.

Participant Two: But they also see things, we try to protect the land above the caves. When we protect the lands under the caves, I think we have an inherent fear, especially in the Southwest with land managers; there have been a lot of problems over the years between ranchers and land managers.

Participant Three: Their concern, about a lot of times is, is my land, which is right next to the federal, is that what they're going to take next.

Participant One: Yeah, are you going to tell me how many cows can I water here or what I can do.

Participant Four: And they are basing that on previous history.

Participant Three: A lot of times previous history, a lot of times it's just rumor people just stirring everybody up but still it's all those perceptions (FG4).

Conflicts with federal officials regarding management and use of public lease lands, as well as fears regarding government intrusions on private lands, were concerns among New Mexico focus groups' participants. Similar concerns were recognized by Caving Event focus group participants. Concerns regarding government intrusions are also addressed in the Landowners section of Designation Risks and Concerns.

A recurring theme among all focus group venues was the idea that "wilderness is out West":

Participant: I guess what I would have to say is that I go back to the term wilderness being a legal and political designation in that wilderness, people in the West, deed-holders like myself public land ranchers, we have a feeling that wilderness is perpetrated on us by the eastern establishment, if you want to call it that. And that these people have the concept that it is primarily federal land anyway and there's little economic impact. When in reality, the local people, the local businessmen, the local extractive industries, and the local governments, are 
bearing the bulk of the economic costs, and that is very detrimental to our local communities (FG8).

New Mexico focus groups' participants expressed the concern that wilderness designations are established in the West by people who like knowing that wilderness exist but do not necessarily interact with it, nor understand the economic impacts on local communities of such designations.

\section{Mammoth Cave Region}

Focus groups raised issues specifically associated with the Mammoth Cave region. Primary discussions occurred among Kentucky focus groups' participants. Limited discussions also occurred in Caving Event focus groups. Discussions touched upon four subject areas: 1) park inception, 2) place attachment, 3) economics, and 4) previous attempts to establish wilderness designation.

Kentucky focus groups discussed the difficulty of enacting a special designation because of some local community member's lack of trust in the Park Service, based on how Mammoth Cave National Park (MCNP) was established:

Participant One: It's going to be really hard because the history of what's happened to landowners that were impacted by Mammoth Cave has been so negative that, I can't imagine people believing the government is going to come in and help them. Period.

Participant Two: No trust. The trust is gone (FG7).

Participant: I think there is a misconception when this became a national park to satisfy some of the people that owned land there, they were going to be given jobs making more money than they were making as farming. Farming was bad. If this becomes a national park, I'm going to get a better job. I'm going get my 40 acres and a mule, in this park so I'm going to agree to let my property go to this national park, but that didn't happen and I don't think the commercial development occurred as much as, [Name], as people thought it would when this became a national park. I think the interstate brought more people here than Mammoth Cave did (FG5).

Kentucky focus group participants briefly discussed how some people lost their land through eminent domain and the bitterness associated with the loses. Discussions also covered the 
disappointments associated with the failure to achieve the expected improvements in economic and commercial development.

Discussions of the creation of MCNP touched upon the idea of place attachment and how it would relate to a cave wilderness designation:

Participant One: Yeah at one time it was farmland.

Participant Two: That's right. And I doubt if you would find a descendant that lives in the park that would call Mammoth Cave a wilderness in any circumstance. Because that's home to those people. That's our home. It's not a wilderness. We've lived there for five or six generations. So see that park is unique, it's not like no one ever lived there. It's a rural community that's been transferred to a national park by demolishing the buildings and letting the vegetation grow. So it's a little bit different than a wilderness out in Alaska. Do you see my point? (FG5).

Participant: Personally I don't think they would [have a special attachment to] the cave, but the surface they would because they've got churches, they got cemeteries they want to visit and if that would obstruct their visiting the park for a picnic or the park where their grandmother lived or visiting the cemetery, or maybe even occasionally, we have a burial there. The government is pretty lenient there if you could trace some ancestry back. To me the local people wouldn't care too much about visiting the cave. But the surface I think they would (FG5).

There was concern that a special designation would prevent access to areas on the surface, in particular access to the churches and cemeteries located within the park boundaries.

Kentucky focus groups discussed concerns over how a special designation, such as cave wilderness, might negatively impact the local economies:

Researcher: You started to say something about if they called part of Mammoth Cave a wilderness area they'd just be getting a foot in the door.

Participant One: Yes.

Researcher: Getting a foot in the door to, what do you think.

Participant One: Call it all a wilderness.

Researcher: Like say if this part of Mammoth Cave is a wilderness then this part's a wilderness too?

Participant One: Not necessarily, but if they got...

Researcher: They'll call all of Mammoth Cave...

Participant One: All Mammoth Cave wilderness.

Participant Two: It's a way for the U.S. government to just to go ahead and stop showing it altogether and shutting it down (FG6). 
Participant One: Not in my backyard, only because of what Mammoth Cave means to this area and to the people who work and live here.

Participant Two: And the economy in this area.

Participant One: Mammoth Cave is why this city is here. I mean [Name] got his thing and I got my thing and [Name] got Diamond. A lot of us would still be here but not as strong as we are. You know what I'm saying. Although we like to think that we're self-sufficient and stuff, we still have this big draw over here that like anywhere else we do feed off of it. Just like the little places out by the Grand Canyon, they feed off the big fish, like any area that has something big, the smaller service stuff. So when you call Mammoth Cave a wilderness area I don't think I would like, I think I'd be opposed to it. (FG6).

Focus group participants expressed concern that a wilderness designation would result in two possibly overlapping events. First, there might be a perception that wilderness designation meant most of or the entire cave was closed to visitation, deterring people from visiting the area. Second, the designation will lead to an eventual closure of the entire cave to visitation by the general public. The concern was that if the cave use changed, resulting in a decrease in visitation, the economy of the region would be negatively impacted.

Concern over how a wilderness designation at Mammoth Cave would eventually result in closure of the cave was supported by the current impression that cave visitation was already being reduced.

Participant One: I'd like to see several more miles [of Mammoth Cave] opened up to the public.

Participant Two: That's what bothers me. They're downsizing instead of...

Participant One: Right.

Participant Three: They have downsized.

Participant Two: I don't like the idea of this cave wilderness thing on that account. That's where I'm coming from.

Participant One: Yeah. But by the same note, I can see, like I said with almost 400 miles of mapped passage, there is no way on God's green earth you're ever going to be able to commercialize all that cave. So I'd like to see Mammoth Cave open up a little bit more of the cave and designate the rest of it as a wilderness area. You know, with restricted access (FG6). 
In a region that relies on the presence of the National Park to attract visitors, the idea that the attraction that draws the visitors, Mammoth Cave, would no longer be open to visitation (or would be perceived not to be) was viewed as a negative aspect of a wilderness designation.

Focus groups' discussions covered difficulties in obtaining a wilderness designation based on a previous wilderness designation attempt. As mentioned in the Terminology Issues and Concerns section, the hearings had generated much ill will and the designation had been rejected.

However, the wilderness attempt had raised the communities' consciousness about the environment. Participant: "In preserving wilderness, we have done more since any possibility of a wilderness designation vanished, to preserve the caves in this area than ever before" (FG7). Because of this, it was felt that perhaps a wilderness designation was no longer necessary to protect the caves.

\section{Cave Wilderness and Private Lands}

Focus groups' discussions addressed private lands adjacent to lands with specially designated caves or private lands with special management designation for caves. Primary discussions occurred among Caving Event focus groups. Limited discussions also occurred in New Mexico and Kentucky focus groups. From focus group discussions, two developed subject areas were identified: private preserves and public access.

Discussions regarding the establishment of a cave wilderness and private landowner relationships focused on landowners' role in cave conservation efforts:

Participant: We tend to be taking this sort of also as a government putting together some regulation. We certainly have conservancies and things like that who are private landowners who are very concerned about preserving wilderness-like qualities in the caves that they manage. So there's maybe another dimension here where you don't have to have some sort of a set of rigid regulations that are government imposed or enforced. A landowner, be it a conservancy or individual, 
can have expectations and requirements and their own set of ways they want to see that resource managed and protected and preserved (FG3).

Participant: I think that the task that would be better to first is that you're trying to designate cave preserves or whatever you want to call it, working with private landowners more so than the feds. Because I think the feds have a lot of regulations already in place to protect resources. There's been a lot more push from up above to start doing that a lot better. Even in multiple use agencies, that start doing a better job of protecting that. As the urban sprawl happens more and more, I think people are valuing the possibilities of getting out on their own and into the woods and everything a lot more than they used to. And the push is a lot more towards preservation than development on federal land already. I think the tougher task is working with landowners and developers, in, more cooperatively in getting some kind of incentives to them themselves set aside caves as preserves with tax incentives or even with land swaps and stuff where it could be open space, you know a lot of states are now trying to buy land themselves and have open space actually it's usually done county by county. But to work on that kind of a designation and say okay, well here's this cave preserve do you want to be a part of it and see if you can get the landowners around to cooperate and not only protect the land but protect the way the surface has looked since they were kids. Because I'm sure they're all seeing interstates blazing through, chain stores, WalMart, sprouting up in the middle of sink holes, all this kind of stuff. That kind of preserve would also leave the family homestead intact for the future as well as the cave itself. It's a much tougher task just because of the fact that it's tougher and that's what we're losing faster than we're losing federal lands. I think that would be a better place to start because we're losing that faster (FG2).

Discussions focused on working with private landowners in preserving wilderness qualities of caves. Options available to landowners included establishing conservation easements, leasing or selling lands to cave conservancies, and establishing agreements with federal agencies. Compensation for landowners could come in the form of tax incentives as discussed in the Benefits to Private Landowners section.

Brief discussions occurred within the Caving Event focus groups regarding access to caves beneath private lands:

Participant One: Currently Mammoth Cave, very much of the system is outside the park so it's under private property. Right now people cannot go into entrances inside the park and go into passages outside the park because of fears and concerns over trespassing underground. But I will maintain that we need to be able to document all those resources and that is a public need for multiple reasons. 
I mean, if you saw Nick Crawford's presentation yesterday about the ways that gaseous and liquid contaminants can move in karst areas. So we have lots of public health rules that, you know, nobody likes the government in their face telling them what they can and cannot do. But some of these things are, and I don't ask for anything any more than just what we need, and certain a base level, we need to know the architecture of a karst landscape if we're going to...

Participant Two: Go exploring

Participant One: Okay. So, that's really what's driving why I'm saying this. We need to have access. And what this would do is actually liberate the landowner from fears of liability when cavers go and map underground on their property if a caver gets hurt on there, will they be sued. And we had to go to them and try to get an individual agreement where they sign on the line and say yes you have permission to pass through the passages on my land. Liability is going to be the first thing that comes to their mind. And then we're going to get stopped I'm afraid. Whereas if we had some kind of a blanket designation for caves, less than wilderness, but more than nothing that provided for access for purposes of documentation, then we'd be covered. It would be good for them and good for us (FG3).

Participant: And I think I agree that as a society we really have to do more to think about how privately owned lands can be maintained in a way that preserves and protects caves and allows access for recreation (FG2).

Obtaining access to the caves for research purposes was discussed in all groups; while access for recreational purposes was only mentioned once. Caving Event focus groups recognized landowner concerns with liability issues and intrusions of strangers on their lands. These specific concerns did not arise in either the Kentucky or New Mexico focus groups.

\section{Education}

Education was an ongoing theme throughout all focus groups' discussions. Generating public awareness of the value of caves was identified as an important feature in the development of cave resources special designation.

Participant: Everybody agrees that education is the most important thing and that's the only thing that is going to get people to change. Legislation or regulation without education doesn't work very well, but sometimes there is not a whole lot of education until you get regulation and then you have to educate people. So sometimes you do need something like this to push educate out more 
and sometimes it just doesn't happen. And if there was some sort of regulation for caves, maybe people would also start getting more education on the matter (FG3).

Participant: If we go through the process of trying to pursue some kind of designation, it should be for the purpose of creating broader community outreach and a broader forum for education about caves and karst obviously for the protection of cave and karst. But in order to protect you've got to educate. So, the education aspect of any kind of designation would just be paramount (FG4).

Participant: Let me raise this question. It seems if we're going to talk about this subject and land and caves, the question is not whether we have wild caves whether we have wilderness, but the question is how are we treating these objects as part of our environment. We rejected, wilderness was rejected at Mammoth Cave area, twenty-five, thirty, however long ago it was. But we have done rather well at what some of us thought was the object of that discussion in our specific acts about sewage and groundwater analysis and things like that. No, not what's the object of our wilderness discussion, what's the object of the action that we're taking. See what I'm trying to do? I'm trying to get away from that loaded term you're using (FG 7).

Focus groups discussed the necessity for legislation and regulations, but noted that education is what really protects the cave. The focus should be on the objective of the special designation, instead of on the special designation itself. In depth discussion occurred in all of the Caving Event focus groups regarding the education of landowners and the public regarding the protection of caves and the karst environment. The Kentucky and New Mexico focus groups touched briefly upon the subject.

Focus groups expressed concern that a wilderness designation would do little to protect the resource if adjacent landowners do not understand the need to protect it, or know how to manage their lands properly. Education is an important key to cave resource protection. As long as there are landowners who do not understand the need for this type of protection, it is not going to be effective. Protection on private lands requires landowner cooperation. If people do not know about it, do not care about it, or do not feel a personal stake in it, then they are not going to want to protect the resource: 
Participant: We don't ever want a cave to get into that condition ever again and I hope that we're smart enough to know what we're doing. But you also have to be smart enough to know how to go about doing that. You have to respect people. You have to respect their history. You have to respect their feelings and opinions. It's a very delicate situation (FG7).

Discussions touched on what effective education is. It requires consideration of the culture of cave regions, including potential political components, so that landowners and the public will be able to make better decisions.

Discussion also occurred regarding caves as educational tools. Caves with special designations could serve as education resources for land managers, cavers, and the public. Such a role did not necessarily require visitation to the specific cave by the resource users. In addition, brief discussions occurred regarding the value of cavers as educational resources because of their knowledge of cave sciences, including the research they conduct or participate in. Cavers have a part to play in the education process.

\section{Summary}

Focus groups' discussions began with the development of definitions for cave types. Discussions covered the following terms and concepts: cave ownership, wild cave, developed cave, show cave, commercial use versus commercial cave, multiple designations and existence of a continuum. Discussions progressed to defining and discussing the concepts of wild, natural and wilderness. Included in these discussions was the defining of the term wilderness cave.

Focus groups' discussions focused on the concept of a special designation for caves such as a cave wilderness. Topics of discussions included: opposition to special designations, problems with the term wilderness, expectations for a special designation such as cave wilderness, and legislative requirements. Discussions then moved onto the positive and negative 
sides of such a designation, including impacts to communities as well as to private landowners.

The importance of education was a theme woven throughout all discussions.

Participant: Well a whole lot of what we believe in the beginning of our discussion may not be the same as what we believe in the end; depending on how many definitions and terminologies, we agree or disagree with (FG7). 


\section{CHAPTER FIVE}

\section{DISCUSSION AND CONCLUSIONS}

In this chapter I discuss research findings from a cave stewardship perspective. First, is a brief discussion of the focus groups' participants. As stakeholders, they are an important component in the development of an ecosystem approach to cave stewardship. Next is a discussion of cave classifications established through focus groups' discussions. This leads into the primary focus of this research, the idea of cave wilderness.

This discourse on the idea of cave wilderness covers issues relevant to defining cave wilderness and criteria to be considered in defining cave wilderness, areas addressed in focus groups' discussions. A definition of cave wilderness is proposed. Legislative considerations and stewardship prescriptions is reviewed. Focus groups' discussions are revisited to provide a validity check for the proposed definition and prescriptions.

The final segment of this chapter includes a proposed cave typology, discussion of implications of research findings and proposed definition of cave wilderness, and conclusions.

\section{Focus Groups}

One of the goals of this research was to work with stakeholders from two cave regions, representing community of place, and stakeholders who used the cave resource for recreational purposes, representing community of interest. Focus groups' participants included stakeholders from three venues: a national Caving Event, and cave regions of Kentucky, and New Mexico. 
Stakeholders from the three focus group venues provided surprisingly similar responses. This may be due to the high percentage of cavers among all venues as well as a high percentage of overlap within the communities of place and interest. Fifty-four participants completed the questionnaire. Forty-one (76\%) of all respondents identified themselves as cavers. This included six of the nineteen (32\%) of the Kentucky and New Mexico focus groups' respondents. Thirtynine percent of the caver identified respondents were from the two states, which included the two study sites. This overlap of the community of place and community of interest is displayed in figure 6 located in chapter four.

Other factors that may attribute to similarities of responses include the occurrence of cave-related tourism in both communities as well as community ties with a local National Park established specifically because of a cave - Mammoth Cave National Park in Kentucky and Carlsbad Caverns National Park in New Mexico. These circumstances most likely aid in establishing a common "cave based language" between the community of interest members (cavers) and community of place members (local citizenry).

Thirteen of the questionnaire respondents described themselves as non-cavers. These individuals came from the Kentucky and the New Mexico focus groups. Six (46\%) indicated that they had been on non-commercial wild cave trips, indicating some degree of familiarity with trip formats similar to caver trips.

All participants (43) who had responded to the commercial cave trip question had been on a commercial trip. A majority $(70 \%)$ of the respondents had been on more than 10 such trips. There were forty-five respondents to the commercial wild cave trip question. Twenty-four (61\%) had participated on at least one such trip. These responses indicate that participants had a high 
degree of familiarity with commercial-based cave trips, further establishing common ground among participants regardless of focus group venue.

Focus group venues exhibited variation in Wilderness area visits. A majority of the Caving Event (97\%) and New Mexico (89\%) respondents had experienced at least one Wilderness area visit. A much smaller portion of the Kentucky respondents (57\%) had experienced a Wilderness area visit. The variation may be an indication of lack of interest in visiting a wilderness area or simply a difference in the availability of wilderness areas. During focus groups' discussions, unless specifically stated, it was not possible to determine if a participant had experienced a visit to a Wilderness area, therefore comments regarding wilderness were not necessarily reflective of actual visitation experience.

\section{Cave Stewardship}

Stewardship of natural resources, especially those that are essentially non-renewable as in the case of caves, requires an understanding of the various conditions the resources may be found in as the result of human usage. Caves are found in states ranging from to destroyed, devoid of original biological and geological features. Somewhere in between the pristine and the destroyed, lie caves that have been developed for tourism purposes, or have experienced some form of resource extraction. There also are caves of varying degrees of wildness. These caves that have been visited by spelunkers, adventure seekers, cavers, and scientists; and have been impacted to one degree or another. Stewardship of caves must not only take into consideration the condition of the resource and modern usage patterns, as well as considering past and potential future usages. 
Stewardship of caves requires management for specific usage(s). The choice between access and protection of the resource can become an issue when managing for various cave usages. On public lands, management can be established through policy or it can be achieved via a legislatively mandated special designation. This research focused on one such designation, cave wilderness. Although Wilderness is a designation that has existed since 1964, it has never been applied specifically to caves; despite several attempts at having a cave or portion of a cave designated Wilderness. The primary intent of this research was to attempt to define cave wilderness, to identify issues associated with a special designation, and to plan an approach for the development of such legislation should it be deemed desirable.

\section{Cave Classification}

In order to establish common ground in discussions regarding cave stewardship, it is important to have clear definitions of terms utilized throughout the discourse. In establishing this nomenclature, focus groups' participants raised three key points. First, non-cavers may have very specific definitions. Second, when defining terms, there are two different perspectives that can be taken - the cave or the cave user. Third, the establishment of definitions may be of importance for integration with policy concepts such as wilderness.

Variations exist among resource users and other members of the public in how resource related terms are defined. These variations may exist because of how the resource are viewed and how it is used or not used. In order to establish open communication channels, it is important that participants use terminology in the same manner. Learning about and understanding the rationale behind the established definitions can facilitate the development of stewardship policies. 
It can be difficult to assign a cave to a specific class particularly when many caves have mixed characteristics. However, providing ways to define a cave or portions of a cave is essential for the development of management policies. Focus groups identified two broad cave classifications, wild and developed. Focus groups clarified the use of the term commercial.

It was not the intent of this research to define gradations from one class to the other. Rather, the intent was to establish working definitions and identify categories within specific classes. It should also be noted, as discussed in focus groups, that these definitions are intended to be useful regardless of public or private ownership of the cave.

The following discussion is based on elements identified during focus groups dialogues.

\section{Commercial Usage}

It has been the custom of cavers and non-cavers alike to use the term commercial cave as a synonym for show cave. However, such a practice clouds issues regarding other revenuegenerating practices occurring within caves. This is especially true if such usage does not modify the interior of the cave to facilitate travel. Focus groups concluded that the term commercial should refer to the cave's usage and not its condition.

Elements identified as defining commercial usage of a cave include: 1) usage generates income, income that may accrue to the user and not the owner of the cave; 2) usage is not limited to tourism activities, but may range from agricultural to resource extraction purposes; 3) usage may vary in degree of impact, from low to highly destructive of the cave environment; 4) usage is not determined by the degree of wildness or development of a cave; and 5) the charging of administrative fees does not necessarily constitute a commercial usage. 
What constitutes commercial usage may vary with the landowner. However, when the intent of an individual or group's visit is to ultimately produce a final product for profit (whether it be photos, video, medical products or other products) there can be no doubt that the cave has been used for commercial purposes. The act of charging an administrative fee, to cover costs incurred in overseeing such projects (profit or non-profit), does not necessarily constitute commercial usage by the landowner. If, on the other hand, the landowner (public or private) gains financially from the venture, then they too may be considered as using the cave for commercial purposes. What is most important is that commercial usage of a cave does not necessarily change its wildness.

It is strongly recommended that the term commercial cave not be used. Instead the term commercial usage should be used when describing a cave's use or discussing management practices and policies.

\section{Wild and Developed}

Bunting (1999) defined wild caves as caves not modified for tourist development. A definition based solely on the user's perspective. This definition is limited, ignoring not only other forms of cave development, but also lacking of descriptive attributes regarding a cave's physical state.

Elements of a wild cave include: 1) it is in its most (close to) natural state, it is undeveloped and substantially unimpacted; 2) visitors are required to take a wild cave on its own terms (there are no improvements to facilitate travel by or to insure the safety of the public visitation typically requires special equipment); 3) modifications that may be acceptable are those intended to allow access to make travel possible may require some expertise to use; 4) a 
wild cave may or may not be mapped; exploration may or may not be an on going process; and 5) it is possible to have commercial usage of a wild cave without detracting from its wildness.

In developing a definition of a wild cave, focus groups used a multi-perspective approach, that of the cave and that of the user. Discussion themes regarding pristineness and naturalness addressed the cave perspective. Discussion themes regarding trails, historic usage and visitor's experience and expertise address the user perspective. Overlap in perspectives occurred during discussions of modifications.

A wild cave can be defined as a cave in a natural state, undeveloped, and substantially unmodified. There are neither improvements to facilitate ease of travel nor safe guards to ensure visitor safety. Visitation beyond the dark zone requires the use of personal lights and may require special clothing and equipment.

An important feature in this definition of a wild cave is the use of the phrase 'substantially unmodified'. The inclusion of this phrase recognizes that humans do have an impact on caves via visitation or surface activities.

Discussions defining acceptable modifications occurred in all focus groups. However, the Caving Event focus groups went into greater detail regarding modifications acceptable in a wild cave. This may be a factor of participants' familiarity with the cave environment. Cavers, having greater experience in caves, thus have a greater awareness of modifications to a cave.

Five elements of cave modifications affect the integrity of a cave: 1) artificial entrances or entrance enhancements are not necessarily deterrents to a cave's wildness; 2) gates were not considered deterrents to a cave's wildness; 3) acceptable modifications are those that make it possible for a trained individual to traverse a portion of a cave or are designed to enhance safety of said individual; 4) modifications designed to facilitate ease of travel detract from the wildness 
of a cave, such modifications are considered forms of development; and 5) modifications that are designed to increase accessibility for non-cavers reduce the cave's wildness and have potential to remove the cave from wild status.

Modifications to a cave can affect the integrity of a cave's wildness. Modifications that were considered acceptable (within limits) included changes effected to gain access to a cave, including enlarging an entrance or digging a cave open. The gating of a cave, while an unfortunate management necessity, did not necessarily detract from a cave's wildness. Gates can in fact aid in protecting a cave's wildness. Allowable modifications included those that made a safe traverse possible for trained individuals. Such modifications included the placement of ropes, bolts, and hangers. As noted in chapter four, modifications are fraught with gray areas, and may need to be addressed on a cave-by-cave basis.

The establishment of trails walks a fine line between wild and developed cave, blurring the distinction between the two. It is fundamental that trails enable people to access the interior of caves. Any trail is considered impact and modification of the cave environs. The type of trail and intent of establishment are important criteria in determining if the trail is or is not a development feature. The intentional establishment of a trail with the goal of confining impact is an example; the construction material will determine whether such a trail is considered a development feature.

Criteria for acceptable trails in wild caves include: 1) trails in wild caves typically develop naturally due to impact from visitation; 2) the potential exists for planning of trail placement for resource protection purposes; 3) trails are un-improved and may be delineated by flagging or by rock cairns; and 4) wild cave trails are not created for ease of traveling. 
Modifications made to facilitate the ease of travel, particularly for unskilled visitors, are considered forms of development. Development can be viewed as any improvement for access and visitation by the general public. Development can eliminate the need for personal lights and other special equipment and clothing, facilitating ease of visitation. In such cases, development is tourism based. Development may also occur for resource extraction and utilization purposes. Development may include infrastructure such as parking lots and rest rooms. However, the establishment of a parking lot does not in and of itself make the cave a developed cave.

Elements of a developed cave include: 1) the cave is not taken on its own terms; 2) development events can vary in type and degree, it may occur in a series of events, at different periods or concurrently; 3) development is often associated with commercial usage, particularly tourism; and 4) a developed cave may not be commercially active.

Show caves provide a different type of in-cave experience than that of a wild cave trip. Elements of show caves include: 1) development for commercial, tourism purposes; 2) visitation typically requires no special skills on the part of the visitor; and 3) purposefully developed trails are designed to enhance the visual experience of the visitor.

Show cave modifications may include lights, developed trails, elevators, stairs and handrails, as well as infrastructure. Improved trails (purposely designed, intentionally laid out and constructed) are a critical element of these types of developed cave. The degree of development may vary and, to the inexperienced visitor, be relatively undetectable. Development may be limited and imperceptible, particularly in caves used primarily for wild cave tours.

The commercial aspect of a show cave implies operation for profit. However, not all show caves are operated with the primary goal of generating profit. Such caves, typically those 
operated by federal or state governments, are operated with a primary goal other than profit generation, though these operations may generate income.

\section{Multiple Designations}

Focus groups agreed that it is possible that a cave may have passages/areas assigned different designations, regardless of whether the cave had been developed and/or commercialized. It was noted that while "the essence of the cave" may give it its primarily designation, it does not preclude the ability to assign other designations to specific areas within the cave. A cave which is partially developed may have "paths less traveled" beyond the developed portions of the cave, and there is potential for existence of wild and unexplored areas. The recognition that a cave may have multi-designations is very important to the idea of special designations.

Focus groups determined that it would be possible for a show cave to have a developed component and still have a wilderness component. Qualifications for determining a wilderness component was that it must be unaffected by activities in the rest of cave. Unaffected must be determined from the human perspective, unaided (visually, aurally, olfactory) and aided (chemically). In addition, the site must have a healthy ecosystem.

\section{Pristineness, Impact and Restoration}

A pristine cave exists at the far end of the spectrum from wild to destroyed. Elements of pristine include: 1) pristine implies no impacts from human subsurface or surface activities; 2) there is gradation in the pristine condition of a wild cave, dependent on how much it has been 
impacted by human activities; 3) a wild cave is no longer pristine once development has begun; and 4) a restored cave, which may appear wild and natural, is not a pristine cave.

Caving Event focus groups were most likely to address the idea of pristine directly, explicitly using the term pristine, whereas the Kentucky and New Mexico focus groups often approached the concept indirectly. These two focus group venues usually did not use the term pristine, but, instead referred to the idea of pristine as "a truly wild cave", one in which man has not entered or has had little impact. This was one of the few times that focus groups approached the same concept utilizing different terminology. Why these groups did not use the specific term pristine is not clear. This is something that may need to be further pursued.

The point at which pristine cave becomes non-pristine is debatable. It may depend on the individual's perception, based on knowledge and the depth of the evaluation process. It may even be dependent on the cave environment itself. Understanding the idea of pristineness and how it is defined may be important in the development of stewardship policies and plans, and should be investigated further.

Discussions regarding wild caves invariably raised the question: "it may look wild, but is it natural?" Wild refers to the physical component of caves, typically referring to the lack of human structures and significant modifications to the cave walls, floor, and formations. Natural refers to the ecological component of caves, the biological communities, as well as geochemical processes. The point had been raised: "How deep does one need to look in order to define pristine?" Is pristineness evaluated on appearance (unaided sensory input) alone or does it include looking deeper (e.g. water chemistry). This point may be of significance in defining cave wilderness and bears further consideration. 
The potential exists for impacted caves to return to a wild(er) condition. Agents of return may be human based (restoration activities) or nature based (e.g. flooding). The return of a cave to a wild(er) state, particularly if it occurs through human intercession, may not mean that it has returned to a natural condition, and it would be very unlikely to return to a pristine condition. The perception of the quality of the restoration may vary depending on an individual's experience and familiarity with cave environment. The perception of wildness and degree of impact will have important considerations in stewardship of specially designated caves.

\section{Cave Typology}

The use of cave classification systems as management tools has come under fire for a variety of reasons. A primary reason is that these systems tend to oversimplify, such that individual cave distinctions and details are lost in the grouping of similar caves into specific type descriptions. These systems often fail to address surface activities that may be detrimental to the cave environs, obscuring the need for, and preventing site-specific management and protection plans (Mullins, 1993). However, a cave classification system can be useful in establishing a common foundation from which discussions can evolve. As such, the following cave typology is not intended for management use; instead, it is intended to provide a foundation for establishing usage of terms in cave stewardship dialogues (see table 6). It addresses the cave environs and its usage.

A cave may be considered to represent several cave types. However, typically if a portion of the cave is developed its overall cave type is developed. Carlsbad Cavern and Mammoth Cave are both examples of caves in which only a small portion of the cave has been developed, yet both caves are typically referred to as being developed, and having wild components. 
Table 6. Cave Types Based on Cave Attributes and Human Impacts and Usage.

\begin{tabular}{|c|c|c|c|}
\hline CAVE TYPE & BROADER GROUP & DESCRIPTION & EXAMPLE \\
\hline \multicolumn{4}{|c|}{ WILD CAVE } \\
\hline \multicolumn{4}{|c|}{ Caves primarily unmodified by intentional human actions. } \\
\hline Wild Cave & Undeveloped & $\begin{array}{l}\text { Caves that are substantially unimpacted, } \\
\text { in which there is no evidence of } \\
\text { development and in which there is little to } \\
\text { no modifications to facilitate ease of } \\
\text { travel by or safety of the general public. }\end{array}$ & Bowden Cave, WV \\
\hline Wilderness Cave & Wild Cave & $\begin{array}{l}\text { Caves with little to no impact, in which } \\
\text { development has not occurred nor have } \\
\text { any modifications been made to facilitate } \\
\text { visitation or safety of the general public. }\end{array}$ & Lechuguilla Cave, NM \\
\hline Pristine Cave & Wild Cave & $\begin{array}{l}\text { Caves in their most natural state, impact } \\
\text { is typically associated with visitation and } \\
\text { may not be readily apparent to the non- } \\
\text { caver visitor. }\end{array}$ & Barancas Cave, NM \\
\hline \multicolumn{4}{|c|}{ DEVELOPED CAVE } \\
\hline \multicolumn{4}{|c|}{ Caves intentionally modified by humans, with modifications typically to physical structure of the cave. } \\
\hline Show Cave & Developed & $\begin{array}{l}\text { Cave in which the physical structure has } \\
\text { been modified or enhanced to facilitate } \\
\text { ease of visitation and visitor safety; may } \\
\text { still have wild portions. }\end{array}$ & Diamond Caverns, KY \\
\hline $\begin{array}{l}\text { Resource Extraction } \\
\text { Cave }\end{array}$ & Developed & $\begin{array}{l}\text { Cave that has been modified to access } \\
\text { and remove the cave's natural } \\
\text { resource(s); many still have wild portions. }\end{array}$ & Saltpeter caves \\
\hline \multicolumn{4}{|c|}{ ADDITIONAL CAVE TYPES } \\
\hline \multicolumn{4}{|c|}{ Caves defined by usage, based on visitation intent or on level of damage by human activities. } \\
\hline Commercial Use Cave & $\begin{array}{c}\text { Developed } \\
\text { Undeveloped }\end{array}$ & $\begin{array}{l}\text { Any venture in which a profit oriented fee } \\
\text { is charged to visit the cave. }\end{array}$ & $\begin{array}{l}\text { A guided wild cave trip } \\
\text { conducted by a for-profit } \\
\text { organization. }\end{array}$ \\
\hline Research Cave & $\begin{array}{c}\text { Developed } \\
\text { Undeveloped }\end{array}$ & $\begin{array}{l}\text { Cave in which scientific studies are } \\
\text { conducted. }\end{array}$ & Lechuguilla Cave, NM \\
\hline Impacted Cave & $\begin{array}{c}\text { Developed } \\
\text { Undeveloped }\end{array}$ & $\begin{array}{l}\text { Caves damaged by visitation, surface } \\
\text { activities, or vandalism. }\end{array}$ & Bowden Cave, WV \\
\hline Destroyed Cave & $\begin{array}{c}\text { Developed } \\
\text { Undeveloped }\end{array}$ & $\begin{array}{l}\text { Caves depleted of original structure and } \\
\text { ecological processes. }\end{array}$ & C. J. Cave, CO \\
\hline
\end{tabular}

A wild cave is defined as a cave in a natural state, undeveloped, substantially unimpacted and unmodified. There are neither improvements to facilitate the ease of travel nor safeguards to ensure visitor safety. Visitation beyond the dark zone requires the use of personal lights and may require special clothing and equipment. A wild cave may or may not be mapped; 
exploration may or may not be an ongoing process. It is possible to have commercial usage of a wild cave without detracting from its wildness.

Wild caves are impacted by human activities. Impact may be a result of intentional acts or be unintentional. Impact can be a result of visitation, surface activities, or inappropriate behaviors (e.g. dumping trash or vandalism). The level of impact may be such that even untrained visitors will notice it.

Acceptable modifications (within limits) that do not affect the integrity of a cave's wildness include: 1) changes effected to gain access to a cave, including enlarging an entrance (entrance enhancement) or digging a cave open (artificial entrances); 2) gating of a cave (while an unfortunate management necessity, it can aid in protecting a cave's wildness); and 3) modifications that make it possible for a trained individual to traverse a portion of a cave or are designed to enhance safety of said person. It is important to note that due to variations in caves, acceptability of a modification should be considered on a cave-by-cave basis.

Wild caves may have trails within them. These trails typically develop naturally due to impact from visitation. However, the potential exists for the planning of trail placement for resource protection purposes. Trails within wild caves are not usually considered as improvements and may be delineated by the use of flagging or rock cairns.

Wilderness and pristine are subsets of wild caves. A wilderness can be pristine. Pristine caves are those caves having little to no impact. Impact is typically associated with visitation (it is rare that any visitation does not result in some small change to a cave). Impact may or may not be noticeable to non-cavers. Undiscovered caves are not necessarily pristine, as they may have been impacted by surface activities. A pristine cave can have wilderness qualities, however, not 
all pristine caves are of a size or configuration to insure a wilderness experience, and thus lack wilderness qualities.

Caves of the wilderness type are those cave in which it is possible to have a wilderness experience, and because they have wilderness qualities. They are also caves having limited impact resulting from visitation. Like pristine caves, the impact may or may not be noticeable by unskilled visitors. Caves in the wilderness category include wilderness caves (those found beneath designated Wilderness areas), defacto cave wilderness and designated cave wilderness (if established). It should be noted that not all wilderness caves necessarily have wilderness qualities. Some may be too small to provide the sense of isolation and remoteness, and others may have excessive impact due to visitation.

Caves in which modifications are made to facilitate the ease of travel and increase accessibility, particularly for unskilled visitors, are considered developed. Development can be viewed as any improvement for access and visitation by the general public. By facilitating ease of visitation, development can eliminate the need for personal lights and other special equipment and clothing. Development may also include infrastructure such as parking lots and rest rooms. However, the establishment of a parking lot does not, in-and-of itself, make the cave a developed cave.

Development can occur for a variety of purposes, including resource extraction and tourism. Tourism is typically associated with show caves. Show caves provide a different type of in-cave experience than a wild cave trip. Visitation typically requires no special skills on the part of the visitor. Show cave modifications typically include lights, developed trails, stairs, and handrails. Improved trails are a critical element of these types of developed cave. These 
purposefully developed trails are designed to enhance the visual experience of the visitor. The degree of development may vary, and in some cases, may be relatively undetected.

Visitation and usage activities within any cave type can result in a heavily impacted cave and may ultimately result in its destruction. Within limits, a cave type may increase in wildness as a result of human or natural caused events. However, while a developed cave may return to a wild state, barring cataclysmic events, it is doubtful that a cave can ever return to a pristine state.

\section{The Continuum of Cave Pristineness}

Focus groups described cave classifications as existing on a continuum from pristine (wild and natural) to heavily impacted/destroyed and included aspects of modification and development. Elements of the continuum included: 1) placement on the continuum is multidirectional, with a cave having the potential to go from wild to developed or impacted to wild again; 2) consideration of where to place a cave or cave passages on the continuum is also based on the type of experience(s) the site has to offer; and 3) placement is non-exclusive - a cave may have multiple site designations and, therefore, have passages that fall on different areas of the continuum. These ideas were important in the development of the cave pristineness continuum model.

As noted in the literature review, wildness can be defined as a function of two independent qualities: naturalness and freedom from cultural (human) control. Wildness increases in two directions along gradients of freedom and naturalness. Freedom progresses from tight cultural control to no-control or self-willed. Naturalness progresses from artificial to pristine (Aplet et al. 1999). 
Humans have a long history of changing surface lands from one landform to another: prairie lands to farm lands, swamp lands to industrial parks, desert lands to recreational and other leisure facilities. Humans have not traditionally changed caves into something else: rather, they have used features of caves for specific purposes. Humans have not exerted control over caves, but they have modified caves to fit specific needs. Defining wildness as a function of naturalness and freedom from human control does not work well when discussing wildness as associated with caves. Woods (1997) presented a similar discussion as Aplet et. al. (1999), though his use of the term wildness can be equated with their term freedom from cultural control. Woods discussed wildness (freedom) and naturalness as values of wilderness. An alternative model is proposed incorporating the ideas of wildness (freedom), naturalness, and wilderness, and introducing the idea of pristineness as the ultimate form of wilderness.

This alternative model defines cave pristineness as a function of three factors, naturalness, wildness, and human perception (see figure 7). Naturalness is defined by intactness of ecological communities and processes; wildness is defined by freedom from human induced physical impacts or structural changes; and human perception is defined by knowledge and depth of view (aided or unaided sensory input). Modifications include removal of cave materials, as well as the introduction of other materials and structures. In addition, the ability of wildness to re-emerge over relatively short periods of time is largely dependent on the cave's environment. In many caves, the hydrological conditions play a significant role in the ability of wildness to reemerge in a relatively short period.

The intent of the Cave Continuum Model is to provide a tool to help clarify ideas in discussions regarding caves, cave stewardship policies, and plans. Understanding how the cave is 


\section{Cave Continuum of Naturalness, Wildness, and Human Perception}

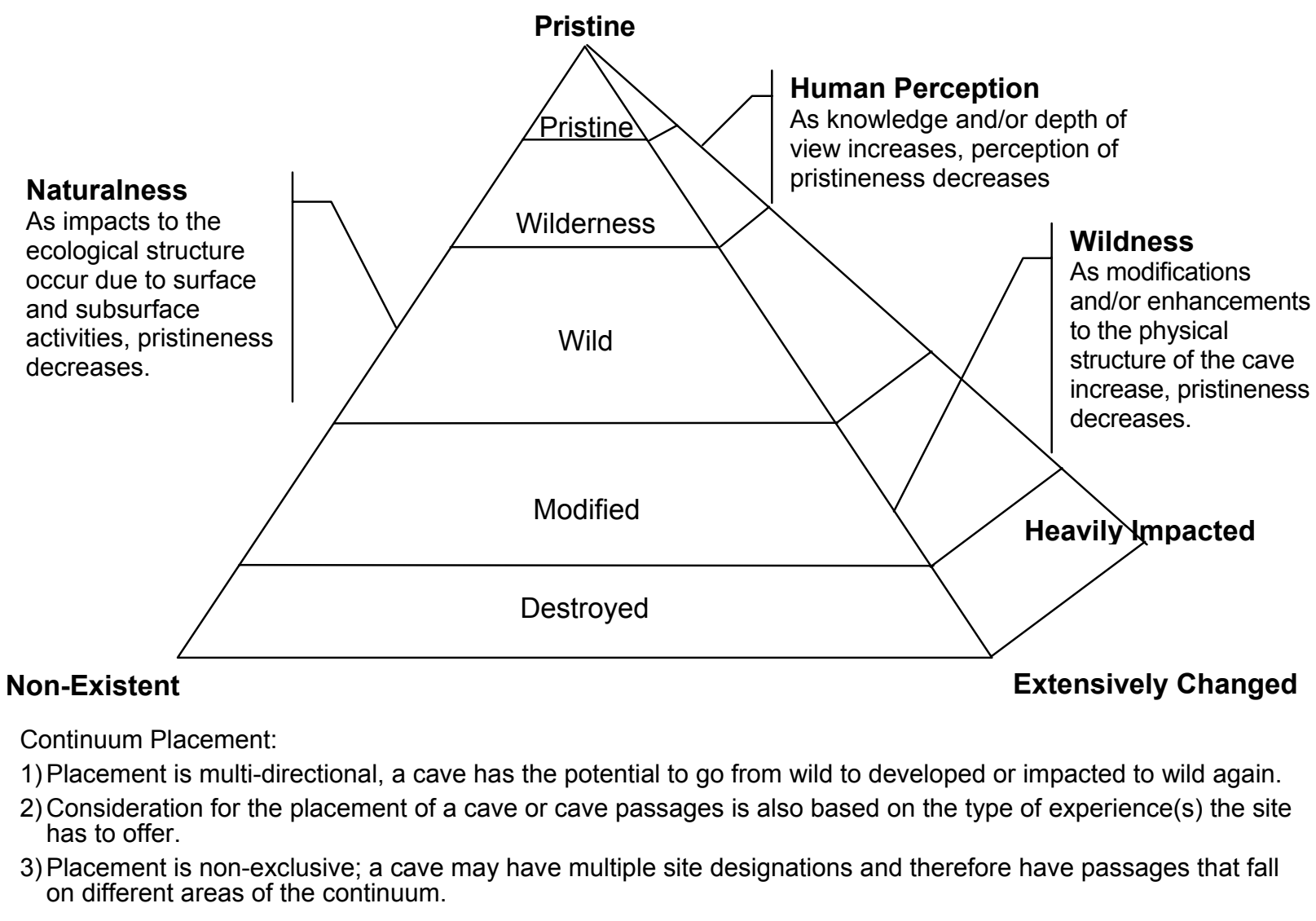

Figure 7. Cave Continuum Based on Naturalness, Wildness, and Human Perspective.

perceived by stakeholders, in terms of its wildness and naturalness, provides a foundation from which discussions can evolve.

In proposing this model, it should be noted that cavescapes are not revertible to prehuman contact geomorphology. As noted in Chapter Two, the majority of caves are formed from dissolutional processes; some caves have origins in other chemical or mechanical processes. Most formations are depositional in nature. Because the evolution of cavescapes typically occurs over geological time (lava and ice caves are two exceptions), there can be no recovery to the geomorphology of pre-human contact. While restoration or natural activities (such as flooding) 
can mitigate many of the human-induced impacts to the point that the cave may appear untouched and be wild, but it will not have reverted to its original state.

Proposed attributes of a cave contributing to its wildness are: 1) the extent the cavescape remains unaltered by human activities; 2) the degree of opportunities for self-sufficiency; and 3) the degree of opportunities for solitude. Attributes contributing to its naturalness are: 1) the extent to which ecological processes remain unimpeded by human impacts; 2) the degree to which it maintains natural biological structure; and 3) the level to which it is unpolluted. As suggested by Aplet et al. (1999) individually these attributes need not be at the highest in cave wilderness; however, jointly, they define the qualities of wildness and naturalness, thus aiding in the measurement of pristineness.

A significant difference between the proposed attributes of this study and those suggested by Aplet et al. (1999) was the elimination of the attribute "remoteness from mechanical devices." Without the use of mechanical devices such as lights, vertical equipment (ascenders and descenders), and in the case of submerged caves/cave passages, scuba gear, rebreathers, and scooters, visitation to and exploration of caves becomes awkward at the least, and impossible at the extreme. The use of vehicles (based on today's technologies) is typically precluded by the physical constraints of most caves. The use of mechanical devices will be addressed further in the discussion of management issues.

The addition of the human perception attribute is a further modification to the Aplet, Thomson, \& Wilbert model. While physical and ecological conditions are factors in determining a cave's pristineness, the human dimension component of pristineness should not be overlooked. The perception of wildness and naturalness, and the degree to which they exist, are subjective. 
Focus groups' participants identified the following factors, which may influence an individual's perception of pristineness:

1. Knowledge (or lack there of) of cave environment.

2. Use of special clothing and equipment.

3. Off-trail experience, including access to restricted areas.

4. Special skills and physical challenge (not required, but may increase perception of degree of wildness).

5. Presence or absence of a guide.

6. Perceptions of safety or risk.

7. Knowledge of (or lack of) cave's history.

8. Location of cave relative to major population centers.

9. Upbringing or experiences (urban versus non-urban).

From a human dimension perspective, the perception of pristineness (wilderness) and the degree of pristineness (wilderness) is subjective; one based on an individual's personal experiences and physical capabilities. Aplet (1999) describes this as the experiential component; the tangible aspect is the biophysical component, which can be observed and objectively described. There is not a clear distinction between the physical reality of wilderness as land and the subjective values which people place on the stimulus of wilderness (ORRRC, 1962). Through the tangible aspects of wildness and naturalness, wilderness moves from an idea to a place, a place in which the idea of wilderness is clearly expressed (Aplet, 1999).

The potential exists for impacted caves to return to a wild(er) condition. Agents of return may be human based (restoration activities) or nature based (e.g. flooding). The return of a cave to a wild(er) state may not mean that it has returned to a natural condition. The perception of the 
quality of the reversion may vary, depending on an individual's experience (cave experiences, understanding of the cave environment). The perception of wildness and type of impact will have important considerations in management and special designation plans.

Understanding both, the social and biophysical components, of wildness are essential in developing an ecosystem approach to managing cave and karst resources. This understanding is also critical to the potential development of special designation for caves, cave wilderness or otherwise.

\section{Cave Wilderness}

It should be noted that all focus groups expressed reservations with using the term wilderness in association with a special designation for caves. In some cases, misgivings had a regional component; however, the fundamental nature of the concern was applicable to either study site (Mammoth Cave Region and Carlsbad Caverns Region). It would appear that community experience regarding Wilderness hearings and the actual implementation of a Wilderness designation has left many people with negative images of legislated wilderness. The idea of wilderness is not what they opposed; it is the legal ramifications (real or imagined) that they opposed. Thus, the use of the term wilderness within a special designation name may elicit such negative responses that the objective of the special designation may never be addressed.

Although various alternative terms were suggested, no one suggestion stood out as being acceptable within or among any of the focus groups. Therefore, the phrase cave wilderness will be used for the remainder of this research report.

While this research will use the term cave wilderness, suggested special designation terms which address focus groups concerns are as follows: 1) Cave Research Site, 2) 
Speleological Reserve, or 3) Site of Extraordinary Interest for Speleological Exploration and Research. It should be noted that the term 'karst' has not been used to prevent exclusion of caves found in non-karstic areas.

\section{Defining Cave Wilderness}

In a 1961 Cave Research Foundation Report, Smith wrote: "The application of wilderness philosophy to caverns is neither a well defined nor a widely thought about concept. It is not an easy concept to develop for speleological wilderness values are alien to much of the human experience" (Smith, 1981, p. 167). Since that time, the wilderness concept has continued to evolve as new values and new uses of wilderness are identified. Indeed, wilderness values of caves have been well documented (Huppert \& Wheeler, 1982, Halliday, 1993a, Chase, 1995).

As mentioned in Chapter Two, the 1962 Outdoor Recreation Resources Review Commission report noted that caves were considered important potential wilderness resources. However, it also noted "It is apparent that special study is needed to develop suitable definitions for these recreation resources, which can be applied in survey and management efforts" (ORRRC, 1962, p.4). Since that time, various authors have offered definitions of cave wilderness as displayed in table 7. However none of these definitions have gained wide acceptance. Difficulties lie in two areas. First, is the lack of a clearly defined intent for a cave wilderness designation, and second, and more importantly, predication of the definition of cave wilderness on the 1964 Wilderness Act definition of wilderness.

Findings of this research suggest the following two items are important aspects in defining the intent of cave wilderness: 
1. To protect and guarantee a wilderness experience. It is not the structure of the cave, but the experience that makes it a wilderness. It is important that people experience caves in a way that preserves them. The sense of isolation, as defined by solitude and remoteness, and the sense of self-sufficiency are important elements in a cave wilderness experience.

2. To protect a cave's scientific values and resources (physical, biological, and other) for study now and in the future. Protection seeks to preserve current and future discovery opportunities. Protection as a scientific resource should be a primary goal, with recreational use a secondary goal.

Watson and Smith (1971) described wilderness as land that can provide people with a wilderness experience. A wilderness experience was described as "consisting of feelings of aesthetic appreciation, of self-reliance, and of remoteness from the ordinary activities and works of man" (Watson \& Smith, 1971, p. 218). Wood (1981) described wilderness as a response that is kindled in the observer. He further suggested that a landscape should not be described as a wilderness landscape, but rather a landscape having qualities of wilderness. Given this, it is not inappropriate to declare a goal of cave wilderness to be the ability to provide a wilderness experience. 
Table 7. Cave Wilderness Definitions.

\begin{tabular}{|c|c|c|}
\hline \multicolumn{3}{|r|}{ Cave Wilderness Definitions } \\
\hline Author & Year & Definition \\
\hline Watson \& Smith & 1971 & $\begin{array}{l}\text { Underground wilderness consists of cave systems that generally appear to } \\
\text { have been affected primarily by the forces of nature, with the imprint of man's } \\
\text { work substantially unnoticeable. }\end{array}$ \\
\hline Stitt \& Bishop & 1972 & $\begin{array}{l}\text { Underground wilderness is that portion of a cave or karst area, lying below } \\
\text { the surface of the earth, which meets the requirements of the Wilderness Act } \\
\text { regarding value and impact on the observer. }\end{array}$ \\
\hline Gamble & 1981 & $\begin{array}{l}\text { Areas from which Man can derive the wilderness experience exists in the } \\
\text { remote areas of cavern systems, where the impact of Man's activities is } \\
\text { largely unnoticeable. Any cave or portion thereof, which has not been } \\
\text { markedly disturbed by tourism or other exploitive activities, therefore includes } \\
\text { substantial tracts of wilderness. }\end{array}$ \\
\hline Wood & 1983 & $\begin{array}{l}\text { [Cave] Wilderness is an area that can provide people with wilderness } \\
\text { experience. The primary purpose of wilderness is recreational and cultural } \\
\text { with ecological values important but secondary. Wilderness experience } \\
\text { consists of feelings of freedom, beauty, empathy with wild nature, and } \\
\text { remoteness from the ordinary works of man. }\end{array}$ \\
\hline Millar & 1994 & $\begin{array}{l}\text { Cave wilderness is a function of the difficulty of ingress/egress, travel within } \\
\text { the cave and/or the feeling of remoteness from the surface. }\end{array}$ \\
\hline
\end{tabular}

The protection and guarantee of a wilderness experience is a modification of the Wilderness Act's qualification, "has outstanding opportunities for solitude or a primitive and unconfined type of recreation." Indeed, it does not necessarily limit the type of recreational activity that may occur and, thus, allows for technological advancements in equipment that would facilitate the low-impact exploration of caves. The use of scuba equipment is an excellent example of an activity that cannot be considered "primitive" by traditional terms. Yet, it allows for recreation and exploration in an element that could not be visited for extended periods of time without the use of advanced technology.

With the statement "may also contain ecological, geological, or other features of scientific, educational, scenic, or historical value," the Wilderness Act places scientific values secondary to that of recreation. The protection of a cave's scientific values and resources, a 
suggested goal of cave wilderness, removes scientific values and resources from a secondary feature to a primary feature of equal if not greater import than the cave's recreational values.

The idea that scientific values should be given consideration over recreational values in a wilderness is not new. Frome (1993) noted that wilderness represent an invaluable scientific resource. In a report to the ORRRC, de Saussure (1962) wrote of caves, wilderness, and scientific values:

...means should be found to permit full scientific use followed by recreational use where there is a demand for it. The scientific value of a cave is similar to the mineral value of a mine; once the resource has been mined out only a hole in the ground remains. Caves, like minerals, are a valuable but non-renewable resource (p. 324).

Findings of this research suggest difficulties in applying the 1964 Wilderness Act to caves, based on two factors: specific features of the Act and perceptions of wilderness developed during the almost forty years of the Act's existence. In defining Wilderness, the Act stipulates: "has at least five thousand acres of land or is of sufficient size as to make practicable its preservation and use in an unimpaired condition." This specificity highlights the difficulty in applying a minimum scale for a cave wilderness. Additionally, it raises questions regarding boundaries for cave wilderness.

The very nature of cave genesis makes specific size specifications an awkward measurement. At best, size might be determined by a three-dimensional area of occupancy. The scale of a cave wilderness may best be determined by the ability to provide for a wilderness experience. Regardless of measurement criteria, any designation implies the existence of boundaries. The establishment of boundaries is a multi-dimensional problem. One consideration is whether the surface must also be declared wilderness. Such a requirement may preclude the designation of caves or portions of caves worthy of cave wilderness designation. Determination 
of subsurface boundaries may be as simple as using the cave's physical boundaries or, in the case of selected areas within a cave, as difficult as defining how distance from human structures and activities is measured. Findings of this research suggest that size should be case specific. The establishment of boundaries should also be case specific. The establishment of the Lechuguilla Cave Protection Area is an example of using geological conditions and features to determine perimeter boundaries and, thus, the size or area of this cave (known and as yet undiscovered) to be protected. Other criteria, such as local and regional hydrology, may be included in establishing the dimensions of a cave wilderness site.

The Wilderness Act was designed for surface environments, environments that tend to be capable of regeneration/renewal. As such, access restrictions only become an issue if it becomes necessary to protect opportunities for solitude, or it becomes a temporary necessity to allow an area to recover from overuse impacts. In some ways, underground wilderness is analogous to above ground wilderness; in other ways caves possess characteristics, values, and vulnerabilities peculiar to caves alone (Wood, 1981, p. 5). In the case of many caves, it is rare to see complete recovery from overuse, although restoration efforts certainly aid in the mitigation of damages and impact. With the understanding that visitation results in some degree of permanent damage, then, access restrictions become a necessity in order to protect scientific values and resources. However, such restrictions do not necessarily equate to restrictions on recreational use of such caves.

The primary user group of caves are the cavers themselves. One activity that cavers participate in is the exploration and mapping of the caves they visit. They document, formally and informally, their findings. While it is true that in their explorations they are recreating, it is 
often also true that they are conducting research, providing much-needed information and data of significant use in the proper stewardship of caves and karst resources.

"Some of the major benefits of caving lie in discovery, investigation, and knowledge building...the input of cavers into the management process... The relationship between cavers and management should be symbiotic; cavers are in part a public to be served and a management resource to be used (Wood, 1981, p. 61).

It may appear that this suggests cave wilderness is only for cavers. In point of fact, it does not. What it does suggest is that cave wilderness is for those who have gained the skills necessary to move through the cave in a safe and responsible manner, and, who also possess the skills and the interest that are necessary to accomplish the project at hand. To those who lack the skills or physical capabilities, access to certain wilderness areas may represent a form of elitism (Murphy, 1996). Those who seek to visit a wilderness may not seek the same types of experiences from that environment. In addition, some recreational values and activities, while serving as a motive for visiting wilderness, can be experienced in other settings. Wilderness access and management policies should give precedence to those whose activities and recreational values strongly depend on those qualities that are unique to that wilderness setting (Bishop, 1983).

Seeking protection for future discoveries acknowledges that resource protection is a primary reason for limiting access to specially designation caves. However, it is also recognized that other caves may offer the desired type of wilderness experience and may be available to the public, thus serving as defacto wilderness.

Caves are essentially fragile, finite resources, filled with natural and cultural values that may not be recoverable once damaged. They provide numerous recreational, research, educational and even employment opportunities for many people (Bunting, 1999). A definition 
of cave wilderness must address the idea that aesthetic and scientific values of wild caves are vulnerable to change and damage by exploration, tourism, scientific research, and recreation uses.

\section{Historic Use}

It is essential to understand that it is not possible to disassociate humans from the "natural history" of caves that have received human visitation. Throughout history, humans have made use of cave environs for a variety of reasons and purposes. They have left behind evidence of their visitations from cave entrance areas down into the depths of the caves. Such usage may or may not affect the perception of the wildness of a cave or alter the sense of a wilderness experience negatively.

Discussion concerning the historic use of caves was introduced by three focus groups, one from each of the study venues. It would appear that historic use of a cave does not necessarily detract from a sense of wildness of the cave, particularly if such use was revealed during the exploratory process. A definition of cave wilderness must address the potential for past human usage of caves that does not negate wilderness values. This topic should be pursued, as it has possible implications in any potential special designation for wild caves.

\section{Surface Lands}

Wilderness has long been associated with surface lands. Results of this study indicate that the establishment of cave wilderness associated with surface wilderness designation is an issue. Some participants felt that the surface had to be wilderness; others did not. Areas of concern included: 1) surface lands not meeting wilderness criteria would preclude the establishment of 
cave wilderness despite meeting any other established criteria, particularly true of the Eastern United States with its history of land development; 2) establishing new surface wilderness areas may interfere with current land uses that are of economic importance to individuals, communities, and regions; and 3) establishment of new surface wilderness would result in loss of private ownership and severing of associated human relationships with the surface lands. A definition of cave wilderness must clearly indicate whether or not surface lands must be wilderness lands.

\section{Wilderness Cave}

The concept of wilderness caves was discussed in five focus group sessions. Wilderness caves were defined as caves found within a designated Wilderness area versus caves potentially designated as wilderness in and of themselves. Most discussions centered on questions regarding protection of these caves as opposed to whether the caves were wilderness. It is important to note that no Wilderness site has been designated as such, based on the wilderness qualities inherent to the caves found there. Nor was the presence of caves an important criterion in the determination of the Wilderness designation. Differentiating between a wilderness cave and a cave wilderness has important philosophical and management implications.

Wilderness is primarily managed for its recreational values and the associated wilderness experience. As such, the wilderness experience recreational values of wilderness caves would be of primary importance in the management of these caves. The National Park Service has an established policy for caves having all entrances in wilderness to be managed as wilderness. The management priorities for Cave Wilderness would be for the protection of scientific values and 
resources, with the wilderness experience an important component. However, the protection of recreational values is not the primary focus of this designation.

Location beneath a designated Wilderness does not preclude legal challenges to enable development and commercialization of portions of a wilderness cave. In 1988, a community based task force was established to investigate the potential development of Lechuguilla Cave despite its location beneath Wilderness lands within Carlsbad Caverns National Park. Although the task force concluded that the cave should be preserved as an undeveloped resource, it still left open the potential of pursuing methods for removing the cave from wilderness protection at a future date. Since then Lechuguilla Cave has received special protection through Congressional legislation, which should preclude any future development threats. In an attempt to protect such caves, the National Park Service has established a policy in which any cave located beneath Wilderness designated lands, and in which all entrances are located under Wilderness, shall be managed as Wilderness. The U.S. Forest Service and the Bureau of Land Management are considering similar policy statements. Note that this does not provide the same protection for the cave if an entrance is found on non-wilderness lands. In addition, policies are subject to change as management's perspective change. As such, a cave found beneath designated surface Wilderness is not guaranteed the type of protection from development that would be conferred with a Congressional special designation.

\section{Research Cave}

The idea of a research cave designation was introduced during one of the New Mexico focus group sessions. Although all focus groups discussed the importance of scientific values 
associated with caves, only one focus group suggested a specific, special designation in recognition of those values.

The proposed designation arose during discussions regarding Lechuguilla Cave (located beneath designated Wilderness within Carlsbad Caverns National Park, NM), its wilderness values, and activities that occur within the cave. It should be noted that the exploration and mapping activities are scientific processes and conducted under specific scientific criteria. Studies conducted to determine the accuracy of the survey concluded that it met professional standards and quality. It should also be noted that the majority of the cavers involved in the exploration and mapping process are doing so as a recreational activity. This example of the overlap between science and recreation is of importance in discussing access issues regarding special designations such as cave wilderness. This overlap of science and recreation will be revisited in the Defining Cave Wilderness section of this chapter.

\section{Developing the Idea of Cave Wilderness}

Concepts evolve out of a complex constellation of impressions, perceptions, and experiences...concepts are a mental image of reality tinted with the theorist's perception, experience, and philosophical bent. They function as a reservoir and an organizational entity and bring order to observations and perceptions. They help to flag related ideas and perceptions without going into detailed descriptions (Meleis, 1985, pg. 127).

Much of the work on wilderness has been confined to the legal definition of wilderness. However, people do not always refer to this definition in their perception of wilderness (Murphy, 1996). To understand the phenomenon of wilderness, Murphy (1996) and Hill (1994) used a phenomenological research approach to explore the meanings associated with wilderness. The same approach was used in this research to clarify the meanings associated with the phenomenon of cave wilderness. In establishing the foundations of meaning for a phenomenon it becomes 
possible to construct sound scientific and political theories, management practices and policy (Pickles, 1983). The defining of a concept, such as cave wilderness, is a way to enhance the knowledge base for the discipline of cave resources stewardship (Parse, 1997).

Rodgers and Knafl (1993) described three elements of concepts. First, concepts are a human construct. Their meanings are not an inherent element that waits to be discovered and they are created to serve the intentions of their users. Second, a concept can convey an impression of a human experience or use the experiences as an indicator. Concepts are separate from the phenomena; they are associated with a phenomenon to affect how an individual comprehends the phenomenon (i.e. the idea of wilderness is not the site itself, it is a description of how the site is perceived and thus, managed). Third, the structure of concepts is such that it is possible to identify the ideas and empirical phenomena that are or are not included.

Various processes have been put forth in defining a concept, many based on the traditional detailed systematic approach, which includes concept identification and attribute verification (Parse, 1997). A different approach is one of concept inventing. In the first approach, the structure of the concept is generated from the research participants. In the second approach, the ideas arise from multiple sources (Bournes, 2000), as is described here:

Concept inventing is a multidimensional all-at-once process of analyzingsynthesizing, bringing to life novel unitary concepts. Concept inventing does not occur in a step-by-step linear fashion, but, rather, entails the rational-intuitive origination of a unique synthetic definition of an idea surfacing from the beliefs and values of the scholar who is creating the concept (Parse, 1997, p. 63).

The elucidation of a concept may result from the interpretation of literature arising from various disciplines, personal experience, as well as other sources, in order to discover the various meanings that may be associated with the abstract concept. The fundamental nature of the concept is defined and is connected to current knowledge. Each conceptualization is unique in 
that the scholar decides which meanings to use in the definition and distinguishes the concept via a logical combination of these chosen meanings (Parse, 1997).

In developing the idea of cave wilderness, a combination of the two approaches was used. The traditional approach was used to identify potential attributes and meanings associated with the concept through the use of focus groups. The findings were complimented with the researcher's own interpretations derived from wilderness and cave wilderness literature from the fields of geography, philosophy, landscape architecture and speleology, as well as from natural resources protection legislation. Thus, ideas and meanings of the concept of cave wilderness arose from the research participants as well as emanating from a synthesis of multiple sources.

\section{Criteria for Defining Cave Wilderness}

Focus groups' discussions on the idea of cave wilderness resulted in the identification of factors important to development of a cave wilderness designation and its associated legislation. The establishment of these factors by the focus groups does not denote support for a cave wilderness or other special designation. These factors were used to develop criteria important in defining the idea of cave wilderness. Criteria evolved from the following concepts: 1) intent, 2) visionary impact, 3) scientific values, 4) experiential values, 5) access issues, 6) resource protection, and 7) educational values.

\section{Intent}

Is the designation for caves (resource protection) or for people (recreation, knowledge)? It is necessary to define what is being protected and from what activities or events. Cave wilderness should not be established primarily for recreational purposes. 


\section{Visionary Impact}

Designation must go beyond the need to protect caves based on today's knowledge and values alone. It needs to address the future; the preservation of cave resources for future generations' needs and values. Preservation for the future protects the potential of future discoveries.

\section{Scientific Values}

Designation must provide protection of the cave's scientific values and resources, for study now and in the future, including preservation of future discovery opportunities. The knowledge gained from scientific investigations can be used for educational and other purposes.

\section{Experiential Values}

Designation must provide for the protection of individuals' ability to have a wilderness experience in the cave, an experience that offers the perceptions of solitude, remoteness, and self-sufficiency.

Access

Access restrictions should occur for the protection of the cave resources. However, special designation should not rest in permanent closure of the cave. Rationales for limiting access include the existence of other caves open to the public for recreational purposes and the ability to provide alternative ways to visit a cave via the use of photographic and videographic imagery.

\section{Resource Protection}

Designation will need to provide protection for physical, biological, and other components of a cave - preservation of the cave's natural state, its original resources, and recognition of resource fragility. It will need to be a tool for protection from activities that would 
degrade the resource. This would include addressing surface as well as subsurface activities that may have adverse impact upon the cave resources. It will also need to provide protection for the human dimension aspect of a cave - protection of physical and social sciences' values, aesthetic values, wilderness values and other values.

\section{Education}

Generating public awareness of the significance of caves was identified as another feature important to developing cave resources special designation. Specially designated caves can serve as educational resources (with or without requiring physical visitation).

\section{Management}

Designation must recognize that each cave is different. It would be necessary to tailor management practices to meet specific cave needs. Specific management should evolve from cave resources (physical and social sciences), and skill requirements.

Based on the above criteria, the following guidelines were used in defining cave wilderness:

1. Recognizes that caves are valuable, non-renewable resources.

2. Protects caves that appear to have been affected primarily by the forces of nature, where the impact of human activities is substantially unnoticeable.

3. Recognizes that impact is change and must be managed.

4. Recognizes the potential for surface usage and activities that do not interfere with the cave environs.

5. Protects scientific and cultural resources and associated values.

6. Protects and guarantees a wilderness experience - solitude, remoteness from the ordinary activities and work of humans, isolation, self-sufficiency. 
7. Recognizes the existence of caves that can provide a wilderness experience and use that is not dependent on a specific site.

8. Recognizes the need to protect for future generations.

9. Recognizes the educational value of cave resources and research.

10. Recognizes that historic use, which does not intrude upon the cave's wildness and the wilderness experience, may be considered acceptable.

In addition to the criteria gleaned from focus groups' discussions, other resources were consulted in developing a cave wilderness definition. These included the 1964 Wilderness Act, the 1968 Wild and Scenic Rivers Act, the 1989 Federal Cave Resources Protection Act, and the Lechuguilla Cave Resources Protection Act, as well as previously proposed cave wilderness definitions.

\section{Proposed Definition of Cave Wilderness}

The definition of a concept results in the creation of a mental image, the concept "symbolizes ideas and meanings, and expresses an abstraction" (Watson, 1979, pp. 61-62). In defining the concept of cave wilderness, it is necessary to consider not only the physical conditions of the cave, but also two other components of wilderness - the feelings evoked when visiting the site and the stewardship goals and objectives. Using the findings of this research, wilderness readings, and other resources, the author proposes the following preamble and definition:

It is recognized that caves are valuable, non-renewable resources; that wilderness caves and other significant wild caves exist and are protected to preserve their recreational values, as well as scientific, educational, and cultural values, for the 
perpetual use, enjoyment, and benefit of all people. It is also recognized that some caves and cave passages, in addition to recreational and educational values, are repositories of scientific and cultural resources of extraordinary value, known and unknown. These same caves exhibit high degrees of wildness and naturalness (the physical reality of wilderness) and the intangible essence of wilderness (solitude, self-sufficiency and sense of remoteness) such that visitation to theses caves evokes a wilderness experience. In order to protect these resources, wilderness qualities, and opportunities for discovery and research, it is proposed that the designation of cave wilderness be established. In recognition of the spirit of exploration and discovery, cave wilderness shall be open to those who desire to meet the cave on its own terms, to explore, discover, and report, thereby contributing to the world's knowledge of speleological and other sciences. It is the hope that such knowledge will be used for education, resource protection and stewardship, and other additional beneficial purposes for all of humankind.

Cave wilderness is defined as: those cave and cave passages exhibiting exceptional scientific and cultural resources, and wilderness qualities. These sites display a high degree of wildness, in which the physical structure and ecological systems are largely unimpacted by humans and in which there is a sense of remoteness from the ordinary activities and works of humans. It is further defined to mean those caves and cave passages in which stewardship shall protect the cave resources, its wilderness values, and future discoveries; and 1) seeks to limit the impact of human visitation, including exploration, discovery and other 
scientific research activities; 2) seeks to protect the sense of solitude, remoteness and self-sufficiency as well as other characteristics of a wilderness experience; 3 ) allows for exploration, discovery and other scientific research activities; 4) recognizes the historic connection of humans and caves, such that evidence of historic human visitation and usage that does not detract from the cave's wildness or wilderness experience is acceptable; and 5) surface activities shall be managed to protect the cave resources and wilderness qualities.

The rationale behind the development of this definition is that it recognizes the essential relationship between the cave, its resources, and the user. This definition recognizes that humans have a past, present, and future history with caves. It recognizes that scientific endeavor can be intertwined with a wilderness experience. An important component of this definition is the incorporation of the ideas of exploration and discovery.

The development of the 1964 Wilderness Act addressed the human dimensional aspect of our nation's lands from a present day perspective, ignoring the historic influence that humans have had (and will continue to have) in shaping the landscape. This oversight was addressed to a certain degree with the 1975 Eastern Wilderness Act. Inclusion of the human component in cavescapes recognizes the history that humans have and will continue to have with caves.

Although the definition of cave wilderness was guided by criteria derived from focus group discussions, an additional component was added that had not been addressed directly during those discussions - the idea of exploration and discovery. Media coverage of modern day exploration tends to focus on either the scientific research or the 'high adventure' components, rarely combining the two, favoring one over the other. In a time when, in the public's eyes, space exploration is for scientists, and mountaineering, caving, and kayaking explorations are viewed 
solely as recreational activities, it is easy to understand the concern of focus group participants that cave wilderness not result in private recreational grounds for cavers. It is important for the public and cavers alike to understand that exploration and mapping are scientific activities (ask the geographers). What this definition attempts to do is to reconcile the recreational attribute of exploratory activities with its professional/scientific attribute. The idea of recreation and exploration coming together in wilderness is not a new one. Indeed, one of the original advocates for wilderness expressed such an idea:

Leopold had to admit that his interest in wilderness grew out of the same romantic fascination with mystery that had driven the exploration and conquest of such areas. Wilderness was a construct that necessarily existed in relation to these phenomena, in a culture without a tradition of exploration and conquest; it would have made little sense. Yet his call to preserve wilderness was deeply critical of the destructive results of exploration.... Wilderness preservation involved much more than a celebration of the explorer's urge, offered as the "Second Great Age of Discovery" waned; it was a gesture of self-control, an admission that the explorer's urge ultimately undermined the values that drove it.

Leopold believed that the urge to explore was a basic one, and that there was a relationship between declining opportunities for true exploration and the rise of a strong national interest in outdoor recreation. "Is it to be expected that [the unknown] shall be lost from human experience," Leopold asked, "without something likewise being lost from human character?" Like many of his generation, he thought such a psychic loss was imminent. His hope was that wilderness preservation would extend opportunities to exercise the explorer's urge without allowing destructiveness to follow in its wake. In promoting wilderness preservation, Leopold tried to have it both ways - to preserve the romance of exploration while jettisoning the destructive logic that came with it. The result, as he understood only too well, was a peculiarly modern amalgam (Sutter, 2002, pp. 79-80).

In combining the idea of exploration and wilderness preservation, Leopold ${ }^{3}$ recognized the possibility to separate exploration from its long association with settlement and development activities. This definition of cave wilderness recognizes that opportunities for future exploration

\footnotetext{
${ }^{3}$ Aldo Leopold, born 1887, died 1948.
} 
can reside within wilderness. Furthermore, it seeks to preserve "the romance of exploration" without its seemingly inherent capacity for promotion of development.

\section{Legislative and Stewardship Prescriptions}

Cave stewardship by prescription allows for a site-specific, holistic management of the cave and its surface environments (karstic or otherwise) and provides for the protection of cave resources (Mullins, 1993). Using stewardship prescriptions allows the flexibility to apply different management practices to different caves and areas within a cave and makes it possible for the preservation of unique features within a cave (Webb, 1997).

All focus groups recognized the need to address cave stewardship on a cave-by-cave basis. Table 8 refers to considerations that will need to be addressed in establishing legislative and stewardship prescriptions, as discussed in the three focus group venues.

\section{Boundaries}

Discussions arose regarding surface and subsurface boundaries for cave wilderness. For some participants, cave wilderness required the surface to be wilderness; for others, the surface only needed to be managed for protection of the cave wilderness resource.

Including the surface as part of a cave wilderness recognizes the difficulty in separating/isolating the subsurface from surface lands. There are important intrinsic environmental connections between the two areas. A holistic approach in wilderness management includes both elements. Some discussion occurred concerning the inclusion of the entire drainage of a region. While it would be ideal, protecting the entire drainage basin would not be practical. A last justification for including the surface in a cave wilderness designation was that it would allow for the inclusion of karst surface features. 
Table 8. Legislative and Stewardship Prescriptions

\begin{tabular}{|c|}
\hline Considerations in the Development of Legislative and Stewardship Prescriptions \\
\hline $\begin{array}{ll}\text { Boundaries } \\
\text { - Surface } \\
\text { - Subsurface - Designation of cave or specific areas within cave } \\
\text { - } \quad \text { Buffer zones }\end{array}$ \\
\hline $\begin{array}{l}\text { Protection } \\
\text { - of Biophysical Scientific Resources } \\
\text { - of Human Dimensions } \\
\text { - of Future Discoveries } \\
\text { - } \text { from Detrimental Activities } \\
\text { - } \text { of current Show Cave components }\end{array}$ \\
\hline $\begin{array}{l}\text { Significance Criteria } \\
\qquad \quad \text { Establishment of Designation Criteria }\end{array}$ \\
\hline $\begin{array}{c}\text { Educational Component } \\
\qquad \quad \text { Development of educational resources to enhance public awareness of significance of caves }\end{array}$ \\
\hline $\begin{array}{l}\text { Management } \\
\bullet \quad \text { Define management practices specific to cave }\end{array}$ \\
\hline $\begin{array}{l}\text { Partnerships \& Agreements } \\
\text { - } \text { Federal and State Agencies } \\
\text { - } \text { Communities } \\
\text { - } \text { Private Landowners } \\
\text { - Conservancies - cave based and other }\end{array}$ \\
\hline
\end{tabular}

Some participants felt that while protecting the surface with the subsurface was ideal, it was not necessary. It was felt that it would be possible to define wilderness underground different from wilderness on the surface. Surface activities should not necessarily preclude underground wilderness designation - although current usage may have to be modified or restricted with such a designation to protect the wilderness below. Indeed, boundaries of surface wilderness often divide ecosystems. Buffer zones and modification of land use practices often occur on lands adjacent to wilderness areas.

Allowing the surface lands overlaying cave wilderness to not be wilderness increases the opportunity for designation of caves that would otherwise not receive special designation. This may be critical in establishing cave wilderness beneath Eastern lands.

The concept of a buffer zone was raised during one focus group discussion. As noted earlier, a buffer zone would aid in the protection of a cave and its resources. Buffer zones may need to consider surface and subsurface drainage basins, as well as consider surface home ranges 
of trogloxenes (cave wildlife that must live part of their life cycles outside the cave). Although the idea of a buffer zone received relatively little comment, it can have significant ramifications for establishing a cave wilderness site.

Although discussions focused on surface/subsurface boundaries, boundaries within caves will be of concern for those caves in which only a portion of the cave may receive the cave wilderness designation. Carlsbad Cavern and Mammoth Cave are examples of caves in which relatively small portions have been developed. The potential exists for the designation of other areas of the cave as wilderness. It should be noted that in both cases neither cave lies beneath Wilderness lands. Because caves vary in structure, use of specific criteria such as time and distance from developed areas, as well as the establishment of buffer zones will need to be determined on a case-by-case basis.

\section{Protection}

Focus groups elaborated on items that special designation legislation needed to address in the protection of cave resources. Special designation would provide lasting protection for the cave and its resources and include the following: 1) protection of the biophysical aspects of a cave - preservation of the cave's natural state, its original resources, as well as recognition of the fragility of cave resources; 2) protection of the human dimensions component of caves protection of physical and social sciences values, aesthetic values, and wilderness values; 3) protection of future discoveries, including exploration, mapping activities and other scientific research; 4) protection from human activities that would degrade the resource, including surface as well as subsurface activities that may have adverse impact upon the cave resources; and 5) provision for special designation that addresses situations in which caves have been developed, particularly show caves, and yet have areas within them that are worthy of special designation. 
The goal is not to stop showing these caves to the public, but rather to protect and provide management tools to ensure protection of specific undeveloped portions of the cave.

Legislation could provide for a range of special protection categories with associated differences in management practices. Cave wilderness would be at the extreme end of the spectrum. Legislation could be used to determine the degree of protection a cave would receive. Multiple categories could address variations in allowable forms of surface land use. Multiple categories could be utilized within caves that contain both developed and wild passageways.

\section{Significance Criteria}

Legislative criteria establishing the significance of a cave need to be similar to those values that legislation attempts to protect. It was noted that significance should be based on all criteria as opposed to meeting one or more of the criteria. Significance will be based on overall criteria, not on a single component. It was also noted that the establishment of criteria must address the idea that significance varies among people with different interests and backgrounds.

\section{Education}

Generating public awareness of the significance of caves was identified as another feature important to developing cave resources special designation. Specially designated caves can serve as educational resources. However, use of the cave as an education tool did not necessarily imply that visitation was required, nor even desirable.

\section{Management}

Focus group discussion of legislation criteria included the importance of having legislation define what is to be regulated. Legislation needs to provide functionality in terms of a management structure. 
The designation needs to recognize that cave wilderness would have to be managed differently than surface wilderness because it is a very different environment. Many surface wilderness management practices are predicated on the "renewability" of the resource. Because caves, in general, are not renewable resources, the use of management practices based on the idea of resource renewability, such as carrying capacity or even level of acceptable change, would not serve to protect the cave resources. Management practices must recognize that caves vary within regions and across the country. It would be necessary to tailor management practices to meet specific cave needs. Specific management practices should evolve from the cave resources themselves (including: physical and social sciences resources, skills requirements).

Cave wilderness legislation would need to address technology issues such as what is allowable and what restrictions will exist. Examples of issues that would have to be addressed include providing for construction of cave gates, use of diving gear, and placement of bolts.

The acceptability of non-traditional uses of a cave (a subject complicated by evolving technology) must be based on the following considerations: 1) it should never damage the resource; 2) it should not interfere with traditional established uses; and 3) it cannot be done elsewhere. Rock climbing activities within caves is both a traditional and non-traditional use of caves. Climbing that occurs to further exploration is an acceptable traditional activity. However, climbing that occurs simply to experience a new environment is a debatable non-traditional use of caves, primarily because of the damage that is associated with the activity. There are few other environments where it is possible to climb upside down; however, such environments can be developed. Just as climbing walls have developed, perhaps so to, climbing caves.

Other issues may include biogeochemical-prospecting. Precedence has been set by biomedical research being conducted at Lechuguilla Cave. The National Park Service is to 
receive a share of the profits that may be generated from the sale of products developed from the biological materials (a component of the cave's natural resource) that have been collected from Lechuguilla Cave.

\section{Partnerships and Agreements}

Focus groups noted the importance of including local participants in development of wilderness management plans. The importance of local individuals' input is underscored by examples of personal sacrifice by those who lost their lands in the creation of Mammoth Cave National Park. Such loses and the associated feelings of lack of control over one's property, color and influence attitudes toward government agencies. In order to gain the support of and cooperation from local communities, it is essential to include them in the development of any natural resources stewardship plans.

Both Kentucky and New Mexico focus groups concluded that cavers should be included in the development of special designation and stewardship practices for the purposes of developing conservation plans and preservation philosophy. However, it was important to understand that such inclusion would not be with the intent to gain recreational access for cavers to the exclusion of all others. The Caving Event focus groups also recognized these concerns.

In addition to community-based partnerships, the potential exists for the inclusion of other government agencies and non-profit organizations in the development of ecosystem based management for cave resources. Such practices are already occurring among federal land managing agencies. Memorandums of Understanding (MOUs) and other agreements have been established with state and federal agencies and other organizations in the management of Wind Cave National Park. 


\section{Validity Check}

Although the proposed definition of cave wilderness and associated stewardship prescriptions were based on focus group discussions, the real test of its validity is whether it addresses the issues raised during focus group discussions.

\section{Opposition}

Focus groups' participants discussed reasons why a special designation, such as cave wilderness designation was unnecessary. As noted in Chapter Four, four themes opposing the need for a special designation were identified. Table 9 compares these themes with the proposed cave wilderness definition and prescriptions in addressing the protection of wilderness and environmental qualities of caves. As indicated, the definition itself does not address any of the themes for opposing a special designation. However, the legislative and stewardship prescriptions address these themes. Both the cave wilderness definition and its associated prescriptions address the protection of wilderness and environmental qualities of a cave.

\section{Wilderness Act Application Problems}

Focus groups discussed difficulties in applying the Wilderness Act to protecting caves. Table 10 looks at the ability of the proposed cave wilderness definition and prescriptions to address problems associated with the application of the Wilderness Act to caves. As can be seen in table 10 , both the definition and prescriptions address each of the problems associated with using the Wilderness Act to establish cave wilderness. 
Table 9 Comparison of Opposition Themes, Cave Wilderness Definition and Prescriptions In Protection of Environmental and Wilderness Qualities of Caves.

\begin{tabular}{|l|c|c|c|c|}
\hline \multicolumn{1}{|c|}{$\begin{array}{c}\text { Opposition } \\
\text { Themes }\end{array}$} & $\begin{array}{c}\text { Wilderness } \\
\text { Qualities }\end{array}$ & $\begin{array}{c}\text { Environmental } \\
\text { Qualities }\end{array}$ & $\begin{array}{c}\text { Cave } \\
\text { Wilderness } \\
\text { Definition }\end{array}$ & Legislative and Stewardship Prescriptions \\
\hline $\begin{array}{l}\text { Natural } \\
\text { obstructions to } \\
\text { visitation }\end{array}$ & Yes & Yes & N/A & $\begin{array}{l}\text { Is dependent on management to provide protection, } \\
\text { in that it seeks to regulate visitation and access. } \\
\text { Supplements natural obstructions limiting visitation. }\end{array}$ \\
\hline $\begin{array}{l}\text { Current } \\
\text { management } \\
\text { policies }\end{array}$ & Yes & Yes & N/A & $\begin{array}{l}\text { Expands upon current policies and management } \\
\text { practices, is permanent, not dependent of support of } \\
\text { current administration }\end{array}$ \\
\hline $\begin{array}{l}\text { Use of Existing } \\
\text { Laws }\end{array}$ & No & Yes & N/A & $\begin{array}{l}\text { Can address the application of current and future } \\
\text { environmental and other resource protection laws } \\
\text { within the legislation }\end{array}$ \\
\hline $\begin{array}{l}\text { Private } \\
\text { landowners }\end{array}$ & No & Yes & $\begin{array}{l}\text { Strongly recommends inclusion of community } \\
\text { members in the development of legislative and } \\
\text { stewardship activities. Could provide for site specific } \\
\text { educational and assistance programs. }\end{array}$ \\
\hline
\end{tabular}

\section{Terminology Issues and Alternatives}

For a variety of reasons (noted in Chapter Four), all focus groups expressed dislike for using the word wilderness in association with a special designation. It was suggested that wilderness not be included in the special designation term. Although there were no alternative suggestions that received positive support even within a focus group, criteria were derived based on focus groups' discussions. Table 11 addresses the ability of the proposed cave wilderness definition and the associated prescriptions to meet the established criteria. As noted in Table 11, the only criterion that the definition and prescriptions together do not achieve is the ability to not 
Table 10. Problems Associated with Application of the Wilderness Act with Proposed Cave Wilderness Definition and Prescriptions.

\begin{tabular}{|c|c|c|}
\hline \multirow{2}{*}{$\begin{array}{l}\text { Problems with Application } \\
\text { of Wilderness Act }\end{array}$} & \multicolumn{2}{|c|}{ Addresses } \\
\hline & Cave Wilderness Definition & Legislative and Stewardship Prescriptions \\
\hline $\begin{array}{l}\text { Designed for surface } \\
\text { environments }\end{array}$ & $\begin{array}{l}\text { Is not predicated specifically on the } 1964 \\
\text { Wilderness Act, addresses both the } \\
\text { surface and subsurface aspects of } \\
\text { designation }\end{array}$ & $\begin{array}{l}\text { Discusses the need to utilize cave } \\
\text { resource specific practices as opposed to } \\
\text { practices based on the idea of resource } \\
\text { renewability/recoverability }\end{array}$ \\
\hline $\begin{array}{l}\text { May be limiting if surface } \\
\text { must be wilderness }\end{array}$ & $\begin{array}{l}\text { Does not dictate that surface lands be } \\
\text { wilderness, suggests only the need for } \\
\text { appropriate usage practices that will not } \\
\text { harm the cave wilderness. }\end{array}$ & $\begin{array}{l}\text { May be similar in concept to Wild and } \\
\text { Scenic Rivers Act, wherein cave } \\
\text { wilderness found beneath surface } \\
\text { Wilderness areas essentially receives } \\
\text { double protection }\end{array}$ \\
\hline $\begin{array}{l}\text { Perception that strings } \\
\text { are attached }\end{array}$ & Does not address this concern. & $\begin{array}{l}\text { Inclusion of local communities in } \\
\text { development of legislation and } \\
\text { stewardship programs may help with } \\
\text { lessening of distrust, however will not } \\
\text { eliminate concerns. }\end{array}$ \\
\hline Visitation problems & Discusses intent of allowable visitation & Expands upon visitation limitations. \\
\hline Not for Private lands & $\begin{array}{l}\text { Does not specifically limit designation to } \\
\text { Federal Lands as does the } 1964 \\
\text { Wilderness Act }\end{array}$ & $\begin{array}{l}\text { Discusses potential to enter in } \\
\text { partnerships with local land owners - } \\
\text { private or government based. }\end{array}$ \\
\hline Wilderness is "out West" & $\begin{array}{l}\text { Eliminates need for surface lands to be } \\
\text { designated Wilderness which may help in } \\
\text { dispelling this perception. }\end{array}$ & $\begin{array}{l}\text { Establishment of cave wilderness criteria } \\
\text { such that is not dependent on surface } \\
\text { wilderness, nor necessarily excludes } \\
\text { historic usage of cave, may help with } \\
\text { changing this perception about where } \\
\text { cave wilderness may occur. }\end{array}$ \\
\hline $\begin{array}{l}\text { Not traditional perception } \\
\text { of Wilderness }\end{array}$ & Expands upon the idea of Wilderness & Expands upon the idea of Wilderness \\
\hline Not in my backyard & Does not address this concern. & $\begin{array}{l}\text { Inclusion of local communities in drafting } \\
\text { legislation and stewardship policies may } \\
\text { help in addressing this concern. }\end{array}$ \\
\hline
\end{tabular}

Table 11. Ability of Proposed Cave Wilderness Definition and Prescriptions to meet Designation Terminology Criteria.

\begin{tabular}{|l|c|c|}
\hline \multirow{2}{*}{ Designation Terminology Criteria } & \multicolumn{2}{c|}{ Addresses } \\
\cline { 2 - 3 } & Cave Wilderness Definition & $\begin{array}{c}\text { Legislative and Stewardship } \\
\text { Prescriptions }\end{array}$ \\
\hline $\begin{array}{l}\text { Needs to distinguish between } \\
\text { subsurface only or inclusion of surface }\end{array}$ & Yes & Yes \\
\hline Must have a clear definition & Yes & Yes \\
\hline Connotations of a pristine quality & Yes & Yes \\
\hline Describes situation of isolation & Yes & Yes \\
\hline $\begin{array}{l}\text { Not the same as saying it is a } \\
\text { designated Wilderness (not predicated } \\
\text { on the 1964 Wilderness Act) }\end{array}$ & $\begin{array}{l}\text { Yes. However, including the term } \\
\text { wilderness may give the initial } \\
\text { impression that it is based on } \\
\text { previous Wilderness Acts. }\end{array}$ \\
\hline $\begin{array}{l}\text { Term does not attract attention, does } \\
\text { not attract additional visitation. }\end{array}$ & No & $\begin{array}{l}\text { May or may not, dependent on } \\
\text { media attention attracted by } \\
\text { legislation and/or sponsoring agency. }\end{array}$ \\
\hline
\end{tabular}


draw attention. In the case of the definition, the term itself uses the word 'wilderness' which was considered to attract attention. Attention attracted by the actual legislation and stewardship of the specially designated cave will be highly dependent on the media attention drawn to the designation. Such attention may be supportive or non-supportive of the designation.

\section{Cave Wilderness Criteria}

Criteria for a cave wilderness designation were established based on focus groups' discussions. Table 12 addresses the ability of the cave wilderness definition and associated prescriptions to meet these criteria. Both the definition and the legislative and stewardship prescriptions address all criteria identified for the establishment of a cave wilderness designation.

\section{Legislative Requirements}

Focus groups discussed the intent of cave wilderness special designation legislation. Factors crucial in the development of such legislation were identified from these discussions. Table 13 shows the ability of the proposed cave wilderness definition and prescriptions to address these requirements. The legislative and stewardship prescriptions addressed all the identified requirements. The proposed definition directly addressed four of the requirements. The designation criteria and the management concerns criteria were addressed on a limited basis. This should not be a problem, as it is the purpose of legislation to elaborate on designation criteria and to address management concerns. Specific details may be relegated to cave specific management plans. 
Table 12. Ability of Proposed Cave Wilderness Definition and Prescriptions to Meet Cave Wilderness Criteria.

\begin{tabular}{|l|c|c|}
\hline \multirow{2}{*}{\multicolumn{1}{|c|}{ Cave Wilderness Criteria }} & \multicolumn{2}{c|}{ Addresses } \\
\cline { 2 - 3 } & Cave Wilderness Definition & $\begin{array}{c}\text { Legislative and Stewardship } \\
\text { Prescriptions }\end{array}$ \\
\hline Wilderness Experience versus Size & $\begin{array}{l}\text { Emphasizes wilderness experience, } \\
\text { no size requirements noted. }\end{array}$ & $\begin{array}{l}\text { Discusses protection of wilderness } \\
\text { experience. Size established specific } \\
\text { to cave/cave passage. }\end{array}$ \\
\hline Science & Yes & \multicolumn{1}{c|}{ Yes } \\
\hline Access & Yes & Yes \\
\hline Boundaries & No & $\begin{array}{l}\text { Established specific to cave/cave } \\
\text { passage. }\end{array}$ \\
\hline
\end{tabular}

Table 13. Legislative Requirements Addressed by Proposed Cave Wilderness Definition and Prescriptions.

\begin{tabular}{|l|c|c|}
\hline \multirow{2}{*}{ Legislative Requirements } & \multicolumn{1}{|c|}{ Addresses } \\
\cline { 2 - 3 } & \multicolumn{1}{|c|}{ Cave Wilderness Definition } & $\begin{array}{c}\text { Legislative and Stewardship } \\
\text { Prescriptions }\end{array}$ \\
\hline Intent & \multicolumn{1}{|c|}{ Yes } & Yes \\
\hline Visionary Impact & \multicolumn{1}{|c|}{ Yes } & Yes \\
\hline Protection & \multicolumn{1}{|c|}{ Yes } \\
\hline Designation Criteria & $\begin{array}{l}\text { It mentions criteria for overall consideration. Specific } \\
\text { criteria (and how to measure, if possible) will need } \\
\text { to be addressed during the legislative process. }\end{array}$ \\
\hline Education & $\begin{array}{l}\text { It discusses the educational component. Cave } \\
\text { specific educational uses will need to be addressed } \\
\text { during the legislative process. }\end{array}$ & Yes \\
\hline Management Concerns & $\begin{array}{l}\text { It addresses broad concerns of protection. } \\
\text { Concerns specific to each cave will need to be } \\
\text { addressed during the legislative process. }\end{array}$ & Yes \\
\hline
\end{tabular}

\section{Designation Benefits \& Rewards}

Focus groups discussed potential benefits and rewards that may be derived from a cave wilderness designation. Table 14 shows whether or not the proposed definition and prescriptions address the identified potential benefits and rewards. Both the definition and the legislative and stewardship prescriptions directly address the quality of life and knowledge and education aspects. The community benefits and benefits to private landowners would need to be addressed on a cave-by-cave basis. 
Table 14 Ability of Proposed Cave Wilderness Definition and Prescriptions to Address Perceived Benefits and Rewards of Designation.

\begin{tabular}{|c|c|c|}
\hline \multirow{2}{*}{ Designation Benefits \& Rewards } & \multicolumn{2}{|r|}{ Addresses } \\
\hline & $\begin{array}{l}\text { Cave Wilderness } \\
\text { Definition }\end{array}$ & Legislative and Stewardship Prescriptions \\
\hline $\begin{array}{l}\text { Quality of Life } \\
\text { - Environment } \\
\text { - } \quad \text { Preservation of wildlands } \\
\text { - } \text { Concern for future generations }\end{array}$ & Yes & Yes \\
\hline $\begin{array}{l}\text { Knowledge \& Education } \\
\text { - } \quad \text { Protection of future discoveries } \\
\text { - } \quad \text { Educational use of new knowledge }\end{array}$ & Yes & Yes \\
\hline $\begin{array}{l}\text { Community Benefits } \\
\text { - Open space } \\
\text { - } \quad \text { Tourism }\end{array}$ & No & $\begin{array}{l}\text { The potential exists for these concerns to } \\
\text { be addressed during the process of } \\
\text { developing the cave specific legislation. It } \\
\text { is dependent on stakeholder involvement. }\end{array}$ \\
\hline $\begin{array}{l}\text { Benefits to Private Landowners } \\
\text { - } \quad \text { Access to special services } \\
\text { - Incentives } \\
\text { - } \quad \text { Economic Benefits }\end{array}$ & No & $\begin{array}{l}\text { The potential exists for these concerns to } \\
\text { be addressed during the process of } \\
\text { developing the cave specific legislation. It } \\
\text { is dependent on stakeholder involvement. }\end{array}$ \\
\hline
\end{tabular}

\section{Designation Risks and Concerns}

Focus groups discussed risks and concerns associated with a cave wilderness designation.

Based on these discussions, three broad themes were identified for all focus groups. Table 15 shows whether the cave wilderness definition and prescriptions address the 'risks and concerns' themes identified during focus groups' discussions. The definition addresses only one issue, access, and that is incomplete. The legislative and stewardship prescriptions have the potential to address all the issues to one degree or another. Because of variations in people's interests and needs (among themselves and over time) it does not appear that designation risks and concerns can ever be fully addressed. No legislation can be all things to all people.

\section{Education}

Education was an important theme in all focus groups. It was viewed as a critical component in cave resources protection programs, with or without associated special designation legislation. As noted in Chapter Four, discussions regarding education programs identified intent, 
special considerations in the program development, and program audiences. An interesting aspect of the discussions was the consideration of cavers as educational resources.

Various state and federal agencies have developed teaching packets for school-aged children. The National Speleological Society has helped in the development of one such program Project Underground, which promotes an understanding of the subsurface environment and cave resources without promoting cave visitation. However, the existence of adult oriented programs is extremely limited, although a few universities offer cave and karst related courses.

What is needed are community based education programs targeting not only local community members and landowners, but also targeting tourists who visit these regions, regardless of cave-related activities. Inclusion of visitors will help promote cave resources protection beyond the boarders of cave regions. In addition, there is a growing need for karst and cave stewardship programs targeting federal and state land managers. These programs need to address the environmental components of karst and caves, as well as the human dimensions including, but not limited to tourism, recreational and environmental protection legislation.

Table 15. Ability of Proposed Cave Wilderness Definition and Prescriptions to Address Perceived Designation Risks and Concerns Themes.

\begin{tabular}{|c|c|c|}
\hline \multirow{2}{*}{$\begin{array}{c}\text { Designation Risks and Concerns } \\
\text { Themes }\end{array}$} & \multicolumn{2}{|r|}{ Addresses } \\
\hline & Cave Wilderness Definition & Legislative and Stewardship Prescriptions \\
\hline $\begin{array}{ll}\text { Societal Issues } \\
\text { - } & \text { Financial costs and } \\
& \text { responsibilities } \\
\text { - } & \text { Government distrust } \\
\text { - } & \text { Limiting the future }\end{array}$ & N/A & $\begin{array}{l}\text { The potential exists for these issues to be } \\
\text { addressed during the process of } \\
\text { developing the cave specific legislation, } \\
\text { dependent on stakeholder involvement. }\end{array}$ \\
\hline $\begin{aligned} & \text { Landowners } \\
& \text { - } \text { Restrictions } \\
& \text { - } \text { Fear } \\
& \text { - } \text { Economic loses } \\
& \text { - } \text { Landowner relationships } \\
&\end{aligned}$ & N/A & $\begin{array}{l}\text { The potential exists for these issues to be } \\
\text { addressed during the process of } \\
\text { developing the cave specific legislation, } \\
\text { dependent on stakeholder involvement. }\end{array}$ \\
\hline $\begin{array}{cl}\text { Access } & \\
- & \text { Public's right to view } \\
\text { - } & \text { Discrimination } \\
\text { - } & \text { Over visitation }\end{array}$ & $\begin{array}{l}\text { Some of these concerns are } \\
\text { addressed on a limited extent. } \\
\text { Further discussions must } \\
\text { occur during the legislative } \\
\text { development process. }\end{array}$ & $\begin{array}{l}\text { The potential exists for these concerns to } \\
\text { be addressed during the process of } \\
\text { developing the cave specific legislation, } \\
\text { dependent on stakeholder involvement. }\end{array}$ \\
\hline
\end{tabular}




\section{Cave Wilderness and Private Lands}

Two themes emerged from focus group discussions: private "cave wilderness preserves" and public access concerns. Discussions regarding private preserves centered around current programs that are currently in existence throughout the country. These included the establishment of conservation easements, cave conservancies, and the possibility of entering into agreements with federal agencies.

Discussions focused on working with private landowners in the protection of qualities of cave resources. Options available to landowners included establishing conservation easements, leasing or selling lands to cave conservancies, and agreements with federal agencies. Compensation for landowners may be in the form of tax incentives as discussed in Chapter Four.

Caving Event focus groups discussed issues regarding access to caves beneath private lands. Interestingly, recreational access was not an issue. Obtaining access to the caves for research purposes, including exploration and mapping was of concern. Caving Event focus groups discussed two landowner issues with allowing access - privacy and liability. These specific concerns did not arise in of either the Kentucky or the New Mexico focus groups venues. It may be that cavers tend to focus on individual landowners and fail to see the community issues, because they do not typically interact with landowners on a community/regional level. 
Implications

\section{Management Implications}

The current lack of support for cave wilderness does not equate to lack of support for cave and karst protection. What this study does indicate is the importance of education and community outreach. Without these, cave stewardship faces a difficult uphill battle.

Education needs to be far reaching, not limited solely to local cave and karst communities. In addition, it needs to reach both adults and children. Educational partnerships need to be created or expanded upon. The Mammoth Cave Educational Initiative is an excellent example such a partnership. The National Park Service (specifically Mammoth Cave National Park) is working with Project Underground, Inc. to conduct workshops for training individuals in the Project Underground curriculum. They are also helping to facilitate these individuals conduct Project Underground activities in schools in Kentucky, Virginia and other areas around the country. Other avenues of community education need to be explored, including the potential of extension service or other university based programs. The National Cave and Karst Research Institute has the potential of taking a leading role in developing and promoting such programs as it begins to carry out its goal of promoting and conduction cave and karst educational programs.

Ek (2002) notes that, historically, caves have been viewed more as recreational resources and less as sites for scientific research. This has often been reflected in the way caves are (or are not) managed. Ek goes on to say that cave and karst processes are often not as well understood by managers compared to other natural resources and processes. Managers who understand caves, cave processes and the cavers, are important in the stewardship of cave resources. At this time, the majority of land managers responsible for the protection and management of cave 
resources are not cavers. It is difficult to properly manage a resource that cannot be easily viewed, whether by foot, automobile, or plane. While it cannot be expected for a manger to be able to visit all caves under her/his management, it must be expected that she/he understand caves. Providing cave-related educational courses for managers should be a priority.

The professionalization of cave resources positions by the federal agencies will do a lot towards validation of cave stewardship. In addition, it will prioritize educational requirements for managers.

The caving community must also take an even more active role in cave stewardship. The number of cavers involved in speleological related research is increasing. They have also begun to practice outside of the academic arena entering into employment in public and private agencies. However, few cavers have actively become involved in cave stewardship on a managerial level. It is difficult to promote cave stewardship among land managers, when it appears that those most knowledgeable are unwilling to participate in management responsibilities as a career course.

Participants in this study noted that the perception of wilderness varied with an individual's experiences. Kliskey (1998) noted that "perceived wilderness environments can be explicitly related to different opportunity settings for different groups of recreationists" (p. 86). The development of wilderness policies for caves similar to those developed by the National Park Service should occur in other land management agencies. Such policies will be important in the development of management plans for wilderness caves, both in terms of wilderness recreational uses and in terms of scientific research.

In seeking to further cave and karst protection, community outreach by federal land management agencies can take several directions. One avenue is to work with state agencies 
toward the development of new or expansion of existing cave and karst protection legislation. The Virginia Cave Board is a state agency that conducts education and environmental projects in karst. They also participate in numerous outreach projects, working with the public, private organizations, and other state agencies. Assistance in development of state based cave stewardship boards similar to the Virginia Cave Board is another potential form of community outreach.

The establishment of cave stewardship-based partnerships with other government agencies, stakeholders in local communities, and caving based organizations may be essential in protecting caves and karst resources outside of federal lands. The Waitomo Landcare Group (New Zealand) is an example of a community-based partnership designed to protect the Waitomo Cave system through sustainable land management practices. Involvement of tourismbased industries resulted in promotion of cave and karst conservation principles through the tourism product delivery processes, exposing visitors to the activities and consequences of living in a karst environment.

In bringing together the various stakeholder groups, the community has been able to achieve both an environmental and economic longevity to the tourism destination. The investment has not been solely economic, but includes social and environmental motivations for belonging, based on shared values and mutual benefits (Pavlovich, 2001, p. 500).

In addition to protection cave and karst resources, participation in cooperative partnerships, such as Waitomo Landcare Group, offers opportunities towards overcoming obstacles (such as lack of trust) the exist between federal land agencies and local communities.

Focus groups' participants discussed the idea of a wilderness experience. In these discussions, the criteria of a sense of isolation as defined by a sense of remoteness and solitude, and a sense of self-sufficiency were important. Hollenhorst and Jones (2001) describe solitude as 
a psychological detachment from society, serving the functions of affirmation of individual will and self-determination, and cultivating the inner world of the self. They note that management for solitude needs to go beyond managing for limited encounters. Visitors' need for freedom and independence while protecting the ecological values of the wilderness resource must be respect. Understanding this aspect of solitude is important in developing cave stewardship plans that can provide opportunities for visitors with a variety of skill levels and agendas as well as protecting the variety of cave resources.

Ecosystem management of cave regions requires an understanding of how stakeholders value the landscape and cavescapes. This study showed that values vary for surface and subsurface environments. It will be important to engage stakeholders from both communities of place and interest in developing and implementing cave resources stewardship plans.

What is most important for the protection of cave and karst resources is not the actual legal designation of cave wilderness for it exists regardless of a national designation. What is most important is that we have the ability to protect cave wilderness, protection which comes with understanding the resource; if we cannot protect for such a wilderness how do we know that we are doing an adequate job protecting caves and karst at other levels and uses?

\section{Theoretical Implications}

This research is one of the first times that idea of a specific landform as wilderness has been explored. "Qualitative research examines phenomena through the eyes of the study participants" (Stein, Anderson, \& Kelly, 1999, p. 412). Using the input of stakeholders from community of place and community of interest initial criteria has been established for defining the intent of a cave wilderness designation. Legislative expectations were also explored. From 
these criteria, as well as wilderness readings and other resources, a definition for the concept of cave wilderness has been proposed. In defining the concept of cave wilderness, consideration was given to the physical conditions of the cave, its wilderness qualities, and the stewardship goals and objectives. This study has laid the foundation for the idea of cave wilderness and should aid in expanding the idea of wilderness.

A model describing the continuum of caves from its most pristine state to destroyed has been developed. The pristineness of a cave is the function of three elements: naturalness, wildness, and human perspective. In this conception, the pristineness of a cave decreases as naturalness and wildness decreases. Pristineness also decreases as knowledge and/or depth of view increases. This model is in accord with an ecosystem management approach. This model will be useful in establishing common ground during dialogues on cave wilderness and stewardship.

The cave continuum model expands upon the conceptual framework of wilderness. It has expanded upon the two-dimensional models proposed by first Woods (1997) and then Aplet, et. al. (1999). This new model includes the ideas of wildness and naturalness, and then adds a third element, the human dimension. This cave continuum model is based on the input from focus groups used in this study. Further study is indicated as such a model has important implications in the use of an ecosystem management approach for wilderness stewardship.

\section{Future Research}

In addition to research needs noted elsewhere in this chapter, there exist other areas for future research consideration. Suggested research needs are as follows: 
Although this research covered cave regions with differing speleogenesis, there are still other cave regions (other communities of place as relates to caves) having other speleogenesis mechanisms and/or differing cultural and economic concerns. Sites such as the Alaska's Tongass Forest caves with its timber based economy, Hawaii's lava caves with their archeological and anthropologic concerns, and Florida's submerged caves are excellent candidates for further investigation of the idea of cave wilderness. It is thought that additional research will identify additional issues that will need to be addressed from legislative and/or stewardship perspectives.

This study made use of stakeholders from both community of interest and community of place. However, there was a strong overlap of community of place and community of interest. While this may provide the study with participants whose perspectives come from both sides of the fence, it may not provide for a clear picture of community of place, particularly as pertains to meanings associated with place, that are not necessarily associated with caves. In addition, the Caving Event participants were selected specifically because of their experience levels. Their views may not be representative of the entire caving community. Of particular importance would be those who have not been involved in caving for an extended period. Also of interest would be those who consider themselves sport cavers and have little interest in participating in other speleo-related activities.

Once it appears that clear picture of cave wilderness and its associated issues has been developed, then it will be useful to test the definition and significance of issues with groups outside of cave regions (other communities of place). This should be done to determine the general population's level of interest in a potential cave wilderness designation. It would also provide an opportunity of determining the level of understanding and interest in cave 
stewardship. This would of value in determining the need for and type of education for communities outside of cave regions.

Another avenue for research would be to visit the idea of cave wilderness with other communities of interest (e.g. climbing, mountaineering and boating communities), to gain an understanding of their perspectives. This may be a necessary area of investigation. It is important to understand if and how non-traditional uses of caves will need to be further addressed in regards to cave stewardship, regardless of any potential cave wilderness designation issues.

This research indicates that meanings of place are separate for surface and subsurface environments. Further research is required as pertains to meanings of place with a focus on the caves themselves. Such understandings may help in discussion of cave stewardship particularly with an ecosystem perspective.

\section{Conclusion}

We, as a nation, have come a long way from considering caves as mere curiosities to recognizing them as critical components of an ecosystem, as well as being ecosystems in and of themselves. Such growth in understanding can be shown through Congressional legislation:

1.) Recognition of caves as national treasures with the establishment of National "Cave" Parks within the National Park System, beginning with Wind Cave National Park, in 1903.

2.) Recognition of caves as important ecological features that need to be documented and protected - Federal Cave Resources Protection Act, 1988.

3.) Recognition of a cave as deserving extraordinary protection measures Lechuguilla Cave Protection Act, 1993. 
4.) Recognition of need for research, education, and promotion of sustainable resource management practices for cave and karst resources - National Cave and Karst Research Institute Act, 1998.

Does this mean that we are ready to bestow upon caves the designation of wilderness, the highest honor our nation can bestow upon a habitat? Perhaps not, as there was a clear lack of support for the designation of cave wilderness by all focus groups involved in this research. Perhaps it was because of the lack of a definitive definition for cave wilderness and a clearly defined intent for legislative action. Without a clear definition and known intent, it is difficult, if not impossible, to address the reasons behind non-support for the establishment of a cave wilderness designation. This research has laid the groundwork for the defining the idea of cave wilderness (by any other name it will still be cave wilderness). Perhaps support will be forth coming. However, it is this researcher's firm belief that cave wilderness will never become a legal designation without the grass root support of the local communities. Similarities and differences among this study's focus groups highlight the critical need for the inclusion of stakeholders in the development of special designation legislation and associated stewardship practices for cave resources. Experiences, perceptions, and history all play a crucial role in how stakeholders approach the planning process.

Just as rivers flow through landscapes of varying ownership, so do caves. Establishment of cave wilderness may require the establishment of partnerships with private and state landowners. Partnerships may also be necessary with local communities as well as other organizations to achieve the goal of cave resources protection. Similar partnerships have been established via the Wild and Scenic River system and the National Trail System. 
If cave wilderness can only be established in conjunction with surface wilderness lands, it will negate the idea of caves being wilderness in and of themselves. It would regulate these caves to wilderness cave status and they will be managed as features of a Wilderness. Although this may not seem like a bad idea, such a requirement would allow significant caves to be placed at risk, simply because they do not reside beneath a designated Wilderness area. A cave with a wilderness designation, located beneath a Wilderness site, can be perceived as receiving double protection, just as Wild designated rivers receive double protection when they pass through Wilderness.

If cave wilderness is established with recreation as its primary focus, it will destroy the very thing that it is trying to protect. It may result in the non-designation of caves that are truly magnificent, but not resilient to the traffic that a recreational-based designation will attract. Would we then be creating a second-class wilderness designation, one based on robustness and not on significance? Such a designation would be untenable.

The idea of wilderness has changed throughout the history of the United States. Instead of lands to be conquered, wilderness now conjures images of wide-open spaces, of mountains, forests, and lakes. Caves are confined spaces of darkness, they lack the sweeping vistas of surface lands; they do not fit the traditional perception of (modern day) wilderness. The time has come to expand the concept of wilderness to include not only caves, but also, the idea that wilderness can be managed with an emphasis on science, education and exploration. The time has come for a Dark Wilderness.

We shall not cease from exploration And the end of all our exploring Will be to arrive where we started And know the place for the first time. Through the unknown, unremembered gate 
When the last of earth left to discover

Is that which was the beginning

T. S. Eliot, Little Gidding 


\section{REFERENCES}

Allison, D. (1999). Cavedweller. New York: Penguin Group.

Aplet, G. H. (1999). On the Nature of wildness: Exploring what wilderness really protects. Denver University Law Review, 76, 347-367.

Aplet, G., Thomson, J., \& Wilbert, M. (1999). Indicators of wildness: Using attributes of the land to assess the context of wilderness. The Wilderness Society. Retrieved June 18, 2000 from http://www.wilderness.net/pubs/science1999/Volume2/Aplet_2-12.pdf.

Baichtal, J. F. (1995). Evolution of karst management on the Ketchikan area of the Tongass National Forest: Development of an ecologically sound approach. In D. L. Pate (Ed.), Proceedings of the 1993 National Cave Management Symposium (pp. 190-202). Carlsbad, NM: National Cave Management Symposium Steering Committee.

Baichtal, J. F.; Swanston, D. N. \& Archie, A. (1996). An ecologically based approach to karst and cave resource management. In G. T. Rea (Ed.), Proceedings of the 1995 National Cave Management Symposium (pp. 10-27). Indianapolis, IN: Indiana Karst Conservancy, Inc.

Barr, N. (1998). Blind descent. New York: G. P. Putnam's Sons.

Baum, L. F. (1900/2003). The wonderful wizard of Oz.

Berger, A. W.; Overbaugh, W. L. \& Stankey, G. H. (1990). Extraction of nonrenewable resources form wilderness: A dilemma of scientific use. In D. W. Lime (Ed.), Managing America's enduring wilderness resource (pp. 292-298). St. Paul: Minnesota Extension Service \& Minnesota Agricultural Experiment Station of the University of Minnesota.

Bishop, P. D., Chertok, F. \& Jason, L. A. (1997). Measuring sense of community: Beyond local boundaries. Journal of Primary Prevention, 18, 193-312.

Bishop, R. B. (1983). Wilderness: Experience, definition, and management. An unpublished Master thesis, California State University - Fullerton.

Bishop, S. (1988). Cave wilderness: Who needs it? NSS News, 46, 433-434.

Bishop, S. G. \& Huppert, G. N. (1990). Taking wilderness underground. In D. W. Lime (Ed.), Managing America's enduring wilderness resource: A conference (pp. 367-370). St. Paul: Minnesota Extension Service \& Minnesota Agricultural Experiment Station of the University of Minnesota. 
Blackwell, B. A. \& Associates LTD (1995). Literature review of management of cave/karst resources in forest environments. Report submitted to the Regional Recreation Officer, Vancouver Forest Region, Nanaimo, BC.

Borden, J. D. \& Brucker, R. W. (2000). Beyond Mammoth Cave: A tale of obsession in the world's largest cave. Carbondale, IL: Southern Illinois Press.

Boston, P. J. (2001). Microbes, minerals, and Mars: The NASA-cave connection. NSS News, $59,70$.

Bournes, D. A. (2000). Concept inventing: A process for creating a unitary definition of having courage. Nursing Science Quarterly, 13, 143-149.

Bricker, K. S. \& Kerstetter, D. L. (2000). Level of specialization and place attachment: An exploratory study of whitewater recreationists. Leisure Sciences, 22, 233-257.

Brucker, R. (2001a). Speleology. Center for Cave and karst Studies, Western Kentucky University. June 17-23, 2001. Unpublished.

Brucker, R. (2001b) Personal Communication. June 20, 2001.

Brucker, R. W. \& Watson, R. A. (1987). The longest cave. Carbondale, IL: Southern Illinois University Press.

Bunting, B. W. (1999). The impacts of recreational caving on the physical environment of wild caves. Unpublished Master's thesis, University of Waikato, New Zealand.

Cahill, T. (1989). A wolverine is eating my leg. New York: Random House.

Cahill, T. (1991). Charting the splendors of Lechuguilla Cave. National Geographic, 179, 34-51.

Camacho, A. I. (1992). A classification of the aquatic and terrestrial subterranean environment and their associated fauna. In A. I. Camacho (Ed.), The Natural History of Biospeleology (pp. 57-103). Madrid: Impreso en Espana.

Cantrill, J. G. (1998). The environmental self and a sense of place: Communication foundations for regional ecosystem management. Journal of Applied Communication Research, 26, 301318.

Carey, M. A. \& Smith, M. W. (1994). Capturing the group effect in focus groups : A special concern in analysis. Qualitative Health Research, 4, 123-127.

Carpenter, B. \& Busch, L. (1993). Subterranean blues. U.S. News \& World Report, 115, 57-59.

Chapman, P. (1993). Caves and cave life. London: Harper Collins Publishers.

Chase, J. E. (1995). It's not all fun or other values to consider during cave management and use. In D. L. Pate (Ed.), Proceedings of the 1993 National Cave Management Symposium (pp. 229-232). Carlsbad, NM: National Cave Management Symposium Steering Committee. 
Conn, H. \& Conn, J. (1977). The Jewel Cave adventure: Fifty miles of discovery under South Dakota. Teaneck, NJ: Zephyrus Press.

Cook, B. \& Borrie, W. (1995). Trends in recreation use and management of wilderness. International Journal of Wilderness, 1. Retrieved March 4, 1999, from www.wilderness.net/ijw/articles/trends.cfm.

Cordell, H. K, McDonald, B., Briggs, J. A., Teasley, R. J., Biesterfeldt, J., \& Mou, S. H. (1997). Emerging markets for outdoor recreation in the United States. Based on the national survey on recreation and the environment. Retrieved September 1, 1999 from www.outdoorlink.com/infosource/nsre/index.htm.

Cordell, H. K., Teasley, J., Super, G., Bergstrom, J. C. \& McDonald, B. (1997). Outdoor recreation in the United States. Results from the national survey on recreation and the environment. Retrieved June 19, 2000 from http://www.fs.fed.us/research/rvur/recreation/publications/outdoor_recreation/tittle.htm.

Culver, D. C. (1986). Cave Faunas. In: Michael E. Soule (Ed.), Conservation biology: The science of scarcity and diversity (427-443). Sunderland, MA: Sinaeur Association, Inc., Publishers.

Culver, D. C. (1989). Cave Life. Evolution and ecology. Cambridge, MA: Harvard University Press.

Culver, D. C. \& Holsinger, J. R. (1992). How many species of troglobites are there? NSS Bulletin, 54, 79-80.

Cunningham, K. I. (1991). Organic and inorganic composition of colored corrosion residues Lechuguilla Cave, preliminary report. NSS News, 49, 252-254.

Curl, R. (1964). On the definition of a cave. Bulletin of the National Speleological Society, 2, 16.

Davidson, J. K. \& Bishop, W. P. (1971). Wilderness resources in Mammoth Cave. A regional approach. Columbus, OH: Cave Research Foundation.

Davis, E. \& Werner, M. (2002). Personal communication.

de Saussure, Raymond, 1962. Cave resources. In: Wilderness and recreation: a report on resources, values, and problems. ORRRC Report No. 3. Appendix B (pp. 322-324). Washington, D.C. Outdoor Recreation Resources Review Commission.

Eastern Wilderness Act of 1975. Public Law 93-622, 88 Stat. 2096; 16 U.S.C. 1132.

Ek, D. W. (2002). Caves and karst of the National Park Service. 2001 National cave and karst management symposium. 
Eliot, T. S. (1942/2003). The Little Gidding. Retrieved March 31, 2003 from http://www.columbiagrangers.org/grangers/index.jsp.

Emerson, R. W. (1876/2000). Illusions, from The conduct of life. Emerson's writings. Retrieved June 18, 2000 from http://www.jjnet.com/emerson/illusions.htm.

Federal Cave Resources Protection Act of 1988. Public Law 88-691, 16 U.S.C. 4301 et seq.; 102 Stat. 4546.

Fleitas, J. (1998). Spinning tales from the world wide web: Qualitative research in an electronic environment. Qualitative Health Research, 8, 283-292.

Ford, D. C. \& Williams, P. W. (1989). Karst geomorphology and hydrology. London: Unwin Hyman.

Freeman, R. R. (1984). Strategic management: A stakeholder approach. Boston: Pitman.

Friedberg, L. (Writer/Producer) \& Nye, B. (Editor) (1992). Mysteries Underground. [Video]. United States: National Geographic Society.

Frome, M. (1993). Wilderness preservation. Public support of wilderness values in science, wildlife and sacred space. A unified series of essays. Unpublished Doctoral dissertation, Union Institute.

Frome, M. (1997). Battle for the wilderness. Rev. ed. Salt Lake City: University of Utah Press.

Gamble, F. M. (1981). Disturbance of underground wilderness in karst caves. International Journal of Environmental Studies, 18, 33-39.

Ganter, J. H. (1990). Caves as unknown wilderness. In D. W. Lime (Ed.), Managing America's Enduring wilderness Resource: A conference (pp. 371-374). St. Paul: Minnesota Extension Service \& Minnesota Agricultural Experiment Station of the University of Minnesota.

Gibert, J. (1997). The importance of ecotones in karstlands. In I. D. Sasowsky, D. W. Fong \& E. L. White (Eds.), Conservation and Protection of the Biota of Karst (pp. 17-19). Charles Town, WV: Karst Waters Institute, Inc.

Gillieson, D. (1996). Caves: processes, development, and management. Oxford, UK: Blackwell Publishers Inc.

Glicksman, R. L. \& Coggins, G. C. (1999). Wilderness in context. Denver University Law Review. 76. Retrieved June 31, 2001 from LexisNexis Academic http://web.lexis-nexis.com.

Goodbar, J. R. (1982). Management techniques of wilderness caves. In R. C. Wilson \& J. J. Lewis (Eds.), National Cave Management Symposia Proceedings (pp. 196-198). Oregon City, OR: Pygmy Dwarf Press. 
Goodbar, J. (1999). Oil and gas drilling in cave and karst areas: A process of mitigating impacts. In R. R. Stitt (Ed.) Proceedings of the 1997 Karst and Cave Management Symposium (pp. 195-199). City, State: National Cave Management Symposium Steering Committee.

Graber, L. H. (1976). Wilderness as sacred space. Eighth in the Monograph Series. Washington, D.C.: Association of American Geographers.

Greider, T. \& Garkovich, L. (1994). Landscapes: The social construction of nature and the environment. Rural Sociology, 59, 1-24.

Griffis, R. B. \& Kimball, K. W. (1996). Ecosystem approaches to coastal and ocean stewardship. Ecological Applications, 6, 708-712.

Gulden, Bob, (2003a). NSS USA long cave list. Retrieved April 3, 2003 from www.pipeline.com/ caverbob/usalong.htm.

Gulden, Bob, (2003b). NSS world long cave list. Retrieved April 3, 2003 from www.pipeline.com/ caverbob/wlong.htm.

Gulden, B. (2003c). NSS world larges room list. Retrieved April 3, 2003 from www.pipeline.con/ caverbob/room.htm.

Gurnee, R. \& Gurnee, J. (1990). Gurnee guide to American caves. Closter, NJ: R. H. Gurnee, Inc.

Haas, G. E.; Herman, E. \& Walsh, R. (1986). Wilderness values. Natural Areas Journal, 6, 3743.

Halliday, W.R. (1993a). Cave wilderness designation in America: A new action proposal. In D. L. Foster, D. G. Foster, M. M. Snow, \& R. K. Snow (Eds.), National Cave Management Symposium Proceedings (pp. 289-291). Horse Cave, KY: The American Cave Conservation Association.

Halliday, W.R. (1993b). How (and why) to inventory cave wilderness values. NSS News, 51, 328-329.

Halliday, W. R. \& Stitt, R. R. (Eds.) (1996). Cave wilderness sourcebook. Unpublished manuscript prepared by the Wilderness Subcommittee of the Conservation Committee of the National Speleological Society. Huntsville, AL: National Speleological Society.

Hallikainen, V. (1995). The social wilderness in the minds and culture of the Finnish people. International Journal of Wilderness, 1, 35-40.

Heberlein, T. A. (1982). What people mean by wilderness: An exploratory look at word associations. In Franklin E. Boteler (Ed.). Wilderness psychology group, third annual conference proceedings, 1982. Morgantown: Division of Forestry, West Virginia University; Recreation Group, Society of American Foresters. 
Hendee, J. C. \& Dawson, C. P. (2002). Wilderness management. Stewardship and protection of resources and values. 3rd edition. Golden, CO: The WILD Foundation. Fulcrum Publishing.

Henderson, K. A. (1991). Dimensions of choice: A qualitative approach to recreation, parks and leisure research. State College, PA: Venture Publishing.

Hill, B. J. (1994). Concepts of wilderness valuation. Unpublished Doctoral dissertation, Clemson University.

Hollenhorst, S. J. \& Jones, C. D. (2001). Wilderness solitude: Beyond the social-spatial perspective. In W. A. Freimund \& D. N. Cole (Comps). Visitor use density and wilderness experience: Proceedings; 2000 June 1-3; Missoula, MT. Proc. RMRS-P-20 (pp. 56-61). Ogden, UT: U.S. Department of Agriculture, Forest Service, Rocky Mountain Research Station.

Hummel, J. B. (1982). Is the underground wilderness concept practical? In R. C. Wilson \& J. J. Lewis (Eds.), National Cave Management Symposia Proceedings (pp. 196-198). Oregon City, OR: Pygmy Dwarf Press.

Huppert, G. N. (1979). Cave conservation in the United States: A historical perspective and analysis. Unpublished Doctoral dissertation, University of Northern Colorado, Greeley.

Huppert, G. N. (1991). Cave wilderness: Why don't we have one? In: Proceedings of the 3rd Symposium on Social Science in Resource Management, 91-92. College Station: Texas A \& M University.

Huppert, G. N. (1993). Underground wilderness: The time is right. In D. L. Foster, D. G. Foster, M. M. Snow, \& R. K. Snow (Eds.), National Cave Management Symposium Proceedings (pp. 263-266). Horse Cave, KY: The American Cave Conservation Association.

Huppert, G. N. (1995). Legal protection for caves in the United States. Environmental Geology, $26,121-123$.

Huppert, G. N. (1999). State cave protection laws. Where next? NSS News, 57, 103-104.

Huppert, G. N. \& Wheeler, B. J. (1982). State legislation concerning the protection of caves. In R. C. Wilson \& J. J. Lewis (Eds.), National Cave Management Symposia Proceedings, (pp. 45-47). Oregon City, OR: Pygmy Dwarf Press.

Huppert, G. N. \& Wheeler, B. J. (1992). The case for underground wilderness. In: E. E. Krumpe \& P. D. Weingart (Eds.). Proceedings of the symposium on Designation and Management of Park and Wilderness Reserves. 4th World Wilderness Congress. Boise: International Wilderness Leadership Foundation and the Department of Resource Recreation and Tourism, College of Forestry, Wildlife and Range Sciences, University of Idaho.

Jacobson, S. K. \& McDuff, M. D. (1998). Training idiot savants: The lack of human dimensions in conservation biology. Conservation Biology, 12, 263-267. 
Jennings, J. N. (1971). Karst. Vol. 7, An Introduction to Systematic Geomorphology. Cambridge, MA: The M.I.T. Press.

Jensen, E. E. (1991). A cave management strategy for Alberta. Unpublished master's thesis, University of Calgary.

Juberthie, C. (2000). The diversity of the karstic and pseudokarstic hypogean habitats in the world. In H. Wilkens, D. C. Culver \& W. F. Humphreys (Eds.), Ecosystems of the World 30, Subterranean Ecosystems (pp. 17-39). New York: Elsevier.

Kerbo, R. (1988). Cave wilderness at Carlsbad Caverns National Park. NSS News, 46, 432-433.

Kerbo, R. C. (1997). Speleology and the National Park Service. NSS News, 55, 102-103.

Kerbo, R., (2000). Cave laws. Retrieved January 26, 2000 from the NSS Discussion Board.

Kerbo, R. \& Roth, J., (1989). Lechuguilla Cave on the edge of wilderness. In G. N. Huppert \& D. R. McClurg (Eds.), 1987 Cave Management Symposium (pp. 56-62). Huntsville, AL: National Speleological Society.

Kiernan, Kevin (1997). Scientific research in karst: environmental impacts. In Cave and karst management in Australasia 11. Proceedings of the eleventh Australasian conference on cave and karst management (pp. 222-233). Australia: Australasian Cave and Karst Management Association \& Parks and Wildlife Service, Tasmania.

Klimchouk, A. B. \& Ford, D. C. (2000). Types of karst and evolution of hydrogeologic setting. In: A. B. Klimchouk, D. C. Ford, A. N., Palmer \& W. Dreybrodt (Eds.), Speleogenesis. Evolution of Karst Aquifers (pp. 45-53). Huntsville, AL: National Speleological Society.

Klimchouk, A. B.; Ford, D, C.; Palmer, A. N. \& Dreybrodt, W. (2000). Introduction. In: A. B. Klimchouk, D. C. Ford, A. N., Palmer \& W. Dreybrodt (Eds.), Speleogenesis. Evolution of Karst Aquifers (pp. 14-19). Huntsville, AL: National Speleological Society.

Kliskey, A. D. (1998). Linking the wilderness perception mapping concept to the recreation opportunity spectrum. Environmental Management, 22,79-88.

Knutson, S. (1994). American Caving Accidents, NSS News, 52, 376.

Krueger, R. A. (1994). Focus groups: A practical guide for applied research (2nd ed). Thousand Oaks, CA: Sage.

Krueger, R. A., 1995. The future of focus groups. Qualitative Health Research, 5, 524-530.

LaMoreaux, P.; Powell, W. J., \& LeGrand, H. E. (1997). Environmental and legal aspects of karst areas. Environmental Geology, 29, 23-32.

Lawrence, J. \& Brucker, R. W. (1975) The caves beyond: The story of the Floyd Collins' Crystal Cave exploration. New York: Funk \& Wagnalls Company. 
Lechuguilla Cave Protection Act of 1993. Public Law 103-169, 103rd Congress, S. 1, December 2, 1993

Lee, W. T. (1924). Recent explorations of a limestone cave in the Guadalupe Mountains of New Mexico reveal a natural wonder of the first magnitude. National Geographic, 45, 1-40.

Lee, W. T. (1925). New discoveries in Carlsbad Cavern. Vast subterranean chambers with spectacular decorations are explored, surveyed, and photographed. National Geographic, 48, 301-319.

Lera, T. (2003). Legal protection for caves and bats at the turn of the millennium. Retrieved March 23, 2003 from http://www.caves.org/section/ccms/bat2k/index.htm.

Lewis, C. S. D. (1995). Sustainable tourism. A case study of Waitomo Caves. Unpublished master thesis. University of Waikato, New Zealand.

Lewis, S. W. \& Baichtal, J. F. (1997). Protecting caves, karst, and bats in the Tongass National Forest, Southeast Alaska. In D. Sasowsky, D. W. Fong \& E. L. White (Eds.), Conservation and Protection of the Biota of Karst, Special Publication 3 (pp. 42- 46). Charles Town, WV: Karst Waters Institute.

Lutz, A. R.; Simpson-Housley, P. \& DeMan, A, F. (1999). Wilderness. Rural and urban attitudes and perceptions. Environment and Behavior, 31, 259-266.

MacGillivray, G., Lorimore, A. \& Judson, S. (Producers), Stephens, J. (Writer) (2001). Journey into amazing caves. [Motion Picture], United States: MacGillivray-Freeman Films.

Maser, C.; Rodiek, J. E. \& Ward, J. W. (1979). Cliffs, talus and caves. In: Thomas, J. C. (Ed.), Wildlife habitats in managed forests: The Blue Mountains of Oregon and Washington. Agriculture Handbook No. 553, (pp. 96-103). Washington D.C.: USDA Forest Service.

McClurg, D. (1988). Reasons why cavers should support wilderness for Lechuguilla Cave. What you can do to help protect Lechuguilla Cave. NSS News, 46, 435- 415.

McDonald, W. J. (1993). Focus group research dynamics and reporting: an examination of research objectives and moderator influences. Journal of the Academy of Marketing Science, 21, 161-168.

Meleis, A. I. (1985). Theoretical nursing. Philadelphia: J. B. Lippincott.

Miles, M. B. \& Huberman, A. M. (1994). Qualitative data analysis: A sourcebook of new methods. Thousand Oaks, California: Sage.

Millar, I. R. (1994). Aurora Cave and Mount Luxmore Caves: Cave management issues. Unpublished report to Te Anau Field Center. Nelson, New Zealand: Department of Conservation. 
Miller, L. (1990). The underground conflict: Should caves be designated as wilderness? Brigham Young University Journal of Public Law, 4, 133-156.

Morgan, D. L. (1988). Focus groups as qualitative research. Newbury Park, CA: Sage.

Morgan, D. L. (1993). Qualitative content analysis: A guide to paths not taken. Qualitative Health Research, 3, 112-121.

Mullins, L. H. (1993). Cave management by prescription an alternative to classification systems. In D. L. Foster (Ed.), 1991 National Cave Management Symposium Proceedings (pp. 267274). Horse Cave, KY: American Cave Conservation Association, Inc.

Murphy, A. P. (1996). The meaning of wilderness. An unpublished doctoral dissertation. Ohio State University.

Nash R. (1982). Wilderness and the American mind. 3rd Rev. ed. New Haven, CT: Yale University Press.

National Cave and Karst Research Institute Act (1998). Public Law 105 - 325, 112 Stat. 3038; 16 U.S.C. 4310.

National Park Service (1974). Draft environmental statement for the master plan and wilderness study for Mammoth Cave National Park released on 24 April 1974

National Speleological Society (1967). A wilderness proposal for Mammoth Cave National Park.

National Speleological Society (1993). Project underground. Huntsville, AL: National Speleological Society.

Nieland, J. (1992). Inventory, evaluation, and management of publicly owned caves in the Western United States and the impact of the Federal Cave Resources Protection Act. In G. T. Rea (Ed.), 6th International Symposium on Vulcanospeleology (pp. 273-279). Huntsville, AL: National Speleological Society, Alabama.

Northup, D, Angert, E., Reysenbach, A., Peck, A., \& Pace, N. (1997). Microbial communities in Sulphur River, Parker Cave: A molecular phylogenetic study. In D. Sasowsky, D. W. Fong \& E. L. White (Eds.), Conservation and Protection of the Biota of Karst, Special Publication 3 (pp. 55-56). Charles Town, WV: Karst Waters Institute.

Northup, D. E., Carr, D L., Crocker, M. T., Hawkins, L. K., Leonard, P., \& Calvin) (1992). Lechuguilla Cave Biological Inventory. Unpublished Report for Carlsbad Caverns National Park, Purchase Order No. PX7170-0-0405

Oelschlaeger, M. (1991). The idea of wilderness. New Haven, CT: Yale University Press.

Outdoor Recreation Resources Review Commission (1962). Study Report No. 3, Wilderness and recreation - A report on resources, values, and problems. Washington DC: [U.S. Government Printing Office]. 
Palmer, A. (1999). Karst geology. Center for Cave and Karst Studies, Western Kentucky University. June 6-12, 1999. Unpublished.

Parse, R. R. (1997). Concept inventing: Unitary creations. Nursing Science Quarterly, 10, 63-64.

Pavlovich, K. (2001). The twin landscapes of Waitomo: Tourism network and sustainability through the landcare group. Journal of Sustainable Tourism, 9, 491-504.

Peck, S. B. (1997). Origin and diversity of the North American cave fauna. In D. Sasowsky, D. W. Fong \& E. L. White (Eds.), Conservation and Protection of the Biota of Karst, Special Publication 3 (pp. 60-66). Charles Town, WV: Karst Waters Institute.

Pickles, J. (1983). Phenomenology, Science and Geography. Cambridge: Cambridge University Press.

Rauch, H. (1999). Karst Geology, Geo. 366. West Virginia University. Fall, 1999. Unpublished.

Rauch, H. (2003). Personal Email communication on March, 27, 2003.

Reams, S; Fish, L.; Burger, P. \& Kambesis, P. (1999). Deep Secrets: The discovery and exploration of Lechuguilla Cave. St. Louis, MO: Cave Books.

Rodgers B. L. \& Knafl, K. A. (1993). Concept development in nursing, foundations, techniques, and applications. Philadelphia: W. B. Saunders Company.

Rolston, H. III (1989). Philosophy gone wild. NY: Prometheus Books.

Sagoff, M. (1992). Settling America or the concept of place in environmental ethics. Journal of Energy, Natural Resources and Environment, 12, 349-418.

Saugey, D. A., Heidt, G. A., \& Heath, D. R. (1988). Utilization of abandoned mine drifts and fracture caves by bats and salamanders: Unique subterranean habitat in the Ouachita Mountains. Presented at the Management of Amphibians, Reptiles and Small Mammals in North America Symposium, Flagstaff, AZ.

Saulnier, C. F. (2000). Groups as data collection method and data analysis technique. Multiple perspectives on urban social work education. Small Group Research, 31, 607-627.

Selin, S. W.; Schuett, M. A. \& Carr, D. S. (1997). Has collaborative planning taken root in the national forests? Journal of Forestry, 95, 25-28.

Shafer, C. S. \& Inglis, G. J. (2000). Influence of social, biophysical, and managerial conditions on tourism experiences within the Great Barrier Reef World Heritage Area. Environmental Management, 25, 73-87.

Shaw, T. R. (1992). History of Cave Science. The exploration and study of limestone caves, to 1900. Sydney: The Sydney Speleological Society. 
Shea, P. A. (1999). Wilderness Act of 1964: Reflections, applications, and prediction: Content: Foreword. Denver University Law Review, 76. 331.

Shin, S. S. \& Jaakson, R. (1997). Wilderness quality and visitors' wilderness attitudes: Management implications. Environmental Management, 21, 225-232.

Smith, P.M. (1981). The Flint Ridge Cave System: A wilderness opportunity. A Cave Research Foundation Report (May, 1961) In: R. A. Watson (Ed), The Cave Research Foundation origins and the first twelve years 1957-1968 (pp. 157-169). Mammoth Cave, KY: The Cave Research Foundation.

Smith, R. (1988). Cave wilderness and Lechuguilla. A park service viewpoint. NSS News, 46, 431-432.

Stein, T. V.; Anderson, D. H. \& Kelly, T. (1999). Using stakeholders' values to apply ecosystem management in an Upper Midwest landscape. Environmental Management, 24, 399-413.

Stitt, R. R. (1976a). State cave protection laws and their enforcement. In National Cave Management Symposium Proceedings (pp. 91-97). Albuquerque, NM: Speleobooks.

Stitt, R. R. (1976b). Wilderness cave management. In National Cave Management Symposium Proceedings (pp. 53-56). Albuquerque, NM: Speleobooks.

Stitt, R. (1977). Human impact on caves. In T. Aley \& D. Rhodes (Eds.), National Cave Management Symposium Proceedings (pp. 35-43). Albuquerque, NM: Speleobooks.

Stitt, R. R. (1982a). An overview of cave management. In R. C. Wilson \& J. J. Lewis (Eds.), National Cave Management Symposia Proceedings (pp. 53-54). Oregon City, OR: Pygmy Dwarf Press.

Stitt, R. R., (1982b). Underground wilderness. In R. C. Wilson \& Lewis, J. J. (Eds.), National Cave Management Symposia Proceedings (pp. 201-203). Oregon City, OR: Pygmy Dwarf Press.

Stitt, R. R. (1983). Cave conservation in the United States of America an overview in 1981. In J. E. Mylroie (Ed.), Eighth International Congress of Speleology, First International Cave Management Symposium Proceedings (pp. 115-121). Murray, KY: Murray State University.

Stitt, R. R. (1985). Overview of conservation and management. In H. Thornton \& J. Thornton (Eds.), National Cave Management Symposia Proceedings, (pp. 15-17). Richmond VA: The American Cave Conservation Association.

Stitt, R. R. (1991). Underground Wilderness and the NSS. NSS News, 49, 26.

Stitt, R. R. (1993). Legal brief. In D. L. Foster, D. G. Foster, M. M. Snow, \& R. K. Snow (Eds.), National Cave Management Symposium Proceedings (pp. 275 - 288). Horse Cave, KY: The American Cave Conservation Association. 
Stitt, R. R. \& Bishop, W. P. (1972). Underground wilderness in the Guadalupe Escarpment. A concept applied. Bulletin of the National Speleological Society, 34, 77-88.

Stokes, T. R. \& Griffiths, P. (2000). A preliminary discussion of karst inventory systems and principles (KISP) for British Columbia. Working Paper 51. Victoria, B.C.: Resources Board, B.C. Ministry of Forests.

Sullivan, N. (1985). Cave management - an overview. In J. E. Vandike (Ed.), Missouri Speleology (pp. 231-236). Rolla, MI Speleological Survey.

Sutter, Paul S. (2002). Driven wild. How the fight against automobiles launched the modern wilderness movement. Seattle: University of Washington Press.

Sweeting, M. M. (1973). Karst Landforms. London: The MacMillan Press.

Taylor, M. R. (1996). Dark Passages. New York: Scribner.

Tousley, R. S. (1976). National Park System objectives and philosophies of cave management. In: National Cave Management Symposium Proceedings (pp. 142-143). Albuquerque, NM: Speleobooks.

Twain, M. (1876/1998). The adventures of Tom Sawyer. Barnes \& Noble Publishing

U.S. Census Bureau (1999). Statistical abstract of the United States. Austin, TX: Hoover's Business Press.

U.S. Census Bureau (2003a). April 5, 2003 from quickfacts.census.gov/qfd/states/21000.html.

U.S. Census Bureau (2003b). April 5, 2003 from quickfacts.census.gov/qfd/states/35000.html

Viles, H. A. (1984) Biokarst: Review and prospect. Progress in Physical Geography, 8, 523-542.

Warren, R. P. (1959). The cave. Random House Trade.

Watson, J. (1979). Nursing: The philosophy and science of caring. Boston: Little, Brown.

Watson, J., Hamilton-Smith, E., Gillieson, D., \& Kiernan K. (Eds.), (1997). Guidelines for cave and karst protection. Cambridge, UK: International Union for Conservation of Nature and Natural Resources.

Watson, R. A. (1966). Notes on the philosophy of caving. NSS News, 24, 54-58.

Watson, R. A. (1976). The adventure of the cave. Washington University Magazine, 47, 9-13.

Watson, R. A. \& Smith, P. M. (1971). Underground wilderness. A point of view. International Journal of Environmental Studies, 2, 217-220. 
Webb, R. (1997). Cave management prescriptions - An alternative to cave classification systems. In: Kent Henderson (ed.) Cave management in Australasia 13. Victoria, Australia: The Australasian Cave and Karst Management Association.

White, W. B. (1988). Geomorphology and Hydrology of Karst Terrains. New York: Oxford University Press.

White W. B. (2000). Development of speleogenetic ideas in the 20th century: The modern period, 1957 to the present. In A. B. Klimchouk, D. C. Ford, A. N. Palmer, \& W. Dreybrodt (Eds.), Speleogenesis: Evolution of Karst Aquifers (pp. 39-43). Huntsville, AL: The National Speleological Society.

Wilde, K. A. (1981). Caves. The Cave and karst resources of New Zealand. Unpublished Bachelor thesis. Lincoln College, New Zealand.

Wilderness Act of 1964. Public Law 88-577, 78 Stat. 890; 16 U.S.C. 1121 (note, 1131-36).

Wild and Scenic Rivers Act of 1968. Public Law 90-542, as amended, 16 U.S.C. 1271-1287.

Williams, P. W. (1993). Environmental change and human impact on karst terrains: An introduction. In P. Williams (ed.) Karst Terrains: Environmental Changes and Human Impact (pp. 1-20). Cremlingen-Destedt, Germany: Catena-Verlag.

Williams, D. R. \& Patterson, M. E. (1999). Environmental psychology: Mapping landscape meanings for ecosystem management. In H. K. Cordell \& J. C. Bergstrom (Eds.), Integrating Social Sciences with Ecosystem Management Human dimensions in assessment, policy, and management. (pp. 141-160). Beverly Hills, CA: Sagemore Publishing.

Wilson, J. (2002). Personal communication. Summer 2002.

Winter, P. L., Palucki, L. J. \& Burkhardt, R. L. (1999). Anticipated responses to a fee program: The key is trust. Journal of Leisure, 31, 207-226.

Wood, M. (1983). Cave Wilderness. The reconciliation of conservation and use. Lincoln College, New Zealand. Unpublished Bachelor's thesis.

Woods, M. (1997). Rethinking wilderness. Unpublished doctoral dissertation. University of Colorado, Boulder.

Worboys, G., Davey, A. \& Stitt, C. (1982). Report on cave classification. In: Cave Management in Australia IV, (pp. 11-18). NSW, Australia: Australian Speleological Federation.

Zuber, R. E. (1977). A compendium of components relevant to cave resource management. Unpublished master's thesis. University of Wisconsin - Madison. 


\section{APPENDIX A}

\section{STATE CAVE RESOURCES PROTECTION ACTS}

\begin{tabular}{|c|c|c|c|c|c|c|c|c|c|c|}
\hline \multicolumn{11}{|c|}{ United States Cave Resources Protection Acts By State } \\
\hline & \multicolumn{7}{|c|}{ Protection Features } & & \multirow[b]{2}{*}{$\begin{array}{l}\text { Specifically } \\
\text { Recognizes } \\
\text { Values }\end{array}$} & \multirow[b]{2}{*}{ Comments } \\
\hline State and Citation & 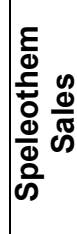 & 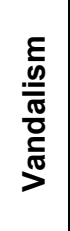 & 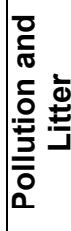 & 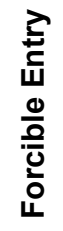 &  & $\begin{array}{l}\frac{\pi}{0} \\
\frac{0}{0} \\
\frac{\xi}{\pi} \\
\frac{\pi}{1}\end{array}$ & 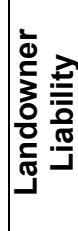 & Penalties & & \\
\hline $\begin{array}{l}\text { ALABAMA } \\
1988 \\
\text { Code of Alabama } \\
9-19-1 \text { to } 9-19-5\end{array}$ & $\stackrel{\infty}{\nu}$ & $\stackrel{\infty}{\circlearrowright}$ & $\stackrel{\infty}{\stackrel{\infty}{\succ}}$ & $\stackrel{\infty}{\nu}$ & 운 & $\stackrel{\infty}{\stackrel{\infty}{\succ}}$ & 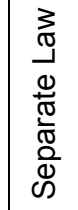 & $\begin{array}{l}\$ 250- \\
\$ 2,000\end{array}$ & & $\begin{array}{l}\text { Addresses liability of } \\
\text { Individuals and groups } \\
\text { during in cave activities } \\
\text { Addresses groundwater } \\
\text { pollution. }\end{array}$ \\
\hline $\begin{array}{l}\text { ARIZONA } \\
\text { ARS 13-3702 } \\
1978\end{array}$ & $\frac{0}{z}$ & $\stackrel{\infty}{\infty}$ & 운 & $\stackrel{\infty}{\infty}$ & 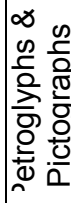 & $\frac{\pi}{0}$ & $\stackrel{\circ}{z}$ & $\begin{array}{l}\$ 750 \\
\text { minimum }\end{array}$ & & \\
\hline $\begin{array}{l}\text { ARKANSAS } \\
\text { ACA 15-20-601 } \\
1989, \text { No. } 523\end{array}$ & $\frac{0}{z}$ & $\stackrel{\infty}{>}$ & $\stackrel{\infty}{\nu}$ & $\stackrel{\infty}{\nu}$ & $\stackrel{\infty}{>}$ & 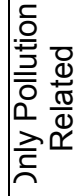 & $\overbrace{}^{\infty}$ & $\begin{array}{c}\$ 500 \\
\text { maximum }\end{array}$ & $\begin{array}{l}\text { Cultural and } \\
\text { Natural } \\
\text { Resources }\end{array}$ & $\begin{array}{l}\text { Addresses potential of } \\
\text { conservation agreement } \\
\text { with Natural Heritage } \\
\text { Commission. }\end{array}$ \\
\hline $\begin{array}{l}\text { CALIFORNIA } \\
\text { CPA 623 } \\
1976,1977,1983\end{array}$ & $\stackrel{\circ}{z}$ & $\stackrel{\infty}{>}$ & $\stackrel{\infty}{>}$ & $\stackrel{\infty}{\nu}$ & $\stackrel{\mathscr{d}}{>}$ & $\stackrel{\infty}{>}$ & $\stackrel{\circ}{z}$ & $\begin{array}{c}\$ 1,000 \\
\text { and/or } \\
1 \text { year } \\
\text { maximum }\end{array}$ & & \\
\hline $\begin{array}{l}\text { COLORADO } \\
\text { CRS } 1963 \\
\text { Article } 1840-18-14 \\
1883\end{array}$ & & & & V & & & 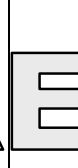 & & $\square$ & $\begin{array}{l}\text { (c) must be posted at } \\
\text { e entrance to be } \\
\text { ective. }\end{array}$ \\
\hline $\begin{array}{l}\text { FLORIDA } \\
\text { Fla. Stat. } 810.13 \\
1973,1980\end{array}$ & $\stackrel{\mathscr{D}}{\succ}$ & $\stackrel{\infty}{>}$ & $\stackrel{\infty}{\nu}$ & $\stackrel{\infty}{\nu}$ & $\stackrel{\circ}{z}$ & $\stackrel{\infty}{>}$ & $\stackrel{\circ}{z}$ & $\$ 1,000$ & & $\begin{array}{l}\text { Address groundwater } \\
\text { pollution. }\end{array}$ \\
\hline
\end{tabular}




\begin{tabular}{|c|c|c|c|c|c|c|c|c|c|c|}
\hline \multicolumn{11}{|c|}{ United States Cave Resources Protection Acts By State } \\
\hline & \multicolumn{7}{|c|}{ Protection Features } & & & \\
\hline State and Citation & 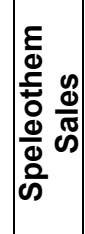 & 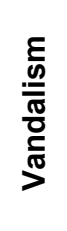 & 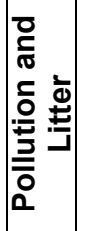 & $\begin{array}{l}\stackrel{P}{\vec{L}} \\
\text { W } \\
\frac{0}{0} \\
\frac{0}{0} \\
\frac{0}{0}\end{array}$ & 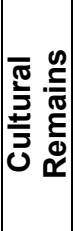 & $\begin{array}{l}\frac{\pi}{0} \\
\frac{0}{0} \\
\frac{E}{\pi} \\
\frac{\pi}{1}\end{array}$ &  & Penalties & $\begin{array}{l}\text { Specifically } \\
\text { Recognizes } \\
\text { Values }\end{array}$ & Comments \\
\hline $\begin{array}{l}\text { GEORGIA } \\
\text { OCGA 12-4-140 } \\
\text { To 12-4-147 } \\
1977,1986,1992\end{array}$ & $\stackrel{\infty}{\stackrel{\infty}{\succ}}$ & $\stackrel{\infty}{\circlearrowright}$ & $\stackrel{\infty}{\succ}$ & $\stackrel{\infty}{\nu}$ & $\stackrel{\circ}{z}$ & $\stackrel{\infty}{>}$ & $\stackrel{\infty}{>}$ & $\begin{array}{l}\$ 50-\$ 1,000 \\
\text { and } 1 \text { year } \\
\text { maximum }\end{array}$ & $\begin{array}{c}\text { Natural } \\
\text { Resources }\end{array}$ & \\
\hline $\begin{array}{l}\text { HAWAll } \\
\text { HRS 6D-1 to 6D-13 } \\
2002\end{array}$ & $\stackrel{\infty}{\stackrel{\infty}{\succ}}$ & $\stackrel{\infty}{\stackrel{\infty}{\succ}}$ & $\stackrel{\infty}{\succ}$ & $\stackrel{\infty}{\nu}$ & $\stackrel{\mathscr{D}}{\succ}$ & $\stackrel{\infty}{\circlearrowright}$ & $\stackrel{\mathscr{D}}{>}$ & $\begin{array}{l}\$ 1,000- \\
\$ 1,500 \\
\text { allows both } \\
\text { civil and } \\
\text { criminal } \\
\text { actions }\end{array}$ & & $\begin{array}{l}\text { Access requires } \\
\text { owner's prior written } \\
\text { consent. } \\
\text { Government } \\
\text { confidentiality of cave } \\
\text { information }\end{array}$ \\
\hline $\begin{array}{l}\text { IDAHO } \\
\text { I.C. } 18-7035 \\
1982\end{array}$ & 인 & $\stackrel{\infty}{\succ}$ & $\stackrel{\mathscr{D}}{\succ}$ & $\stackrel{\infty}{\nu}$ & $\stackrel{\mathscr{D}}{>}$ & $\stackrel{\infty}{\nu}$ & 우 & $\begin{array}{l}\$ 300 \text { and } / o r \\
1 \text { months } \\
\text { maximum }\end{array}$ & & \\
\hline $\begin{array}{l}\text { ILLINOIS } \\
525 \text { ILCS } 5 / 1 \text { et. Seg. } \\
1971,1972,1985\end{array}$ & $\frac{0}{2}$ & $\stackrel{\infty}{\nu}$ & $\stackrel{\infty}{>}$ & $\stackrel{\infty}{\varnothing}$ & $\stackrel{\mathscr{D}}{\succ}$ & $\stackrel{\infty}{>}$ & $\stackrel{\infty}{>}$ & $\$ 2,500$ & & $\begin{array}{l}\text { Addresses potential to } \\
\text { create state based cave } \\
\text { resources protection } \\
\text { and management } \\
\text { program. }\end{array}$ \\
\hline $\begin{array}{l}\text { INDIANA } \\
\text { BICA 35-43-1-3 } \\
\text { PL 177-1983 } \\
1983\end{array}$ & 요 & $\stackrel{\infty}{\succ}$ & $\stackrel{\infty}{\stackrel{\infty}{\infty}}$ & $\stackrel{\infty}{\nu}$ & $\stackrel{\infty}{\succ}$ & $\stackrel{\infty}{\succ}$ & 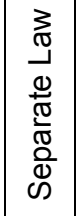 & $\begin{array}{l}\$ 250- \\
\$ 2,500\end{array}$ & & \\
\hline $\begin{array}{l}\text { KENTUCKY } \\
\text { KRS } 433.870 \text { to } .885 \\
1948,1988\end{array}$ & $\stackrel{\infty}{\stackrel{\infty}{\succ}}$ & $\stackrel{\infty}{\nu}$ & $\stackrel{\infty}{>}$ & $\stackrel{\infty}{\varnothing}$ & $\stackrel{\mathscr{D}}{\succ}$ & $\stackrel{\infty}{\succ}$ & $\stackrel{\mathscr{D}}{\succ}$ & $\$ 250-\$ 500$ & & $\begin{array}{l}\text { Addresses obstruction } \\
\text { of movement of air or } \\
\text { animals into/through } \\
\text { cave. } \\
\text { Excavation or removal } \\
\text { of cultural resources } \\
\text { requires permit. }\end{array}$ \\
\hline $\begin{array}{l}\text { LOUISIANA } \\
\text { LRS. } 1977 \\
\text { Title } 41-13-1601 \\
1970\end{array}$ & & & & $V$ & & & ㅁ & & 5 & $\begin{array}{l}\text { A plies to caves on } \\
\text { lic land. }\end{array}$ \\
\hline
\end{tabular}




\begin{tabular}{|c|c|c|c|c|c|c|c|c|c|c|}
\hline \multicolumn{11}{|c|}{ United States Cave Resources Protection Acts By State } \\
\hline & \multicolumn{7}{|c|}{ Protection Features } & \multirow[b]{2}{*}{ Penalties } & \multirow[b]{2}{*}{$\begin{array}{l}\text { Specifically } \\
\text { Recognizes } \\
\text { Values }\end{array}$} & \multirow[b]{2}{*}{ Comments } \\
\hline State and Citation & 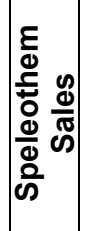 & 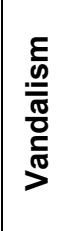 & 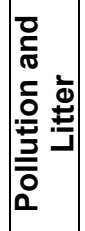 & 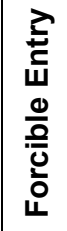 & 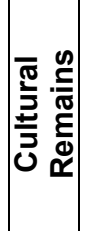 & $\begin{array}{c}\frac{\pi}{0} \\
\frac{0}{0} \\
\varepsilon \\
\frac{\pi}{\pi} \\
\frac{\pi}{1}\end{array}$ & 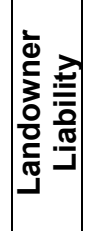 & & & \\
\hline $\begin{array}{l}\text { MAINE } \\
12 \text { MRS 544-I to N } \\
2001\end{array}$ & i & $\stackrel{\infty}{\stackrel{\nu}{\succ}}$ & $\stackrel{\infty}{\stackrel{\infty}{\infty}}$ & $\stackrel{\infty}{\infty}$ & 㝏 & $\stackrel{\infty}{\infty}$ & $\stackrel{\infty}{\stackrel{\infty}{\nu}}$ & $\begin{array}{c}\$ 1,000 \text { and } 6 \\
\text { months } \\
\text { maximum }\end{array}$ & $\begin{array}{l}\text { Historical } \\
\text { Scientific }\end{array}$ & $\begin{array}{l}\text { All field investigations, } \\
\text { explorations, \& recovery } \\
\text { operations must ensure } \\
\text { that the ability to } \\
\text { recover \& preserve } \\
\text { cultural, scientific, \& } \\
\text { education information is } \\
\text { not impeded. }\end{array}$ \\
\hline $\begin{array}{l}\text { MARYLAND } \\
\text { MNRCA 5-14 } \\
5-1401 \text { to } 5-1406 \\
1978\end{array}$ & $\stackrel{\infty}{\rightleftharpoons}$ & $\stackrel{\mathscr{D}}{\nu}$ & $\stackrel{\infty}{\rightleftharpoons}$ & $\stackrel{\infty}{\stackrel{\infty}{\nu}}$ & $\stackrel{\infty}{\rightleftharpoons}$ & $\stackrel{\mathscr{D}}{\nu}$ & $\stackrel{\mathscr{D}}{\check{\nu}}$ & $\begin{array}{l}\$ 500 \text { and } / \text { or } \\
6 \text { months } \\
\text { maximum per } \\
\text { section } \\
\text { violation }\end{array}$ & & $\begin{array}{l}\text { Gates must allow free } \\
\text { and unimpeded access } \\
\text { to bats, insects, aquatic } \\
\text { fauna, water, and air. } \\
\text { Excavation or removal } \\
\text { of cultural resources } \\
\text { requires permit. }\end{array}$ \\
\hline $\begin{array}{l}\text { MISSOURI } \\
578.200 \text { R.S.Mo } \\
578.200 \text { to } 578.225 \\
\text { L. } 1980 \text { H.B. } 1192 \\
1980\end{array}$ & 우 & $\stackrel{\infty}{\succ}$ & 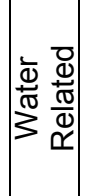 & $\stackrel{\infty}{\succ}$ & 우 & 우 & 2 & $\$ 1,000$ & & $\begin{array}{l}\text { Specifically addresses } \\
\text { clean water regulations } \\
\text { and laws }\end{array}$ \\
\hline $\begin{array}{l}\text { MONTANA } \\
\text { MCA 23-2-901 to } 908 \\
1993\end{array}$ & $\stackrel{\infty}{\rightleftharpoons}$ & $\stackrel{\infty}{\stackrel{\infty}{\succ}}$ & $\stackrel{\infty}{\rightleftharpoons}$ & $\stackrel{\infty}{\infty}$ & 高 & $\stackrel{\infty}{\stackrel{\infty}{\succ}}$ & $\stackrel{\mathscr{D}}{\succ}$ & $\begin{array}{c}\$ 500- \\
\$ 2,000 \\
\text { and/or } 60 \\
\text { maximum }\end{array}$ & & \\
\hline $\begin{array}{l}\text { NEW MEXICO } \\
\text { NMSA 30-15-5 } \\
1981\end{array}$ & 우 & $\stackrel{\infty}{\longleftarrow}$ & $\stackrel{\mathscr{D}}{\succ}$ & $\stackrel{\infty}{\infty}$ & $\stackrel{\infty}{\rightleftharpoons}$ & $\stackrel{\infty}{>}$ & 우 & $\begin{array}{c}\$ 1,000 \text { and } 6 \\
\text { months } \\
\text { maximum }\end{array}$ & & \\
\hline $\begin{array}{l}\text { NORTH CAROLINA } \\
\text { NCGS } 14-159.20 \text { to } \\
.23 \\
1987\end{array}$ & 2o & $\stackrel{\infty}{\infty}$ & 2 & $\stackrel{\infty}{2}$ & 足 & 2 & $\stackrel{\mathscr{D}}{\succ}$ & $\begin{array}{l}\$ 150-\$ 500 \\
\text { and/or } 10 \\
\text { days }-6 \\
\text { months }\end{array}$ & & \\
\hline $\begin{array}{l}\text { OHIO } \\
\text { ORCA } 1517.21 \text { to } .26 \\
1989\end{array}$ & $\stackrel{\infty}{\stackrel{\infty}{\nu}}$ & $\stackrel{\infty}{\infty}$ & $\stackrel{\infty}{>}$ & $\stackrel{\infty}{\circlearrowright}$ & $\stackrel{\infty}{\infty}$ & $\stackrel{\infty}{\succ}$ & 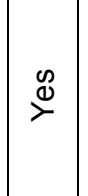 & $\begin{array}{l}\$ 500- \\
\$ 1,000 \text { plus } \\
\text { restitution }\end{array}$ & $\begin{array}{l}\text { Natural } \\
\text { Historic } \\
\text { Scientific } \\
\text { Cultural }\end{array}$ & $\begin{array}{l}\text { Addresses potential to } \\
\text { create state based cave } \\
\text { resources protection } \\
\text { and management } \\
\text { program }\end{array}$ \\
\hline
\end{tabular}




\begin{tabular}{|c|c|c|c|c|c|c|c|c|c|c|}
\hline \multicolumn{11}{|c|}{ United States Cave Resources Protection Acts By State } \\
\hline & \multicolumn{7}{|c|}{ Protection Features } & \multirow[b]{2}{*}{ Penalties } & \multirow[b]{2}{*}{$\begin{array}{c}\text { Specifically } \\
\text { Recognizes } \\
\text { Values }\end{array}$} & \multirow[b]{2}{*}{ Comments } \\
\hline State and Citation & 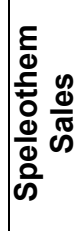 & $\begin{array}{l}\frac{g}{0} \\
\frac{\underline{\underline{T}}}{\frac{\pi}{0}} \\
\frac{\mathrm{C}}{\pi} \\
>\end{array}$ & 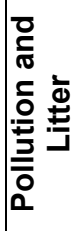 & 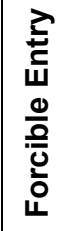 & 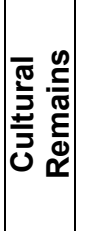 & $\begin{array}{l}\frac{\pi}{0} \\
\frac{0}{0} \\
\frac{E}{\pi} \\
\frac{\pi}{1}\end{array}$ & 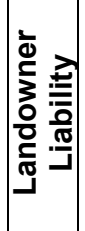 & & & \\
\hline $\begin{array}{l}\text { OKLAHOMA } \\
21 \text { OS } 1789 \\
1967\end{array}$ & \& & $\stackrel{\infty}{\stackrel{\infty}{\nu}}$ & $\stackrel{\infty}{\stackrel{\infty}{\succ}}$ & \& & 우 & $\stackrel{\infty}{\infty}$ & 운 & $\begin{array}{l}\$ 500 \text { and } / \text { or } \\
1 \text { year } \\
\text { maximum }\end{array}$ & & $\begin{array}{l}\text { Protects cave biota } \\
\text { found outside the cave. } \\
\text { Allows for destruction of } \\
\text { predatory terrestrial } \\
\text { mammals and } \\
\text { poisonous snakes. }\end{array}$ \\
\hline $\begin{array}{l}\text { PENNSYLVANIA } \\
32 \text { PS } 5601 \text { to } 5607 \\
1989\end{array}$ & 官 & $\stackrel{\mathscr{D}}{\succ}$ & $\stackrel{\infty}{\supset}$ & $\stackrel{\infty}{\infty}$ & $\stackrel{\infty}{\supset}$ & $\stackrel{\infty}{\infty}$ & 우 & $\begin{array}{l}\$ 100- \\
\$ \$ 1,000 \text { or } \\
30 \text { days } \\
\text { maximum }\end{array}$ & $\begin{array}{l}\text { Natural } \\
\text { Historic } \\
\text { Scientific } \\
\text { Cultural }\end{array}$ & \\
\hline $\begin{array}{l}\text { SOUTH DAKOTA } \\
\text { South Dakota Compile } \\
\text { Laws } 1967 \\
\text { Title 22-34-9, Title } \\
34-20 \\
1939,1965\end{array}$ & & & & & & & ᄃ & & $\square$ & \\
\hline $\begin{array}{l}\text { TENNESSEE } \\
\text { TCA } 11-5-108\end{array}$ & 官 & $\stackrel{\infty}{\stackrel{\infty}{\succ}}$ & 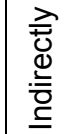 & $\stackrel{\infty}{>}$ & 운 & $\stackrel{\infty}{\succ}$ & $\stackrel{\circ}{z}$ & $\begin{array}{l}\$ 500- \\
\$ 1,000\end{array}$ & & \\
\hline $\begin{array}{l}\text { TEXAS } \\
\text { TNRC } 201.001 \text { to } .043 \\
1977,1979\end{array}$ & $\stackrel{\mathscr{D}}{\succ}$ & $\stackrel{\mathscr{D}}{\nu}$ & $\stackrel{\infty}{\stackrel{\infty}{\succ}}$ & $\stackrel{\infty}{\succ}$ & z & i & $\stackrel{\circ}{z}$ & $\$ 50-1,500$ & & $\begin{array}{l}\text { Separate law protects } \\
\text { bats. }\end{array}$ \\
\hline $\begin{array}{l}\text { VIRGINIA } \\
\text { VCA } 10.1-1000 \text { to } \\
1008 \\
1966,1979,1988\end{array}$ & $\stackrel{\mathscr{\infty}}{\succ}$ & $\stackrel{\mathscr{D}}{\succ}$ & $\stackrel{\infty}{\check{\nu}}$ & $\stackrel{\infty}{\circlearrowright}$ & $\stackrel{\infty}{\supset}$ & $\stackrel{\mathscr{E}}{\succ}$ & $\stackrel{\mathscr{D}}{\succ}$ & $\begin{array}{c}\$ 500- \\
\$ 2,500 \text { and } \\
\text { up to } 12 \\
\text { months } \\
\text { maximum per } \\
\text { section }\end{array}$ & $\begin{array}{l}\text { Natural } \\
\text { Historic } \\
\text { Scientific } \\
\text { Cultural }\end{array}$ & $\begin{array}{l}\text { Establishes Cave Board } \\
\text { Excavation or removal } \\
\text { of cultural resources } \\
\text { requires permit. }\end{array}$ \\
\hline $\begin{array}{l}\text { WEST VIRGINIA } \\
\text { WVC 20-7A-1 to -6 } \\
1977\end{array}$ & $\stackrel{\mathscr{D}}{\succ}$ & $\stackrel{\mathscr{D}}{\succ}$ & 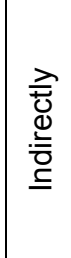 & $\stackrel{\infty}{\nu}$ & $\stackrel{\infty}{\stackrel{\infty}{\succ}}$ & $\stackrel{\infty}{>}$ & $\stackrel{\infty}{\nu}$ & $\begin{array}{l}\$ 150-\$ 500 \\
\text { and/or } 10 \\
\text { days }-6 \\
\text { months per } \\
\text { section }\end{array}$ & & $\begin{array}{l}\text { Gates must allow free } \\
\text { and unimpeded access } \\
\text { to bats, insects, aquatic } \\
\text { fauna, and air. } \\
\text { Excavation or removal } \\
\text { of cultural resources } \\
\text { requires permit. }\end{array}$ \\
\hline
\end{tabular}




\begin{tabular}{|c|c|c|c|c|c|c|c|c|c|c|}
\hline \multicolumn{11}{|c|}{ United States Cave Resources Protection Acts By State } \\
\hline & \multicolumn{7}{|c|}{ Protection Features } & \multirow[b]{2}{*}{ Penalties } & \multirow[b]{2}{*}{$\begin{array}{c}\text { Specifically } \\
\text { Recognizes } \\
\text { Values }\end{array}$} & \multirow[b]{2}{*}{ Comments } \\
\hline State and Citation & 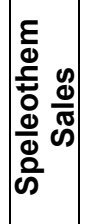 & $\begin{array}{l}\frac{\varepsilon}{\frac{0}{\pi}} \\
\frac{\sqrt{\pi}}{0} \\
\frac{c}{\pi} \\
>\end{array}$ & 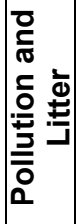 & 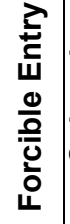 & 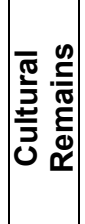 & $\begin{array}{l}\frac{\pi}{0} \\
\frac{0}{0} \\
\xi \\
\frac{5}{\pi} \\
\frac{\pi}{1}\end{array}$ & 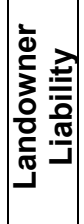 & & & \\
\hline \multicolumn{11}{|l|}{$\begin{array}{l}\text { WYOMING } \\
\text { Wyoming Statutes } \\
\text { Ann. 1957 } \\
\text { Title 6-10-107 } \\
\text { Effective } 1909\end{array}$} \\
\hline $\begin{array}{l}\text { PUERTO RICO } \\
12 \text { LPRA } 1143 \\
1985\end{array}$ & $\stackrel{\infty}{\stackrel{\infty}{\infty}}$ & $\stackrel{\infty}{\infty}$ & $\stackrel{\infty}{\stackrel{\infty}{\succ}}$ & $\stackrel{\mathbb{\infty}}{\nu}$ & $\stackrel{\infty}{\circlearrowright}$ & $\stackrel{\infty}{\nu}$ & 우 & $\begin{array}{c}\$ 10,000 \\
\text { maximum } \\
\text { and/or } 6 \\
\text { months to } 5 \\
\text { years }\end{array}$ & $\begin{array}{l}\text { Natural } \\
\text { Historic } \\
\text { Scientific } \\
\text { Cultural }\end{array}$ & $\begin{array}{l}\text { Addresses development } \\
\text { over cave and karst } \\
\text { features. } \\
\text { Requires government } \\
\text { consent and permit for } \\
\text { various activities. }\end{array}$ \\
\hline $\begin{array}{l}\text { CHEROKEE NATION } \\
1987\end{array}$ & z & $\stackrel{\infty}{\circlearrowright}$ & $\stackrel{\infty}{\rightleftharpoons}$ & io & z & $\stackrel{\infty}{\succ}$ & 우 & $\begin{array}{l}\$ 500 \text { and } / o r \\
1 \text { year } \\
\text { maximum }\end{array}$ & & $\begin{array}{l}\text { Protects cave biota } \\
\text { found outside the cave. } \\
\text { Allows for destruction of } \\
\text { predatory terrestrial } \\
\text { mammals and } \\
\text { poisonous snakes. } \\
\text { Duplicate of } 1967 \\
\text { Oklahoma Act }\end{array}$ \\
\hline
\end{tabular}

Huppert, 1995, Huppert \& Wheeler, 1982, Lera, 2003 


\section{APPENDIX B}

\section{FEDERAL CAVE RESOURCES PROTECTION ACT OF 1988}

Public Law 88-691, 100th Congress, S. 2, November 18, 1988

\section{AN ACT}

To protect cave resources on Federal lands, and for other purposes.

Be it enacted by the Senate and House of Representatives of the United States of America in Congress assembled,

\section{SECTION 1. SHORT TITLE.}

This Act may be referred to as the "Federal Cave Resources Protection Act of 1988".

SECTION 2. FINDINGS, PURPOSES, AND POLICY.

(a) FINDINGS The Congress finds and declares that

(1) significant caves on Federal lands are an invaluable and irreplaceable part of the Nation's natural heritage; and

(2) in some instances, these significant caves are threatened due to improper use, increased recreational demand, urban spread, and a lack of specific statutory protection.

(b) PURPOSES. The purposes of this Act are

(1) to secure, protect, and preserve significant caves on Federal lands for the perpetual use, enjoyment, and benefit of all people; and

(2) to foster increased cooperation and exchange of information between governmental authorities and those who utilize caves located on Federal lands for scientific, education, or recreational purposes.

(c) POLICY. It is the policy of the United States that Federal lands be managed in a manner which protects and maintains, to the extent practical, significant caves.

SECTION 3. DEFINITIONS. For purposes of this Act:

(1) CAVE. The term "cave" means any naturally occurring void, cavity, recess, or system of interconnected passages which occurs beneath the surface of the earth or within a cliff or ledge (including any cave resource therein, but not including any vug, mine, tunnel, aqueduct, or other manmade excavation) and which is large enough to permit an individual to enter, whether or not the entrance is naturally formed or manmade. Such term shall include any natural pit, sinkhole, or other feature which is an extension of the entrance. 
(2) FEDERAL LANDS. The term "Federal lands" means lands the fee title to which is owned by the United States and administered by the Secretary of Agriculture or the Secretary of the Interior.

(3) INDIAN LANDS. The term "Indian lands" means lands of Indian tribes or Indian individuals which are either held in trust by the United States for the benefit of an Indian tribe or subject to a restriction against alienation imposed by the United States.

(4) INDIAN TRIBE. The term "Indian tribe" means any Indian tribe, band, nation, or other organized group or community of Indians, including any Alaska Native village or regional or village corporation as defined in, or established pursuant to, the Alaska Native Claims settlement Act (43 U.S.C. 1601 et seq.).

(5) CAVE RESOURCE. The term "cave resource" includes any material or substance occurring naturally in caves on Federal lands, such as animal life, plant life, paleontological deposits, sediments, minerals, speleogens, and speleothems.

(6) SECRETARY. The term "Secretary" means the Secretary of Agriculture or the Secretary of the Interior, as appropriate.

(7) SPELEOTHEM. The terra "speleothem" means any natural mineral formation or deposit occurring in a cave or lava tube, including but not limited to any stalactite, stalagmite, helictite, cave flower, flowstone, concretion, drapery, rimstone, or formation of clay or mud.

(8) SPELEOGEN. The term "speleogen" means relief features on the walls, ceiling, and floor of any cave or lava tube which are part of the surrounding bedrock, including but not limited to anastomoses, scallops, meander niches, petromorphs and rock pendants in solution caves and similar features unique to volcanic caves.

\section{SECTION 4. MANAGEMENT ACTIONS.}

(a) REGULATIONS. Not later than nine months after the date of the enactment of this Act, the Secretary shall issue such regulations as he deems necessary to achieve the purposes of this Act. Regulations shall include, but not be limited to, criteria for the identification of significant caves. The Secretaries shall cooperate and consult with one another in preparation of the regulations. To the extent practical, regulations promulgated by the respective Secretaries should be similar.

(b) IN GENERAL. The Secretary shall take such actions as may be necessary to further the purposes of this Act. Those actions shall include (but need not be limited to) -

(1) identification of significant caves on Federal lands:

(A) The Secretary shall prepare an initial list of significant caves for lands under his jurisdiction not later than one year after the publication of final regulations using the significance criteria defined in such regulations. Such a list shall be developed after consultation with appropriate private sector interests, including cavers.

(B) The initial list of significant caves shall be updated periodically, after consultation with appropriate private sector interests, including cavers. The Secretary shall prescribe by policy or regulation the requirements and process by which the initial list will be updated, including management measures to assure that caves under consideration for the list are protected during the period of consideration. Each cave recommended to the Secretary by interested groups for possible inclusion on the list of significant caves shall be considered by the Secretary according to the requirements prescribed pursuant to this paragraph, and shall be added to the list if 
the Secretary determines that the cave meets the criteria for significance as defined by the regulations.

(2) regulation or restriction of use of significant caves, as appropriate;

(3) entering into volunteer management agreements with persons of the scientific and recreational caving community; and

(4) appointment of appropriate advisory committees.

(c) PLANNING AND PUBLIC PARTICIPATION. The Secretary shall -

(1) ensure that significant caves are considered in the preparation or implementation of any land management plan if the preparation or revision of the plan began after the enactment of this Act; and

(2) foster communication, cooperation, and exchange of information between land managers, those who utilize caves, and the public.

SECTION 5. CONFIDENTIALITY OF INFORMATION CONCERNING NATURE AND LOCATION OF SIGNIFICANT CAVES.

(a) IN GENERAL. Information concerning the specific location of any significant cave may not be made available to the public under section 552 of title 5, United States Code, unless the Secretary determines that disclosure of such information would further the purposes of this Act and would not create a substantial risk of harm, theft, or destruction of such cave.

(b) EXCEPTIONS. Notwithstanding subsection (a), the Secretary may make available information regarding significant caves upon the written request by Federal and State governmental agencies or bona fide educational and research institutions. Any such written request shall, at a minimum -

(1) describe the specific site or area for which information is sought;

(2) explain the purpose for which such information is sought; and

(3) include assurances satisfactory to the Secretary that adequate measures are being taken to protect the confidentiality of such information and to ensure the protection of the significant cave from destruction by vandalism and unauthorized use.

\section{SECTION 6. COLLECTION AND REMOVAL FROM FEDERAL CAVES.}

(a) PERMIT. The Secretary is authorized to issue permits for the collection and removal of cave resources under such terms and conditions as the Secretary may impose, including the posting of bonds to insure compliance with the provisions of any permit:

(1) Any permit issued pursuant to this section shall include information concerning the time, scope, location, and specific purpose of the proposed collection, removal or associated activity, and the manner in which such collection, removal, or associated activity is to be performed must be provided.

(2) The Secretary may issue a permit pursuant to this subsection only if he determines that the proposed collection or removal activities are consistent with the purposes of this Act, and with other applicable provisions of law.

(b) REVOCATION OF PERMIT. Any permit issued under this section shall be revoked by the Secretary upon a determination by the Secretary that the permittee has violated any provision of this Act, or has failed to comply with any other condition upon which the permit was issued. Any such permit shall be revoked by the Secretary upon assessment of a civil penalty against the permittee pursuant to section 8 or upon the permittee's conviction under section 7 of this Act. The Secretary may refuse to issue a permit under this section to any 
person who has violated any provision of this Act or who has failed to comply with any condition of a prior permit.

(c) TRANSFERABILITY OF PERMITS. Permits issued under this Act are not transferable.

(d) CAVE RESOURCES LOCATED ON INDIAN LANDS.

(1) Upon application by an Indian tribe, the Secretary is authorized to delegate to the tribe all authority of the Secretary under this section with respect to issuing and enforcing permits for the collection or removal of any cave resource, or to carrying out activities associated with such collection or removal, from any cave resource located on the affected Indian lands.

(2) In the case of any permit issued by the Secretary for the collection or removal of any cave resource, or to carry out activities associated with such collection or removal, from any cave resource located on Indian lands (other than permits issued pursuant to subparagraph (A)), the permit may be issued only after obtaining the consent of the Indian or Indian tribe owning or having jurisdiction over such lands. The permit shall include such reasonable terms and conditions as may be requested by such Indian or Indian tribe.

(3) If the Secretary determines that issuance of a permit pursuant to this section may result in harm to, or destruction of, any religious or cultural site, the Secretary, prior to issuing such permit, shall notify any Indian tribe which may consider the site as having significant religious or cultural importance. Such notice shall not be deemed a disclosure to the public for purposes of section 5 .

(4) A permit shall not be required under this section for the collection or removal of any cave resource located on Indian lands or activities associated with such collection, by the Indian or Indian tribe owning or having jurisdiction over such lands.

(e) EFFECT OF PERMIT. No action specifically authorized by a permit under this section shall be treated as a violation of section 7 .

\section{SECTION 7. PROHIBITED ACTS AND CRIMINAL PENALTIES.}

(a) PROHIBITED ACTS.

(1) Any person who, without prior authorization from the Secretary knowingly destroys, disturbs, defaces, mars, alters, removes or harms any significant cave or alters the free movement of any animal or plant life into or out of any significant cave located on Federal lands, or enters a significant cave with the intention of committing any act described in this paragraph shall be punished in accordance with subsection (b).

(2) Any person who possesses, consumes, sells, barters or exchanges, or offers for sale, barter or exchange, any cave resource from a significant cave with knowledge or reason to know that such resource was removed from a significant cave located on Federal lands shall be punished in accordance with subsection (b).

(3) Any person who counsels, procures, solicits, or employs any other person to violate any provisions of this subsection shall be punished in accordance with section (b).

(4) Nothing in this section shall be deemed applicable to any person who was in lawful possession of a cave resource from a significant cave prior to the date of enactment of this Act.

(b) PUNISHMENT. The punishment for violating any provision of subsection (a) shall be imprisonment of not more than one year or a fine in accordance with the applicable provisions of title 18 of the United States Code, or both. In the case of a second or 
subsequent violation, the punishment shall be imprisonment of not more than 3 years or a fine in accordance with the applicable provisions of title 18 of the United States Code, or both.

SECTION 8. CIVIL PENALTIES.

(a) ASSESSMENT.

(1) The Secretary may issue an order assessing a civil penalty against any person who violates any prohibition contained in this Act, any regulation promulgated pursuant to this act, or any permit issued under this Act. Before issuing such an order, the Secretary shall provide such person written notice and the opportunity to request a hearing on the record within 30 days. Each violation shall be a separate offense, even if such violations occurred at the same time.

(2) The amount of such civil penalty shall be determined by the Secretary taking into account appropriate factors, including

(A) the seriousness of the violation;

(B) the economic benefit (if any) resulting from the violation;

(C) any history of such violations; and

(D) such other matters as the Secretary deems appropriate. The maximum fine permissible under this section is $\$ 10,000$.

(b) JUDICIAL REVIEW. Any person aggrieved by an assessment of a civil penalty under this section may file a petition for judicial review of such assessment with the United States District Court for the District of Columbia or for the district in which the violation occurred. Such a petition shall be filed within the 30-day period beginning on the date the order assessing the civil penalty was issued.

(c) COLLECTION. If any person fails to pay an assessment of a civil penalty -

(1) within 30 days after the order was issued under subsection (a), or

(2) if the order is appealed within such 30-day period, within 10 days after court has entered a final judgment in favor of the Secretary under subsection (b), the Secretary shall notify the Attorney General and the Attorney General shall bring a civil action in an appropriate United States district court to recover the amount of penalty assessed (plus costs, attorney's fees, and interest at currently prevailing rates from the date the order was issued or the date of such final judgment, as the case may be). In such an action, the validity, amount, and appropriateness of such penalty shall not be subject to review.

(d) SUBPOENAS. The Secretary may issue subpoenas in connection with proceedings under this subsection compelling the attendance and testimony of witnesses and subpoenas duces tecum, and may request the Attorney General to bring an action to enforce any subpoena under this section. The district courts shall have jurisdiction to enforce such subpoenas and impose sanctions.

\section{SECTION 9. MISCELLANEOUS PROVISIONS.}

(a) AUTHORIZATION. There are authorized to be appropriated $\$ 100,000$ to carry out the purposes of this Act.

(b) EFFECT ON LAND MANAGEMENT PLANS. Nothing in this Act shall require the amendment or revision of any land management plan the preparation of which began prior to the enactment of this Act. 
(c) FUND. Any money collected by the United States as permit fees for collection and removal of cave resources; received by the United States as a result of the forfeiture of a bond or other security by a permittee who does not comply with the requirements of such permit issued under section 7; or collected by the United States by way of civil penalties or criminal fines for violations of this Act shall be placed in a special fund in the Treasury. Such moneys shall be available for obligation or expenditure (to the extent provided for in advance in appropriation Acts) as determined by the Secretary for the improved management, benefit, repair, or restoration of significant caves located on Federal lands.

(d) Nothing in this Act shall be deemed to affect the full operation of the mining and mineral leasing laws of the United States, or otherwise affect valid existing rights.

\section{SECTION 10. SAVINGS PROVISIONS.}

(a) WATER. Nothing in this Act shall be construed as authorizing the appropriation of water by any Federal, State, or local agency, Indian tribe, or any other entity or individual. Nor shall any provision of this Act --

(1) affect the rights or jurisdiction of the United States, the States, Indian tribes, or other entities over waters of any river or stream or over any ground water resource;

(2) alter, amend, repeal, interpret, modify, or be in conflict with any interstate compact made by the States; or

(3) alter or establish the respective rights of States, the United States, Indian tribes, or any person with respect to any water or water-related right.

(b) FISH AND WILDLIFE. -- Nothing in this Act shall be construed as affecting the jurisdiction or responsibilities of the States with respect to fish and wildlife. 


\section{APPENDIX C}

\section{LECHUGUILLA CAVE PROTECTION ACT OF 1993}

Public Law 103-169, 103rd Congress, S. 1, December 2, 1993

\section{AN ACT}

To protect Lechuguilla Cave and other resources and values in and adjacent to Carlsbad Caverns National Park.

Be it enacted by the Senate and House of Representatives of the United States of America in Congress assembled,

SECTION 1. SHORT TITLE.

This Act may be cited as the "Lechuguilla Cave Protection Act of 1993".

SECTION 2. FINDING.

Congress finds that Lechuguilla Cave and adjacent public lands have internationally significant scientific, environmental, and other values, and should be retained in public ownership and protected against adverse effects of mineral exploration and development and other activities presenting threats to the areas.

\section{SECTION 3. LAND WITHDRAWAL.}

(a) Withdrawal. Subject to valid existing rights, all Federal lands within the boundaries of the cave protection area described in subsection (b) are hereby withdrawn from all forms of entry, appropriation, or disposal under the public land laws; from location, entry, and patent under the United States mining laws; and from disposition under all laws pertaining to mineral and geothermal leasing, and all amendments thereto.

(b) Land Description. The cave protection area referred to in subsection (a) shall consist of approximately 6,280 acres of lands in New Mexico as generally depicted on the map entitled "Lechuguilla Cave Protection Area" numbered 130/80,055 and dated April 1993.

(c) Publication, Filing, Correction, and Inspection.

(1) As soon as practicable after the date of enactment of this Act, the Secretary of the Interior (hereinafter referred to as the "Secretary") shall publish in the Federal Register the legal description of the lands withdrawn under subsection (a) and shall file such legal description and a detailed map with the Committee on Energy and Natural Resources of the United States Senate and the Committee on Natural Resources of the United States House of Representatives.

(2) Such map and legal description shall have the same force and effect as if included in this Act except that the Secretary may correct clerical and typographical errors. 
(3) Copies of such map and legal description shall be available for inspection in the appropriate offices of the Bureau of Land Management.

\section{SECTION 4. MANAGEMENT OF EXISTING LEASES.}

(a) Suspension. The Secretary shall not permit any new drilling on or involving any Federal mineral or geothermal lease within the cave protection area referred to in section 3(a) until the effective date of the Record of Decision for the Dark Canyon Environmental Impact Statement, or for 12 months after the date of enactment of this Act, whichever occurs first.

(b) Authority To Cancel Existing Mineral or Geothermal Leases. Upon the effective date of the Record of Decision for the Dark Canyon Environmental Impact Statement and in order to protect Lechuguilla Cave or other cave resources, the Secretary is authorized to cancel any Federal mineral or geothermal lease in the cave protection area referred to in section 3(a); or enter into negotiations with the holder of a Federal mineral or geothermal lease in the cave protection area referred to in section 3(a) to determine appropriate compensation, if any, for the complete or partial termination of such lease.

\section{SECTION 5. ADDITIONAL PROTECTION AND RELATION TO OTHER LAWS.}

(a) In General. In order to protect Lechuguilla Cave or Federal lands within the cave protection area, the Secretary, subject to valid existing rights, may limit or prohibit access to or across lands owned by the United States or prohibit the removal from such lands of any mineral, geological, or cave resources: Provided, That existing access to private lands within the cave protection area shall not be affected by this subsection.

(b) No Effect on Pipelines.--Nothing in this title shall have the effect of terminating any validly issued right-of-way, or customary operation, maintenance, repair, and replacement activities in such right-of-way; prohibiting the upgrading of and construction on existing facilities in such right-of-way for the purpose of increasing capacity of the existing pipeline; or prohibiting the renewal of such right-of-way within the cave protection area referred to in section 3(a).

(c) Relation to Other Laws. Nothing in this Act shall be construed as increasing or diminishing the ability of any party to seek compensation pursuant to other applicable law, including but not limited to the Tucker Act (28 U.S.C. 1491), or as precluding any defenses or claims otherwise available to the United States in connection with any action seeking such compensation from the United States.

\section{SECTION 6. AUTHORIZATION OF APPROPRIATIONS.}

There is hereby authorized to be appropriated such sums as may be necessary to carry out this Act: Provided, That no funds shall be made available except to the extent, or in such amounts as are provided in advance in appropriation Acts. 


\section{APPENDIX D}

\section{WILDERNESS ACT OF 1964}

Public Law 88-577, 88th Congress, S. 4, September 3, 1964

\section{AN ACT}

To establish a National Wilderness Preservation System for the permanent good of the whole people, and for other purposes.

Be it enacted by the Senate and House of Representatives of the United States of America in Congress assembled,

\section{SHORT TITLE}

SECTION 1. This Act may be cited as the "Wilderness Act." WILDERNESS SYSTEM ESTABLISHED STATEMENT OF POLICY

\section{SECTION 2.}

(a) In order to assure that an increasing population, accompanied by expanding settlement and growing mechanization, does not occupy and modify all areas within the United States and its possessions, leaving no lands designated for preservation and protection in their natural condition, it is hereby declared to be the policy of the Congress to secure for the American people of present and future generations the benefits of an enduring resource of wilderness. For this purpose there is hereby established a National Wilderness Preservation System to be composed of federally owned areas designated by the Congress as "wilderness areas," and these shall be administered for the use and enjoyment of the American people in such manner as will leave them unimpaired for future use and enjoyment as wilderness, and so as to provide for the protection of these areas, the preservation of their wilderness character, and for the gathering and dissemination of information regarding their use and enjoyment as wilderness; and no Federal lands shall be designated as "wilderness areas" except as provided for in this Act or by a subsequent Act.

(b) The inclusion of an area in the National Wilderness Preservation System notwithstanding, the area shall continue to be managed by the Department and agency having jurisdiction thereover immediately before its inclusion in the National Wilderness Preservation System unless otherwise provided by Act of Congress. No appropriation shall be available for the payment of expenses or salaries for the administration of the National Wilderness Preservation System as a separate unit nor shall any appropriations be available for additional personnel stated as being required solely for the purpose of managing or administering areas solely because they are included within the National Wilderness Preservation System. 


\section{DEFINITION OF WILDERNESS}

(c) A wilderness, in contrast with those areas where man and his own works dominate the landscape, is hereby recognized as an area where the earth and its community of life are untrammeled by man, where man himself is a visitor who does not remain. An area of wilderness is further defined to mean in this Act an area of undeveloped Federal land retaining its primeval character and influence, without permanent improvements or human habitation, which is protected and managed so as to preserve its natural conditions and which (1) generally appears to have been affected primarily by the forces of nature, with the imprint of man's work substantially unnoticeable; (2) has outstanding opportunities for solitude or a primitive and unconfined type of recreation; (3) has at least five thousand acres of land or is of sufficient size as to make practicable its preservation and use in an unimpaired condition; and (4) may also contain ecological, geological, or other features of scientific, educational, scenic, or historical value.

\section{NATIONAL WILDERNESS PRESERVATION SYSTEM - EXTENT OF SYSTEM SECTION 3.}

(a) All areas within the national forests classified at least 30 days before the effective date of this Act by the Secretary of Agriculture or the Chief of the Forest Service as "wilderness," "wild," or "canoe" are hereby designated as wilderness areas. The Secretary of Agriculture shall -

(1) Within one year after the effective date of this Act, file a map and legal description of each wilderness area with the Interior and Insular Affairs Committees of the United States Senate and the House of Representatives, and such descriptions shall have the same force and effect as if included in this Act: Provided, however, That correction of clerical and typographical errors in such legal descriptions and maps may be made.

(2) Maintain, available to the public, records pertaining to said wilderness areas, including maps and legal descriptions, copies of regulations governing them, copies of public notices of, and reports submitted to Congress regarding pending additions, eliminations, or modifications. Maps, legal descriptions, and regulations pertaining to wilderness areas within their respective jurisdictions also shall be available to the public in the offices of regional foresters, national forest supervisors, and forest rangers.

(b) The Secretary of Agriculture shall, within ten years after the enactment of this Act, review, as to its suitability or nonsuitability for preservation as wilderness, each area in the national forests classified on the effective date of this Act by the Secretary of Agriculture or the Chief of the Forest Service as "primitive" and report his findings to the President. The President shall advise the United States Senate and House of Representatives of his recommendations with respect to the designation as "wilderness" or other reclassification of each area on which review has been completed, together with maps and a definition of boundaries. Such advice shall be given with respect to not less than one-third of all the areas now classified as "primitive" within three years after the enactment of this Act, not less than two-thirds within seven years after the enactment of this Act, and the remaining areas within ten years after the enactment of this Act. Each recommendation of the President for designation as "wilderness" shall become effective only if so provided by an Act of Congress. Areas classified as "primitive" on the effective date of this Act shall continue to be administered under the rules and regulations affecting such areas on the effective date of this Act until Congress has determined otherwise. Any such area may be increased in size by the President at the time he submits his recommendations to the Congress by not more than five thousand acres with no more than one thousand two hundred and eighty acres of such increase in any one compact unit; if it is proposed to increase the size of any such area by 
more than five thousand acres or by more than one thousand two hundred and eighty acres in any one compact unit the increase in size shall not become effective until acted upon by Congress. Nothing herein contained shall limit the President in proposing, as part of his recommendations to Congress, the alteration of existing boundaries of primitive areas or recommending the addition of any contiguous area of national forest lands predominantly of wilderness value. Notwithstanding any other provisions of this Act, the Secretary of Agriculture may complete his review and delete such area as may be necessary, but not to exceed seven thousand acres, from the southern tip of the Gore Range-Eagles Nest Primitive Area, Colorado, if the Secretary determines that such action is in the public interest.

(c) Within ten years after the effective date of this Act the Secretary of the Interior shall review every roadless area of five thousand contiguous acres or more in the national parks, monuments, and other units of the national park system and every such area of, and every roadless island within, the national wildlife refuges and game ranges, under his jurisdiction on the effective date of this Act and shall report to the President his recommendation as to the suitability or nonsuitability of each such area or island for preservation as wilderness. The President shall advise the President of the Senate and the Speaker of the House of Representatives of his recommendation with respect to the designation as wilderness of each such area or island on which review has been completed, together with a map thereof and a definition of its boundaries. Such advice shall be given with respect to not less than one-third of the areas and islands to be reviewed under this subsection within three years after enactment of this Act, not less than two-thirds within seven years of enactment of this Act, and the remainder within ten years of enactment of this Act. A recommendation of the President for designation as wilderness shall become effective only if so provided by an Act of Congress. Nothing contained herein shall, by implication or otherwise, be construed to lessen the present statutory authority of the Secretary of the Interior with respect to the maintenance of roadless areas within units of the national park system.

(d)(1) The Secretary of Agriculture and the Secretary of the Interior shall, prior to submitting any recommendations to the President with respect to the suitability of any area for preservation as wilderness:

(A) give such public notice of the proposed action as they deem appropriate, including publication in the Federal Register and in a newspaper having general circulation in the area or areas in the vicinity of the affected land;

(B) hold a public hearing or hearings at a location or locations convenient to the area affected. The hearings shall be announced through such means as the respective Secretaries involved deem appropriate, including notices in the Federal Register and in newspapers of general circulation in the area: Provided, That if the lands involved are located in more than one State, at least one hearing shall be held in each State in which a portion of the land lies;

(C) at least thirty days before the date of a hearing advise the Governor of each State and the governing board of each county, or in Alaska the borough, in which the lands are located, and Federal departments and agencies concerned, and invite such officials and Federal agencies to submit their views on the proposed action at the hearing or by no later than thirty days following the date of the hearing.

(2) Any views submitted to the appropriate Secretary under the provisions of (1) of this subsection with respect to any area shall be included with any recommendations to the President and to Congress with respect to such area. 
(e) Any modification or adjustment of boundaries of any wilderness area shall be recommended by the appropriate Secretary after public notice of such proposal and public hearing or hearings as provided in subsection $(\mathrm{d})$ of this section. The proposed modification or adjustment shall then be recommended with map and description thereof to the President. The President shall advise the United States Senate and the House of Representatives of his recommendations with respect to such modification or adjustment and such recommendations shall become effective only in the same manner as provided for in subsections (b) and (c) of this section.

\section{USE OF WILDERNESS AREAS}

SECTION 4.

(a) The purposes of this Act are hereby declared to be within and supplemental to the purposes for which national forests and units of the national park and wildlife refuge systems are established and administered and -

(1) Nothing in this Act shall be deemed to be in interference with the purpose for which national forests are established as set forth in the Act of June 4, 1897 (30 Stat.11), and the Multiple-Use Sustained-Yield Act of June 12, 1960 (74 Stat. 215).

(2) Nothing in this Act shall modify the restrictions and provisions of the Shipstead-Nolan Act (Public Law 539, Seventy-first Congress, July 10, 1930; 46 Stat. 1020), the Thye-Blatnik Act (Public Law 733, Eightieth Congress, June 22, 1948; 62 Stat. 568), and the Humphrey-ThyeBlatnik-Andersen Act (Public Law 607, Eighty-fourth Congress, June 22, 1956; 70 Stat. 326), as applying to the Superior National Forest or the regulations of the Secretary of Agriculture.

(3) Nothing in this Act shall modify the statutory authority under which units of the national park system are created. Further, the designation of any area of any park, monument, or other unit of the national park system as a wilderness area pursuant to this Act shall in no manner lower the standards evolved for the use and preservation of such park, monument, or other unit of the national park system in accordance with the Act of August 25, 1916, the statutory authority under which the area was created, or any other Act of Congress which might pertain to or affect such area, including, but not limited to, the Act of June 8, 1906 (34 Stat. 225; 16 U.S.C. 432 et seq.); section 3(2) of the Federal Power Act (16 U.S.C. 796 (2); and the Act of August 21, 1935 (49 Stat. 666; 16 U.S.C. 461 et seq.).

(b) Except as otherwise provided in this Act, each agency administering any area designated as wilderness shall be responsible for preserving the wilderness character of the area and shall so administer such area for such other purposes for which it may have been established as also to preserve its wilderness character. Except as otherwise provided in this Act, wilderness areas shall be devoted to the public purposes of recreational, scenic, scientific, educational, conservation, and historical use.

\section{PROHIBITION OF CERTAIN USES}

(c) Except as specifically provided for in this Act, and subject to existing private rights, there shall be no commercial enterprise and no permanent road within any wilderness area designated by this Act, and except as necessary to meet minimum requirements for the administration of the area for the purpose of this Act (including measures required in emergencies involving the health and safety of persons within the area), there shall be no temporary road, no use of motor vehicles, motorized equipment or motorboats, no landing of aircraft, no other form of mechanical transport, and no structure or installation within any such area. 


\section{SPECIAL PROVISIONS}

(d) The following special provisions are hereby made:

(1) Within wilderness areas designated by this Act the use of aircraft or motorboats, where these uses have already become established, may be permitted to continue subject to such restrictions as the Secretary of Agriculture deems desirable. In addition, such measure may be taken as may be necessary in the control of fire, insects, and diseases, subject to such conditions as the Secretary deems desirable.

(2) Nothing in this Act shall prevent within national forest wilderness areas any activity, including prospecting, for the purpose of gathering information about mineral or other resources, if such activity is carried on in a manner compatible with the preservation of the wilderness environment. Furthermore, in accordance with such program as the Secretary of the Interior shall develop and conduct in consultation with the Secretary of Agriculture, such areas shall be surveyed on a planned, recurring basis consistent with the concept of wilderness preservation by the Geological Survey and the Bureau of Mines to determine the mineral values, if any, that may be present; and the results of such surveys shall be made available to the public and submitted to the President and Congress.

(3) Notwithstanding any other provisions of this Act, until midnight December 31, 1983, the United States mining laws and all laws pertaining to mineral leasing shall, to the same extent as applicable prior to the effective date of this Act, extend to those national forest lands designated by this Act as "wilderness areas"; subject, however, to such reasonable regulations governing ingress and egress as may be prescribed by the Secretary of Agriculture consistent with the use of the land for mineral location and development and exploration, drilling, and production, and use of land for transmission lines, waterlines, telephone lines, or facilities necessary in exploring, drilling, production, mining, and processing operations, including where essential the use of mechanized ground or air equipment and restoration as near as practicable of the surface of the land disturbed in performing prospecting, location, and, in oil and gas leasing, discovery work, exploration, drilling, and production, as soon as they have served their purpose. Mining locations lying within the boundaries of said wilderness areas shall be held and used solely for mining or processing operations and uses reasonably incident thereto; and hereafter, subject to valid existing rights, all patents issued under the mining laws of the United States affecting national forest lands designated by this Act as wilderness areas shall convey title to the mineral deposits within the claim, together with the right to cut and use so much of the mature timber there from as may be needed in the extraction, removal, and beneficiation of the mineral deposits, if needed timber is not otherwise reasonably available, and if the timber is cut under sound principles of forest management as defined by the national forest rules and regulations, but each such patent shall reserve to the United States all title in or to the surface of the lands and products thereof, and no use of the surface of the claim or the resources there from not reasonably required for carrying on mining or prospecting shall be allowed except as otherwise expressly provided in this Act: Provided, That, unless hereafter specifically authorized, no patent within wilderness areas designated by this Act shall issue after December 31, 1983, except for the valid claims existing on or before December 31, 1983. Mining claims located after the effective date of this Act within the boundaries of wilderness areas designated by this Act shall create no rights in excess of those rights which may be patented under the provisions of this subsection. Mineral leases, permits, and licenses covering lands within national forest wilderness areas designated by this Act shall contain such reasonable stipulations as may be prescribed by 
the Secretary of Agriculture for the protection of the wilderness character of the land consistent with the use of the land for the purposes for which they are leased, permitted, or licensed. Subject to valid rights then existing, effective January 1, 1984, the minerals in lands designated by this Act as wilderness areas are withdrawn from all forms of appropriation under the mining laws and from disposition under all laws pertaining to mineral leasing and all amendments thereto.

(4) Within wilderness areas in the national forests designated by the Act, (1) the President may, within a specific area and in accordance with such regulations as he may deem desirable, authorize prospecting for water resources, the establishment and maintenance of reservoirs, water-conservation works, power projects, transmission lines, and other facilities needed in the public interest, including the road construction and maintenance essential to development and use thereof, upon his determination that such use or uses in the specific area will better serve the interests of the United States and the people thereof than will its denial; and (2) the grazing of livestock, where established prior to the effective date of this Act, shall be permitted to continue subject to such reasonable regulations as are deemed necessary by the Secretary of Agriculture.

(5) Other provisions of this Act to the contrary notwithstanding, the management of the Boundary Waters Canoe Area, formerly designated as the Superior, Little Indian Sioux, and Caribou Roadless Areas, in the Superior National Forest, Minnesota, shall be in accordance with regulations established by the Secretary of Agriculture in accordance with the general purpose of maintaining, without unnecessary restrictions on other uses, including that of timber, the primitive character of the area, particularly in the vicinity of lakes, streams, and portages: Provided, That nothing in this Act shall preclude the continuance within the area of any already established use of motorboats.

(6) Commercial services may be performed within the wilderness areas designated by this Act to the extent necessary for activities which are proper for realizing the recreational or other wilderness purposes of the areas.

(7) Nothing in this Act shall constitute an express or implied claim or denial on the part of the Federal Government as to exemption from State water laws.

(8) Nothing in this Act shall be construed as affecting the jurisdiction or responsibilities of the several States with respect to wildlife and fish in the national forests.

\section{STATE AND PRIVATE LANDS WITHIN WILDERNESS AREAS SECTION 5.}

(a) In any case where State-owned or privately owned land is completely surrounded by national forest lands within areas designated by this Act as wilderness, such State or private owner shall be given such rights as may be necessary to assure adequate access to such Stateowned or privately owned land by such State or private owner and their successors in interest, or the State-owned land or privately owned land shall be exchanged for federally owned land in the same State of approximately equal value under authorities available to the Secretary of Agriculture: Provided, however, That the United States shall not transfer to a State or private owner any mineral interests unless the State or private owner relinquishes or causes to be relinquished to the United States the mineral interest in the surrounded land.

(b) In any case where valid mining claims or other valid occupancies are wholly within a designated national forest wilderness area, the Secretary of Agriculture shall, by reasonable regulations consistent with the preservation of the area as wilderness, permit ingress and egress 
to such surrounded areas by means which have been or are being customarily enjoyed with respect to other such areas similarly situated.

(c) Subject to the appropriation of funds by Congress, the Secretary of Agriculture is authorized to acquire privately owned land within the perimeter of any area designated by this Act as wilderness if (1) the owner concurs in such acquisition or (2) the acquisition is specifically authorized by Congress.

\section{GIFTS, BEQUESTS, AND CONTRIBUTIONS} SECTION 6.

(a) The Secretary of Agriculture may accept gifts or bequests of land within wilderness areas designated by this Act for preservation as wilderness. The Secretary of Agriculture may also accept gifts or bequests of land adjacent to wilderness areas designated by this Act for preservation as wilderness if he has given sixty days advance notice thereof to the President of the Senate and the Speaker of the House of Representatives. Land accepted by the Secretary of Agriculture under this section shall become part of the wilderness area involved. Regulations with regard to any such land may be in accordance with such agreements, consistent with the policy of this Act, as are made at the time of such gift, or such conditions, consistent with such policy, as may be included in, and accepted with, such bequest.

(b) The Secretary of Agriculture or the Secretary of the Interior is authorized to accept private contributions and gifts to be used to further the purposes of this Act.

\section{ANNUAL REPORTS \\ SECTION 7.}

At the opening of each session of Congress, the Secretaries of Agriculture and Interior shall jointly report to the President for transmission to Congress on the status of the wilderness system including a list and descriptions of the areas in the system, regulations in effect, and other pertinent information, together with any recommendations they may care to make. 
APPENDIX E

RESEARCH QUESTIONNAIRE 


\section{Dear Participant:}

Thank you for taking the time to fill out this questionnaire and for participating in the Cave Wilderness study. The following questions are to determine your cave-related experience, perceptions of caves and caving, wilderness experience, and to gather socio-demographic information. It should take approximately 15 to 20 minutes to complete this questionnaire. Participation in this study is strictly voluntary and responses will be kept confidential. Please fill out the questionnaire to the fullest extent possible. Once again, thank you for your time in completing this questionnaire and in participating in this Cave Wilderness inquiry.

Patricia E. Seiser

WVU Division of Forestry 320 Percival Hall

Morgantown, WV 26506

(304) 293-2555 ext. 2304

E-mail: pseiser@wvu.edu

\author{
Phenomena \\ Of \\ Cave Wilderness \\ Research Project 2002
}




\section{Caving Experiences:}

1. How many times have you taken commercial cave tours?

2. How many times have you taken commercially guided spelunking/wild cave tours?

3. What best describes the type of caver you currently are (check all that apply):

$\begin{array}{lll}\text { Not a Caver } & \square \text { Please go to question } & 13 . \\ \text { Novice Caver } & \square & \text { Cave Scientist } \\ \text { Sport Caver } & \square & \text { Cavern Diver } \\ \text { Explorer } & \square & \text { Cave Diver } \\ \text { Surveyor } & \square & \text { Retired Caver } \\ \text { Other } & \square & \square\end{array}$

If you checked other or have additional comments please explain here:

\section{Caver Questions:}

4. Briefly describe your caving experience (local, regional, national, international):
7. Other speleo memberships:

8. How many caves have you visited in Kentucky?

9. How many cave trips have you been on in Kentucky?

10. How many caves have you visited in New Mexico?

11. How many cave trips have you been on in New Mexico?

12. Why do you cave?

\section{Non-Caver Questions:}

13. If you are not a caver, how many times have you taken a non-commercial wild cave trip?

14. How many caves have you visited in Kentucky?

15. How many cave trips have you been on in Kentucky?

16. How many caves have you visited in New Mexico?

17. How many cave trips have you been on in New Mexico?

18 . Why do you not cave?

5. Number of years caving:

6. NSS Membership: Yes 


\section{Meaning of Caves:}

19. What do caves mean to you?

20. What does caving mean to you?

\section{Wilderness Experience:}

21. Have you ever visited a wilderness area?

22. Why did you visit?

23. Do you plan to visit a wilderness area in the future?

24. How do you know about "cave wilderness"? (check all that apply)

Read about

Discussion with others

Own thoughts

Have not previously given it any thought

Other $\square$ (Please explain):

\section{Socio-Demographic Information}

These last questions are important in helping us learn more about the people participating in this study. All of the information is STRICTLY CONFIDENTIAL and WILL NOT be associated with you as an individual.

26. What is your age?

27. Gender: F $\mathrm{M}$

28. Race:

29. Formal Education (check highest level achieved):

Grade School

Some High School

Highs School Graduate/GRE

Technical/Vocational School

Some College

College Graduate

Masters Level

Doctoral Level

30 . What is your occupation?

31. Annual Income:

$\begin{array}{llll}\text { Under 15,000 } & \square & 15-24,999 & \square \\ 25-34,999 & \square & 35-49,999 & \square \\ 50-74,999 & \square & 75-99,999 & \square \\ 100,000 \text { and above } & \square & & \end{array}$


Comments: 


\section{APPENDIX F}

\section{QUESTIONNAIRE RESULTS}

A brief review of questionnaire findings was presented in chapter four. This appendix presents findings in details.

Questionnaires were completed during focus group sessions. Fifty-four participants (90\%) submitted a questionnaire, though not all answered all questions. Thirty-five of the thirtynine participants (90\%) in the Caving Event focus groups submitted questionnaires. All nine $(100 \%)$ of the Kentucky focus groups' participants submitted questionnaires. Ten of the twelve (83\%) participants in the New Mexico focus groups submitted questionnaires.

\section{Demographics}

\section{Gender}

Thirteen of the sixty focus group members were female, accounting for $22 \%$ of the total participants. Forty-seven males represented $78 \%$ of the focus group participants. Ten females attended the Caving Event focus groups, comprising 26\% of these focus groups' participants. Three females attended the Kentucky focus groups, making up 33\% of these focus groups' members. There were no female New Mexico focus groups' participants.

Table 16 displays gender values based on questionnaire respondents. The Caving Event focus groups' respondents were composed of nine (26\%) females and twenty-six (74\%) males. 
Kentucky focus groups' respondents were three (33\%) females and six $(66 \%)$ males. New Mexico focus groups' respondents were $100 \%$ male with ten respondents.

Table 16. Demographics By Focus Groups Venue.

\begin{tabular}{|c|c|c|c|c|c|}
\hline & $\begin{array}{c}\text { CAVING EVENT } \\
n=35\end{array}$ & $\begin{array}{c}\text { KENTUCKY } \\
n=9\end{array}$ & $\begin{array}{c}\text { NEW MEXICO } \\
n=10\end{array}$ & $\begin{array}{c}\text { TOTAL } \\
\mathrm{n}=54\end{array}$ & $\%$ \\
\hline \multicolumn{6}{|c|}{ Gender } \\
\hline Female & 9 & 3 & 0 & 12 & 22 \\
\hline Male & 26 & 6 & 10 & 42 & 78 \\
\hline \multicolumn{6}{|c|}{ Ages } \\
\hline $20-29$ & 1 & 0 & 0 & 1 & 2 \\
\hline $30-39$ & 6 & 1 & 0 & 7 & 13 \\
\hline $40-49$ & 13 & 0 & 2 & 15 & 28 \\
\hline $50-59$ & 9 & 2 & 1 & 12 & 22 \\
\hline $60-69$ & 1 & 5 & 4 & 10 & 19 \\
\hline $70-79$ & 0 & 0 & 2 & 2 & 4 \\
\hline $80-89$ & 0 & 0 & 1 & 1 & 2 \\
\hline No Response & 5 & 1 & 0 & 6 & 11 \\
\hline \multicolumn{6}{|c|}{ Education } \\
\hline HS Grad/GED & 1 & 2 & 3 & 6 & 11 \\
\hline Some College & 5 & 2 & 1 & 8 & 15 \\
\hline Bachelor & 15 & 1 & 4 & 20 & 37 \\
\hline Masters & 9 & 4 & 2 & 15 & 28 \\
\hline Doctorate & 5 & 0 & 0 & 5 & 9 \\
\hline \multicolumn{6}{|c|}{ Income Range } \\
\hline$<15,000$ & 1 & 1 & 0 & 2 & 4 \\
\hline $15-24,999$ & 2 & 1 & 1 & 4 & 7 \\
\hline $25-34,999$ & 3 & 2 & 2 & 7 & 13 \\
\hline $35-49,999$ & 7 & 1 & 1 & 9 & 17 \\
\hline $50-74,999$ & 11 & 1 & 2 & 14 & 26 \\
\hline $75-99,999$ & 1 & 0 & 1 & 2 & 4 \\
\hline$>99,999$ & 3 & 2 & 3 & 8 & 15 \\
\hline No Response & 7 & 1 & 0 & 8 & 15 \\
\hline
\end{tabular}

\section{Race}

There was almost no racial diversity within the focus groups' participants. Fifty-three of the respondents were of Caucasian descent. One respondent was of Asian descent.

\section{Age}

Focus groups respondents' ages ranged from twenty-nine to eighty-one. Caving Event focus groups respondents' median age was 47.5, with a standard deviation of 8.97. Both 
Kentucky and New Mexico focus groups respondents' median age was 62. Standard deviation for Kentucky was 11.3 and New Mexico was 12.59 .

For additional analysis, ages were grouped by decade. Age range break out by focus groups venues is found in table 16. Thirteen (43\%) Caving Event respondents fell into the 40-49 age range. This percentage was higher than the $31 \%$ (fifteen) for all focus groups' respondents. In Kentucky and New Mexico focus groups, the majority of respondents' fell into the 60-69 age range. Kentucky had five (56\%) respondents and New Mexico had four (40\%) of the respondents in this age range. Overall, 77\% (thirty-seven) of all respondents fell into the 40-69 age range.

\section{Education}

Of the fifty-four participants who had completed the questionnaire, all have at least a high school degree. Twenty (37\%) of the respondents have Bachelor degrees, fifteen (28\%) have Master degrees, and five (9\%) have Doctorate degrees (see Table 16).

Of the thirty-five responding Caving Event focus groups' participants, twenty-nine (83\%) have a Bachelor degree or higher: fifteen (43\%) Bachelors, nine (26\%) Masters, and five (14\%) Doctorates. Three of the five Doctorate holders work in the field of speleology, as a microbiologist, geochemist, or karst hydrologist.

Five of the nine (56\%) Kentucky focus groups' participants have college degrees, one Bachelor and four Masters. The Masters accounted for $44 \%$ of all participants in the Kentucky focus groups.

Six of the ten $(60 \%)$ responding New Mexico focus group members have college degrees; including two Masters. The four Bachelors account for $40 \%$ of the responding New Mexico focus groups' participants. 


\section{Annual Income}

Forty-six of the focus groups' participants responded to the annual income range question (see table 16). Thirty percent of the overall respondents (fourteen) earned $\$ 50,000-74,999$ annually. Twenty percent (nine) had annual earnings of $\$ 35,000-49-999$. Annual income varied among the three focus group venues, as shown in Table 16.

\section{Caver versus Non-Caver Demographics}

As noted earlier, forty-one (76\%) of focus groups' respondents identified themselves as cavers. All thirty-five Caving Event focus groups' respondents identified themselves as cavers; accounting for $65 \%$ of all respondents. Four (44\%) of the Kentucky focus group respondents identified themselves as cavers ( $7 \%$ of all respondents). Two (20\%) of the New Mexico focus group respondents identified themselves as cavers ( $4 \%$ of all respondents).

The high percentage of cavers within the focus groups is possibly attributable to the lower number of participants within the Kentucky and New Mexico focus groups, relative to the number of Caving Event participants, though there is nothing to suggest that the percentage caver/non-caver for Kentucky or New Mexico would decrease or increase. It should be noted that the number of participants is too low to suggest that they represent the overall populations for their respective regions. Table 17 lists caver and non-caver demographics 
Table 17. Caver and Non-Caver Demographics.

\begin{tabular}{|c|c|c|c|c|c|}
\hline & $\begin{array}{c}\text { CAVER } \\
\mathrm{n}=41\end{array}$ & $\begin{array}{c}\text { NON-CAVER } \\
n=13\end{array}$ & $\begin{array}{c}\text { TOTAL } \\
n=54\end{array}$ & CAVER \% & NON-CAVER \% \\
\hline \multicolumn{6}{|c|}{ FOCUS GROUP } \\
\hline \begin{tabular}{|l|} 
Caving Event \\
\end{tabular} & 35 & 0 & 35 & 85 & 0 \\
\hline Kentucky & 4 & 5 & 9 & 10 & 38 \\
\hline New Mexico & 2 & 8 & 10 & 5 & 62 \\
\hline \multicolumn{6}{|c|}{ GENDER } \\
\hline Female & 10 & 2 & 12 & 24 & 15 \\
\hline Male & 31 & 11 & 42 & 76 & 85 \\
\hline \multicolumn{6}{|c|}{ AGE RANGE } \\
\hline $20-29$ & 1 & 0 & 1 & 3 & 0 \\
\hline $30-39$ & 7 & 0 & 7 & 20 & 0 \\
\hline $40-49$ & 13 & 2 & 15 & 37 & 17 \\
\hline $50-59$ & 9 & 3 & 12 & 26 & 25 \\
\hline $60-69$ & 4 & 5 & 9 & 11 & 42 \\
\hline \begin{tabular}{|l|}
$70-79$ \\
\end{tabular} & 1 & 1 & 2 & 3 & 8 \\
\hline $80-89$ & 0 & 1 & 1 & 0 & 8 \\
\hline No Response & 6 & 1 & 7 & - & - \\
\hline \multicolumn{6}{|l|}{ Education } \\
\hline HS Grad/GED & 2 & 4 & 6 & 5 & 31 \\
\hline \begin{tabular}{|l|} 
Some College \\
\end{tabular} & 7 & 1 & 8 & 17 & 8 \\
\hline \begin{tabular}{|l|} 
Bachelor \\
\end{tabular} & 16 & 4 & 20 & 39 & 31 \\
\hline \begin{tabular}{|l|} 
Masters \\
\end{tabular} & 11 & 4 & 15 & 27 & 31 \\
\hline Doctorate & 5 & 0 & 5 & 12 & 0 \\
\hline \multicolumn{6}{|c|}{ Income Range } \\
\hline$<15,000$ & 1 & 1 & 2 & 3 & 8 \\
\hline $15-24,999$ & 2 & 2 & 4 & 6 & 17 \\
\hline $25-34,999$ & 4 & 3 & 7 & 12 & 25 \\
\hline $35-49,999$ & 8 & 1 & 9 & 24 & 8 \\
\hline \begin{tabular}{|l|}
$50-74,999$ \\
\end{tabular} & 12 & 2 & 14 & 35 & 17 \\
\hline 75-99,999 & 1 & 1 & 2 & 3 & 8 \\
\hline$>99,999$ & 6 & 2 & 8 & 18 & 17 \\
\hline No Response & 7 & 1 & 8 & - & - \\
\hline
\end{tabular}

Race

Forty of the caver identified respondents described themselves as Caucasian. One individual described herself/himself as Asian. All non-cavers identified themselves as Caucasian.

\section{Gender}

Table 17 displays caver versus non-caver gender information. Ten of the responding females identified themselves as cavers, accounting for twenty-four percent of the identified 
cavers. Two females identified themselves as non-cavers. They accounted for fifteen percent of the non-cavers.

Thirty-one of the male focus groups' respondents identified themselves as cavers accounting for $76 \%$ the identified cavers. Eleven of the male respondents identified themselves as non-cavers. They accounted for $85 \%$ of the total non-caver.

Age

The median age for cavers was 48 , with a standard deviation of 10.89 . The median age for none-cavers was 60.5, with a standard deviation of 13.2. Table 17 displays age ranges (by decade) based on caver / non-caver breakout. Thirty-seven percent of the cavers fell into the 4049 age range and $26 \%$ fell into the $50-59$ age group. These two age ranges account for $63 \%$ of the identified cavers. For the non-cavers, $42 \%$ fell into the $60-69$ age group and another $25 \%$ fell into the 50-59 age group. These two age ranges account for $67 \%$ of the identified non-cavers.

\section{Education}

The education background of the responding participants identifying themselves as cavers or non-cavers is described in Table 17. Seventy-eight percent of the cavers hold a postsecondary degree. Thirty-nine percent of the cavers hold Bachelors, 27\% hold Masters, and 12\% hold a Doctorate. Sixty-two percent of the non-cavers hold either a Bachelors or Masters degree. Thirty-one percent hold bachelors and another $31 \%$ hold a Masters. 


\section{Annual Income}

Annual income for cavers and non-cavers is described Table 17. Fifty-nine percent of the cavers fell into one of two income ranges; $35 \%$ earned $\$ 50,000$ - $\$ 74,000$ a year and $24 \%$ earned $\$ 35,000$ - $\$ 49,999$ annually. Twenty-five percent of the non-cavers earned $\$ 25,000$ - 34,999.

\section{Comparisons of Caver, Non-Caver, and Focus Groups Venues}

Demographical comparisons among caver, non-caver, and focus groups venues, show few direct correlations. There are some similarities in trends among cavers and Caving Event focus groups. This would be expected as all Caving Event participants identified themselves as cavers. Other than similarities in trends, there is limited direct relationship demographically to focus groups venues. This suggests that despite the high percentage of cavers relative to noncavers, demographics possibly has little to no bearing on this study's findings.

\section{Gender}

Gender percentages for cavers correlate with those of the Caving Event focus groups and the total participants. Non-cavers gender percentages did not correlate with any focus groups nor total participants. See figure 8 for comparisons.

Age

The 40-49 age range accounted for highest percentages for cavers (37\%), the Caving Event focus groups (43\%) and overall participants (31\%). Among non-cavers, the highest percentage (42\%) fell in the 60-69 age range. This correlated roughly with the New Mexico 
focus groups high of $40 \%$ in the same age range. Figure 9 displays comparisons of ages by caver, non-caver, and focus groups venues.



Figure 8. Comparison of Gender by Caver, Non-Caver, and Focus Groups Venues.

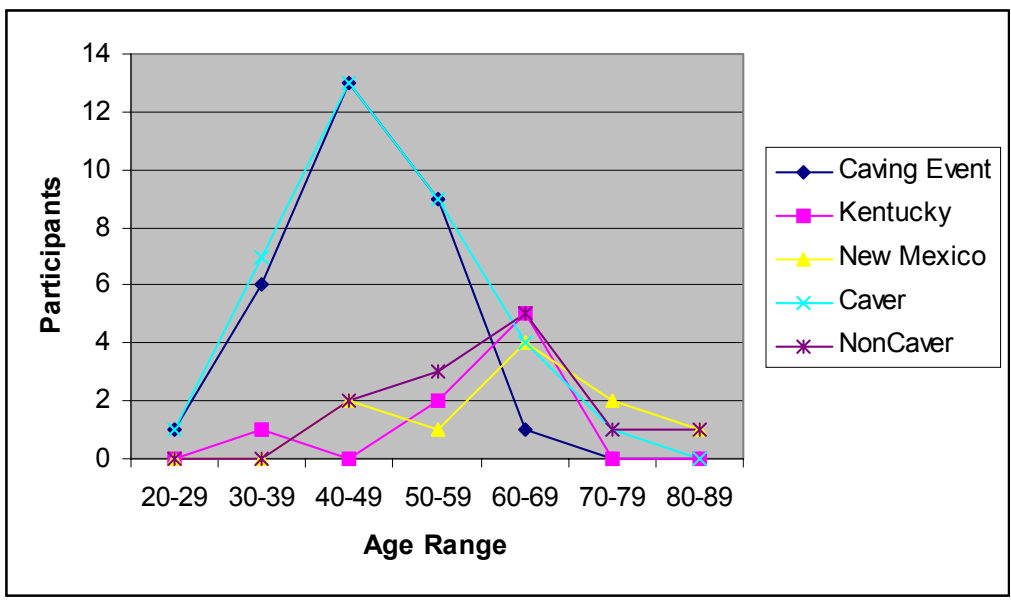

Figure 9. Comparison of Age Ranges by Caver, Non-Caver, and Focus Groups Venues.

\section{Education}

Holders of Bachelor degrees had highest percentages for the Caving Event focus groups, New Mexico focus groups, overall participants, cavers and non-cavers, 43\%, 40\%, 37\%, 39\% and $31 \%$ respectively. Kentucky and non-cavers had high percentages for Master Degrees, 44\% and $31 \%$ respectively (see figure 10 ). 


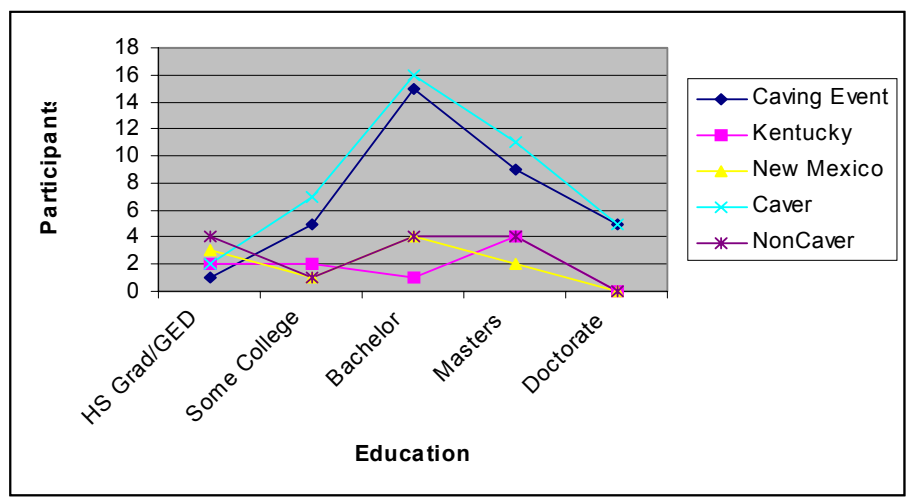

Figure 10. Comparison of Education by Caver, Non-Caver, and Focus Groups Venues.

\section{Annual Income}

Highest percentages for Caving Event focus groups (39\%), overall participants (30\%) and cavers (35\%) fell in the $\$ 50,000-74,999$ range. Highest percentages (25\% each) for Kentucky and non-cavers fell in the $\$ 25-34,999$ range (see figure 11 ).

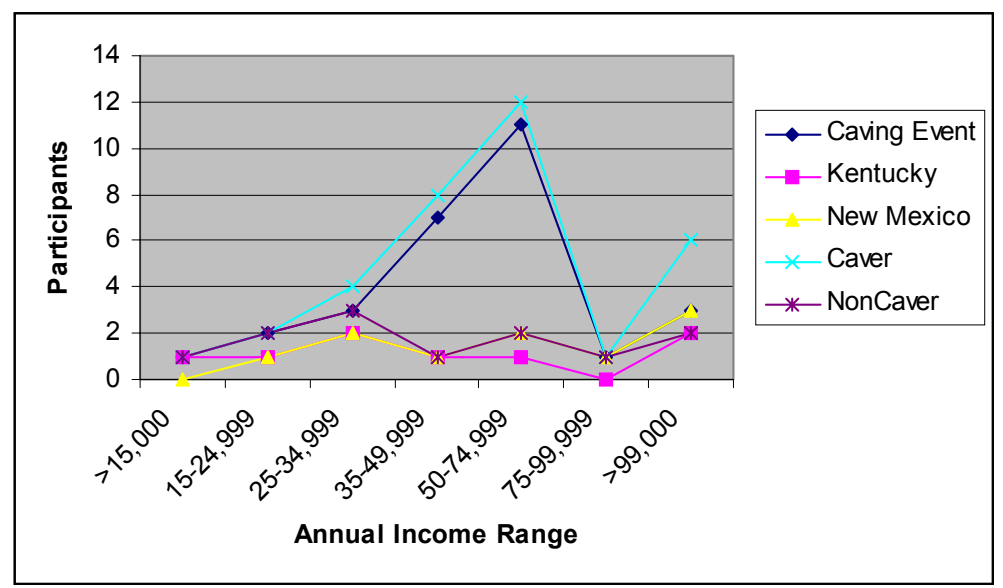

Figure 11. Comparison of Annual Income by Caver, Non-Caver, and Focus Groups Venues.

\section{Participants' Caving Experiences}

The questionnaire covered caving experiences for cavers and non-cavers alike. Caving experience questions covered commercial cave tours and wild cave trips, as well as experiences 
specific to Kentucky and New Mexico caves. Responses were not limited to a particular timeframe, in order to gain an understanding of participants' experiences with caves during their lifetimes. Cavers were asked additional questions pertaining to their cave-related background.

\section{In-Cave Experience}

What constituted a commercial cave trip or commercial spelunker/wild cave trip was left to the respondents' interpretation. In addition, there were participants within all three focus group venues who had served as a cave guide at one time or another; some were still active. Thus, it was left up to the discretion of those individuals who had led commercial trips to include or not include these trips in their personal counts.

Responses to questions regarding numbers of trips varied in type. Some were framed as estimates, others were framed in terms of more than or less than a specific number. Due to the variety of responses, it was decided to group responses in ranges that best described overall responses.

\section{Commercial Trips}

Forty-three $(72 \%)$ participants responded to the question regarding having taken a commercial cave trip (see Table 18). Thirty percent of the total respondents had participated on 10-25 commercial cave trips. Another eleven (26\%) had participated on 26-50 trips. These numbers indicate a familiarity with commercial cave trips for all participants.

Thirty-three (85\%) of the Caving Event focus groups' participants responded to the question. Eleven (33\%) respondents had been on 10-25 trips and ten (30\%) had been on $25-50$ trips. These ranges accounted for $63 \%$ of all Caving Event respondents. 
Five (56\%) Kentucky focus group participants responded to the question. Two (40\%) respondents had been on 50-100 trips and two (40\%) had been on more than 100 commercial cave trips. Together these ranges accounted for $80 \%$ of the respondents.

Five (42\%) New Mexico focus group participants responded to the question. Two (40\%) of the respondents had been on 10-25 trips.

Table 18. Commercial and Guided Wild Cave Tours by Focus Group Venues.

\begin{tabular}{|c|c|c|c|c|c|}
\hline & $\begin{array}{c}\text { CAVING EVENT } \\
n=35\end{array}$ & $\begin{array}{c}\text { KENTUCKY } \\
n=9\end{array}$ & $\begin{array}{c}\text { NEW MEXICO } \\
n=10\end{array}$ & $\begin{array}{c}\text { TOTAL } \\
\mathrm{n}=54\end{array}$ & $\%$ \\
\hline \multicolumn{6}{|c|}{ Commercial Cave Trips } \\
\hline $1-10$ & 4 & 0 & 1 & 5 & 9 \\
\hline $11-25$ & 11 & 0 & 2 & 13 & 24 \\
\hline $26-50$ & 10 & 1 & 0 & 11 & 20 \\
\hline $51-100$ & 3 & 2 & 1 & 6 & 11 \\
\hline$>100$ & 5 & 2 & 1 & 8 & 15 \\
\hline No Response & 2 & 4 & 5 & 11 & 20 \\
\hline \multicolumn{6}{|c|}{ Commercial Guided Wild Cave Trips } \\
\hline 0 & 14 & 5 & 2 & 21 & 39 \\
\hline $1-5$ & 17 & 1 & 2 & 20 & 37 \\
\hline $6-10$ & 1 & 0 & 0 & 1 & 2 \\
\hline $11-25$ & 0 & 0 & 1 & 1 & 2 \\
\hline$>100$ & 2 & 0 & 0 & 2 & 4 \\
\hline No Response & 1 & 3 & 5 & 9 & 17 \\
\hline
\end{tabular}

\section{Commercial Spelunker/Wild Cave Tour}

Forty-five $(75 \%)$ of all participants responded to the question on commercial spelunker/wild cave tour participation (see Table 18). Twenty-one (47\%) had not participated on a commercial wild cave trip. Another twenty (44\%) had participated on one to five commercially guided wild cave tours. Overall, numbers indicate some degree of familiarity with commercial wild cave trips.

Thirty-four (87\%) of the Caving Event focus groups' participants responded to the question. Fourteen (41\%) had not participated in a commercial spelunker/wild cave tour; seventeen $(50 \%)$ had participated on one to five commercially guided cave trips (this includes an individual whose three trips had been underwater). 
Six $(67 \%)$ of the Kentucky focus groups' participants responded to the question. Five (83\%) participants had not participated on a commercially guided wild cave trip. Only one (17\%) had been on a commercial guided wild cave tour.

Five (42\%) New Mexico focus groups' participants responded to the question. Two (40\%) respondents had not been on any trips, and another two (40\%) had been on 1-5 commercially guided wild cave tours.

\section{Caver Caving Experience}

\section{Caving Areas}

Thirty-seven cavers responded when asked to describe caving experience in terms of areas caved in (see table 19). Thirty-three of the Caving Event focus group cavers responded: two (6\%) local; seven (21\%) regional; five (15\%) regional and international; four (12\%) national; and fifteen (46\%) national \& international Three of the Kentucky focus group cavers responded: two (67\%) local and one (33\%) national. One of the New Mexico focus group cavers responded and described caving as primarily local.

Table 19. Areas Cavers Caved by Focus Groups Venues.

\begin{tabular}{|c|c|c|c|}
\hline & $\begin{array}{c}\begin{array}{c}\text { CAVING EVENT } \\
\mathrm{n}=35\end{array}\end{array}$ & $\begin{array}{c}\text { KENTUCKY } \\
n=4\end{array}$ & $\begin{array}{c}\text { NEW MEXICO } \\
n=2\end{array}$ \\
\hline \multicolumn{4}{|c|}{ Caving Area(s) } \\
\hline Local & 2 & 2 & 0 \\
\hline Regional & 7 & 0 & 1 \\
\hline National & 4 & 1 & 0 \\
\hline Regional \& International & 5 & 0 & 0 \\
\hline National \& International & 15 & 0 & 0 \\
\hline No Response & 2 & 1 & 1 \\
\hline
\end{tabular}




\section{Caving Related Memberships}

Memberships in speleo-related organizations may be indicative of interest in caving. Thirty-seven (90\%) of the cavers held a membership in at least one cave-related organization (see table 20).

Table 20. Caving Related Memberships.

\begin{tabular}{|c|c|c|c|}
\hline \multicolumn{2}{|c|}{$\begin{array}{c}\text { CAVING EVENT } \\
\mathrm{n}=35\end{array}$} & $\begin{array}{c}\text { KENTUCKY } \\
\mathrm{n}=4\end{array}$ & $\begin{array}{c}\text { NEW MEXICO } \\
\mathrm{n}=2\end{array}$ \\
\hline \multicolumn{3}{|c|}{ NSS Membership } \\
\hline Yes & 35 & 0 & 0 \\
\hline No & 0 & 3 & 1 \\
\hline No Response & 0 & 1 & 1 \\
\hline \multicolumn{5}{|c|}{ Number of Other Speleo Memberships } \\
\hline 0 & 2 & 0 & 1 \\
\hline 1 & 6 & 2 & 0 \\
\hline 2 & 8 & 0 & 0 \\
\hline 3 & 6 & 0 & 0 \\
\hline 4 & 1 & 0 & 0 \\
\hline $4+$ & 1 & 0 & 0 \\
\hline 5 & 1 & 0 & 0 \\
\hline $5+$ & 1 & 0 & \\
\hline 7 & 1 & 0 & \\
\hline
\end{tabular}

Of the forty-one respondents who described themselves as cavers, forty (98\%) responded to the question regarding membership in the National Speleological Society (NSS). All thirtyfive of the cavers from the Caving Event focus groups had memberships in the NSS. The three responding Kentucky focus group cavers did not hold an NSS membership. Only one of the New Mexico focus group cavers responded; he/she did not have a current membership in the NSS.

Thirty-one $(76 \%)$ of the cavers noted memberships in other speleological organizations. Speleo-memberships included: local grotto (cave club); regional memberships; state speleological surveys; (specific) cave survey projects; NSS section memberships; international grottos and organizations; regional and state cave conservancies; Cave Research Foundation (CRF); and the American Cave Conservation Association (ACCA). 


\section{Kentucky and New Mexico Cave Experiences}

Because two focus groups localities were based specifically on cave regions (Mammoth Cave region, Kentucky and Carlsbad Caverns region, New Mexico), it was important to identify the level of familiarity participants from the three focus groups venues had with caves in those two states (see Table 21).

Visitation to Kentuckian and New Mexican caves varied among the three focus groups venues. As can be seen from Table 21, responding cavers from the Caving Event focus groups showed high degrees of familiarity with caves from both states. However, unlike the $100 \%$ Kentucky cave visitation, not all respondents had visited a New Mexico cave. However, a higher percentage (35\%) had greater than 50 New Mexico cave trips when compared to $21 \%$ for over 50 Kentucky cave trips. As might be expected, Kentucky focus groups' cavers showed greater familiarity with Kentucky caves than with New Mexico caves. The reverse was true for New Mexico focus groups' cavers.

The degree of familiarity non-cavers have with caves may have some bearing on how they perceive the need for cave protection. As noted previously, there were no non-caver respondents from the Caving Event focus groups. 
Table 21. Caver Kentucky and New Mexico Cave Experiences.

\begin{tabular}{|c|c|c|c|}
\hline FOCUS GROUPS & $\begin{array}{c}\text { CAVING EVENT } \\
\mathrm{n}=35\end{array}$ & $\begin{array}{c}\text { KENTUCKY } \\
n=4\end{array}$ & $\begin{array}{c}\text { NEW MEXICO } \\
n=2\end{array}$ \\
\hline \multicolumn{4}{|c|}{ Kentucky Visited Caves } \\
\hline 0 & 0 & 0 & 1 \\
\hline $1-5$ & 16 & 1 & 1 \\
\hline $6-10$ & 6 & 1 & 0 \\
\hline $11-25$ & 6 & 2 & 0 \\
\hline $26-50$ & 5 & 0 & 0 \\
\hline $51-100$ & 0 & 0 & 0 \\
\hline$>100$ & 2 & 0 & 0 \\
\hline \multicolumn{4}{|c|}{ Kentucky Cave Trips } \\
\hline 0 & 0 & 0 & 1 \\
\hline $1-5$ & 13 & 0 & 1 \\
\hline $6-10$ & 6 & 1 & 0 \\
\hline $11-25$ & 7 & 0 & 0 \\
\hline $26-50$ & 2 & 1 & 0 \\
\hline $51-100$ & 3 & 1 & 0 \\
\hline$>100$ & 4 & 1 & 0 \\
\hline \multicolumn{4}{|c|}{ New Mexico Caves Visited } \\
\hline 0 & 5 & 3 & 0 \\
\hline $1-5$ & 10 & 1 & 0 \\
\hline $6-10$ & 2 & 0 & 0 \\
\hline $11-25$ & 7 & 0 & 2 \\
\hline $26-50$ & 8 & 0 & 0 \\
\hline $51-100$ & 2 & 0 & 0 \\
\hline$>100$ & 1 & 0 & 0 \\
\hline \multicolumn{4}{|c|}{ New Mexico Cave Trips } \\
\hline 0 & 5 & 3 & 0 \\
\hline $1-5$ & 5 & 1 & 0 \\
\hline $6-10$ & 2 & 0 & 1 \\
\hline $11-25$ & 4 & 0 & 1 \\
\hline $26-50$ & 7 & 0 & 0 \\
\hline $51-100$ & 5 & 0 & 0 \\
\hline$>100$ & 7 & 0 & 0 \\
\hline
\end{tabular}

\section{Non-Caver Caving Experience}

\section{Non-Commercial Wild Cave Trip}

Six of the twelve reporting non-cavers participated in non-commercial wild cave trips (reference Table 22). Two (50\%) of the responding non-cavers from the Kentucky focus groups had participated in non-commercial wild cave trips. One had participated on one trip and the other had participated in twenty wild cave trips. Four (50\%) of the New Mexico focus groups' non-cavers reported having participated in non-commercial wild cave trips. These responses 
indicate some degree of familiarity with wild cave experiences among the responding non-caver participants.

Table 22. Non-Cavers' Non-Commercial Wild Caving Trips.

\begin{tabular}{|l|c|c|c|}
\hline FOCUS GROUPS & $\begin{array}{c}\text { CAVING EVENT } \\
\mathrm{n}=0\end{array}$ & $\begin{array}{c}\text { KENTUCKY } \\
\mathrm{n}=4\end{array}$ & $\begin{array}{c}\text { NEW MEXICO } \\
\mathrm{n}=8\end{array}$ \\
\hline \multicolumn{2}{|c|}{ Non-Commercial Wild Caving Trips } \\
\hline 0 & NA & 2 & 4 \\
\hline 1 & NA & 1 & 0 \\
\hline 2 & NA & 0 & 2 \\
\hline 3 & NA & 0 & 1 \\
\hline 15 & NA & 0 & 0 \\
\hline 20 & NA & 1 & \\
\hline
\end{tabular}

Kentucky and New Mexico Visited Caves and Cave Trips

Kentucky and New Mexico focus groups' non-cavers showed similar cave visitation patterns (see Table 23). All responding non-cavers had visited at least one cave in their respective states. Within each focus groups venues, one non-caver visited a cave(s) in the other state. These responses indicate non-caver participants have some degree of familiarity with caves within their corresponding state. However, these same non-caver participants have little to no familiarity with caves from the other locality.

\section{Wilderness Experience}

Familiarity with Wilderness may or may not have bearing on wilderness discussions. Focus group participants were asked if they had ever visited a Wilderness area and if they would visit again (reference Table 24). The majority of respondents from the New Mexico and Caving Event focus groups had previously visited a Wilderness area, 89\% (8) and 97\% (33) respectively. Four $(57 \%)$ of the seven Kentucky respondents had visited wilderness. This indicated varying degrees of experience with Wilderness areas. It should also be noted that with greater numbers of 
Wilderness areas in the West than in the East, it would not be unexpected to find a difference in Wilderness experience between New Mexico and Kentucky focus group participants.

Table 23. Non-Caver Kentucky and New Mexico Caving Experience.

\begin{tabular}{|c|c|c|c|}
\hline FOCUS GROUPS & $\begin{array}{c}\begin{array}{c}\text { CAVING EVENT } \\
n=0\end{array} \\
\text { C. }\end{array}$ & $\begin{array}{c}\text { KENTUCKY } \\
n=5\end{array}$ & $\begin{array}{c}\text { NEW MEXICO } \\
n=8\end{array}$ \\
\hline \multicolumn{4}{|c|}{ Kentucky Visited Caves } \\
\hline 0 & NA & 0 & 7 \\
\hline $1-5$ & NA & 1 & 1 \\
\hline $6-10$ & NA & 2 & 0 \\
\hline $11-15$ & NA & 0 & 0 \\
\hline $16-20$ & NA & 1 & 0 \\
\hline Other & NA & 1 & 0 \\
\hline \multicolumn{4}{|c|}{ Kentucky Cave Trips } \\
\hline 0 & NA & 0 & 7 \\
\hline $1-10$ & NA & 2 & 1 \\
\hline $11-25$ & NA & 1 & 0 \\
\hline $26-50$ & NA & 0 & 0 \\
\hline 100 & NA & 1 & 0 \\
\hline Other & NA & 1 & 0 \\
\hline \multicolumn{4}{|c|}{ New Mexico Caves Visited } \\
\hline 0 & NA & 4 & 0 \\
\hline $1-5$ & NA & 1 & 4 \\
\hline $6-10$ & NA & 0 & 1 \\
\hline $11-15$ & NA & 0 & 1 \\
\hline $16-20$ & NA & 0 & 1 \\
\hline Other & NA & 0 & 1 \\
\hline \multicolumn{4}{|c|}{ New Mexico Cave Trips } \\
\hline 0 & NA & 4 & 0 \\
\hline $1-10$ & NA & 1 & 2 \\
\hline $11-25$ & NA & 0 & 2 \\
\hline $26-50$ & NA & 0 & 0 \\
\hline 100 & NA & 0 & 2 \\
\hline Other & NA & 0 & 2 \\
\hline
\end{tabular}

Plans to visit Wilderness again did not show the same pattern as in Wilderness visitation. Only the Caving Event respondents showed a high percentage of repeat visitation interest (94\%). Both Kentucky and New Mexico focus groups' respondents showed marked decrease in interest in repeat visitation compared to original visitation $25 \%$ and $43 \%$ respectively. 
Table 24. Wilderness Experience by Focus Group participants.

\begin{tabular}{|l|c|c|c|}
\hline \multicolumn{1}{|c|}{ FOCUS GROUPS } & $\begin{array}{c}\text { CAVING EVENT } \\
\mathrm{n}=35\end{array}$ & $\begin{array}{c}\text { KENTUCKY } \\
\mathrm{n}=9\end{array}$ & $\begin{array}{c}\text { NEW MEXICO } \\
\mathrm{n}=10\end{array}$ \\
\hline \multicolumn{4}{|c|}{ Visited Wilderness } \\
\hline Yes & 33 & 4 & 8 \\
\hline No & 1 & 3 & 1 \\
\hline No Response & 1 & 2 & 3 \\
\hline \multicolumn{7}{|c|}{ Plant to Visit Wilderness Again } \\
\hline Yes & 29 & 1 & 3 \\
\hline No & 1 & 2 & 1 \\
\hline No Plans / Don't Know & 1 & 1 & 3 \\
\hline No Response & 4 & 5 & \\
\hline
\end{tabular}

